\title{
The Selection of Cabinet Ministers in the Australian
}

\section{Federal Parliament}

\author{
Michael Coleman Dalvean
}

March 2012

A thesis submitted for the degree of Doctor of Philosophy of The Australian National University. 



\section{Declaration}

The contents of this thesis are the results of original research and have not been submitted for a higher degree to any other university or institution. A section of the work in Chapter 3 is due to appear in an abridged form in an ANU publication in 2012.

Michael Dalvean

School of Politics and International Relations

Australian National University 


\section{Acknowledgements}

This thesis reflects a number of influences on my way of thinking. My approach to using statistics effectively began in 1984 at Monash University when the late Professor Keith Septimus Frearson taught me the value of using statistics to try to understand complex phenomena. Several years later as a student in the Department of Philosophy at the University of Adelaide I was introduced to artificial neural networks and the ideas associated with machine learning. More recently, Dr Fred Gale of the University of Tasmania provided me with encouragement, support and intellectual direction in using these techniques when he supervised my honours thesis.

The current thesis could not have reached its current form without the input from my supervisor Professor Keith Dowding. From the time of my first phone call in late 2007 with Professor Dowding I found that he was open to considering all types of approaches to intellectual problems, the one requirement being that whatever approach is taken, it should be subjected to rigorous analysis.

Many others have helped me on my way, particularly the advisors on my panel, Professor Ian McAllister and Professor Paul t'Hart. Furthermore, all members of the Political Science and International Relations department have, at some time or another, provided me with insights and ideas. In particular, John Nethercote has been an invaluable source of information on Australian politics as has Jane O’Dwyer. Further afield, Professor Peter John of Manchester University provided me with excellent advice on sections of the thesis. 
Proof reading was done by Dr Kim Wells. His contribution complied with Standards D and E of the Australian Standards for Editing Practice as specified by the ANU Policy on the Editing of Research Theses by Professional Editors.

I must thank Ian Wood for his input on data mining and machine learning. My ability to apply the latest methods from this sphere is largely due to his encouragement and advice. I must also thank Penelope and Ian Marshall for their support and encouragement over the last four years.

On a personal note I would like to thank Leila for her love and support as well as her tolerance of my chaotic lifestyle. 


\begin{abstract}
The two fundamental questions addressed in this thesis are 1) what are the characteristics that are associated with an Australian federal parliamentarian becoming a cabinet minister, and 2) how do these characteristics help a parliamentarian become a cabinet minister? I examine the standard representational and institutional explanations for cabinet appointment decisions such as geography, party/faction, gender and house (Senate vs House of Representatives) and find they do not account for more than $25 \%$ of cabinet appointments. I therefore turn to individual characteristics of cabinet ministers. I use education, linguistic/cognitive style, and biographical data to develop a classification model. Using data mining, I isolate three characteristics that explain a high proportion of the appointments to cabinet over the period under examination. These variables are: i) having a legal qualification: ii) entering parliament at an early age: and iii) using abstract language. These three variables explain approximately $78 \%$ of cabinet appointments over the period under investigation. I argue that these variables are associated with cabinet appointment because they tap into a particular set of cognitive and behavioural characteristics that are beneficial in demonstrating cabinet potential. An important insight from the analysis is that, in selecting parliamentarians to serve in cabinet, personal factors are more important than representational factors.
\end{abstract}




\section{Contents}

DECLARATION

CHAPTER 1: INTRODUCTION.......................................................................................... 1

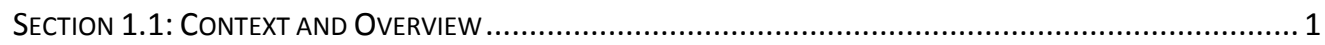

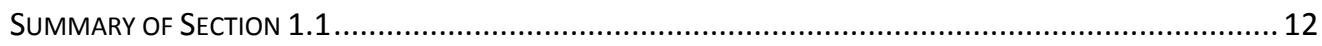

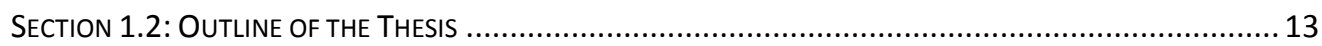

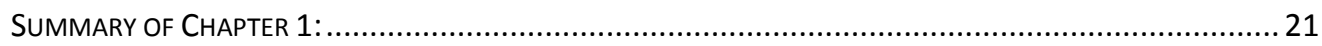

CHAPTER 2: AN OVERVIEW OF THE RESEARCH ..................................................................22

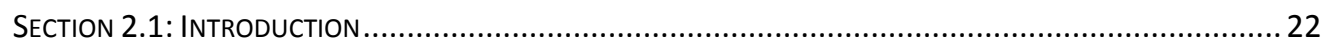

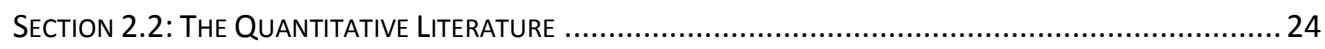

SECTION 2.3: The INTERNATIONAL QUalitATIVE RESEARCH.................................................. 36

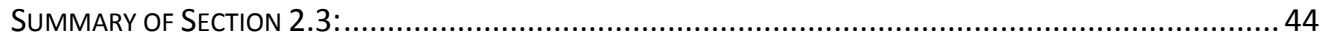

Section 2.4: The Australian QualitAtive Literature ......................................................... 45

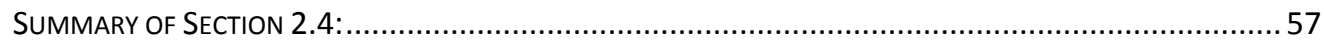

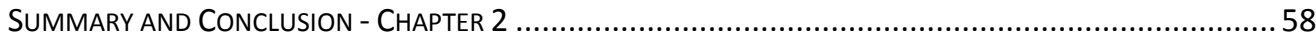

CHAPTER 3: REPRESENTATIONAL AND INSTITUTIONAL FACTORS .......................................62

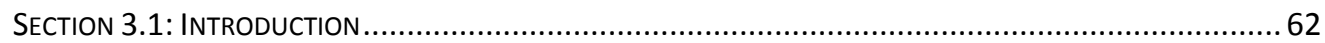


Section 3.2: RIFs: Australian Federal Context .65

Section 3.3: What Would Perfectly Mirrored Representation look Like? . .72

Section 3.1.1: National Party Representation .................................................................... 74

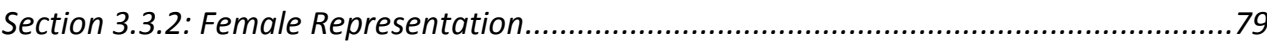

Section 3.3.3: New South Wales Representation ........................................................83

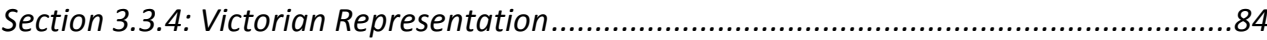

Section 3.3.5: Representation of South Australia..........................................................85

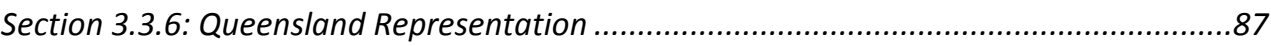

Section 3.3.7: Representation of Western Australia .....................................................89

Section 3.3.8: Representation of the NT, the ACT and Tasmania.....................................91

Section 3.3.9: Senate Representation ......................................................................95

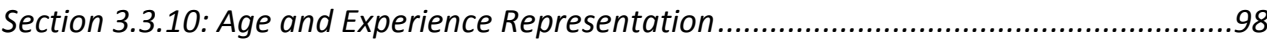

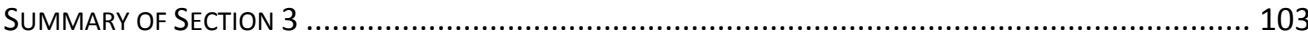

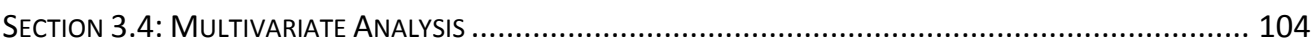

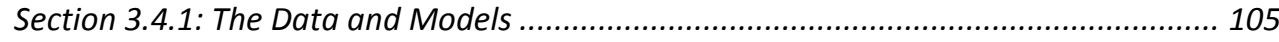

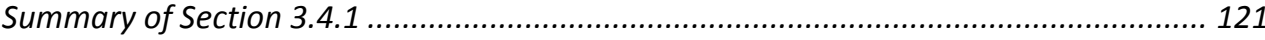

Section 3.4.2: Explanation of the Results .................................................................... 122

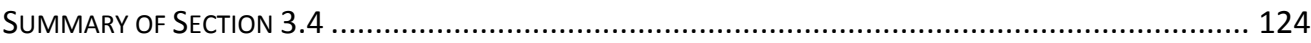

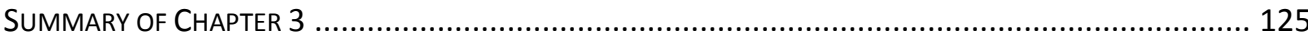

CHAPTER 4: TOWARDS A METHOD OF MEASURING MINISTERIAL ABILITY........................... 128

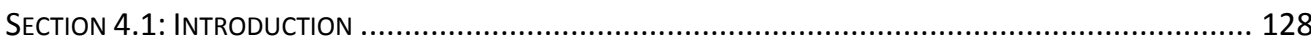

Section 4.2: Education AS A Marker of Cognitive StyLE ................................................. 133

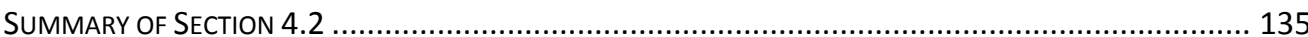

Section 4.3: Verbal Behaviour as a Marker of Cognitive Style .......................................... 136

Section 4.3.1: Maiden Speeches as a Source for Speech Behaviour.............................. 137

Section 4.3.2: Deriving Independent Variables from Texts ...................................... 142 
SUMMARY OF SECTION 4.3.

Section 4.5: Linguistic InQuiRy And Word Count And Personnel Selection.

SUMMARY OF SECTION 4.5

CHAPTER 4 SUMMARY AND CONCLUSION

CHAPTER 5: AN APPROACH TO MODELLING USING DATA MINING

SECTION 5.1: INTRODUCTION 164

SeCtion 5.2: TRAditional Statistics ANd Data Mining 165

SUMMARY OF SECTION 5.2. 171

SECTION 5.3: DATA MINING ISSUES

SUMMARY OF SECTION 5.3 197

SUMMARY OF CHAPTER 5 198

CHAPTER 6: MODELLING FACTORS ASSOCIATED WITH CABINET APPOINTMENT .200

SECTION 6.1: INTRODUCTION 200

Section 6.2: Study Design, SAMple And PReView of the Findings. 201

SUMMARY OF SECTION 6.2 207

SECtion 6.3: The SAMPLE 208

SUMMARY OF SECTION 6.3 215

Section 6.4: The DATA 216

SUMMARY OF SECTION 6.4. 223

Section 6.5: The Modelling Process.

SUMMARY OF SECTION 6.5

SECTION 6.6: THE COMMITTEE.

SUMMARY OF SECTION 6.6 
SECTION 7.1: INTRODUCTION 241

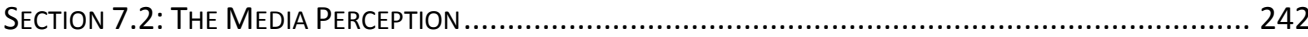

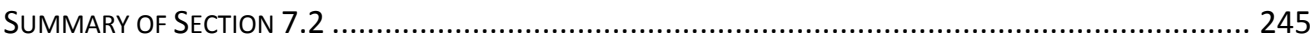

SeCtION 7.3: SIMILARITY BIAS AND THE SELECTION OF LEGALLY TRAINEd INDIVIDUALS .......................... 246

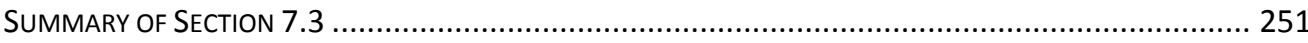

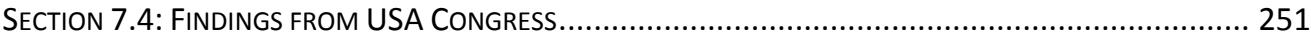

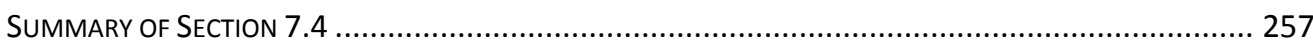

Section 7.5: Cognitive SkiLl - “Chunking” ANd the CASE Brief............................................. 258

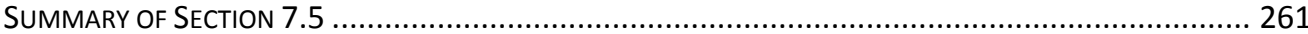

SECTION 7.6: OBSERVATIONS FROM EMPIRICAL STUDIES ............................................................... 261

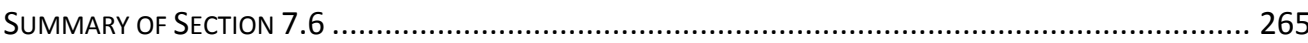

Section 7.7: The VALUe OF Skills Derived from Legal Training ........................................... 266

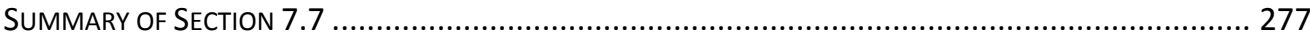

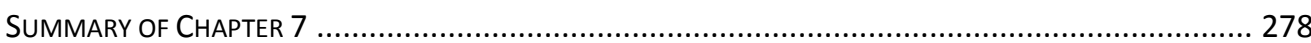

CHAPTER 8: PARLAGE AND THE DYNAMICS OF AMBITION ......................................... 281

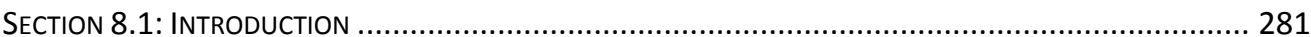

Section 8.2: OVerVIEW of Age At Entry to Parliament ....................................................... 282

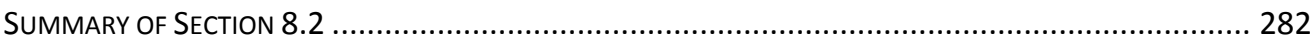

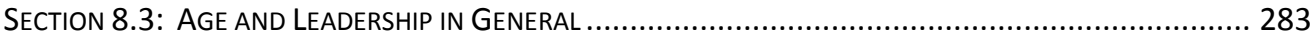

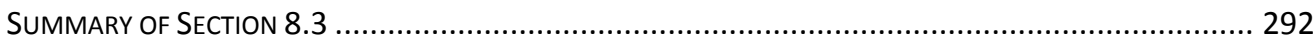

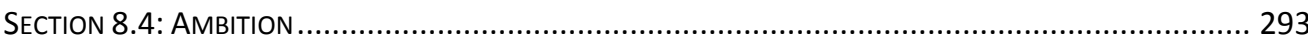

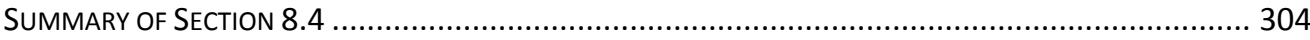

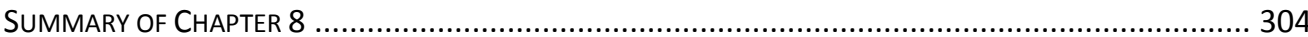

CHAPTER 9: ABSTRACT VERSUS CONCRETE THINKING AND CABINET SELECTION ................ 306

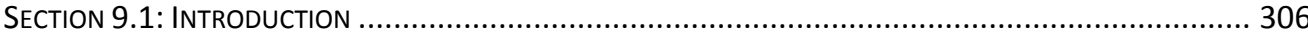

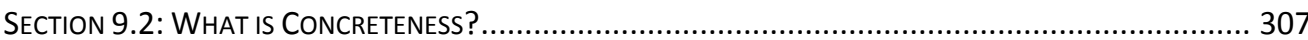

viii 
SUMMARY OF SECTION 9.2 310

Section 9.3: SOME EfFectS of Differing LeVels of AbStraction

SUMMARY OF SECTION 9.3

SeCtion 9.4: Concreteness AS A MARKer of the LeVEl of Construal

SUMMARY OF SECTION 9.4

Section 9.5: Case Studies from the Speech Sample

SUMMARY OF SECTION 9.5

CHAPTER 9 SUMMARY AND CONCLUSION

CHAPTER 10: THESIS SUMMARY AND CONCLUSION

SECTION 10.1: INTRODUCTION. 335

SECTION 10.2: THESIS SUMMARY

Section 10.3: CM Selection may be a Species of Personnel Selection. 344

SUMMARY OF SECTION 10.3. 349

Section 10.4: Methods and approach: Problems and Possible Extensions 349

SUMMARY OF SECTION 10.4: 356

SECTION 10.5: POSSIBLE APPLICATIONS. 357

SUMMARY OF SECTION 10.5 . 359

SECTION 10.6: CONCLUSION. 360

BIBLIOGRAPHY

APPENDIX 2: COHORT DETAILS ( $\mathbf{N}=384$ )

APPENDIX 3: DATA USED FOR COMMITTEE MODELLING .451 


\section{List of Figures}

FIGURE 3.1: EXPECTED AND ACTUAL QUEENSLAND CMs 1996-2007................................. 88

FIGURE 3.2: EXPECTED AND ACTUAL LNPC SENATE CMs 1996-2007. .................................. 97

FIGURE 3.3: AVERAGE AGE - LNPC PARLIAMENT AND CABINET 1996-2007.................... 100 FIGURE 3.4: AVERAGE EXPERIENCE - LNPC PARLIAMENT AND CABINET: 1996-2007..... 102 FIGURE 6.1: RANKING of 109 VARIABLES ON THE BASIS OF T-TESTS 228 


\section{List of Tables}

TABLE 2.1: LOGISTIC REGRESSION RESULTS FROM O'MALLEY (2006)....................................32

TABLE 3.1: PERCENTAGE RIFS - LNPC 1996-2007 ..........................................................73

TABLE 3.2: LNPC AND NP MEMBERS AND NP PROPORTION - 1996-2007 ............................76

TABLE 3.3: ACTUAL AND EXPECTED LNPC AND NP REPRESENTATION 1996-2007 ...................76

TABLE 3.4: FEMALE CM REPRESENTATION 1996-2007 ...................................................81

TABLE 3.5: NSW CM REPRESENTATION 1996-2007 ....................................................84

TABLE 3.6: VICTORIAN CM REPRESENTATION 1996-2007 ................................................84

TABLE 3.7: SOUTH AUSTRALIAN CM REPRESENTATION 1996-2007 ....................................86

TABLE 3.8: QUEENSLAND CM REPRESENTATION 1996-2007 ...............................................88

TABLE 3.9: WEST AUSTRALIAN CM REPRESENTATION 1996-2007 ........................................90

TABLE 3.10: TASMANIAN REPRESENTATION IN PARLIAMENT 1996-2007 .............................92

TABLE 3.11: TASMANIAN CM REPRESENTATION 1996-2007 ..........................................92

TABLE 3.12: NT REPRESENTATION: PARLIAMENT 1996-2007 ..............................................93

TABLE 3.13: NT CM REPRESENTATION 1996-2007.....................................................93

TABLE 3.14: ACT REPRESENTATION: PARLIAMENT 1996-2007 ...........................................94

TABLE 3.15: ACT CM REPRESENTATION 1996-07 ........................................................94

TABLE 3.16: SENATE CM REPRESENTATION 1996-2007 ...................................................96

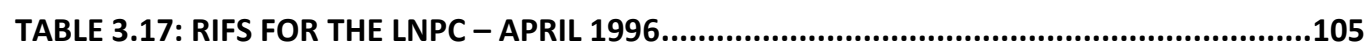

TABLE 3.18: DATA FOR LOGISTIC REGRESSION -ABBOTT AND TROETH 1996 - 2007............107

TABLE 3.19: LNPC REPRESENTATIONAL DATA - POOLED CROSS-SECTIONS ...........................108 
TABLE 3.21: ACCURACY METRICS FOR LNPC MODELS .115

TABLE 3.22: PARAMETER ESTIMATES - ALP MULTIVARIATE ANALYSIS 118

TABLE 3.23: ACCURACY METRICS FOR ALP MODELS 120

TABLE 5.1: HYPOTHETICAL COMMITTEE MODELS 195

TABLE 6.1: COHORT BY PARTY AND MINISTERIAL RANK 209

TABLE 6.2: SAMPLE WITHOUT BBS, PSS AND JMS IN PARLIAMENT AT FEBRUARY '08 210

TABLE 6.3: FINAL MODELLING SAMPLE 213

TABLE 6.4: VARIABLES WITH $P<.01$ ON TESTS OF DIFFERENCES IN MEANS 229

TABLE 6.6: INTER-CORRELATIONS BETWEEN CM AND 7 INDEPENDENT VARIABLES .231

TABLE 6.7: HOLDOUT SAMPLE CLASSIFICATION ACCURACY - FOUR MODELS 232

TABLE 6.8: ACCURACY OF MODELS CREATED WITH LAW, ARTS, PARLAGE AND CONAV...... 233 TABLE 6.9: PARAMETER ESTIMATES OF MODEL 1 233

TABLE 6.9: SUMMARY CLASSIFICATION RESULTS FOR 5 MODELS 235

TABLE 6.11: ODDS RATIOS FOR VARIABLES IN 5 MODELS. 237

TABLE 7.2: CM APPOINTER AND APPOINTEE LEGAL TRAINING STATUS 249

TABLE 8.1: DESCRIPTIVE DATA FOR PARLAGE - AGE AT ENTRY TO PARLIAMENT 282

TABLE 8.2: AGE AT ENTRY (PARLAGE) AND AGE AT APPOINTMENT FOR CMS 287 


\section{Chapter 1: Introduction}

\section{Section 1.1: Context and Overview}

Barry Jones did not become a cabinet minister whereas Gareth Evans did. Was this due to differences in ability, social skill or political judgment? Alternatively, was it because Evans represented the appropriate faction, state or house? The same questions could be asked as to why Peter McGauran, Martin Ferguson and David Kemp became cabinet ministers while their brothers and fellow parliamentarians Julian, Laurie and Rod, respectively, did not. Despite the extensive commentary on cabinet appointments by commentators, leaders and ministers themselves, the reasons for cabinet appointments have not been systematically studied in the Australian setting. It is the intention of this thesis to address the issue in an analytical way.

Standard explanations of cabinet appointments are based on various criteria. One common explanation is the "representational" explanation. The idea here is that leaders attempt to make their cabinets representative of the various competing geographical, gender, factional and other groups vying for representation, and that this explains a large proportion of cabinet appointments. Weller, for example refers to ministerial selection in the Liberal National Party coalition as a "...jigsaw: balancing the powerful states, the Senate and the coalition" (Weller 2007, p199).

Related to the representational variables are those that could be described as "institutional" variables. These are variables that, due to the nature of the institution of 
parliament, have an influence on cabinet appointment decisions. For example, the institutional arrangements of the Liberal National Party Coalition (LNPC) are such that the National Party must be given cabinet appointments as close as possible to their representation in the parliamentary LNPC: if National Party members make up $20 \%$ of the parliamentary LNPC then the national party must be given $20 \%$ of cabinet positions. Another such representational factor is the relative representation of the two Houses: there is some expectation that a party's parliamentary representation in terms of the relative number of Senators and House of Representatives members should be mirrored in cabinet.

Age and experience are also referred to as being important factors in the allocation of cabinet positions. However, there is a difference between these and the representational and institutional factors (RIFs) in that a leader is often justified in selecting a cabinet that does not represent the age or experience profiles of parliament as a whole. In general, a cabinet is expected to be more experienced than the parliament as a whole. Similarly, a leader may decide to increase the number of older cabinet ministers (CMs) if she wants to create an image of seniority, experience and gravitas but has the option of selecting younger members if she needs to infuse cabinet with "new blood". This same trade-off is a feature of appointments and dismissals in the UK parliament (Alderman and Cross 1985: 397-399). Thus, a leader is not expected to simply mirror the age and experience profiles of the parliament in her cabinet.

As well as the above variables, the literature also refers to more ephemeral qualities such as "talent". Interestingly, however, such qualities are often acknowledged but seldom analysed in any way. A good example of this is Weller who holds that junior 
ministerial roles are essentially "soft positions for the loyal, but not massively talented, ministers who would never reach cabinet rank" (Weller 2007: 197). The implication here is that cabinet ministers have levels of "talent" that exceed those of junior ministers. However, no analysis of such ephemeral qualities is given.

The purpose of this thesis is to address the issue of the characteristics of parliamentarians that lead to appointment to cabinet and to explain why these characteristics lead to cabinet appointment. Are there representational and institutional factors that are important and, if so, why are they important? Conversely, is there a set of more ephemeral qualities that are important and why do these lead to cabinet appointment?

Thus, the basic questions I wish to address in this thesis can be stated quite simply: what are the characteristics of the Australian federal parliamentarians who become cabinet ministers and why are these characteristics associated with success at becoming a cabinet minister?

To some extent this thesis seems to be associated with classic leadership studies on legislative pathways which examine the factors that lead to recruitment to the legislature (Ranney 1965; Matthews 1984; Norris 1997). The legislative recruitment or "pathways to power" literature examines the characteristics of individuals who enter the legislature. These studies tend to use methods such as surveys of legislators to come up with broad descriptions of the kinds of individuals who become legislators. Because the procedure is based on surveys of individuals there is no definitive study or control group. In this respect such studies tend to be descriptive. However this thesis is quite 
different in that it uses a method akin to a case-control approach. In this thesis I am interested in the differences between those members of the legislature who rise to cabinet positions and those who do not. As such, the group that does not rise is a quasicontrol group. The thesis involves determining the differences between those who become senior ministers and those who do not. As we shall see, individual differences in cognitive style are an important part of the analysis.

As cognitive style is an essential component of the method I use it is important to preface the issue of how I get a measure of cognitive style for the parliamentarians under examination. Ideally I would administer a battery of tests and the results would be used as the independent variables in the analysis. However, this is impractical. Instead I use two other broad markers of cognitive style: education and linguistic behaviour. I also use a set of biographical variables which I interpret as being potential markers of differences in cognitive style.

Education is an important marker of cognitive style. As I will show, there is research that demonstrates that not only are people with particular cognitive styles attracted to particular subject areas but particular subject areas can have an influence on an individual's way of thinking. Thus, the specific educational subject studied by a parliamentarian is a good marker of their cognitive style. Six different subject areas were included in the initial modelling. I will demonstrate, however, that only backgrounds in Law and Arts are associated with accession to cabinet and that, of these two subject areas, only the former has discriminative power. The finding that there is an association between a legal background and accession to high political office is consistent with findings in the international literature. Kerby (2009) for example found 
that legal education was associated with cabinet appointments in Canada. However, the current thesis is the first time the association has been found using Australian Federal data.

The second set of markers of cognitive style I use is derived from speech. The speech uttered by an individual is a highly individual marker of the way they reason and see the world. However, the parliamentary setting is not ideal for finding examples of the idiosyncratic aspects of the speech of individuals given the penchant for parliamentarians to rely on speeches prepared by others. Furthermore, a large number of individuals, such as backbenchers, speak little. One way around to get representative speech samples is to use the first or "maiden" speech delivered in parliament. This is usually delivered by neophyte parliamentarians who do not have the staff or resources to have their speech prepared. Thus the first speech is a very good source for highly individual linguistic behaviour. For each parliamentarian in the sample I break down the first speech into linguistic variables using the program Linguistic Inquiry and Word Count (LIWC) which reduces text to 68 linguistic variables. These variables have been found to be associated with a vast array of psychological and cognitive phenomena (Tausczik and Pennebaker 2010). As well as the LIWC variables I use a number of psycholinguistic variables derived from the Paivio, Yuille and Madigan (1968) and Clarke and Paivio (2004) word norms. I will show that there is good evidence that parliamentarians who use relatively abstract language are more likely to become cabinet ministers. This is the first time this has been found in any parliamentary setting, Australian or international. 
Another set of variables I use is derived from the biographical background of individuals. I examine such variables as gender, and age at the time of entry to parliament. It is possible that these variables influence the way parliamentarians conceive of the world and therefore affect their cognitive style and, as a consequence, their chances of becoming a CM. The main finding here is that the age at the time of entry to parliament (Parlage) is the only significant biographical variable associated with becoming a CM. The earlier an individual enters parliament the more likely they are to become a CM. This observation has been made in other contexts. Buck (1963) and King (1981) made the same observation in relation to the UK parliament and Schlesinger (1966) in relation to accession to high political office in the US. Kerby (2009) found a negative quadratic effect of age on the probability of appointment to cabinet in the Canadian parliament with the maximum probability at age 42 after which the probability declines. In this thesis I find that there is a negative association between the age at which an individual enters parliament and the likelihood of becoming a CM. This is the first time such a finding has been made in the context of the Australian Federal system. Following Buck (1963), King (1981) and Schlesinger (1966) I explain this phenomenon in terms of ambition: those who enter parliament at a younger age have a higher base rate of ambition and this is manifested in a higher propensity to seize opportunities as they arise.

Cognitive style and related phenomena such as psychological traits have been used as a basis for much research on the behaviour of leaders in office. It is important to distinguish between this tradition and the approach I intend to take in this thesis. The leader trait branch of the leadership literature takes as its sample those who have risen to 
high levels of leadership such as prime ministers and presidents. Differences between leaders in terms of behaviour in office, charismatic appeal and policy choice are explained terms of differences in individual leadership "traits". Herman's (2005) Leadership Trait Analysis, Winter's (1987) motive profile analysis and Tetlock's (1983) integrative complexity fall into this category. While I have derived number of insights from these approaches it should be stressed that this literature is quite separate from the major questions being addressed in this thesis. One way to conceptualise the basic difference is to point out that I am trying to work out who gets to the top of the pyramid while Leadership Trait Analysis is concerned with the behaviour of individuals already at the top of the pyramid. In other words, my analysis concerns the differences between leaders and non-leaders while the leader trait analysis concerns differences between leaders.

The context of this thesis is the Australian federal parliamentary system. No other study on the Australian federal system has dealt with the selection of ministers by specifically looking for characteristics that explain cabinet appointments. There have been studies on recruitment to the legislature such as Studlar and McAllister (1991) and McAllister (1997). There have also been descriptive studies of individual ministers (e.g.: Weller 1989; 1999; Aubin 1999; Scott 1999), cabinet government (Weller 2007), and ministers in general (Tiernan and Weller 2010). But there has been no systematic analysis of the differences between those who rise to senior ministerial positions and those that do not. Thus, the current thesis is an extension of the Australian literature.

This thesis is unusual in the cabinet appointment literature in that it is analytical rather than descriptive. There is a plethora of descriptive and qualitative work on senior 
ministers and leaders. In chapter 2 I will survey a small selection of this work. Despite the interest in the field, however, there has been little systematic analysis of the characteristics of those who get to cabinet using a case-control design. Two exceptions are those of O'Malley (2006) and Kam et al (2010) which deal with the Irish and UK parliaments respectively. It should be noted, however, that there is a significant literature on the tangentially related area of de-selection which I will also consider in Chapter 2.

Because I Use a case-control design I can make claims about the appointment of Australian cabinet ministers that cannot otherwise be made. For example, one of the most interesting outcomes of the analysis is that the single most powerful predictor of an individual's likelihood of becoming a CM is the possession of a legal education. That is, notwithstanding that the legislature in general has a substantial number of legally trained individuals, possessing a legal education significantly increases the odds of an individual becoming a CM. This observation cannot be made definitively by undertaking a descriptive study. What is required is a case-control study which includes a sample of legislators who became CMs, a sample of legislators who did not become CMs, and a method of systematically comparing them. It is this that the current thesis provides and, because of this, it is possible to derive positive statements that go beyond impressionistic descriptions.

Another aspect of the thesis that is of interest is that it demonstrates that in the Australian Federal system, the commonly accepted explanation for CM appointments is only partially correct. As mentioned above, the conventional explanation for cabinet appointments includes the idea that individuals are selected for CM positions because 
they satisfy certain representational and institutional demands. That is, they represent the interests or aspects of the institution of parliament such that they are regarded as being necessarily included in cabinet to balance the competing demands. This thesis finds that such representational and institutional factors explain only a very small proportion of the cabinet appointments.

The idea that identifiable and measurable variables associated with cognitive style can be used to determine who has cabinet potential has implications for the wider leadership literature. There is a plethora of research on ephemeral qualities such as charismatic leadership, transformational leadership, transactional leadership and a variety of similar concepts. While there is some statistical support for these ideas in a broad sense they tend to use as a starting point the idea that "leadership" is an actual quality. By finding that there are highly predictive markers of cognitive style that differentiate between those who are likely to get to cabinet and those that are not, I am claiming that selection for high political office may be akin to personnel selection. I make the claim that the idea of "leadership" is at worst a reification of concrete qualities and at best a useful shorthand to refer to these. The idea that the identification of senior political figures may be reducible to a mechanistic procedure, while interesting, may be disconcerting to some.

My statement of the basic research questions contains two questions in that I wish to first identify the characteristics that lead to cabinet appointment and secondly to explain why these characteristics lead to cabinet appointment. This second part of the exercise is essential if we wish to engage in a scientific as opposed to a merely technical exercise. The explanatory phase of the exercise is of interest because it shows that 
phenomena identified in the broader psychology and political science literature can be seen to be at play in cabinet appointments in the Australian federal parliament. Consider, for example, the observation alluded to above that a text-derived measure of concreteness of language is associated with decreased odds of a legislator becoming a $\mathrm{CM}$ in the Australian federal parliament. The identification of this variable as an important predictor is part of the first research question in which the identification of the important predictive variables is the focus. However, the second part of the research question, the explanation as to why the identified variables are predictive of cabinet appointments, is a separate exercise. Having identified that concreteness of language is a predictive variable it is important to explain why this is so. To do this it is necessary to look at the wider research on the relationship between concrete language and persuasion, leadership effectiveness, popularity and even such ephemeral characteristics as the ability to make generalisations. In this way this thesis is able to incorporate the wider literature on political and leader selection and thus situates itself in the broader research that has preceded it.

The final issue that needs to be addressed in this section is the modelling method. In the first part of the thesis I will use traditional hypothesis testing to examine a number of RIFs that are associated with cabinet appointment in the literature. I will demonstrate that this results in a model that is able to explain no more than $25 \%$ of cabinet appointments. I therefore turn to personal characteristics to explain cabinet appointments. In order to look for other explanatory variables based on personal characteristics I survey a vast number of linguistic variables derived from maiden speeches. This means that I need to use a method unlike hypothesis testing. Searching 
through vast amounts of data calls for using data-mining methods. A major advantage of using data mining is that a number of variables that may not have been considered in a standard hypothesis testing approach can be discovered. The data mining algorithm trawls through a large number of candidate independent variables in order to identify those that are most strongly associated with the dependent variable. This in itself makes the discovery process innovative. We might not, for example, have been likely to hypothesise that there would be an association between a high level of abstract language use in a first speech and the probability of becoming a $\mathrm{CM}$ by engaging in ex ante hypothesising about the nature of CMs. The data-mining approach enables us to come up with such unforseen associations and as such enables a more extensive understanding of what makes a CM.

Data mining models are assessed by their ability to classify a "holdout sample". The procedure is to build a model using one portion of the data and test the model on a portion of the data that has not been used to create the model. The latter portion is the holdout sample. The idea is that a model is more likely to have captured an important association if it can be shown that the independent variables are robustly associated with the dependent variable. A high holdout sample classification accuracy is a very good indication that the model is not merely finding associations that are statistically significant but which have weak overall predictive power. This test is important because searching through a large number of potential independent variables can result in finding variables that are related to the dependent variable by chance alone. Testing using a holdout sample reduces the probability of this. We will see that, using holdout samples, the models created are able to correctly classify neophyte parliamentarians as 
future CMs or non-CMs with an accuracy of above $70 \%$. This is a good indication that the variables associated with cabinet appointment have been identified.

\section{Summary of Section 1.1}

In this section I have attempted to give a broad overview of the issues I wish to address in this thesis. I have noted that there is a great deal discussion of those who rise to high levels in the Australian federal parliament. I have also noted that there is little analytical discussion of what the underlying characteristics of those who do so might be. I have stated that I wish to address the issue by determining the characteristics of those who become CMs in the Australian federal parliament and by explaining why these characteristics are associated with appointment to cabinet. I have pointed out that the standard explanation is that representational and institutional factors are the most prominent reason for cabinet appointments and have also pointed out that this is not my finding. Instead, I find that cognitive factors provide a better explanation. I have pointed out that the legislative recruitment literature tends to be descriptive in that, unlike my approach, it does not use a case-control design. I have outlined my approach to the issue of deriving independent variables for my study and have pointed out that the basic analysis will focus on educational variables, biographical variables and linguistic variables derived from the first speeches of parliamentarians. Given the prominence of cognitive style in my study I mentioned another stream of literature that uses cognitive elements - the leader trait school of thought. I differentiated this school from my approach because, although this literature uses a cognitive approach as I do, it focuses on leaders to the exclusion of non-leaders. As such it is only peripherally related to the 
kinds of issues I wish to address. I have shown that, while the questions I am addressing are related to a number of issues that are prominent in the descriptive Australian leadership literature, this thesis departs from such studies in that it uses a case-control design. This enables me to make statements about the differences between those that get to the top and those that do not. I have pointed out that after identifying the predictive variables, the second part of the research question involves explaining why these variables are important and that this involves looking at the wider literature on cognitive style. Finally, I addressed the issue of the modelling method to be used in identifying the predictive variables. The data mining approach has the advantages that more explanatory variables can be considered than would be feasible in traditional hypothesis testing and that, because the classification accuracy is the criterion of judging a model, the variables must be strongly associated with the dependent variable. This means that the variables isolated are very likely to be the important factors at play in cabinet appointments.

\section{Section 1.2: Outline of the Thesis}

So far in this chapter I have presented an overview of the methods and overall approach I will be using in this thesis. I would now like to present a summary of the steps to be taken in the remaining chapters.

In Chapter 2 I present an overview of the research that has been done on ministerial selection in order to see how others have approached the question as to the characteristics associated with selection for cabinet positions. Much of the material I 
review is based on research from the UK because of the parallels between the Australian and UK parliamentary systems. I also review some of the work done on ministerial selection in continental Europe and Ireland. Because there is little parallel between the Australian and US ministerial roles I do not cover the literature on cabinet selection in the US. However the Canadian literature is relevant due to the Canadian parliament's Westminster origin and I therefore briefly cover some Canadian work. The overall impression from the review is that there are three major strands in the literature: the qualitative, the quantitative and the historical/biographical. I attempt to extract from these approaches a set of characteristics that may be helpful in solving the first research question. The extracted characteristics fall into two main categories: representational and institutional factors such as gender and geographical area of origin, and personal factors such as age, experience and "talent".

In Chapter 3 I concentrate on the representative and institutional factors (RIFs) that I have identified as being applicable in the Australian context. These are State/Territory represented, gender, party (in the LNPC), faction (in the ALP), House (HOR or Senate), age and experience. I use a cross sectional approach to test the hypothesis that these factors differ between those who become CMs and those who do not. I find a weak but statistically significant effect of age and experience. The analysis reveals that approximately $25 \%-26 \%$ of cabinet appointments can be explained using these variables leaving approximately $74 \%-75 \%$ unexplained. I conclude that RIFs are not important in determining who becomes a CM. I then briefly address the apparent paradox that prime ministers apparently put a great deal of effort into ensuring that 
cabinets are representative and yet the RIFs do not explain the vast majority of cabinet appointments.

Having failed to find convincing evidence that RIFs are able to explain more than a small proportion of the appointments to cabinet I devote Chapter 4 to the development of ideas as to how personal factors can be measured and used to determine whether there are significant differences between those who are appointed to cabinet and those that are not. The first method I examine for capturing individual cognitive style is education. I survey the literature on the relationship between personality/cognitive style and education and conclude that there is good evidence that education can be used as a marker of the way an individual perceives the world and interacts with it. As such, those with different types of education will be likely to perceive the world differently and interact with it differently, and it is these differences that may account for differences in their success in becoming CMs. I then go on to examine another way of capturing highly personal markers of psychological and cognitive style: speech. In particular I use the first speech in federal parliament. This is because the first speech is delivered in similar circumstances by all parliamentarians. I briefly review a number of methods of using text to derive characteristics of individuals. I then give an overview of the two methods I use to analyse the speech samples in this thesis. The first is set of linguistic measures is derived from LIWC (Pennebaker and King 1999); the second is a set of linguistic variables based on 32 psycholinguistic measures derived from Paivio et al (1968) and Clarke and Paivio (2004). These two methods are used to convert the texts of parliamentarians into numeric variables. 
Finally, I discuss the issue of biographical variables. I include in the analysis only 2 specific biographical variables and one further variable representing the circumstances in which the first speech was delivered. I explain that these biographical variables may provide some way of tapping into the psychological profiles of parliamentarians and are therefore possible variables that could explain why some individuals become CMs while others do not.

In Chapter 5 I continue with methodological issues, this time focusing on the modelling method to be used. The first problem to deal with is how to select the variables to be used in the analysis. LIWC produces 68 variables from each text and psycholinguistic variables provide 32 . As well as these I use six educational variables and three biographical variables. Thus, there are 109 variables. This situation clearly calls for a method to analyse the data that goes beyond traditional statistical methods. Therefore, in order to select the variables to produce a model that is able to classify parliamentarians into $\mathrm{CMs}$ and non-CMs, I use data-mining. In Chapter 5 I discuss the aims and methods of data mining and, from this discussion, determine how best to solve the problem at hand. In particular, I emphasise that the method of assessing the models produced will be based on classification accuracy using separate training and hold-out groups. This method increases the probability that the relationships found in the data are robust. Furthermore I use the concept of a "committee" classifier. This is a method used in data mining that maximises the classification accuracy of a set of models by allowing each model to "vote" on the outcome.

Having discussed the variables in Chapter 4 and the modelling method in Chapter 5 I turn to the actual modelling process in Chapter 6. An important part of the 
modelling process is the sample design and I detail the cohort used as a basis for the study and then explain how the final sample was derived. The next stage in the process is to describe in detail how the variables were derived. In chapter 4 I present an overview of this and it is in Chapter 6 that I provide the details of how the independent variables are derived. I then explain the use of the "committee" method of classification (Dietterich 2000). This method involves the creation of five different testing and training divisions of the data and the creation of five models, all of which are judged to have classification accuracies beyond chance. The final "classifier" consists of the averaged results of all five models in the "committee". Having given an overview of the committee method I describe how each individual model in the committee is created. The first stage is the division of the data into training and test sets. This is an important part of the process because it ensures that the analysis is done only on the training set and the test set is "held out" and used only for the testing of the model. I then describe how the independent variables are screened using t-tests so that only those likely to provide a good "signal" in the data are retained. I find that 7 variables are significant at the $\mathrm{p}<.01$ level. These are then used to create a "naïve" model which has a test set classification accuracy at borderline $(\mathrm{p}<.1)$ level. This is the baseline model and attempts are made to improve its accuracy by eliminating redundant variables. Redundant variables are defined as variables in the training set that are more correlated with each other than the dependent variable. Removing redundant variables results in a model with 2 variables. The holdout sample classification accuracy of this model is 74\%. Having completed Model 1 of the committee I then go on and repeat the model building process four more times with independently generated random holdout samples. Three of the committee models have three variables while two have two 
variables. Using committee classification averaging (Dietterich 2000) I then combine the five models to create a committee classifier which, on the basis of the out-of-sample classifications, has an accuracy of approximately 78\%. Across the "committee" of five models it becomes apparent that there are three basic variables that are associated with being appointed to cabinet: possessing a legal qualification, entering parliament at a relatively early age and using abstract language.

By isolating three characteristics that are associated with accession to cabinet I have essentially answered the first research question. The next three chapters are devoted to explaining why the three variables I have identified as being associated with becoming a CM should be so associated. In Chapter 7 I discuss the effect of having a legal qualification. I discuss a number of reasons as to why having a legal qualification should be associated with becoming a CM. I begin by discussing the popular press' impression of the over-representation of lawyers in parliament. I follow this with a consideration of the possibility that similarity bias is the explanation. That is, I examine the possibility that legally trained individuals (LTIs) are selected for cabinet because it is the legally trained who are doing the selection. I find there is no statistical support for this idea. I then look at the international discussion on the relationship between legal education and high political office. This association has been noted in the US setting such that those with legal backgrounds have significantly higher levels of representation on influential Congressional committees than the non-legally trained. I examine the given reasons for this and conclude that technical expertise in the process of legislation as well as early ambition are the possible reasons for this. The remainder of the chapter is devoted to examining the specific skills that legal training bestows upon individuals. 
Using empirical research on the association between legal training and cognitive style I identify a number of cognitive ways of thinking that are emphasised in legal training. I provide an analysis of how these could be of value to an aspiring CM.

In Chapter 8 I discuss the negative effect of Parlage, the age of arrival in parliament, on the probability of becoming a CM. I find that there is support in the literature for the idea that the age at entry to parliament is a proxy for ambition. I also examine a number of alternative possibilities for the association between age of entry to parliament and the likelihood of subsequent accession to cabinet and conclude that ambition is the most appropriate explanation. I find support for my conclusion from the data as well as two biographical accounts.

In Chapter 9 I turn to the question of why using concrete language should be negatively associated with $\mathrm{CM}$. I first define concreteness as a measure of the extent to which a word can be represented by an image presented to one or more of the senses. I then demonstrate that the variables I use to measure concreteness tap into this same concept or something very similar. I go on to point out a number of psychological correlates of concreteness and abstraction. A tendency to use concrete language is likely to have a number of behavioural and cognitive correlates. I bring these ideas under the rubric of the psychological level of construal (Trope and Liberman 2010). The idea here is that some individuals have a more global way of looking at the world while others have a more local and detailed orientation. The former tend to use abstract language while the latter concentrate on the concrete. My contention is that the linguistic measures of concreteness are highly correlated with the psychological level of construal. That is, those whose language is relatively abstract have a higher psychological level of 
construal while those parliamentarians with relatively concrete language have a relatively low level of construal. The characteristics associated with a high level of construal, such as long term planning, an ability to see the bigger picture and the ability to generalise, are more likely to be associated with the qualities associated with leadership. I can therefore explain the negative association between concrete language and $\mathrm{CM}$ by saying that those with more concrete speech are likely to have a lower level of construal. They are therefore less likely to conceive of the world in a way that a those charged with executive responsibilities need to be able to do. I test the idea that concreteness as measured in the speech sample is a measure of the level of construal by examining a dyad consisting of the highest scorer on concreteness in the sample with the lowest scorer in order to determine if there is evidence they have differing psychological levels of construal. I find there is support for this. I conclude that concreteness is negatively linked to becoming a CM because those with high levels of concreteness in their speeches have a lower level of psychological construal and therefore have fewer of the cognitive habits of mind associated with leadership.

In Chapter 10 I review the findings of the thesis and offer a number of further observations. The most prominent is that there is little need for anything akin to a discussion of a separate category of "leadership" in relation to CMs. In fact, CM selection can simply be seen as a species of personnel selection. This is not to suggest that there is no significant difference between those who become CMs and those who do not. On the contrary CMs have a very different set of characteristics compared with non-CMs. However, to posit a characteristic over and above the base level characteristics that lead to their success is a reification akin to what traditional baseball 
scouts engage in when looking for "talent" as opposed to specific measurable characteristics (Lewis 2004: 9). In this chapter I also suggest a number of shortcomings of the approach used in this thesis and make some suggestions as to how these shortcomings could be addressed. Finally I refer to two practical applications of the findings of the thesis.

\section{Summary of Chapter 1:}

In this chapter I have presented an overview of the thesis. Importantly, this includes a statement of the basic research questions. I have also situated the thesis within the literature and have explained why the thesis is an extension of the existing literature. I have also presented an outline of the thesis including a broad description of the steps I intend to take.

In the next chapter I will embark on a literature review in order to determine the kinds of approaches that have been made to the question of cabinet appointments in systems similar to those of Australia as well as in the Australian system. 


\section{Chapter 2: An Overview of the Research}

\section{Section 2.1: Introduction}

In Chapter 1 I outlined two basic research questions. These were as follow:

1) What are the characteristics of the Australian federal parliamentarians who become cabinet ministers?

2) Why are these characteristics associated with success at becoming a cabinet minister?

In this Chapter, I will begin the search for the answer to research question 1 by reviewing the literature on ministerial appointment. The purpose of this chapter is to attempt to glean from the literature a set of characteristics which have been found by others to be associated with appointments to ministerial positions. It should be stressed that some of this literature deals with promotion to various levels of the ministry. That is, it does not deal exclusively with appointments to cabinet. While some of this literature on appointments to junior executive positions is not directly relevant to the appointment of CMs, insights can be gained from it because some of the factors that are associated with promotions to junior positions are also associated with promotions to more senior positions. Furthermore, much of the literature on ministerial appointments does not distinguish between junior and senior appointments and to exclude these studies because they were not specific enough would significantly reduce the available sources. 
Another point that should be noted is that most of the literature cited is from non-Australian sources. The reason for this is that much of the research on ministerial selection has come from research on the European parliaments. While this research may be only tangentially applicable to the Australian context, insights gained from the research on the UK parliament will be more directly applicable due to the close parallels between the Australian and UK systems.

The literature falls into three broad categories: quantitative research; qualitative research; and biographical/historical accounts. Each one of these can provide some insights into the question. However, it should be pointed out that the specific questions I wish to answer have only been systematically studied in a very small proportion of the literature. There are many studies that are peripheral to the issue but there are very few that specifically attempt to determine what characteristics lead to a new entrant to parliament becoming a cabinet minister at some time in the future. This is partly because there is a tradition in leadership studies of focusing on those who rise to the top. While studies of such individuals are grist to the mill of any serious researcher of leadership, concentrating on these alone leads to a problem of selection on the dependent variable (Geddes 1990). As Kerby says:

We cannot begin to address the causes of ministerial appointment unless we extend our analysis beyond those MPs who are appointed to cabinet by including those MPs who have the possibility of being appointed but were not. Failure to do so invites selection bias on the dependent variable (Kerby 2009: 595, italics in original). 
Thus, in much of what follows I will try to distil from the literature factors that distinguish those who rise to senior positions from those who do not.

\section{Section 2.2: The Quantitative Literature}

In this section I review a selection of the kinds of studies that have been done on issues relating to the selection and de-selection of ministers. It is not suggested that these are representative of the entire field. However, they do give a good idea of the approaches that have been taken and the variables that have been used. The variables identified in these studies give a good overview of the kinds of variables that are likely to be useful in developing a cabinet selection model. It should be noted however, that most of these studies do not directly compare those who have been selected for senior positions with those that have not.

The first issue to deal with is the distinction between selection studies and deselection studies. This thesis is concerned with the selection of CMs. However, there is a stream of the literature which deals with de-selection. That is, it looks at the factors that lead to the characteristics of CMs that lead to their removal from cabinet. Although these are not directly relevant to the issue of selection it is worthwhile noting some of the findings.

A good recent example of the de-selection literature is Berlinski, Dewan and Dowding (2007) which examines the influences on a minister's "risk" of losing their position in cabinet. In this study a Cox proportional hazards framework is used to model the time to the resignation of a minister. The finding is that Oxbridge education and 
female gender have a significant effect on reducing hazard. Also significant are ministerial rank, which reduces hazard, and ministerial experience, which increases hazard.

An extension of the above study is Berlinski, Dewan and Dowding (2010) which examines the effect of ministerial performance as well as that of the government as a whole on the likelihood that a minister will resign. The measure of ministerial performance is the number of calls for the resignation of the minister reported in The Times while the measure of performance for the government is the number of call for the resignation of the other ministers reported in The Times (Berlinski et al 2010: 562). Observable traits of ministers controlled for are gender, educational background, rank and nobility. There are also controls for whether the individual had experience in a previous government and whether she received a resignation call in that government. Various controls are included for the government in which the minister served such as size of the majority as well as a dummy for different leaders which enables different baseline hazard rates to be compared as between different leaders.

The study shows that, where a minister faces a first resignation call, her hazard rate rises relative to that of a colleague who has not had any call for her resignation. For a second and subsequent resignation call the hazard rate rises again. For a minister who has no calls for his/her resignation, a unit increase in the cumulative calls for resignations of other ministers decreases her hazard rate. Thus, there is evidence for both relative assessment and collective responsibility. 
In a further specification of the model, two interaction terms are included which consist of i) a dummy for first resignation call $\mathrm{x}$ the cumulative government calls and ii) a dummy for second resignation call $\mathrm{x}$ the cumulative government calls. The idea here is to test for the possibility that the hazard rate of an individual minister is affected by the interplay between the performance of the minister and the performance of the government. Only the first interaction term is statistically significant. Specifically, it shows that, upon receiving a first resignation call, a minister's hazard rate increases by $6 \%$ for every call for a resignation that has been made for a colleague. This clearly shows the link between collective and individual responsibility. In other words, an individual minister will suffer the consequences of the failings of her colleagues (Berlinski, Dewan and Dowding 2010: 568).

While this study gives a good indication of the reasons why a minister might be de-selected, it does not give us an insight into reasons why a parliamentarian who is not a minister might be selected to be a minister. Having said this, it is clear that performance is likely to be an important issue but the reasons why parliamentarians are selected to be ministers are likely to be quite different from the reasons why ministers are de-selected, largely because parliamentarians who have not been ministers have no public performance upon which the public might judge their suitability for office.

Before leaving the issue of de-selection it is worthwhile noting that there is a stream of the literature that deals with cabinet durability (Alt 1975; King, Alt, Burns and Laver 1990; Grofman and van Roosendaal 1997). This stream of the literature deals with the extent to which cabinets as a whole are likely to change. The standard variables used to explain cabinet durability are based on the political and institutional factors that 
influence cabinet formation. These include party strength, ideological composition of parties that form the government coalition, fractionalisation and constraints on the leader to call early elections and a number of similar variables. There is evidence that these standard factors that are associated with cabinet duration are unrelated to ministerial de-selection (Huber and Martinez-Gallardo 2008).

I now move on to the section of the literature that is more likely to cast light on ministerial selection than the de-selection and cabinet durability literature - the analytical quantitative literature that has directly addressed the minister selection issue.

One of the earliest studies of ministerial selection is Buck (1963) which compares MPs who did not rise to CM positions with those who did. The major finding is that the MPs who entered parliament at an earlier age and those who received an early promotion to junior roles such as parliamentary private secretary are more likely to become senior ministers. The conclusion drawn by Buck is that it is those who have deliberately chosen a career in politics that become senior ministers. Those who later go on to become CMs enter the House of Commons at an earlier age and "... seize the opportunity..." for promotion once there (Buck 1963: 631).

One of the few recent studies that addresses the issue of cabinet appointment is Kerby (2009). Using data for the period 1935-2008 and a Cox proportional hazards approach, this study uses the time from becoming a member of the government party to the time of appointment to cabinet to model the probability that a given MP will 
experience an appointment event at time T given that she has "survived" up to that point without the event occurring. Those MPs who cease to be a member of the government party before they are appointed to cabinet are treated as censored. The implicit idea here is that those who are appointed earlier are considered more suitable than those who are not. The two extremes of suitability are represented by the member who is appointed to cabinet but does not yet have a seat in the HOC and the permanent backbencher (Kerby 2009: 596).

The independent variables are divided by Kerby into the personal and the political. The personal variables include those that members bring to parliament as new members. These are gender, university education, legal training and age at appointment. Also included are personal factors that vary after becoming members: previous ministerial experience, margin of victory in the MP's electorate, and whether the MP has challenged the PM for leadership. Political factors are the share of seats held by the government party in the MP's region (Western Canada, Ontario, Quebec and Atlantic Canada), the size in percentage of the government party's majority, a dummy variable for Liberal party status, and prime minister's term (1-5). The study does not include Senators because senators are not elected in the Canadian system, nor are they generally appointed to cabinet positions (Kerby 2009: 609).

Kerby's first model includes variables for gender, legal qualification, university education and age. All these variables are significant at the $\mathrm{p}<.01$ level. Female gender,

1 The term "survived" here is used in the Hazard modelling sense in that it denotes a characteristic of having not "suffered" a condition to which she was under some "risk" of "suffering". These terms have a negative connotation but clearly an increased "risk" of becoming a member of cabinet is a positive event and "survival" in this context actually means languishing on the backbench or in some junior ministerial role. As such I will use the term "chance rather than "risk" in the remainder of the discussion. 
legal education, university education and age up to 42 increase chance of being appointed to cabinet with legal education being the most influential. Legal education increases the chance of appointment to cabinet by 1.31 percentage points.

A second model includes years of previous ministerial experience, margin of victory in the MP's electorate, leadership challenger status, regional seat share and government majority in the HOC. The results show that previous ministerial experience is highly significant, increasing the risk of appointment by 373 percentage points over those without previous ministerial experience. Being a leadership challenger increases the chance of appointment by 123 percentage points. For each unit increase in the MP's electoral majority there is a $1 \%$ increase in chance of appointment, indicating that there is an advantage for MPs who do well electorally. However, the government's vote share in the MP's region is slightly negatively associated with chance of appointment, indicating that an MP who wishes to become a $\mathrm{CM}$ is at an advantage if her party does not do well in her region. Similarly, as the government's vote share in the HOC increases, chances of appointment fall slightly but significantly $(\mathrm{p}<.01)$. In contrast to the results in the first model, the university education variable is not significant $(p<.1)$ in the second model. However, the legal education variable is still significant $(\mathrm{p}<.01)$ but, in comparison with the first model, has a lower influence on chances of appointment, increasing the chance by only 70 percentage points in comparison with 131 for the first model.

The third model includes dummy variables for the Prime Minister's second, third, fourth and fifth terms. Only the second and third of these are significant $(p<.01$ and $\mathrm{p}<.05$ respectively). These variables indicate that an MP who is not appointed in the 
PM's first term suffers a significant decrease in chances of appointment to cabinet in the PM's subsequent terms. An MP who had not been appointed to cabinet in the first term has a $70 \%$ lower chance of appointment in the PM's second term, and a $61 \%$ lower chance of appointment in the PM's third term. This indicates that the PM very early in her tenure as PM selects a cabinet that is the most durable from the individuals available. Those who are not selected are highly unlikely to be selected subsequently.

The major advantage of the Kerby study in terms of informing the current thesis is that it considers personal as well as representational and institutional factors. The most interesting aspect of the study is that it highlights the role of education and, specifically indicates that a legal education is likely to be a useful indicator of future success as a CM. This supports the idea that education is likely to be an important factor. However, it is worth noting that, in this particular instance, it is not the education per se that is being selected for. Kerby (personal communication, August 1 2011) has pointed out that in an interview with a particular Canadian Prime Minister it emerged that there was a tendency to select lawyers for cabinet positions in the Canadian parliament because individuals who had been screened by the Bar association were less likely to have "skeletons in the closet".

A disadvantage of the study for the current purposes is that it uses survival analysis rather than a method that can enable classification of individuals. Survival analysis enables the identification of variables that influence the "risk" of an event happening to an individual. However, it does not enable us to classify individuals into CMs and non-CMs. 
O’Malley (2006) uses logistic regression which means that the ministerial selection procedure is seen as a classification problem. The study's main emphasis is on the institutional, legal and political influences on the selection of ministers in the Irish Taoisigh.

A significant element of the study is that it explores ministerial selection in a context of a very small pool of potential ministers. Due to the size and nature of the institution, 30 members must be chosen for junior and cabinet roles out of the approximately 80 members who are legally and politically eligible. Furthermore, the pool is such that interpersonal rivalries as well as loyalties to play a significant part in ministerial appointment. Another important factor that differentiates the Taoisigh from other comparable systems is that the turnover of members of the legislature is quite low. This situation, coupled with the relatively small numbers to draw from, makes it difficult to dismiss CMs because a dismissal is likely to have a significant negative effect on personal relations in the party. All these factors lead to a situation in which reshuffles are less common than in other Westminster systems such as the UK and Canada (O’Malley 2006: 320).

O'Malley cites a number of other issues that must be taken into account in CM appointments such as geographical representation and internal party politics as well as the need to create a stable majority in the context of factions and coalitions. He also discusses the common issue of trading off loyalty for talent and other issues associated with selection on the basis of character. These ideas are discussed quite frequently in the literature. However, where the O’Malley study differs from the majority of discussions is that it addresses ministerial selection essentially using a case-control design. 
Variables included in the modelling are age, years since first elected, a dummy taking the value of 1 if the member has tertiary ("third level") education, personal vote as a proportion of the electoral quota, ${ }^{2}$ a dummy taking the value of 1 if the member had previously been a junior minister, the percentage party vote in the member's constituency, a dummy taking the value of 1 if the member is in the junior government party of a coalition, and a dummy taking the value of 1 if the member is from Dublin and environs. There are three models: a combined parties model and models for the two main parties Fianna Fáil and Fine Gael. The results of the analysis are as follow:

Table 2.1: Logistic Regression Results from O'Malley (2006)

\begin{tabular}{|l|lll|}
\cline { 2 - 4 } \multicolumn{1}{l|}{} & Full model & Fianna Fáil & Fine Gael \\
\hline Age & 0.99 & 1.01 & 1.02 \\
Years since first elected & $1.05^{* * *}$ & 1.02 & 1.03 \\
Third level educated & $2.68^{* * *}$ & $2.21^{* *}$ & $3.88^{* *}$ \\
Personal vote as \% of quota & $13.9^{* * *}$ & $37.33^{* * *}$ & $108.49 * * *$ \\
Previously a junior minister & $1.64^{*}$ & $3.26^{* * *}$ & 0.37 \\
Party vote in constituency \% & 1.71 & $308.61^{* *}$ & 0.04 \\
TD in junior govt' party & 1.28 & - & - \\
Dublin and environs & - & 1.31 & 2.05 \\
Pseudo R-squared & 0.18 & 0.275 & 0.198 \\
n & 1077 & 710 & 225 \\
\hline
\end{tabular}

Source: O’Malley 2006: 332. Note: Coefficients are odds ratios; ${ }^{*} \mathrm{p}<.05 ; * * \mathrm{p}<.01 ; * * * \mathrm{p}<.001$.

\footnotetext{
${ }^{2}$ The Taoisigh uses a version of the Single Transferrable vote to select members.
} 
Age is not significant in any of the models. According to O'Malley this is because ministers are appointed on the basis of how well known they are (O'Malley 2006: 331). The close knit personal nature of the small pool means that a member will not be appointed to cabinet unless she is known and the only way to get known is to have experience in parliament. ${ }^{3}$ There evidence for this in the full model in which the experience variable "Years since first elected" is significant. Tertiary education is significantly $(\mathrm{p}<.001)$ associated with increased odds of being a CM; in Fine Gael the odds ratio is 3.88 indicating that having a tertiary education increases the odds of being a CM by a factor of almost 4 . The lowest odds ratio for tertiary education out of the three models is that for Fianna Fáil at 2.21. Thus, across the board, tertiary education is a highly positive influence on cabinet appointment. The effect of having a high proportion of personal votes as a proportion of the electoral quota is a powerful influence on cabinet membership with odds ratios of 13.9, 37.33 and 108.49 for the full model, Fianna Fáil and Fine Gael models respectively. However, the effect of the party vote in the member's constituency is only significant in the Fianna Fáil model (odds ratio $=308.61, \mathrm{p}<.001)$. Having held a junior ministerial post is a positive influence on future cabinet membership for the full model (odds ratio 1.64, $\mathrm{p}<.05$ ) and the Fianna Fáil model (odds ratio 3.26, p<.001).

The O'Malley study includes variables that capture to some extent the characteristics of individuals likely to enter cabinet. It could be said that personal vote count, junior ministerial experience and tertiary education tap into underlying character traits. As with the Kerby (2009) study, the role of education is important. However, age

\footnotetext{
${ }^{3}$ The personalistic nature of Irish politics with its emphasis on local networks of support has been noted by others such as Gallagher (1985) and Marsh (1981).
} 
is not important and the reasons for this are related to the particular circumstances of the Irish parliamentary system.

A second study which uses a case-control approach is Kam, Bianco, Sened and Smyth (2010). This study uses a cross-sectional approach to examine the appointment of CMs and shadow CMs in the UK parliament over the period 1987-2005 on the basis of the extent to which they represent the ideological position of the other MPs in the broader party. The dependent variable is a dummy taking a score of 1 if, in a given parliamentary term, an MP was appointed to cabinet or shadow cabinet immediately after a general election or a change in the party leadership. All other MPs are scored 0 in that term including those who were appointed to cabinet in a mid-term shuffle. The ministerial selection variables included in the initial specification of the models are: first term promotion, which takes are value of 1 if the MP had a promotion to a noncabinet ministerial role in their first term and 0 if they did not; age at the start of the term; Experience at the start of the term; experience squared at the beginning of the term (to account for possible non-linear effects of experience); Oxbridge education, which takes a value of 1 for Oxbridge education and 0 otherwise; government, which takes a value of 1 if the MP's party was in government and a value of 0 if not and; dissenting votes, which is the number of dissenting roll call votes the MP cast in the previous term. All of these were found to be significant without including the variables for ideology. Positive coefficients were found for first term promotion, experience and Oxbridge education. The remaining variables had negative coefficients.

The next stage of the analysis involved introducing ideological variables. Ideology of individual MPs was based on a survey of MPs, data from which was 
analysed using principal components to yield two basic policy dimensions: 1) a leftright dimension, and 2) a dimension measuring support for the devolution of power from Westminster. Using these dimensions the Euclidian distances between individual MPs' ideal points and those of their parties and leaders were calculated. The findings indicate that an MP who is ideologically closer to their party's general ideological position is significantly more likely to be appointed to cabinet even after controlling for the standard ministerial selection variables cited above. The distance between an MP's ideological position and that of their leader was not significant.

The studies cited above are characteristic of the approach taken in the quantitative literature in general. In the Berlinski Dewan and Dowding (2007; 2010) studies it is existing ministers who are the subjects of the research and it is de-selection which is examined. There are several insights that are available from this stream of the literature in that there are clearly institutional and political, as well as personal characteristics, that influence leaders' decisions. However, these studies are not as relevant to the topic of selection as the Kerby (2009), O’Malley (2006) and Kam et al (2010) studies. These latter three studies deal with selection rather than de-selection.

The next stage in the attempt to find useful variables is to survey the qualitative literature. The purpose of this is to identify the most important variables for ministerial selection according to the descriptive and historical accounts. As with the quantitative literature, much of the literature is peripheral to my aim but there are observations which can inform the process of model building. 


\section{Section 2.3: The International Qualitative Research}

This section will concentrate on two major figures in the European qualitative research: Blondel (1991) and Rose (1975). These works represent approaches to ministerial selection which are often cited. The two approaches are contrasting in that they emphasise quite different characteristics, with Blondel emphasising the institutional settings in which ministerial skills can be attained, and Rose emphasising the more ephemeral characteristics of talent and ability.

\section{Blondel}

Blondel (1991) accounts for ministerial selection almost entirely in terms of institutional processes. In his conception of the process “...the only way to understand fully the nature of the ministerial career in cabinet government is to view it not just as emerging 'normally' from but as being truly part of a parliamentary career..." (Blondel 1991:8). Blondel cites Bagehot as the originator of this idea in that Bagehot considered cabinet to be a committee of parliament (Bagehot 1963: 66-7, cited in Blondel 1991:8). However, Blondel says that the committee conception of the ministry does not completely reflect the current reality because the technical and managerial complexities of the function of ministers are such that there is a greater gap in knowledge and experience between ministers and parliamentarians than existed in the past.

Blondel points out that in cabinet government systems in general, parliamentary origin is not a legal requirement. All that is required is that ministers be members of the legislature during their period as minister. From this he draws the conclusion that parliamentary origin is only relevant to ministerial selection if the individual has spent a 
significant portion of their working life in parliament. Blondel's idea is that in systems where there is a long pre-ministerial career, the system's emphasis will be on electoral representative practice, the reason being that an individual's long term expertise will be centred around representing their constituents in the hope of being re-elected. Where, on the other hand, ministers come from a system in which there is generally no substantial pre-ministerial career, managerial and technical skills will be emphasized (Blondel 1991: 11).

As well as political representation skills mentioned above, Blondel points out that a potential minister can develop specializations in particular fields through the Parliamentary committee system. In this way a parliamentarian can develop and apply specific technical skill in the scrutiny of legislation and administration, if not real decision making (Blondel 1991: 11).

Actual training in management, Blondel says, must be acquired by ministers before or during their parliamentary careers. Jobs that foster such skills are those in business, the civil service, interest groups or local and regional government. An alternative source of skill development is to become a junior minister in government. The role of junior minister, according to Blondel, was created to relieve the administrative burdens on more senior ministers as well as to provide a way of shaping party political representation in government, particularly in coalition governments (Blondel 1991: 12). Junior ministers in these roles can develop their own skills relevant to more senior positions while having access to the skills of managers in such positions. 
Blondel holds that, to be fully trained, a parliamentarian should have had a preministerial managerial or professional career. As most parliamentarians are not elected to the legislature until the age of 30 , some such pre-ministerial training is likely to have occurred in the pre-parliamentary stage. The parliamentary career is seldom the first, although choice of career may be on the basis of a desire for a future parliamentary career. Similarly, there is a cluster of professions from which parliamentarians tend to be drawn. Lawyers, teachers, party officials, and interest group organisers are most likely candidates. Businessmen and senior civil servants are less likely to be drawn to parliament but, if they do enter parliament, are more likely to accede to ministerial office because they are more likely to have the skills that general parliamentarian do not have (Blondel 1991: 13).

Overall, Blondel's position is that the background of ministers results in a perpetuation of the particular skills that are sought after in ministries. Pre-ministerial careers may supply specialist skills that cannot be developed by merely being an electoral representative in parliament. Furthermore, pre-ministerial time in parliament offers the possibility of developing the skills acquired in the previous career specialization via the committee system. As well of these sources of ministerial training, there is another factor influencing the supply of experienced ministers: training and recruitment are self-reinforcing. The effect of parliamentarians being drawn from a select cluster of occupations is that a particular set of skills is given prominence in most systems (Blondel 1991: 13). Thus, the skills that are selected for will be those that those who are attracted to parliament will already possess to some extent. 
It can be seen that Blondel emphasizes the development of skill sets and technical expertise in the training of potential ministers. However, he does not explain the process by which skill and expertise are assessed and ministers are sifted. His analysis seems incomplete without an account of factors other than skill and expertise required in the selection of ministers.

\section{Rose}

Rose (1975) takes an "inductive" approach to the problem and holds that ministerial selection is a process that is conditioned by the conventions and rules that have evolved in selecting ministers in the past. Thus the important issue is the kind of person the system elevates to ministerial positions rather than the characteristics of a potential minister (Rose 1975: 4).

According to Rose, there are three general considerations: factional and social representativeness, loyalty to the prime minister, and competence. Rose holds that these three characteristics must be either balanced within the individual, with a deficit in one or the other(s) being made up for by a surplus in the remainder(s), or there must be a similar trade-off within the cabinet as a whole.

Rose holds, as do other theorists, that the inclusion of factional representatives in the cabinet is a necessity however he also sees it as a potential benefit for the Prime Minister because it effectively silences potential critics via the convention of cabinet solidarity (Rose 1975: 6). This is quite a departure from the point of view that the need to incorporate representational or institutional interests is purely a cost or constraint. It 
implies that the PM has the opportunity to trade the costs of factional inclusion against the benefits.

Berlinski et al (2007), point out that the interests of the PM and her ministers may diverge. Similarly, Rose states that ministers are more likely to be interested in the performance of the government than the PM. The reason for this is that the PM is more likely to consider loyalty and representativeness as important ministerial characteristics than competence because his/her survival is dependent on a party vote. The competence of ministers is an instrumental aspect of government which has a less direct effect on the survival of the PM than loyalty and representativeness. Furthermore, he opines that the promotion of competence threatens the PM in that a large pool of competent ministers provides a large pool for his/her replacement (Rose 1975: p9).

Rose holds that the pool of potential ministers is substantially less than the number of MPs due to practical considerations such as age (between 30 and 70 being optimum), experience, and personal grounds such as ideological extremity, poor physical or mental health, and improper business or sexual association. The PM is left with a pool of approximately $2 / 3-3 / 5$ of the MPs. Of these, half will need to be given ministerial appointments or some kind in order to fill the required posts. Thus, there is a sense that in the lower levels of the ministry the leader has to choose ministers such that the talent level of the marginal ministers is lower than might be desired. At cabinet level, the competition is greater but the candidate calibre is higher so the issue is not so much who is appointed as what particular job they get (Rose 1975: 14). 
In terms of personal characteristics that mark an MP as having qualities that signal potential minister, the key skill is verbal ability: "Verbal skill goes beyond mere verbal fluency or rhetorical tricks. It also includes the ability to show conviction and in some cases, knowledge of complex matters" (Rose 1975: 15). According to Rose, verbal skill seems to underlie almost every aspect of a minister's performance. The following is a list of the roles distilled from Rose's account of a minister's duty:

i. Being responsible for all that is done in his/her department including potentially politically "explosive" issues;

Speaking in the HOC on behalf of his/her department to advance the department as well as to defend the government against criticism;

ii. Representing the department in inter-departmental negotiations and in Cabinet. This involves negotiating over administrative details, and competing with other departments for funds and parliamentary time for the passage of department related bills;

iii. Acting as spokesman to and negotiator with interest groups affected by the department;

iv. Presenting and publicizing the department through the media;

v. Presenting ideas in Cabinet on broad issues not related to his/her department (Rose 1975: 17).

All but i) are highly verbally intensive activities. Thus, verbal skill is an implicit requirement in most of the activities undertaken by a minister. 
The social interaction required in the HOC is such that successful ministers learn skills that reduce the effect of different social backgrounds among ministers. Personal relations skills include dealing with people in Westminster and being able to work with other politicians both co-operatively and competitively. This is, according to Rose, quite different from the "gladhandling" required in election campaigning (Rose 1975: 15).

As we have seen, Blondel (1991) considers that much of the training required for a minister can come from expertise derived from work in a committee. Similarly, Rose holds that the committee system gives an MP the opportunity to learn something of the subject matter needed in Parliament. But according to Rose, a minister cannot learn in the HOC all the skills required to be a minister. Skills that must be developed outside the HOC, according to Rose, include dealing with high volumes of paperwork and the ability to delegate tasks to civil servants without losing control over them. These, moreover, are not skills that are acquired by someone in the role of junior minister (Rose 1975: 16). In keeping with his inductive account, which considers the institution as the force which elevates certain types of people, Rose does not attempt to explain what kind of person develops these skills. Instead, he describes the institutional circumstances in which a minister has to function and infers that those who are able to function in such an environment have the required skills.

In order to further illustrate the kind of institutional background that results in people with certain skills being "selected", Rose draws from a then unpublished study of British cabinet ministers by Heady (1974). Heady breaks the work of a cabinet minister into three basic roles: 1) departmental representative; 2) departmental chief executive and; 3) key issues minister. These roles are described as follows: 
i. A departmental representative presents the work of the department to all external parties including other departments. HOC training here is invaluable in that ideas must be presented orally and the minister must relate well to others. To a large extent the basic skill is that of image management;

ii. A departmental chief executive requires a forensic commitment to departmental administrative detail. An acute sense of judgment is required in choosing between alternatives when the administrative process throws up alternative ways of doing things. Maintaining the flow of work through the department is essential because it is necessary to keep abreast of all that is happening in the department;

iii. A key issues minister must decide which issues the department is going to emphasize given the multitude of tasks and the scarcity of time. This is not a problem where a disaster forces the issue on a minister because the minister's discretion is not required. However, in circumstances where there is no such disaster a minister must make a decision and, in doing so, implicitly decides what issues to ignore. To some extent tasks can be delegated to junior minister and civil servants. However, the choice of what to delegate itself requires the exercise of judgment.

Rose holds that, of the three roles, that of the key issues minister most correctly characterizes the cabinet minister. This is because it is the initiation of programs reflecting the minister and her party's values that make a minister's influence felt. Conversely, the chief executive has no such influence on the on-going activities of the department and a chief executive's Permanent Under-Secretary could equally choose 
methods of prosecuting the administrative process. Similarly, the departmental representative does not necessarily promote policies or programs that are his own or those of his party (Rose 1975: 19).

This account, based on Heady's characterization of a minister's role, ties together Rose's previous general observations and in particular emphasizes the verbal communication skills required of a minister. But there is another skill which is important: the skill of judgment. Rose makes reference to the need for ministers to allocate their time, select the most appropriate of a number of alternatives of various kinds, and prioritize tasks and issues. This goes beyond the technical and bureaucratic skills mentioned by Blondel (1991).

\section{Summary of Section 2.3:}

The studies by Blondel (1991) and Rose (1975) only discuss ministers without in-depth comparisons with non-ministers. Therefore, they potentially suffer from the problems associated with selection on the dependent variable (Geddes 1990). However, they do offer insights into what might be helpful in a model of ministerial selection. Clearly, Rose holds that verbal ability is important. Thus, a model that intends to capture the qualities required of CMs should have some way of capturing verbal skills or proclivities. Furthermore, Rose emphasises that a minister needs to have good judgment. In contrast to Rose, Blondel holds that the institutional setting is important. However, Blondel's conception of the institutional setting is quite different from the institutional setting that is featured in the quantitative literature. One way to 
conceptualise his approach is to say that MPs enter parliament with a range of skills and ministers "emerge" from this system according to the extent to which they have developed the required skills. It is hard to see how Blondel's conception can be used to inform the current enterprise.

\section{Section 2.4: The Australian Qualitative Literature}

In the Australian literature there are no analytical accounts of how a Federal Australian parliamentarian rises to the ministry. However, there are biographical and descriptive accounts, and, from what can be learnt from such accounts, it seems that the process is very similar to the process that occurs in the UK with similar influences of representational and institutional factors setting constraints on the Prime Minister. The qualitative accounts of the role of personality and personal characteristics also provide a good source of ideas as to what makes a minister, with verbal ability again surfacing as an important characteristic. Finally, the biographical accounts provide some idea of the kinds of general qualities that lead to an individual rising to cabinet.

\section{Representational and Institutional Factors}

There is little systematic discussion of representational or institutional influences on ministerial selection in the academic literature. Where reference to these types of variables is made the reference tends to be descriptive. I mentioned above that Weller (2007) makes the observation that the selection process for LNPC ministers is like a “...jigsaw: balancing the powerful states, the Senate and the coalition" (Weller 2007: 
199). Tiernan and Weller (2010) make a similar claim pointing out that there are pressures on a leader to take account of the various demands to include geographical, factional, parliamentary (HOR vs Senate) and gender interests. Age is also an issue, although there are conflicting demands. The age structure of cabinet is said to require not simply a mirror image of the age structure of parliament but instead an allowance for the arrival of "new blood" (Henderson 2000). Similarly, experience is valued highly so we would expect an astute leader to make her cabinet on average more experienced than the average parliamentarian. Factions are perceived to be important variables in the discussion of ministerial selection, particularly in the ALP. There are also factions in the LNPC but, being a coalition the two LNPC parties are effectively the most significant two factions.

The descriptive observations from the Australian literature mirror the observations made in the quantitative literature. It will be recalled that Kerby (2009) and O’Malley (2006) included variables for MP's geographical regions. Buck (1963), Kerby (2009) and O’Malley (2006) and Kam (2010) included variables for age. Kam (2010) and O'Malley (2006) included a variable representing the length of experience of an MP in parliament. In the tangential de-selection literature, Berlinski et al (2007; 2010) include a variable for gender and find that female gender increases the risk of deselection. In the qualitative literature Rose (1975) mentioned the importance of geographical, factional and social representativeness. The point here is that the general findings in the international literature that factors unrelated to personal ability and personality are taken into account by leaders in their selection of ministers is mirrored in the Australian qualitative literature. 


\section{Personality and Behavioural Factors}

Barry Cohen, a junior minister in the Whitlam and Hawke governments, gives a slightly frivolous account of parliamentary life in Australia in How to Become Prime Minister. He observes that to be marked as possible minister material you need to have “...applied yourself assiduously to your parliamentary responsibilities, made some impressive speeches, produced excellent papers on aspects of party policy and received good media coverage on a couple of subjects in which you have specialized" (Cohen 1990: 227). Cohen points out that these activities must be directed to different individuals depending on which party or coalition a parliamentarian is from. For LNPC parliamentarians it is necessary that the leader notice these activities as it is the leader who both selects ministers and allocates portfolios. In the case of the ALP it is the Caucus which must notice an aspiring minister as, traditionally, the ALP traditionally Caucus elects the ministry/shadow ministry while the leader merely allocates portfolios. It should be noted that there is some evidence that Rudd departed from this tradition and made his selection unilaterally although his selection of ministers took place after "consulting widely with the leadership group and the transition-to-government team" (Tiernan and Weller 2010: 27).

Cohen's account is interesting because the specific qualities he mentions - skills in parliament, media liaison, policy development and speechmaking - are often mentioned by others in their accounts of why certain individuals rose to the ministry. In the following account of how Fraser selected ministers we will see that some of these 
qualities are mentioned. However, the most interesting aspect of the account of Fraser's ministerial appointment process is that it seems to have been opaque to Fraser himself.

Weller's (1989) account of how Fraser selected ministers casts light on the ministerial selection process because, paradoxically, it demonstrates that perhaps leaders themselves do not know how they select CMs. Fraser basically gives different and conflicting accounts of how he selected ministers. In one account, Fraser says that he selected ministers not on the basis of personality but on the basis of their ability to cope with the pressures of the job. Thus, Fraser claims he eschewed personality in the selection of then backbencher Senator Fred Chaney for a ministerial role. Fraser says he chose Fred Chaney even though Chaney had not voted for Fraser as Liberal party leader. Chaney was surprised to get such support from a man he had not himself supported. According to the account given by Fraser, Chaney's lack of support was irrelevant as Fraser felt that, with the leadership contest over, the party needed to function as a unit and Chaney had the talent needed in the ministry (Weller 1989: 62). This seems to be an objective, or at least non-personality based appointment process. However, Fraser is subsequently quoted as saying, in reference to the Chaney appointment "...[y]ou think that the guy can do the job without having enumerated the particular things about him that led you to the conclusion. You are just convinced in your own mind and that's your judgment of people" (Weller 1989: 63). This subjective assessment seems to be based on some aspect of "personality" which, according to the earlier account, Fraser eschewed for the purposes of ministerial selection. Thus, we have an objective account of Chaney's selection and a subjective account, both from the same source. 
To complicate the picture, Fraser gives an entirely different account of the reasons for appointing the then junior minister John Howard to cabinet. In relation to the Howard appointment, Fraser claims he assessed parliamentarians' abilities by their records. John Howard was chosen to succeed Philip Lynch as Treasurer in 1977 because “...[Howard] had performed well as minister for Special Trade Representations and could debate well” (Weller 1989, p63). The latter quality was seen as particularly valuable in election campaigning. This objective approach seems to be similar to the objective account of Chaney's appointment. However, it should be noted that in the objective account of Chaney's appointment, no actual qualities were mentioned: Fraser simply states that Chaney "had the talent" but what objective qualities this talent was assessed on is not stated. This contrasts with the case of Howard in which two qualities were specifically enumerated. In short, it is difficult to find any systematic thought in Fraser's appointment process. This is not to say that he did not have a systematic method, merely that he may have been more subjective than he imagined. This is not unusual in the identification of talent. Lewis (2004) points out that the selection of professional baseball players is, traditionally, a subjective assessment of objective qualities. Thus, a traditional baseball scout will subjectively assess the ability of a junior baseball player on the objective ability to score home runs. Whether or not an individual has a high rate of scoring home runs is an objective phenomenon. However, when asked how they make their decisions, that is, how they determine an individual's objective ability to score home runs, talent scouts tend to be as subjective as Fraser was in his account of his appointment of ministers while appearing to be using objective criteria. 


\section{Biographical Accounts}

The main problem with biographical accounts is that they tend to deal almost exclusively with the most prominent parliamentarians - the CMs and, to a lesser extent, JMs. Since federation there have been only 8 auto/biographical accounts of backbenchers (Selth 2007: 102). Thus, using biographical accounts involves the danger that the analysis could be skewed due to selection on the dependent variable (Geddes 1990). With this caveat in mind I would like to survey the biographical accounts of two of the best political performers in recent years: John Howard and Kevin Rudd. These two individuals provide good sources for the kinds of qualities that should be considered as differentiating between those that are $\mathrm{CM}$ material and those that are not. As we will see there are some characteristics revealed by both these individuals that have been noted in the literature on ministerial selection in general.

\section{John Howard}

The above discussion about Fraser's selection method was intended to highlight the fact that even when asked to explain their choices directly, a leader might not be fully aware of his reasons for making a decision. However, the discussion also brings into the foreground the early career of a superb political performer - John Howard. It is worthwhile to cover his early career in some detail as it demonstrates some of the skill required of an MP determined to rise up the political ladder. Furthermore, it shows how three of the qualities highlighted by Cohen - assiduous attention to parliamentary duties, giving well received speeches, and getting good media coverage - were the qualities that enabled Howard to rise through the ranks. 
The first stage in Howard's elevation from the backbench occurred when his party, the Liberal Party, was in opposition and he was selected by Fraser to be Chief Opposition Whip. This occurred less than 12 months after Howard entered parliament. Howard was considered a good choice as Chief Opposition Whip because he had developed good organizational skills through his work in the NSW branch. However, two days later shadow junior minister Bob Ellicott resigned and Howard was elevated to the junior shadow ministry in the roles of shadow spokesman on Consumer Affairs and Commerce as well as the shadow Attorney-General's representative in the Lower House. Less than 12 months later the LNPC won the 1975 Federal Election and Howard became Minister for Business and Consumer Affairs. His portfolio ranked third in the outer ministry (Errington and van Onselen 2007: 61). By December 1977 at the age of 38 he was Federal Treasurer.

Why was Howard promoted so quickly? Was it because he impressed people around him or was it because Fraser saw talent and rewarded it. Some evidence is provided by Errington and van Onselon (2007) who state that soon after arriving in parliament Howard had won respect of other politicians for the effort he put into the party, and had earned praise for his talent even from those whom he had crossed such as then Liberal Party leader Billy Sneddon (Errington and Onselon 2007: 59). This supports the objective interpretation of Fraser's procedure. Fraser seems to have been particularly impressed with Howard's parliamentary performance. While still in opposition, Fraser expressed to journalists how impressed he was that Howard was willing to "...mix it with Labor on the floor of Parliament" (Errington and Onselon 2007: 59). The motif of promotion for parliamentary performance we saw in Rose 
(1975) and Cohen (1990) is repeated here. It should be noted that praise for Howard's parliamentary performance may not have been confined to his own party. Errington and van Onselen report that in April 1975, while an opposition front bencher, Howard spoke on the Racial Discrimination Bill criticizing the inclusion of a provision for harsh civil penalties for proven cases of discrimination. His argument was that government coercion would be less effective than conciliation and education (Errington and Onselen 2007: 60). The bill was eventually passed without the coercive provision. Thus, either Howard had been able to convince the ALP government with his argument or he had successfully exploited a weakness in the government's ideological makeup such that those in the ALP who supported the coercive approach could no longer justify their position. Either explanation provides an example of an impressive parliamentary instinct and it is possible that this is the kind of performance that Fraser responded to.

It should be stressed that during this period, Howard was assiduously cultivating journalists and was being open and friendly to all he met, even when the openness was forced (Errington and Onselen 2007: 60). This is an important factor to consider in the overall explanation of Fraser's decision to appoint Howard to the Government ministry in November 1975. One of the considerations facing Fraser may have been how he could justify to the public not including in the government a member who was known and ostensibly liked and admired by the public.

One other factor possibly contributing to Howard's rise was the presence of two of his political mentors on the senior frontbench (Errington and Onselen 2007: 60). There are accounts of successful members mentioning the importance of mentors in their rise through the ranks: Keating mentions Lang (Kelly 2011: 10); Latham mentions 
Whitlam (Donovan 2004: 280). This is in keeping with Camp's study of the Mexican elite of the late $20^{\text {th }}$ century which emphasizes the importance of a mentor giving general advice in the process of building up a career (Camp 2002: 24). One of the observations in Camp's study is that a high proportion of Mexican elite members had mentors who were in the same power circle (Camp 2002: 24). Such mentors could give advice and moral support at times of crisis as well as providing overall strategic input. Thus, it is possible that Howard was able to benefit from the presence of his mentors on the frontbench, a position which gave them a particularly good insight into the interstices of the party which they could pass on to their protégé.

The account of Howard's accession to the ministry brings into focus more than just Fraser's procedure: it highlights the role of Howard himself. That is, although the leader and other institutional factors may be important considerations in explaining the rise of a minister, the individual's skills clearly play an important role. Howard had personal networking skills, speechmaking skills, parliamentary skills, media skills and a keen sense of judgment on political matters. In the following account of Rudd's rise from backbencher to senior opposition minister we will see a similar collection of personal qualities at play.

\section{Kevin Rudd}

When Rudd was a new backbencher in the ALP opposition in 1998 he was ambitious to be more than "just a good local member" and intended to be the person next in line to be the shadow Foreign Minister. An equal concern was to ensure that he held on to his own electorate (Stuart 2007: 105). The electoral situation was precarious: 
Rudd was concerned that the 1998 swing to Labor which gave him his seat was a reversal of the anti-Labor swing of 1996 and he was concerned that it might swing back at the next election. For this reason he took on the task of getting to speak to as many of his constituents as possible. His rationale was that they would get to like him if they knew him (Stuart 2007: 105). In order to raise his profile he made himself available to reporters and engaged in the usual activities of a backbencher such as weekly visits to shopping centres.

However, his commitment went beyond mere contact. He seemed to be genuinely interested in his constituents' concerns. One example of the extent to which he would involve himself in local affairs was his support of his electorate's opposition to the expansion of Brisbane Airport. The local concern was that the expansion would increase air traffic over the area and have adverse impacts on the quality of life and property values. Rudd's method was to gather as much information as he could and then take the issue to court. Stuart reports that Rudd spoke to "every pilot he could get hold of" and that he would contact international airports to find out details of the possible effects of different wind patterns on the noise level (Stuart 2007: 128). Legal proceedings to prevent the expansion were not successful and there was some suggestion that Rudd was using the issue to gain political credibility in his electorate (Stuart 2007: 129). However, the campaign had the intended effect of significantly raising his profile in the electorate.

As well demonstrating his ability to raise his profile, this episode gives another insight into Rudd's potential. We saw that Rose's (1975) account of a minister includes the ability to discuss issues outside their department's ambit. This suggests that it is 
adaptable generalists who do well as cabinet ministers. With the airport issue, Rudd demonstrates this kind of highly adaptable behaviour. There is no suggestion that Rudd was a specialist in Blondel's (1991) sense in relation to airport planning. But his willingness to tackle technical issues in which he had no previous background seems to be a paradigm example of the kind of generalist adaptability that marks successful ministers in the Anglo-Australian model.

Three years after he had arrived in parliament, Rudd was appointed to a senior role in the opposition executive as spokesman on foreign affairs. In order to do this he had to displace the incumbent Foreign Affairs spokesman, long running ALP party identity Laurie Brereton who had been a CM in Keating's cabinet. Thus, a relative neophyte had replaced a stalwart. The qualities that propelled Rudd seem to have been ambition, attention to detail, a willingness to engage with his constituents, and an ability to successfully network within his party. These are characteristics that are easily subsumed within the typologies presented by Rose (1975). But there is another aspect of Rudd's character which seems to have been instrumental in his success. As the following episode demonstrates, Rudd seems to have been highly open to ways of addressing any impediments that he, or others, saw in his attempt to rise within the party.

In late 2003, when Crean's leadership of the Labor party was being contested, Rudd had considered running as a candidate. Rudd felt that he had credibility within the party because he had, by this stage, played a significant role in the development of the Labor party's policy on the invasion of Iraq. This experience included successfully staving off criticism that he had not been sufficiently decisive in his initial stance on 
Iraq. Despite this success he was advised by Tasmanian backbencher Harry Quick that he lacked sufficient humility to be supported by the party. Part of the problem, according to Quick was Rudd's 'diplomatic' language which was intended to project an aura of 'invincibility' (Stuart 2007: 152). According to Stuart, Rudd was taken aback by Quick's criticism as he had considered Quick, being a factional independent and a fellow Christian, as a likely supporter. Quick's comments led to his realization that he had to do something differently in order to become leader. At about the same time a group of backbenchers approached him and said that the leaders of the party were not taking account of what the backbenchers were saying.

Soon after these discussions Rudd began a religious discussion group which involved getting to know backbenchers better. He also began making frequent casual visits to other parliamentarians and generally making himself more accessible (Stuart 2007: 155). The important point about this episode is that it shows that Rudd had not lost sight of his own weakness in his rise through the party structure. He was willing to take on board what others were saying. Importantly, these comments were not coming from the upper reaches of the hierarchy - they were coming from those who were below him in the hierarchy.

If we were to compare the accounts of both Rudd and Howard there are several similarities that emerge. The most prominent is that both courted the attention of the wider community. In Howard's case it was the media that he used to gain attention, and in doing so he also got the attention of his party. In Rudd's case it was a high profile issue that affected his electorate. In both cases the effect was the same in that their profile was lifted. This seems to bear out Cohen's (1990) observations that it is 
necessary to get the attention of the leader. Another similarity between Howard and Rudd that emerges is that they were both highly skilled in the kind of parliamentary behaviour that Rose claims is essential for an aspiring minister. In Howard's case it was his networking ability that led to him getting a reputation throughout the party and, eventually, with the leader. In Rudd's case it was the behind the scenes negotiation with parliamentary colleagues that may have accounted for his rapid rise. Thus, in both cases, there is evidence of skill in the ways of working within the institution of parliament.

\section{Summary of Section 2.4:}

I began this section with some representative examples of the way the Australian qualitative literature discusses the importance of representational and institutional variables. I followed with a qualitative interpretation by an ex-minister, Barry Cohen, of the qualities that lead to appointment to the ministry. These were essentially skills associated with parliamentary performance, the media, policymaking and speechmaking. All these skills have one basic aim - to get the attention of those who do the ministerial selections. I then gave an account of how an ex-Prime Minister, Malcolm Fraser, accounted for his cabinet appointments. There was some overlap of the accounts of Cohen and Fraser with Fraser mentioning how Howard's parliamentary and speechmaking skill had prompted him to elevate Howard. However, an interesting outcome of the account of CM selection given by Fraser is that it was contradictory and applied inconsistently. I then went on to cover the early careers of two prominent CMs, Rudd and Howard. Both seem to have had one of the qualities enumerated by Cohen the ability to get the attention of the media. They also both seem to have had excellent 
skills in terms of working within the institution of parliament. Rudd seems to have exemplified the generalist minister typology that Rose (1975) says is the archetypal Westminster minister. Howard had the speechmaking qualities referred to by Cohen as being essential for an aspiring minister. Thus, the two cases seem to exemplify the skills enumerated by Cohen and also several enumerated by Rose in the previous section.

A final point should be made about the sources discussed in this section: verbal facility is at a premium in the majority of the activities enumerated by Cohen (1990) that ministers must excel in and which I have mentioned in relation to the reasons for Howard and Rudd's swift rise to ministerial status. In particular, Cohen mentions three skills which are verbally based: parliamentary speaking; negotiation with party colleagues; and liaising with the media. These three skills were associated with Howard's rise and the second two with Rudd's. As I mentioned in the previous section, Rose also makes a similar point about the prominence of verbal skills (Rose 1975: 15). Thus, there is consistent evidence that the role of verbal ability must be considered in any definitive analysis of what makes a CM.

\section{Summary and Conclusion - Chapter 2}

The quantitative and qualitative studies discussed above can be seen as a starting point for my investigation. There is a sense in which they all contribute to an understanding of how a parliamentarian rises from the backbenches to cabinet. However, only three of the studies discussed above deal directly with the problem of differentiating between cabinet ministers and non-cabinet ministers: Buck (1963), 
O’Malley (2006), and Kam et al (2010). To some extent Kerby (2009) deals with the problem but his study is only indirectly related to the problem in that the aim of his study is to determine the factors underlying the time to appointment of ministers.

What can be gleaned from the quantitative studies is that age and experience and some measure of education are likely to be useful in explaining cabinet appointments. Geography may be less useful: the geographical variables in Kerby (2009) and O’Malley were not significant while Kam et al (2010) do not include any geographical variables in their models. Finally, Kam et al (2010) indicates that gender is also likely to be useful. Thus, we have some starting point for how to approach the problem using insights gained from the four quantitative studies that most closely address the problem we are trying to solve.

It is difficult to see how Blondel's (1991) approach can be used to determine a set of characteristics that we could use to differentiate between those that were likely, and those that were not likely, to become CMs. Blondel (1991) gives no account of how ministers are assessed. His emphasis is on the institution of parliament and how it might be used to give potential ministers the skills they require. Rose (1975) on the other hand, gives a descriptive account of what he sees as necessary in a minister. One of the key issues that emerges from Rose's account is that verbal facility underlies almost all of the skills that a minister must have.

The descriptive Australian literature also gives us some ideas as to how to proceed. The observations from Weller (2004) and Tiernan and Weller (2010) about the importance of representational and institutional factors suggest that these are likely to be 
useful in explaining cabinet appointments. Included in such representational issues are the factional (in the ALP) and party (in the LNPC) demands on the leader to accommodate conflicting interests. As such, some account will need to be taken of these in the cabinet appointment models.

Cohen's (1990) observations are of most use in reinforcing the point made by Rose that ministers need to be verbally adept. Cohen does not state the importance of verbal skills directly but he does enumerate several skills, all of which require a high degree of verbal facility, thus complementing Rose's (1975) observation that verbal facility is important in a minister. Taken with what we observed in the accounts of Howard and Rudd - that the skills that led to their rise were essentially verbally based Rose's and Cohen's observations seem apposite. We will therefore need some indication of verbal ability at some point in our analysis.

Given the above observations, it is clear that both representational and institutional factors as well as "individual" factors such as verbal ability and education are likely to be important. I will begin the process of examining these factors in the next chapter by focusing on the representational and institutional factors. I will use a traditional hypothesis testing approach to determine whether a set of standard representational and institutional factors are significantly associated with cabinet appointments to the Howard ministry over the period 1996-2007. I will also look at appointments to the ALP shadow cabinet over a smaller time frame. I will then be in a position to determine whether representational and institutional factors are important in determining appointments to the frontbench. 
The Selection of Cabinet Ministers in the Australian Federal Parliament 


\section{Chapter 3: Representational and Institutional Factors}

\section{Section 3.1: Introduction}

In the previous chapter I examined a selective representation of the literature on ministerial appointment in order to determine what characteristics have been found to be associated with appointment to cabinet. I found that there were two broad sets of variables. On the one hand there are the representational and institutional factors (RIFs). These are the factors which a leader must take into account in order to make her cabinet "representative" of the various competing interests and institutional demands within the party. On the other hand there are individual factors which pertain to the individual independent of the RIFs such as verbal ability. In this Chapter I will examine the role of RIFs in the allocation of cabinet positions. I will first define what a RIF is using examples from the Australian federal parliamentary context. I will then develop a list of RIFs that are likely to be useful in explaining cabinet appointments in the Australian federal parliamentary context. The bulk of this analysis will come from the public discussion of cabinet appointments in the Howard government over the period 19962007. The interesting aspect of this part of the analysis is that it seems to be pressure to allocate cabinet posts on the basis of RIFs from the media as well as the party and the public at large that affects decisions of the leader. The importance of this aspect of the appointment procedure is that it casts light on how much pressure the leader is under to change the representational structure of cabinet to mirror the representational makeup of parliament. I will follow the public debate on the various RIFs with a descriptive 
account of whether the leader actually did respond to changes in the parliamentary proportions of the various RIFs by making changes to cabinet.

After the descriptive exercise I turn to the analytical question of whether the RIFs influence the probability of an individual becoming a CM. I do this because the literature points to an important role of RIFs in determining $\mathrm{CM}$ appointments. Furthermore, it makes intuitive sense that, if leaders work hard to ensure that cabinet reflects the makeup of parliament, there should be an advantage in coming from a large state or faction because your chances of being selected as a CM are increased. However, as I will demonstrate in the analytical part of the exercise, this is not the case. An analysis of cabinet appointments using logistic regression will demonstrate that, of the RIFs, only age and experience and dummy variables for three states are statistically significantly associated with cabinet appointments and the practical influence of each these factors is weak. I conclude the chapter with an explanation for this highly counterintuitive finding.

Before I begin the investigation it is worthwhile pointing out that the emphasis in this chapter will be on the LNPC over the period 1996-2007. I will attempt to provide some account of the Labor opposition over the same period to see whether the forces at work in both groups are similar. However, there is a problem with looking at the opposition over that period in that, during this period, there was a return to a longstanding ALP policy of recording all shadow ministers as being members of a general ministry rather than dividing them into a cabinet and a junior ministry. This is partly a historical tradition; Whitlam initially included all ministers in his first ministry in 1972 in a "super ministry" in which there was no distinction between junior and cabinet 
ministers (Freudenberg 2009: 257). Labor leaders have since had a propensity to do the same at various times, including much of the period under discussion. The effect of this is that over the study period of 1996-2007 we have only two years in which there is a breakdown of the ALP ministry into an inner and outer shadow ministry. These are the years 2005 and 2006. For the remaining years it is possible to come to an approximation of the cabinet by considering the importance of the portfolio. However, given variations in the importance of portfolios over time, using this as a criterion this could result in systematic errors that could significantly affect the generality of any findings. As such I will focus on these two years for the analysis of the ALP shadow cabinet appointment dynamics. This means that I will not have a 12 year time series for each of the RIFs as I do for the LNPC. Nevertheless, in the section in which I use panel data to attempt to predict shadow cabinet appointments I will demonstrate that the ALP data for the years 2005-6 enable me to say that there is some evidence that experience is important in the allocation of shadow cabinet positions.

A second issue with the ALP data is that, because the ALP was in opposition over the period in question, the nature of the media coverage was quite different compared with the coverage of the government. This is not to say that there was not concern expressed by regional and sectional interest groups when there was a perception that the ALP shadow ministry was not an adequate reflection of the parliamentary representation of those groups. However, the salience of the issues was lower and therefore the coverage significantly lower in terms of volume and vehemence.

For the above reasons I will focus my main attention on the LNPC. In Section 3.3 I will discuss a 12 year time series of cabinet appointments and include observations 
from the public debate that occurred in parallel with the appointments. In section $3.4 \mathrm{I}$ will test, using multivariate analysis, the proposition that cabinet appointments were connected to the parliamentary representation of states and territories, gender, house and party. I will also examine the influence of age and experience.

\section{Section 3.2: RIFs: Australian Federal Context}

I discussed in Chapter 2 the view in the literature that a Prime Minister is under pressure to allocate cabinet positions to reflect the representation of the party in parliament as a whole. Thus, a parliamentary party made up of $20 \%$ Queenslanders, for example, should have a cabinet of $20 \%$ Queenslanders. If an election were to lead to a decrease in the proportion of the party's parliamentary representation of Queenslanders there would be pressure on the leader to decrease the representation in cabinet of Queenslanders and increase the representation in cabinet of the states whose representation in parliament has increased. Similar arguments apply for factions (in the ALP), gender, house (House of Representatives versus the Senate) and, in the LNPC, the representation of the Liberal Party vis-à-vis the National Party.

There are three other factors which, while strictly speaking not RIFs, should be considered for inclusion in this part of the analysis because they are related to the pressures the leader is under to appease various interest groups. These are age, experience and, possibly, electoral performance.

Age and experience are slightly different from the other RIFs in that it is accepted that the experience and age of cabinet is not necessarily meant to mirror the average age and experience of parliament. The logical reciprocity in the relationship 
between these means that a leader who opts for a cabinet that is too young will end up with a cabinet that is not sufficiently experienced and vice versa. Thus, the leader is more likely to be concerned with getting the right balance of age and experience in her cabinet than in strictly mirroring the age and experience structure of parliament in the cabinet. Furthermore, a leader is justified in creating a cabinet that is experienced. However, a leader may also be under pressure to ensure that there are periodic infusions of "new blood" (Henderson 2000). This will be the case if there is a very significant difference between the average age of the cabinet and the average age of parliament. Thus, it is clear that simple representational issues may not be directly applicable to these variables but there is a representational element to them. As such it seems that age and experience should be included in the overall analysis of RIFs.

Electoral performance is not a representational factor in the sense of state, gender, party or house. However, there is some anecdotal evidence that Howard used electoral performance as a basis for awarding ministerial positions, albeit to the outer ministry (Errington and van Onselon 2007: 252; Milne 1998; 2003). Furthermore, Tiernan and Weller claim that ministers in the Howard and Rudd governments tended to hold seats that were "safe" and "fairly safe" (Tiernan and Weller 2010: 34). On this basis it could be said that electoral performance may be a representational factor in that there is pressure on the leader to give "representation" in the ministry to those who perform well electorally. It should be re-iterated that Kerby (2009) and O’Malley (2006) found a positive association between electoral performance and ministerial appointment. For these reasons I need to consider how to deal with electoral performance. 
The first issue is whether there is any evidence in the Australian context of cabinet positions being awarded on the basis of electoral performance. The answer is that there is not. The only indication that Howard considered electoral performance in allocating ministerial positions is in the context of junior ministerial positions, not cabinet positions: Jackie Kelly and Dana Vale were said to have been given positions in the junior ministry due to their electoral success (Milne 1998; 2003).

One closer examination the situation is far from clear. It seems that Howard needed a justification for the appointment of Jackie Kelly to the junior ministry and he used electoral performance as the justification. His justification for appointing her was that she had managed to win a traditionally Labor seat in a by-election with a significant margin (Errington and van Onselon 2007: 252). But there were concerns that this was not a valid justification because others had done similarly well electorally but not been similarly rewarded. Glen Milne put the case in the following words in The Australian

Howard's standard line has been to praise Kelly's performance as a marginal seats campaigner. Yet her critics have compiled statistics showing that on October $3[1998$, the date of the election] six other Liberal MPs also held the swings against them to under one per cent: in Hughes, La Trobe, Deakin, Gray, Makin and Leichhardt. What differentiates these results from Kelly, they ask (Milne 1998).

The real reason for Kelly's appointment, according to Milne (1998) was that it was a case of "teacher's pet" and Howard needed a justification for promoting her. 
In the case of the appointment of Dana Vale to the junior ministry there was no such evidence of favouritism. Thus it is possible that Howard rewarded her electoral success with a junior ministry. Nevertheless, even if Vale's appointment to the junior ministry was based on her electoral success, the fact remains that there is no evidence Howard allocated cabinet positions on the basis of electoral performance.

How do we account for Tiernan and Weller's (2010: 34) observation that ministers in the Rudd and Howard governments held safe and fairly safe seats? The first point that should be made about this observation is that there is no comparison with non-ministers so it is possible that, on average, non-ministers also held safe and fairly safe seats. The second point that can be made is that if there were a relationship between ministerial appointment and electoral performance, there is no way of telling, from the information provided, what the direction of causation was. An individual who has a marginal seat and subsequently becomes a minister will have higher name recognition and this could be manifested in a higher vote at subsequent elections. This is quite a different phenomenon from the leader awarding seats on the basis of performance but the result is the same - there is a positive association between having a relatively safe seat and being a minister. Which of these phenomena is at play is not made clear by Tiernan and Weller (2010).

The possible confounding effects of name recognition spills over into a third point that needs to be addressed. Kerby (2009) and O'Malley (2006) found a positive relationship between electoral success and ministerial appointment and I therefore need to consider carefully whether electoral performance may indeed be a factor I need to take into account, notwithstanding the concerns raised above. My answer to this is that 
the Kerby (2009) and O’Malley (2006) studies may have found the positive relationship between cabinet appointment and electoral performance due to the confounding effect of name recognition discussed above. As mentioned above, a person who is appointed as a minister in one period will tend to have higher visibility, and consequent name recognition, than someone who has always been a backbencher and this may have a direct effect on her vote share in a subsequent period. Thus it may be that, in the Kerby (2009) and O’Malley (2006) studies, CMs get a higher proportion of votes because they are $\mathrm{CMs}$ or were $\mathrm{CMs}$ in a previous period rather than because individuals who get higher votes are given CM positions. Both the O’Malley (2006) and Kerby (2009) studies use cross sectional studies involving "repeated measures" of individuals over time and it is therefore possible that name recognition is the causative factor. It is important to note that Kam et al (2010), who also used a cross sectional design, did not include electoral performance in their "standard" set of ministerial appointment variables. This is possibly because it is difficult to control for this confounding effect, although it should be noted that no such comment was made in that study. As the methodology in this chapter is effectively cross-sectional it is important to avoid the possible confounding effect of name recognition.

A final reason for not including electoral margin as a factor associated with cabinet appointments is that it is not possible to derive a common marginality measure for all Australian federal parliamentarians. This is because the HOR and the Senate use very different voting systems. The HOR uses the alternative vote while the Senate uses the single transferable vote. Thus, the "margin" means quite different things in the case of the Senate and the HOR. A second complication is that some Senators are appointed 
by the State governments when a state has a casual vacancy in the Senate. This means that in a given year it is possible that some individuals may have no electoral margin at all. The problem of having different voting systems in the two houses of parliament is not an important issue in a system such as Canada's where ministers are only rarely drawn from the upper house. Kerby excluded senators from his analysis because they are not elected members of parliament but as the number of CMs drawn from the Senate are relatively low this was not a major problem. In Ireland all but two of the maximum 15 members of cabinet must come from the Dáil Éireann (Lower House). If non-Dáil members are chosen they must be members of the Seanad Éireann (Upper House) but this occurs rarely (O’Malley 2006: 324). Therefore, O'Malley was able to disregard the Seanad in his study. Thus, Kerby (2009) and O'Mally (2006) were able to include measures of electoral success in their analysis because they focused on one house with one voting system. However in the Australian system ministers are typically drawn from both houses so the difference in voting systems presents an obstacle to including a common measure for marginality in any account of ministerial selection.

To summarise the above discussion, there is no evidence from the Australian literature that cabinet appointments have been made on the basis of electoral performance. Furthermore, there is no statistical evidence of an association between marginality and ministerial status: even if there were such a relationship it is possible that the relationship was due to name recognition rather than direct awarding of a ministerial position on the basis of electoral performance. Finally, there is no way, in the Australian system, to derive a common measure of marginality for all parliamentarians. 
Given the above considerations I will exclude electoral data from the representational models. The RIFs that will be considered are as follow:

\author{
Age \\ Experience \\ State/Territory \\ Gender \\ Party (Liberal Party, National Party) \\ House (HOR/Senate)
}

I will begin the next section of this chapter with a consideration of what "expected" representation entails and how to conceptualise it. Next, I will examine the various representation factors to see whether they significantly deviate from the "expected" level of representation. The idea here is that, the literature notwithstanding, I must examine whether the reality and the theory converge. That is, I must consider whether the leaders do actually allocate cabinet positions on the basis of RIFs. To do this I will need to calculate the "expected" number of ministers for each RIF. The expected number of ministers for a given representational factor is the number of ministers we would expect to be appointed on the basis of that representational factor if the leader appointed cabinet positions in proportion to the parliamentary representation of that factor. I will then need to compare the expected number with the actual number of ministers appointed. I will demonstrate that, during the Howard government, there were situations in which the expected and actual were quite closely connected. Thus 
there is evidence to support the literature. However, I will also demonstrate that there were situations in which there were substantial deviations.

I will include a consideration of the public discussion of the individual RIFs. This is because it is worthwhile to try to determine how the process is understood from the point of view of the actors themselves. In order to do this I will undertake a brief and selective survey of the changes to the frontbench as they were initially reported in the media. This provides a good overview of the public discussion because it involves direct quotations from the ministers, parties and leader as well as input from commentators. By doing this it is possible to see the kinds of issues that the actors consider as important in influencing the shape of the ministry. It should be noted that this overview must be incomplete given the large amount of coverage these issues get.

\section{Section 3.3: What Would Perfectly Mirrored Representation Look Like?}

In this section I wish to explore how the cabinet would appear if the leader attempted to select individuals for inclusion in cabinet in order that the RIFs were represented in cabinet according to their proportions in parliament. The following analysis uses data taken from the Hansard of the first session in parliament for each year over the period 1996-2007. From this data it is possible to determine the individuals present and to record their state/territory, party (Liberal or National), house (HOR/Senate). If an individual changed their state/territory, party or house during a given year this is reflected in the data for the following year. Gender is derived from the names of the individuals. Data for age and experience were derived from time of entry 
to parliament and date of birth from the various editions of the Parliamentary Handbook of the Commonwealth of Australia (1996-2008). Also used was the online edition of the Parliamentary Handbook available on the website of the Australian Parliament House (www.aph.gov.au) as at May 2008. Where there was any conflict between the book version of the Parliamentary Handbook and the online version, the latter was taken as the definitive source given that it was more likely to have been corrected.

Table 2.1 shows the relative proportions of the RIFs excluding age and experience $^{1}$ for the LNPC in Parliament over the period of the Howard government 1996-2007. Senators, for example, represented 27\% of the LNPC in Parliament in 1996. On average over the 12 year period, Senators made up $30 \%$ of the LNPC parliamentary cohort with a standard deviation of $1.5 \%$.

Table 3.1: Percentage RIFs - LNPC 1996-2007

\begin{tabular}{|l|cccccccccccccc|}
\cline { 2 - 14 } \multicolumn{1}{c|}{} & 1996 & 1997 & 1998 & 1999 & 2000 & 2001 & 2002 & 2003 & 2004 & 2005 & 2006 & 2007 & Mean & Stdev \\
\hline Senate & 27 & 28 & 28 & 32 & 30 & 31 & 30 & 30 & 28 & 29 & 31 & 31 & 30 & 1.5 \\
Female & 18 & 19 & 21 & 23 & 23 & 23 & 22 & 22 & 22 & 20 & 21 & 21 & 21 & 1.6 \\
Vic & 21 & 21 & 21 & 21 & 21 & 21 & 20 & 20 & 19 & 20 & 19 & 19 & 20 & 0.8 \\
NSW & 26 & 27 & 27 & 28 & 28 & 28 & 28 & 28 & 28 & 26 & 26 & 26 & 27 & 0.9 \\
Qld & 22 & 22 & 22 & 21 & 21 & 20 & 21 & 21 & 21 & 21 & 22 & 22 & 21 & 0.8 \\
Tas & 5 & 5 & 5 & 4 & 4 & 4 & 4 & 4 & 4 & 6 & 6 & 6 & 5 & 0.8 \\
SA & 12 & 12 & 12 & 13 & 13 & 13 & 13 & 13 & 13 & 11 & 11 & 11 & 12 & 0.7 \\
WA & 10 & 10 & 11 & 11 & 11 & 11 & 12 & 12 & 12 & 13 & 13 & 13 & 12 & 1.0 \\
ACT & 1 & 1 & 1 & 1 & 1 & 1 & 1 & 1 & 1 & 1 & 1 & 1 & 1 & 0.0 \\
NT & 2 & 2 & 2 & 1 & 1 & 1 & 2 & 2 & 2 & 2 & 2 & 2 & 1 & 0.3 \\
NP & 18 & 18 & 18 & 18 & 17 & 17 & 14 & 14 & 14 & 12 & 13 & 13 & 15 & 2.3 \\
\hline
\end{tabular}

The theory states that a prime minister will need to take these RIFs into account when selecting his cabinet. In 1996, for example, perfectly mirrored representation would mean that cabinet would consist of $27 \%$ senators, $18 \%$ females, $21 \%$ Victorians etc. Thus, in a cabinet of 15 persons, we would expect to see, in 1996, approximately 4

\footnotetext{
${ }^{1}$ Age and experience will be dealt with separately below.
} 
senators $(.27 * 15=4.05), 3$ females $(.18 * 15=2.7), 3$ Victorians $(.21 * 15=3.15)$, and so on for the other RIFs other than age and experience. As stated above, age and experience are slightly different and I will demonstrate below that these have their own distinctive patterns.

In the sections that follow I will descriptively examine the RIFs by selectively surveying the public debate in order to determine the extent to which Howard was under pressure to alter the representation of his cabinet. I will then examine, in relation to each of the RIFs, the extent to which the actual number of CMs deviated from the expected number.

\section{Section 3.1.1: National Party Representation}

The representation of the National Party (NP) in the LNPC gives us a good starting point for analysing RIFs in general because it is the only LNPC representational factor that approximates perfectly mirrored representation.

The public discussion of National Party representation is less controversial than the discussion of other RIFs. This is because there is an explicit Coalition Agreement which states that the number of ministers selected from the National Party will mirror the parliamentary representation of the National Party. Thus, there is little room for variation. However, there are times when controversial issues arise. An issue emerged in January 2006 when, as a result of a reduction in the number of NP junior ministers from 5 to 4, National Party members felt aggrieved and threatened to vote against government legislation in future (Schubert et al. 2006). Rather than address the 
concerns which emerged in relation to the outer ministry, Howard defended his move by saying that the National Party was over-represented in Cabinet. In fact, the NP was only marginally over-represented in cabinet and any reduction in cabinet representation would have resulted in under-representation. I will re-visit this controversy below when I consider the specific figures. At this stage it is important to note that what this controversy illustrates is that Howard was acutely aware of the fine-grained analysis that had to be applied to NP representation in order to fulfil the Coalition Agreement.

I demonstrated above that in order to measure the extent to which parliamentary representation of RIFs is reflected in cabinet we must start with the the expected number of members in relation to a particular RIF. This is the number of ministers we would expect given the proportional representation of the RIF in parliament (the Parliamentary Proportion) multiplied by the numerical size of the cabinet.

The RIF under discussion here is National Party representation. The Parliamentary Proportion of National Party parliamentarians is the number of National Party Parliamentarians divided by the total number of LNPC Members. Thus, the Parliamentary Proportion for the NP at any time $t_{1}$ is given by

No. of members of NP in Parliament $\mathrm{t}_{\mathrm{t}}$ / No. of members of the LNPC in Parliament $t_{t}$

Table 3.2 gives the figures for the calculation of the Parliamentary Proportion of NP parliamentarians for the period 1996-2007. 
Table 3.2: LNPC and NP Members and NP Proportion - 1996-2007

\begin{tabular}{|l|cccccccccccc|c|c|}
\cline { 2 - 13 } \multicolumn{1}{c|}{} & 1996 & 1997 & 1998 & 1999 & 2000 & 2001 & 2002 & 2003 & 2004 & 2005 & 2006 & 2007 & Mean & StDev \\
\hline No. LNPC in Parlt' & 129 & 130 & 131 & 117 & 115 & 114 & 117 & 117 & 116 & 122 & 126 & 126 & 122 & 6.39 \\
No. NP in Parlt' & 23 & 23 & 23 & 21 & 19 & 19 & 16 & 16 & 16 & 15 & 16 & 16 & 19 & 3.18 \\
Parl' \% NP & $18 \%$ & $18 \%$ & $18 \%$ & $18 \%$ & $17 \%$ & $17 \%$ & $14 \%$ & $14 \%$ & $14 \%$ & $12 \%$ & $13 \%$ & $13 \%$ & $15 \%$ & $2 \%$ \\
\hline
\end{tabular}

In Table 3.2 we can see that the number of members of the National Party in parliament in 1996 was 23 and the number of members of the LNPC was 129 . Thus, the Parliamentary Proportion of NP members was $23 / 129=.18$ or $18 \%$. To use this to determine the expected number of NP CMs we need to take into account the size of the cabinet. Table 3.3 shows that in 1996 the number of LNPC cabinet ministers was 15 .

Table 3.3: Actual and Expected LNPC and NP Representation 1996-2007

\begin{tabular}{|l|cccccccccccc|c|c|}
\cline { 2 - 15 } \multicolumn{1}{c|}{} & 1996 & 1997 & 1998 & 1999 & 2000 & 2001 & 2002 & 2003 & 2004 & 2005 & 2006 & 2007 & Mean & StDev \\
\hline No. LNCP CMs & 15 & 15 & 16 & 17 & 17 & 17 & 17 & 17 & 17 & 17 & 17 & 18 & 16.67 & 0.89 \\
No. NP CMs & 3 & 3 & 3 & 3 & 3 & 3 & 3 & 3 & 3 & 3 & 3 & 3 & 3.00 & 0.00 \\
Exp' No. NP CMs & 2.7 & 2.7 & 2.8 & 3.1 & 2.8 & 2.8 & 2.3 & 2.3 & 2.3 & 2.1 & 2.2 & 2.3 & 2.53 & 0.31 \\
\hline
\end{tabular}

The expected number of NP CMs in 1996 is the parliamentary proportion of NP members from Table $3.2\left(.18_{1996}\right)$ multiplied by the total number of CMs from Table 3.3 $\left(15_{1996}\right)=.18 * 15=2.7$. This is the number of NP CMs we would expect if the leader were attempting to mirror the NP parliamentary representation in the cabinet. In fact, as we can see from Table 3.3, the actual number of CMs from the NP was 3. This is effectively as close as possible to get to perfectly mirrored representation in that year. To call the difference between the actual and expected of .3 (3-2.7) an "overrepresentation" would be incorrect. The fractional result of 2.7 for the expected number of CMs is not interpretable as it is not possible to make a fractional appointment of an individual in order to achieve perfect representation. To put this into context consider a 
situation in which the leader tried to reduce the "over-representation" by reducing the number of NP CMs to 2 in 1996. This would have resulted in under representation. Thus, fractional differences in actual and expected representation should realistically be ignored. The important issue is whether actual and expected CMs differ by 1 or more.

So far I have examined one year only: 1996 but Table 3.3 shows the 12 year trend. The figure for the mean number of actual NP CMs (3) is simply the average of the actual number of CMs over the 12 year period. Similarly, the mean number of expected NP CMs (2.53) is the average number of expected NP CMs over the period. There is a significant ${ }^{2}$ difference between these but, as I demonstrated above, the difference is fractional (less than one) and therefore not important. The final figure of interest is the correlation between the expected and actual number of ministers. The correlation between the expected and actual number of CMs shows the extent to which changes in the expected number of CMs gave rise to changes in the actual number of ministers. If the leader attempted to change cabinet representation of NP CMs as parliamentary representation of NP CMs changed over time, we would expect that this figure would be positive. It should be noted that it is not possible to calculate this figure in the case of the NP because as Table 3.3 shows, the actual number of ministers did not vary.

With an objective measure of the expected number of CMs it is now possible to revisit the re-shuffle in 2006 discussed above. The number of NP members in Cabinet was 3 in 2005 and 2006 and Table 3.3 shows that the expected numbers were 2.1 and

\footnotetext{
${ }^{2}$ A p-value of below .05 can be interpreted as evidence for a difference between two means despite the low sample size $(n=12)$. However, due to the low sample size, a p-value above .05 cannot be interpreted as evidence of no difference between the two means.
} 
2.2 in 2005 and 2006 respectively. However, the difference is fractional and therefore difficult to eliminate without creating subsequent slight under-representation. Realistically, therefore, despite Howard's statement, the Nationals were not overrepresented in Cabinet. Furthermore, any reduction would have resulted in underrepresentation.

Over the long term, the representation of the NP comes as close as possible to perfect representation. For the 12 year period, the mean actual number of NP CMs was 3 while the mean expected number of NP CMs was 2.53. This fractional difference is significant $(\mathrm{p}<.01)$ but the difference between these figures is less than one indicating that there was no realistic over-or under-representation.

The NP scenario demonstrates the "gold standard" in cabinet ministerial representation in that there was a very close mirroring between the actual and expected number of NP CMs with insignificant differences between the expected and actual figures. This supports the view in the literature which holds that a leader is under pressure to apportion ministerial positions according to the parliamentary representation. It will become apparent that several of the RIFs are not represented in cabinet in proportion to their parliamentary proportions. The reason that National Party representation is paradigmatic is the Coalition Agreement which states as a requirement of the on-going coalition that the NP be represented in the Cabinet as closely as possible to its parliamentary representation. 


\section{Section 3.3.2: Female Representation}

Female representation provides a good contrast with NP representation because it is the most unrepresentative of all the remaining RIFs. This is possibly why the debate over the period 1996 - 2007 was spirited.

In the public discussion in general, the Howard government seemed to be concerned with issues of performance rather than gender representation. These issues became salient in October 1997 when Howard replaced CM Senator Amanda Vanstone with Senator David Kemp because of concern that concern Vanstone “...could not sell the array of policies being developed to tackle unemployment..." and because Howard had “...been impressed by Dr Kemp's aggressive selling of the Government's hardedged policies on schools and training, particularly literacy" (Short 1997a). Vanstone was demoted to the junior ministerial role of Justice Minister. Thus, there was a seemingly genuine concern that Vanstone's demotion was due to unsatisfactory performance. However the public debate focused on the fact that the female representation in cabinet had fallen.

Soon after Vanstone's demotion another controversial issue emerged when the Status of Women portfolio, which up until then was a portfolio with cabinet rank, was taken from a cabinet minister, Senator Jocelyn Newman and re-assigned to a junior minister, Judith Moylan. These individuals remained cabinet and junior ministers respectively but it was the portfolio that was re-assigned. The relative representation of women in cabinet did not change. However, in conjunction with the demotion of Senator Vanstone, it signalled a reduction, in the eyes of some, of the importance Howard placed on women's issues. According to Short, Howard had initially wanted to 
remove Moylan from her junior minister role as Minister for Family Services due to Moylan's inability to deal with the ALP's criticism of matters relating to the administration of nursing homes: Howard did not sack her due to pressure from Moylan's fellow WA Liberals (Short 1997a). It is interesting to note that at the same time as the above changes took place, Howard elevated two female backbenchers to parliamentary secretary positions. This was described by Short as being motivated by a desire to reduce the negative backlash that resulted from the changes that were seen as detrimental to female representation (Short 1997a).

In June 2000 there was speculation from "senior coalition figures" that the then sole woman in cabinet, Senator Jocelyn Newman, was intending to quit politics (Harvey 2000). The article stated that because Senator Newman was the only woman in the Cabinet, if she were to quit then Howard would have an obligation to promote another woman. Towards the end of the year Newman did in fact quit thus initiating a reshuffle. The reshuffle, on 19 December 2000, resulted in a fall in the number of women parliamentary secretaries by 1 and a fall in the number of junior ministers by 1 while the number of ministers at Cabinet Level remained at 1 with Newman being replaced by Senator Amanda Vanstone. Michelle Grattan echoed the rest of the popular press in her coverage of the reshuffle stating that, in contrast to Howard's insistence about quotas not being important to Liberal women, Vanstone's gender was crucial for her reelevation to cabinet (Grattan 2000).

In January 2007 Vanstone was sacked and the issue of quotas for women in the LNPC ministry arose again. Howard was quoted as saying "I don't think talented women in the Liberal Party do these [gender representation] sums every time there's an 
adjustment made - I think that is a rather patronising, old-fashioned view to take...Most of the talented women in the Liberal Party take the view that you've got to make decisions - sometimes they fall in favour of more women, sometimes they don't" (Schubert 2007). Thus, Howard seems to have been aware that the issue had high salience in the electorate and the media.

The above sample from the public discussion represents only a fraction of the discussion that took place in relation to the issue of female representation in cabinet. Much of the rancour with which the public debate about female representation in cabinet, as well as Howard's defensiveness, can be put down to the chronic underrepresentation of women in cabinet. Female representation in parliament averaged $21 \%$ over the period. This gave rise to an average expected number of female CMs of 3.54 over the 12 year period but actual cabinet representation averaged only 1.83 .

Table 3.4: Female CM Representation 1996-2007

\begin{tabular}{|l|cccccccccccc|c|c|}
\cline { 2 - 7 } \multicolumn{1}{c|}{} & 1996 & 1997 & 1998 & 1999 & 2000 & 2001 & 2002 & 2003 & 2004 & 2005 & 2006 & 2007 & Mean & StDev \\
\hline No. Fem' CMs & 2 & 2 & 1 & 1 & 1 & 1 & 2 & 2 & 2 & 3 & 3 & 2 & 1.83 & 0.72 \\
Exp' No. Fem' CMs & 2.7 & 2.9 & 3.3 & 3.9 & 3.8 & 3.9 & 3.8 & 3.8 & 3.7 & 3.3 & 3.5 & 3.7 & 3.52 & 0.40 \\
\hline
\end{tabular}

At the Cabinet Level there is a significant $(\mathrm{p}<0.01)$ difference between the long term expected (3.54) and actual (1.83) number of ministers. Thus, the representation of females in the LNPC over the period 1996-2007 shows a significant level of long term under-representation of 1 individual $(3.54-1.83=1.7)$. In the individual years 1998 2001 the under-representation was at two, reaching almost three in 1999 when the actual number was 1 and the expected number was 3.9. 
The next question is whether Howard changed the proportion of women in cabinet as the proportion of women in parliament changed. To ascertain this we need to look at the correlation between the expected and actual number of CMs over the 12 year period. Unfortunately, due to the small sample size of $n=12$, we cannot say that there is evidence that the number of actual ministers changed relative to the expected number of ministers. The reason for this is that the correlation of -.34 is not high enough with to establish an effect beyond mere chance. ${ }^{3}$

The standard arguments in the literature about representation do not apply to female representation in the LNPC cabinet over the period under discussion. The case of female representation provides a stark contrast to NP representation in that there is a significant departure from expected representation. The public's realization of this had an effect on the public debate and Howard responded to the concerns defensively in the media. It is possible that the reduce under-representation in the later part of the period were in response to the criticisms Howard received for the significant underrepresentation in the early part of the period (Table 3.4). However, I will demonstrate below that the situation is not as simple as the descriptive analysis above suggests. I have considered only the univariate situation. After controlling for other factors, I will demonstrate that there is no significant effect of being female on selection for cabinet. The actual reason for the lower level of female representation in cabinet is that women tend to be less experienced than men in parliament and it is the lack of experience of

\footnotetext{
${ }^{3}$ With a sample size of 12 , correlation coefficients with absolute values of .575 and .701 are significant at the $\mathrm{p}<.05$ level and $\mathrm{p}<.01$ (two tailed) respectively. Absolute values of correlation coefficients below these are not significant.
} 
women that leads to their lower level of representation. I will return to this issue in Section 3.4 below.

\section{Section 3.3.3: New South Wales Representation}

At several times over the period 1996-2007 NSW was significantly overrepresented. The public debate reflects this and Howard received a significant amount of criticism for giving cabinet a bias in favour of his own state (NSW).

On 25 June 2005 a report appeared in The Age which announced the end of a long-running feud between two Victorian branches of the Liberal Party, the CostelloKroger branch and the Kennett branch. One of the putative reasons for the ceasefire was the concern that Sydney was becoming the de facto capital of Australia (Age, June 25 2005: 10). The article states that the tension between the Prime Minister John Howard (NSW) and the Treasurer Peter Costello (Vic) was possibly based on a geographical difference rather than the usually stated conflict over leadership succession. A reshuffle that followed the resolution of the putative rift resulted in a decrease in the number of NSW CMs suggesting that Howard was responding to the newly unified Victorians who could now speak with one voice in opposing NSW over-representation.

The data show that there was support for the idea that NSW was overrepresented. Parliamentary representation of NSW over the 1996-2007 period averaged $27 \%$ with a high of $29 \%$ in 2004 and a low of $26 \%$ in the years 1996-97 and 2005-07. As shown in Table 3.5 this yielded an average expected number of NSW CMs of 4.55 over the period compared with the actual of 5.92. 
Table 3.5: NSW CM Representation 1996-2007

\begin{tabular}{|l|cccccccccccc|c|c|}
\cline { 2 - 15 } \multicolumn{1}{c|}{} & 1996 & 1997 & 1998 & 1999 & 2000 & 2001 & 2002 & 2003 & 2004 & 2005 & 2006 & 2007 & Mean & StDev \\
\hline No. NSW CMs & 5 & 5 & 5 & 6 & 5 & 6 & 6 & 6 & 6 & 7 & 6 & 8 & 5.92 & 0.90 \\
Exp' No. NSW CMs & 4.0 & 4.0 & 4.3 & 4.8 & 4.7 & 4.8 & 4.8 & 4.8 & 4.8 & 4.5 & 4.5 & 4.7 & 4.55 & 0.31 \\
\hline
\end{tabular}

This difference is significant at the $\mathrm{p}<.05$ level indicating a consistent overrepresentation of one individual at least $(5.92-4.55=1.37)$. Given the consistency and level of over-representation of NSW in Cabinet it is surprising that the public debate was not more vehement, particularly in 2007 when the over-representation of NSW in cabinet had risen to 4 individuals with the actual at 8 and the expected at 4.7.

More so than any other state, NSW was over-represented. Clearly, this means that other states/ territories had to be under-represented to counterbalance the numbers.

\section{Section 3.3.4: Victorian Representation}

At cabinet level there is a significant $(\mathrm{p}=0.01)$ difference between the mean expected (3.34) and actual (4.08) number of Victorian cabinet ministers (Table 3.6) but the difference is less than 1 indicating that the long term number of expected and actual number of ministers was effectively equal.

\section{Table 3.6: Victorian CM Representation 1996-2007}

\begin{tabular}{|l|cccccccccccc|c|c|}
\cline { 2 - 14 } \multicolumn{1}{c|}{} & 1996 & 1997 & 1998 & 1999 & 2000 & 2001 & 2002 & 2003 & 2004 & 2005 & 2006 & 2007 & Mean & StDev \\
\hline No. Vic CMs & 4 & 4 & 5 & 5 & 5 & 5 & 4 & 4 & 4 & 3 & 3 & 3 & 4.08 & 0.79 \\
Exp' No. Vic CMs & 3.1 & 3.1 & 3.3 & 3.5 & 3.5 & 3.6 & 3.3 & 3.3 & 3.2 & 3.3 & 3.2 & 3.4 & 3.34 & 0.15 \\
\hline
\end{tabular}

Furthermore, the expected and actual numbers are positively correlated $(\mathrm{r}=.56$, $\mathrm{p}<.1)$. Thus, there is some evidence that Howard adjusted the number of actual ministers in response to changes in the number of Victorian LNPC parliamentarians. 


\section{Section 3.3.5: Representation of South Australia}

Like NSW, South Australia experienced a long term trend of overrepresentation. However this fact rarely spilled into the public debate.

As we have seen, the two occasions on which South Australian Senator Amanda Vanstone's was sacked from Cabinet, in 1997 and 2007, were seen as losses to gender representation. There was almost no discussion in the mainstream press of that fact that removing South Australian Vanstone redressed the over-representation of SA. This may have been because the extent of gender under-representation was greater than the extent of South Australian over-representation.

There was no reason given for the long term over-representation of South Australia by Howard other than his standard explanation of ministerial appointments being based on talent. Thus, in 2007 when SA's over-representation was addressed, the debate took place in terms of the talent issue. Vanstone was replaced by Malcolm Turnbull (NSW) who had been a parliamentary secretary. In a feature on the reshuffle in The Australian in January 2007 (Australian January 24: 13) there was particular emphasis on the fact that Turnbull's role was to be as Environment and Water resources minister and that the promotion was, as Howard was at pains to emphasise, designed to capitalize on Turnbull's talents which had been admirably demonstrated in his role as parliamentary secretary. This is possibly why no mention is made of the fact that Turnbull's appointment meant that NSW was over-represented by three individuals at Cabinet level. Thus, it seems that the public had accepted Howard's idea that significant variations from perfectly mirrored representation were acceptable when promotion to 
CM was talent based. However, the South Australian Adelaide Advertiser, as might be expected given its regional bias, pointed out that the loss of Vanstone signalled a reduction of SA representation in Cabinet (Advertiser January 25 2007, p18). The report failed to mention that the actual number of SA Cabinet Members equalled the expected number of 2 (Table 3.7).

Table 3.7: South Australian CM Representation 1996-2007

\begin{tabular}{|l|cccccccccccc|c|c|}
\cline { 2 - 15 } \multicolumn{1}{c|}{} & 1996 & 1997 & 1998 & 1999 & 2000 & 2001 & 2002 & 2003 & 2004 & 2005 & 2006 & 2007 & Mean & StDev \\
\hline No. SA CMs & 4 & 4 & 3 & 3 & 3 & 4 & 4 & 4 & 4 & 4 & 3 & 2 & 3.50 & 0.67 \\
Exp' No. SA CMs & 1.9 & 1.8 & 2.0 & 2.2 & 2.2 & 2.2 & 2.2 & 2.2 & 2.2 & 2.0 & 1.9 & 2.0 & 2.06 & 0.15 \\
\hline
\end{tabular}

The long term trend of over-representation at the Cabinet level for South Australia is evident from Table 3.7 which shows that the mean expected number of Cabinet ministers was 2.06 while the means actual was 3.5. This difference is significant $(\mathrm{p}<.01)$. The actual and expected numbers are correlated but not significantly $(\mathrm{r}=.12, \mathrm{~ns})$ so we cannot say that there is evidence that the number of actual ministers changed in response to changes in the expected number of ministers.

I have shown that NSW and SA had long periods of over representation while Victoria had a sporadic period in which it was over-represented. The important point here is that these instances of over-representation add up and this means that other states must carry the burden by being under-represented. I will show below that there are two states in particular that carried the burden. 


\section{Section 3.3.6: Queensland Representation}

Queensland was significantly under-represented in cabinet over the 1996-2007 term. There was a great deal of discussion of why this was the case in the popular press. It seems that much of the pressure on Howard to increase Queensland's representation was ameliorated by his insistence, and that of others, that there was a lack of talent in Queensland.

In 2000 a reshuffle occurred in which the actual number of QLD ministers in cabinet was reduced to 1 while the corresponding expected number of CMs was 3.4. Franklin (2000) writing in the Queensland based Courier Mail opined that the lack of Queensland representation after the reshuffle was due to the absence of renewal of potential candidates. This had led to a situation in which sincere, but untalented, "timeservers" were all that remained in the Queensland branches. The Queensland party leaders were reluctant to remove mediocre performers and then blamed "southern bias" when the ministerial positions were not allocated to Queenslanders. Franklin felt that the entrenched systems of rewards for time servers dissuaded talented and ambitious people from entering politics in Queensland. The upshot was that “...the Queensland Liberals did not provide potential Cabinet members for grooming back in 1996”.

Whatever the actual reasons Howard had for not promoting Queenslanders to Cabinet, the fact is that there was significant long term under-representation of Queensland in cabinet. There is a significant $(\mathrm{p}<.01)$ difference between the mean expected number (3.56) and mean actual number (1.75) of Ministers equivalent to almost two individuals (Table 3.8). 
Table 3.8: Queensland CM Representation 1996-2007

\begin{tabular}{|l|cccccccccccc|c|c|}
\cline { 2 - 14 } \multicolumn{1}{c|}{} & 1996 & 1997 & 1998 & 1999 & 2000 & 2001 & 2002 & 2003 & 2004 & 2005 & 2006 & 2007 & Mean & StDev \\
\hline No. Qld CMs & 1 & 1 & 1 & 1 & 2 & 1 & 2 & 2 & 2 & 2 & 3 & 3 & 1.75 & 0.75 \\
Exp' No. Qld CMs & 3.4 & 3.3 & 3.5 & 3.6 & 3.5 & 3.4 & 3.5 & 3.5 & 3.5 & 3.6 & 3.8 & 4.0 & 3.56 & 0.18 \\
\hline
\end{tabular}

The expected and actual figures are positively correlated $(r=.76, p<.05)$ which shows that there was an attempt to react to changes in the parliamentary representation over time but, given the entrenched under-representation, the effect was that the expected and actual figures moved in parallel so that the actual number of QLD CMs never reached the expected. The situation is depicted in Figure 3.1.

Figure 3.1: Expected and Actual Queensland CMs 1996-2007

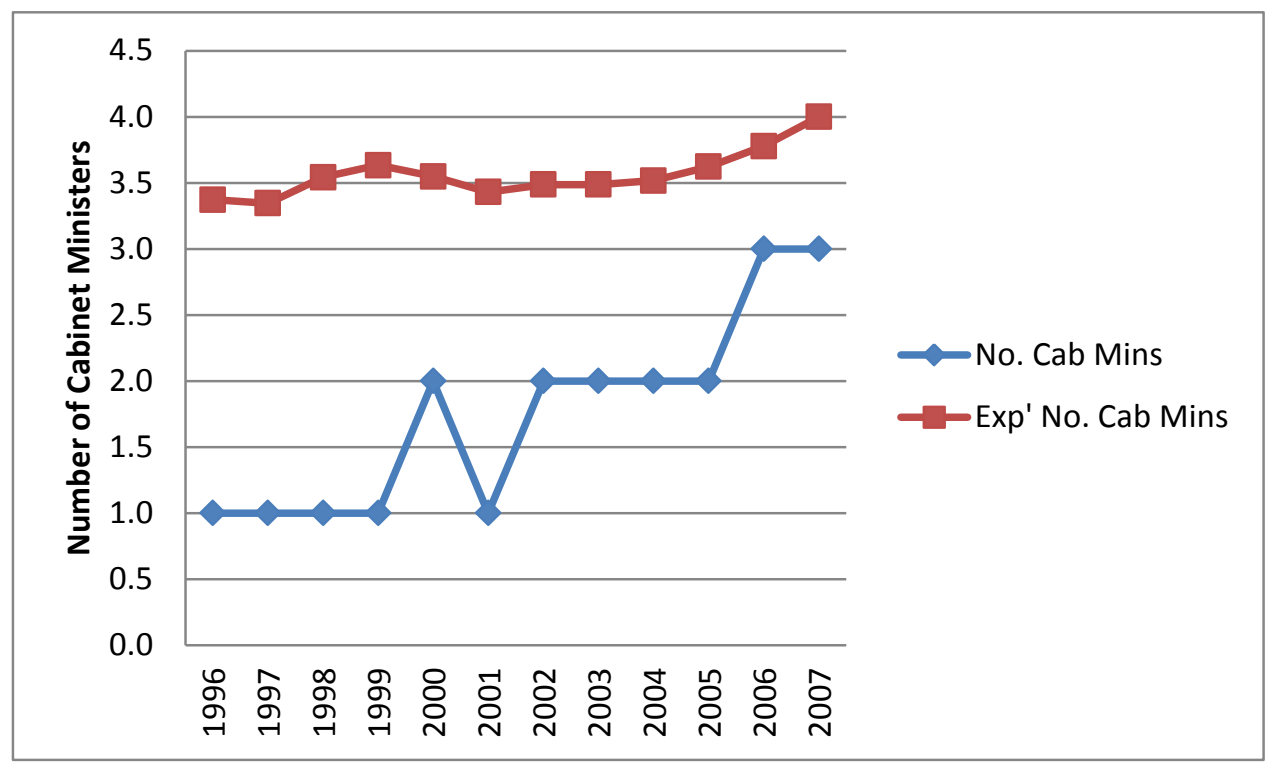

There is an obvious attempt to vary the number of actual CMs to match the changes in the expected number. However, the gap between expected and actual numbers never closes.

Queensland is one of the states that suffered significant under-representation to counterbalance over representation of other states at various times. 


\section{Section 3.3.7: Representation of Western Australia}

In 1996-1997 there were no CMs from WA despite the figures for the expected number of CMs being 1.6 and 1.5 respectively. A report in The Australian in October 1997 suggests that problems with the WA branch may have led Howard to disregard state balance:

Liberal sources said Mr Howard was not impressed with the [West Australian branch of the party] after years of damaging internal battles involving expelled former WA Senator Noel Crichton-Brown. Furthermore, West Australian Allan Rocher won Perth's safest Liberal seat of Curtin as an independent in 1996 after being "dumped by the party in a bitter pre-selection battle" (Price and Short 1997).

But there was pressure on Howard to appoint a CM from WA. WA State Premier Richard Court said that WA liberals should be included in Federal Cabinet given that "the state [was] producing $26 \%$ of Australia's export wealth (Price and Short 1997).

On 6 October a re-shuffle was announced and the Attorney General portfolio, previously a junior ministerial portfolio, was elevated to a cabinet portfolio and, along with it, the serving Attorney General, Daryl Williams. There was some suggestion that Williams' promotion was not entirely related to his ability. It was reported in The Australian that Howard was concerned that Williams was unable to control the statutory 
authorities he had responsibility for and that he lacked overall political ability (Short and McKenzie, 1997). The implication is that the elevation of Williams may have been due to a desire to redress the lack of WA representation in Cabinet.

After the election of October 9 2004, The West Australian reported Liberal sources as saying that, given WA liberals had won two seats from Labor at the October election, "...there was a case to elevate one more West Australian to Cabinet" (Middleton 2004). In fact, the expected number of ministers had barely changed. Prior to the election it was 2.1 (see Table 3.9) and after the election it was 2.2, with the actual number of CMs remaining the same at 1 both before and after the election. In other words, WA Liberals winning two seats from Labour did not substantially affect the level of under-representation. It is interesting to note that the WA liberals needed the election wins of 2004 to justify a claim to extra representation even though they were already entitled to an extra seat before the election. The actual number of CMs was 1 in both years so there was under-representation of 1 individual both before and after the election. This under-representation had existed since 2002 and was not actually addressed until 2006. This highlights the fact that the public debate quite often ignored the reality of the data.

The long term expected number of WA CMs was 1.94 which is almost 1 individual more than the long term actual number of CMs.

Table 3.9: West Australian CM Representation 1996-2007

\begin{tabular}{|l|cccccccccccc|c|c|}
\cline { 2 - 15 } \multicolumn{1}{c|}{} & 1996 & 1997 & 1998 & 1999 & 2000 & 2001 & 2002 & 2003 & 2004 & 2005 & 2006 & 2007 & Mean & StDev \\
\hline No. WA CMs & 0 & 0 & 1 & 1 & 1 & 1 & 1 & 1 & 1 & 1 & 2 & 2 & 1.00 & 0.60 \\
Exp' No. WA CMs & 1.5 & 1.5 & 1.7 & 1.9 & 1.9 & 1.9 & 2.0 & 2.0 & 2.1 & 2.2 & 2.2 & 2.3 & 1.94 & 0.25 \\
\hline
\end{tabular}


The difference in these long term means is significant at the $p<.01$ level. The actual and expected numbers were positively correlated $(\mathrm{r}=.85, \mathrm{p}<.01)$ which indicates that there was an attempt to change the number of actual number of CMs as the number of expected CMs changed over time. However, as with the case of Queensland, there was a gap between the two parallel sets of figures for much of the time but, unlike the case of QLD, the gap eventually closed in 2006-7 when the expected number of ministers was 2.2 and 2.3 respectively while the actual was 2 for both years.

The most salient aspect of WA representation is that there were large portions of the period in which there was an under-representation of 1 individual. In the years 19961997 and 2002 to 2005 there was a good representational argument for increasing the number of WA CMs. However, as we saw from a sample of the media debate, there was little impetus to address the issue at these times.

\section{Section 3.3.8: Representation of the NT, the ACT and Tasmania}

The remaining two Territories and the state of Tasmania are quite different from the other states due to the low numbers involved. I will deal with each briefly before going on to other RIFs.

To illustrate the problem the effect of small numbers it is worthwhile looking at the calculation of the parliamentary proportion for Tasmania which, as explained above, is the basis for the calculation of the expected number of CMs. Table 3.10 shows that, over the period 1996-2007 the average number of LNPC parliamentarians from all states and territories was 122 while the average number of LNPC parliamentarians from 
Tasmania was 6 . Thus, on average, Tasmanians represented $5 \%$ of the total number of LNPC parliamentarians.

Table 3.10: Tasmanian Representation in Parliament 1996-2007

\begin{tabular}{|l|cccccccccccc|c|c|}
\cline { 2 - 14 } \multicolumn{1}{c|}{} & 1996 & 1997 & 1998 & 1999 & 2000 & 2001 & 2002 & 2003 & 2004 & 2005 & 2006 & 2007 & Mean & StDev \\
\hline LNCP (Aust) & 129 & 130 & 131 & 117 & 115 & 114 & 117 & 117 & 116 & 122 & 126 & 126 & 122 & 6.39 \\
LNCP (Tas) & 7 & 7 & 7 & 5 & 5 & 5 & 5 & 5 & 5 & 7 & 8 & 8 & 6 & 1.27 \\
Parl' \% of TAS & $5 \%$ & $5 \%$ & $5 \%$ & $4 \%$ & $4 \%$ & $4 \%$ & $4 \%$ & $4 \%$ & $4 \%$ & $6 \%$ & $6 \%$ & $6 \%$ & $5 \%$ & $1 \%$ \\
\hline
\end{tabular}

With such a low parliamentary proportion of Tasmanian parliamentarians, the expected number of CMs averages .84 over the period 1996- 2007.

Table 3.11: Tasmanian CM Representation 1996-2007

\begin{tabular}{|l|cccccccccccc|c|c|}
\cline { 2 - 14 } \multicolumn{1}{c|}{} & 1996 & 1997 & 1998 & 1999 & 2000 & 2001 & 2002 & 2003 & 2004 & 2005 & 2006 & 2007 & Mean & StDev \\
\hline No. Tas CMs & 1 & 1 & 1 & 1 & 1 & 0 & 0 & 0 & 0 & 0 & 0 & 0 & 0.42 & 0.51 \\
Exp' No. Tas CMs & 0.8 & 0.8 & 0.9 & 0.7 & 0.7 & 0.7 & 0.7 & 0.7 & 0.7 & 1.0 & 1.1 & 1.1 & 0.84 & 0.15 \\
\hline
\end{tabular}

In the years 1996 to 2000 there was effective equality of expected and actual number of Tasmanian CMs with actual $\mathrm{CMs}=1$ and expected number of Tasmanian CMs varying between .7 and .9 . However, had there been no Tasmanian CM over this period we could also argue that this would have been justified until the expected number was equal to or greater than 1. Similarly, in the period $2001-2004$ when the actual fell to 0 and the expected was at .7 , it is difficult to argue that Tasmania was underrepresented given the fractional number of expected CMs. Thus, over the period $1996-$ 2004, there is an argument both for and against appointing a CM. As it turned out, for five of these years 1996-2000 there was 1 actual CM while thereafter there was no actual CM. In 2005 the expected number of CMs rose to 1 and in 2006 and 2007 to 1.1 so there was no longer any representational case for not appointing a CM. However, no 
Tasmanian $\mathrm{CM}$ was appointed. We can therefore say that there was underrepresentation in these years.

However, if we look at the situation over the long term a different interpretation is possible in that the periods of deviation from actual and expected representation cancel each other out. The mean actual number of CMs was .42 and the mean expected .84. There was, therefore, over the period as a whole, effective equality of expected and actual number of CMs.

As Table 3.12 shows, the NT makes up only $1 \%$ of LNPC parliamentary representation. As such there is some justification for the proposition that it is not entitled to ministerial representation at all on the strictly representational argument. This is possibly why no CM was appointed from the NT over the period 1996-2007.

Table 3.12: NT Representation: Parliament 1996-2007

\begin{tabular}{|l|cccccccccccc|c|c|}
\cline { 2 - 12 } \multicolumn{1}{c|}{} & 1996 & 1997 & 1998 & 1999 & 2000 & 2001 & 2002 & 2003 & 2004 & 2005 & 2006 & 2007 & Mean & StDev \\
\hline LNCP (Aust) & 129 & 130 & 131 & 117 & 115 & 114 & 117 & 117 & 116 & 122 & 126 & 126 & 122 & 6.39 \\
LNCP (NT) & 2 & 2 & 2 & 1 & 1 & 1 & 2 & 2 & 2 & 2 & 2 & 2 & 2 & 0.45 \\
Parl' \% of NT & $2 \%$ & $2 \%$ & $2 \%$ & $1 \%$ & $1 \%$ & $1 \%$ & $2 \%$ & $2 \%$ & $2 \%$ & $2 \%$ & $2 \%$ & $2 \%$ & $1 \%$ & $0 \%$ \\
\hline
\end{tabular}

Table 3.13: NT CM Representation 1996-2007

\begin{tabular}{|l|cccccccccccc|c|}
\cline { 2 - 14 } \multicolumn{1}{c|}{} & 1996 & 1997 & 1998 & 1999 & 2000 & 2001 & 2002 & 2003 & 2004 & 2005 & 2006 & 2007 & Mean \\
\hline No. NT CMs & 0 & 0 & 0 & 0 & 0 & 0 & 0 & 0 & 0 & 0 & 0 & 0 & 0.00 \\
Exp' No. NT CMs & 0.2 & 0.2 & 0.2 & 0.1 & 0.1 & 0.1 & 0.3 & 0.3 & 0.3 & 0.3 & 0.3 & 0.3 & 0.24 \\
\hline
\end{tabular}

The case of the ACT is similar to that of the NT except that the representation of the ACT in terms of the LNPC's parliamentary representation is even lower than that of the NT, with an average of less than $1 \%$ leading to a mean number of expected CMs of .14 over the 12 year period (Table 3.15 ). 
Table 3.14: ACT Representation: Parliament 1996-2007

\begin{tabular}{|l|cccccccccccc|c|c|}
\cline { 2 - 14 } \multicolumn{1}{c|}{} & 1996 & 1997 & 1998 & 1999 & 2000 & 2001 & 2002 & 2003 & 2004 & 2005 & 2006 & 2007 & Mean & StDev \\
\hline LNCP (Aust) & 129 & 130 & 131 & 117 & 115 & 114 & 117 & 117 & 116 & 122 & 126 & 126 & 122 & 6.39 \\
LNCP (ACT) & 1 & 1 & 1 & 1 & 1 & 1 & 1 & 1 & 1 & 1 & 1 & 1 & 1 & 0.00 \\
Parl' \% of ACT & $1 \%$ & $1 \%$ & $1 \%$ & $1 \%$ & $1 \%$ & $1 \%$ & $1 \%$ & $1 \%$ & $1 \%$ & $1 \%$ & $1 \%$ & $1 \%$ & $1 \%$ & $0 \%$ \\
\hline
\end{tabular}

Table 3.15: ACT CM Representation 1996-07

\begin{tabular}{|l|cccccccccccc|c|c|}
\cline { 2 - 7 } \multicolumn{1}{c|}{} & 1996 & 1997 & 1998 & 1999 & 2000 & 2001 & 2002 & 2003 & 2004 & 2005 & 2006 & 2007 & Mean & StDev \\
\hline No. ACT CMs & 0 & 0 & 0 & 0 & 0 & 0 & 0 & 0 & 0 & 0 & 0 & 0 & 0.00 & 0.00 \\
Exp' No. ACT CMs & 0.1 & 0.1 & 0.1 & 0.1 & 0.1 & 0.1 & 0.1 & 0.1 & 0.1 & 0.1 & 0.1 & 0.1 & 0.14 & 0.01 \\
\hline
\end{tabular}

It is therefore not unexpected that the ACT, like the NT, did not have a CM over the period 1996-2007.

To summarise this section on the geographical areas with small populations, we can see that the small state of Tasmania instantiated an intermediate situation in which there was an argument both ways as to whether an individual should have been appointed to cabinet in the early years while in the latter years there was underrepresentation. Taking mean figures for the period as a whole there was virtual equality of expected and actual representation. In the case of the NT and ACT, the numbers were so small that it would have been more difficult to argue that an individual should be appointed from these areas. This was borne out in that there were no $\mathrm{CM}$ appointments from these areas over the period. Finally, it should be noted that the public debate seems to accept that the smaller geographical regions should be given lower rates of representation. The debate is largely acquiescent on issues associated with small region representation with the majority of attention being devoted to the more populous geographical regions. 


\section{Section 3.3.9: Senate Representation}

In the public discussion, proportionality in the senate is generally not a contentious issue. It is accepted that there should be some attempt at representing the Senate in cabinet in terms of its parliamentary representation but the issue is not pursued vehemently. For example, when Senator Jim Short resigned his junior ministerial role in 1996 due to breach of the ministerial guidelines involving a conflict of interest, there was talk in the media of a possible "reassignment of ministerial duties in the Senate" (Daley 1996). Little more was said on the issue. Similarly, a reshuffle in the following year elicited the following statement: "Howard [...] must keep a proper balance between ministers drawn from the House of Representatives and the Senate. The Senate is already seen as over-represented. This would virtually put a stop to [Senator] Ian Macdonald being promoted, even though he is from Queensland" (Short 1997b).

Another point of view is that talent is more important than adhering to strict representation. Commenting on the likely replacements for three Senators who left the ministry in late 2005, another commentator made the following remark: "All three ministers who [have left] the ministry are Senators. At least one of the three replacements will surely have to be a senator. But given the balance of talent, it is likely that two of the newcomers will come from the House of Representatives" (Canberra Times, January 26 2006:12).

A re-shuffle in 2007 after Senator Rod Kemp vacated his junior ministerial position in early 2007 raised the issue of workload: "Liberal senators believe Senator Kemp's free position must be filled by another member of the Upper House and are lobbying hard for Senate representation...[...]...Without a Senate replacement, the 
seven remaining ministers would face a heavy workload representing Lower House ministers" (Anderson 2007). In relation to the same reshuffle it was stated that “...[w]hile the likely winners [of a ministerial appointment] include Parliamentary Secretary for water [HOR member] Malcolm Turnbull and Parliamentary Secretary for Citizenship [HOR member] Andrew Robb, speculation is growing that Liberal Senator Michael Ronaldson and Nationals Senator Fiona Nash may secure a promotion to boost the dwindling representation of senators in the Ministerial ranks" (Maiden 2007).

The general tenor of the public discussion is far less ardent than that in relation to the other RIFs. This may explain why the Howard government was able to allow high and variable divergences from expected Senate representation over his period of government. Table 3.16 shows that the long term average expected number of Senatorial CMs was 4.94 and the average figure for the actual number of senatorial CMs was 4.17.

Table 3.16: Senate CM Representation 1996-2007

\begin{tabular}{|l|cccccccccccc|c|c|}
\cline { 2 - 13 } \multicolumn{1}{c|}{} & 1996 & 1997 & 1998 & 1999 & 2000 & 2001 & 2002 & 2003 & 2004 & 2005 & 2006 & 2007 & Mean & StDev \\
\hline No. Sen' CMs & 4 & 4 & 3 & 4 & 4 & 4 & 5 & 5 & 4 & 6 & 4 & 3 & 4.17 & 0.83 \\
Exp' No. Sen' CMs & 4.1 & 4.2 & 4.5 & 5.4 & 5.2 & 5.2 & 5.1 & 5.1 & 4.8 & 4.9 & 5.3 & 5.6 & 4.94 & 0.47 \\
\hline
\end{tabular}

There is a significant $(\mathrm{p}<.01)$ difference between these figures but the difference is $4.94-4.17=.77$ which is a fractional value indicating an inconsequential difference. Thus, on the face of it, actual and expected numbers of CMs were equivalent in the long term. However, throughout the period there were significant deviations from perfectly mirrored representation. For example, over 1998-2001 there was under-representation of 1 and this persisted until 2002 when expected and actual numbers converged. In 2005 
there was an instance of over representation of 1. In 2006 the over-representation reversed to under-representation of 1 and this increased to under-representation of 2 in 2007. The situation is best explained by referring to Figure 3.2 which graphically shows expected and actual number of senatorial CMs over the 12 year period.

Figure 3.2: Expected and Actual LNPC Senate CMs 1996-2007.

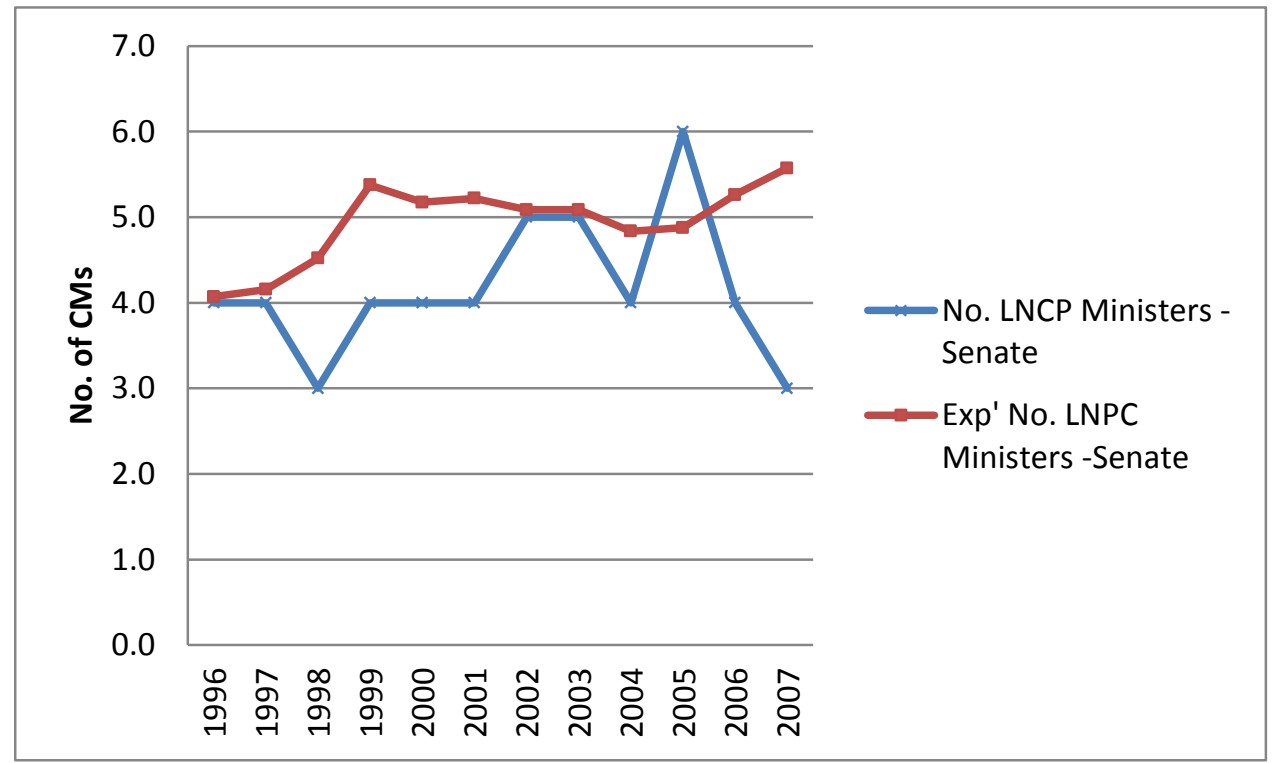

Senate representation is unusual in that it is the only representational factor which experiences reversals from significant under-representation to significant overrepresentation. The jump in the actual number of senators in 2005 coincides with the coalition gaining majority control of the Senate after the election in 2004. Thus it is possible that the greater number of $\mathrm{CM}$ positions reflected the greater number of seats held by LNPC parliamentarians. However, as the graph demonstrates, this situation was short lived. 


\section{Section 3.3.10: Age and Experience Representation}

Age and experience representation are different from the other representation factors because, unlike the other RIFs, it is quite justified for the leader to make a conscious attempt to differentiate the representational structure of the cabinet from that of parliament. It would be considered legitimate, for example, for a leader to appoint CMs who were more experienced than the average LNPC parliamentarian. Similarly, it would be considered appropriate for a leader to specifically choose a cabinet that, for example, exemplified the infusion of "new blood" (Henderson 2000). In short, age and experience are not the same as the RIFs we have considered so far which, theoretically, should take the representational structure of parliament as the blueprint for the representational structure of the cabinet.

The public discussion of age and experience reflects the fact that both qualities can be seen as positive or negative depending on how extreme they are. An overly young cabinet is likely to be criticized for being inexperienced while an experienced cabinet is likely to be criticized for being too old.

In a reshuffle in December 2000 which was brought on by the resignation of three experienced ministers, the new ministry was described in The Australian as "...a new-look team with an emphasis on youth and social policy to lead into next year's election campaign" (Henderson 2000). The report mentioned that Senator Newman had told Howard that she was "... willing to make way for fresh blood by voluntarily leaving the ministry". The reshuffle had replaced two cabinet ministers and one junior minister in their 60s with ministers in their 40s. However a quote from Howard emphasised the talent aspect of the reshuffle rather than the youth/new blood aspect: "It display[ed] the 
depth of talent, the reservoir of very able people within the Government, that three very long-serving, senior and highly respected colleagues can be departing the ministry, and [there was] immediately available [...] talented people in different areas of the Government to take their places." However the Adelaide Advertiser included a quote from Howard in which he emphasised the youth aspect of the changes. Howard is quoted as saying "[t]he point in relation to all of them is that no matter how well you're going in something, you do reach a point where some kind of generational change is desirable...I've had those sorts of discussions with Jocelyn [Newman] and with John Moore and I think all of them see the merit of what has happened" (Coorey 2000).

The age and experience themes emerged again in relation to a reshuffle in November 2001. The Canberra Times described the reshuffle in the following terms: "Howard's desire to push his own type of coalition politician, the need for new talent, and the need to retain experience at the highest levels were the forces behind his reshuffle" (Canberra Times November 25 2001, p20).

The above quotations from the public debate are a small sample of the discussion on the issues of age and experience but they convey the theme that exists in the debate in general - that there is a trade-off between age and experience. Howard is on record as saying that age is a factor in ministerial appointments. There is a similar argument with experience. As I mentioned at the beginning of this section, it is seen as legitimate for a leader to make appointments in order to skew the ministry towards greater experience while ensuring there is sufficient "new blood" on occasion. 
How did the various reshuffles affect the age structure of Cabinet? Figure 3.3 shows the average age of all LNPC parliamentarians (including CMs) for each year of the period 1996-2007 as well as the average age of CMs over the same period. ${ }^{4}$ The average age of both LNPC parliamentarians and LNPC CMs rose of the period 19962007. In only two years, 2001 and 2007 was the average age of CMs lower than that of LNPC parliamentarians as a whole.

Figure 3.3: Average Age - LNPC Parliament and Cabinet 1996-2007

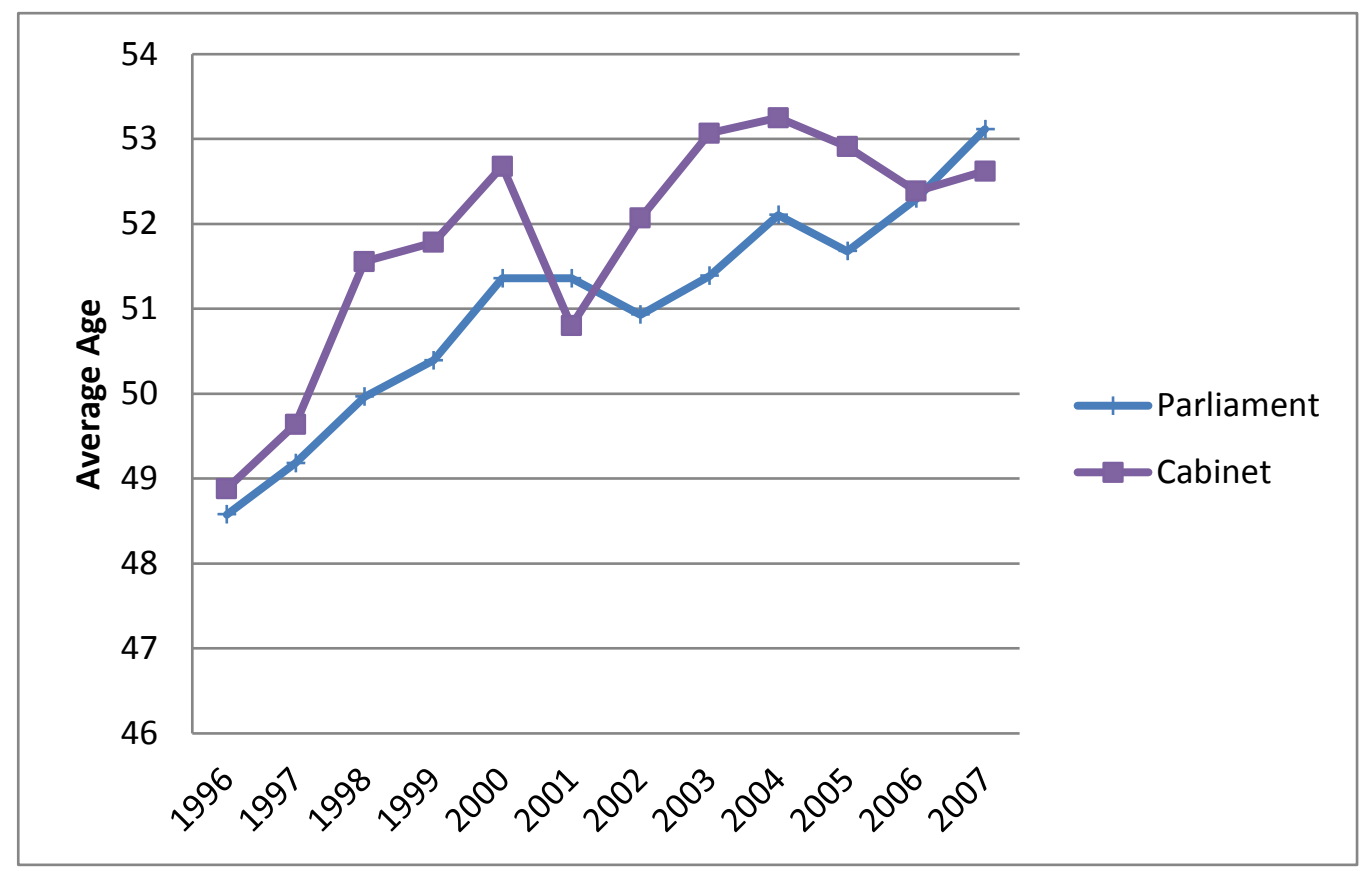

The long term average age of LNPC parliamentarians was 51.03 while that of LNPC CMs was 51.80. These figures are not significantly different $(\mathrm{p}=.17)$, although it should be noted that with a sample size of $n=12$ this conclusion cannot be definitive. The long term growth in the average age of LNPC parliamentarians is the logical outcome of there being a large number of long term parliamentarians. Falls in the

\footnotetext{
${ }^{4}$ Data for Figure 3.3 are calculated from dates of birth given in the Parliamentary Handbook of the Commonwealth of Australia online edition www.aph.gov.au, accessed May 2008. 
average age are associated with elections in which older parliamentarians retire and are replaced by younger parliamentarians. The same can be said of CMs to some extent except that there was a major fall in the average age of CMs in 2001 which reflects the departure of Jocelyn Newman and John Moore, both in their 60s. A declining trend is evident in the period 2004-2006 which reflects the departure of CMs such as David Kemp and Daryl Williams and replacements with younger ministers.

The interesting observation that can be made about the age structure of cabinet is that, although there was no obvious statement of it explicitly, Howard effectively mirrored the age structure of the parliament in the cabinet. The trends, although not identical, are very similar $(\mathrm{r}=.83, \mathrm{p}<.01)$ and the average ages of CMs and LNPC parliamentarians are very close.

In the case of experience in parliament there is a definite difference between LNPC parliamentarians as a whole and CMs. Figure 3.4 shows that there is a rising trend in both groups over the period 1996-2007..$^{5}$ There is, however, a persistent gap. The gap gives rise to a significant $(\mathrm{p}<.01)$ difference between the average number of years of experience of LNPC parliamentarians (8.77 years) and that of CMs (13.74 years). On average, CMs had approximately five years more experience than parliamentarians as a whole. The number of years of experience both for parliament as a whole and for CMs grows as time passes due to the fact that a substantial number of parliamentarians are in office for the duration of the period due to electoral success. The

5 Data for Figure 3.3 are calculated from dates of parliamentary service given in the Parliamentary Handbook of the Commonwealth of Australia, online edition, www.aph.gov.au, accessed July 2008. 
falls in 2002 and 2005 are due to incoming new parliamentarians and outgoing experienced parliamentarians in the elections immediately preceding these years.

Figure 3.4: Average Experience - LNPC Parliament and Cabinet: 1996-2007

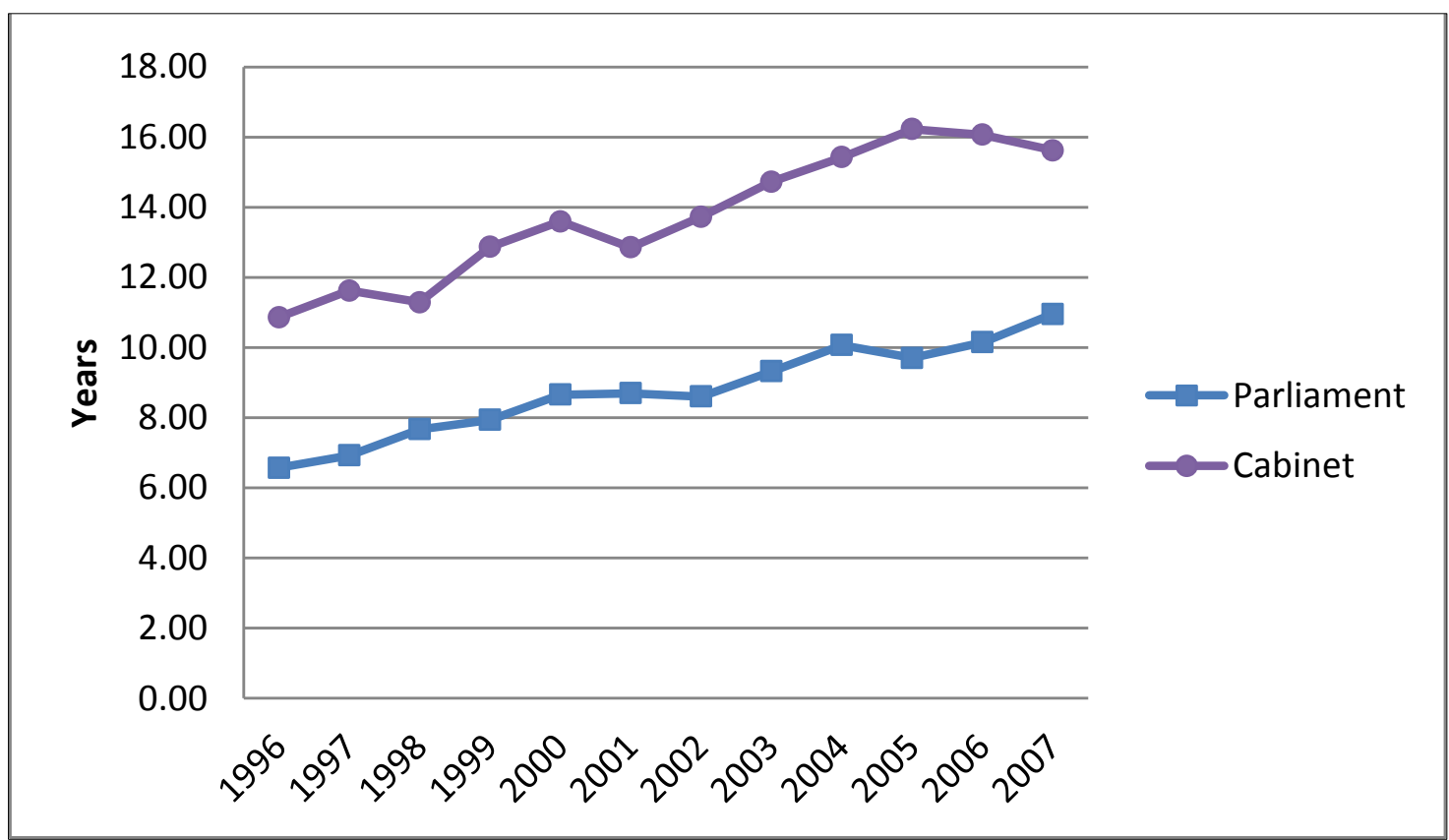

There is evidence of a possible trade-off between age and experience. The average difference in experience between parliament as a whole and cabinet is 4.97 years. If we look at the year 2005, the difference in experience grows to 6.53 years (Parliament $=9.70$, Cabinet $=16.23)$. The gap closes to 5.92 and 4.67 in the following two years respectively. This could be taken as evidence that Howard was trying to reduce the overall age of the cabinet while maintaining an acceptable level of experience. 


\section{Summary of Section 3}

In this section I have considered various RIFs at cabinet level. For the non-age and experience variables there are four basic scenarios:

1) Predominant over-representation, where the factor is over-represented for most years over the study period. This is the situation with NSW cabinet representation.

2) Chronic under-representation, there the factor is under-represented for the entire study period. An example of this is female cabinet representation.

3) Equality of actual and expected representation, where the representation is as would be expected. The best example of this is the NP which has a high equality of expected and actual representation for all three levels of the ministry.

4) A period of under-representation followed by a compensating period of overrepresentation. This is the situation with only one factor - Senate representation.

The age and experience variables constitute a different set of factors. There seems to be some relationship between them such that one is traded off for another so that a balance is created.

The question I must now address is whether the instances in which there is not equality of actual and expected representation are evidence that in general the parliamentary representational structure is not mirrored in the representational structure of the cabinet. That is, are the deviations from expected representation of such magnitude and duration that there is doubt cast upon the theory that the parliament's representational structure is mirrored in the ministry? Alternatively, are the aberrations 
we have seen small in the scheme of things such that they do not have a significant effect on the overall representativeness of cabinet?

The importance of this question is that it has a direct bearing on the chances of a member of the LNPC becoming a CM. The literature has maintained that the constraints on a leader to conform to the representational structure of parliament are significant influences on the probability of being appointed to the cabinet. The public debate has shown that the politicians, the leader and the commentators are aware of these constraints and there is, in most cases, pressure on the leader to conform to them. It is also clear from the public debate that the leader is often at pains to justify deviations from strictly representational appointments to cabinet. The question is how systematic the deviations are and whether or not deviations affect the chances of the individual member to be appointed to cabinet. This is the subject of the next section.

\section{Section 3.4: Multivariate Analysis}

In the previous section I descriptively examined the RIFs and found that there were significant deviations from proportional representation for several factors while for most factors there was close to correct proportional representation with minor deviations. The purpose of this section is to test whether, taken as a whole, the RIFs can significantly affect cabinet appointments. This is an important question because if there is a significant distortion in a representational factor then, if that representational factor applies to a parliamentarian, her chances of being selected as a CM will be affected. In this section I will analytically determine whether the RIFs I have discussed above are 
able to explain CM appointments. It will be seen that the RIFs only explain a small proportion of CM appointments. I will conclude the section with a discussion of why this counterintuitive finding should be the case when there is a great deal of effort made by leaders to select their cabinets to mirror, to a large extent, the parliamentary representation of RIFs.

\section{Section 3.4.1: The Data and Models}

The idea of the models discussed in this section is to determine whether the RIFs influence the probability of the individual parliamentarian becoming a CM. One way of doing this is to take a cross section of the parliamentary party at a given time and see if a relationship can be discerned between the parliamentary proportions and cabinet proportions with respect to each representational factor. Table 3.17 shows the RIFs for the LNPC in April 1996 just after the LNPC won the Federal election and John Howard needed to select his first cabinet. There were 129 members of the LNPC in parliament and of these 15 were CMs.

Table 3.17: RIFs for the LNPC - April 1996

\begin{tabular}{|cccccccccccccc|}
\hline $\mathrm{n}$ & Senate & Female & Vic & NSW & Qld & Tas & SA & WA & ACT & NT & NP & Av' Age Av' Exp' \\
129 & 35 & 23 & 27 & 34 & 29 & 7 & 16 & 13 & 1 & 2 & 23 & 48.6 & 6.6 \\
\hline
\end{tabular}

Of the 129 LNPC members, 35 were senators, 23 were female, 27 were from Victoria, and so on. The representational literature suggests that, with 34 members, more CMs should come from NSW while significantly fewer should come from Tasmania with only 7 representatives in parliament. However, it is important to note 
that this data does not reveal how the each of the RIFs influences the probability of any given individual being a CM. The general probability of a member of the LNPC being a $\mathrm{CM}$ is $15 / 129=.12$. The important point, however, is whether the RIFs affect this probability. For example, does coming from Victoria increase or decrease an LNPC parliamentarian's probability of being a CM? Similarly, does being 52 and having 10 years' experience influence chances of selection as a CM? To answer these questions I will consider the characteristics of the entire cohort of 129 LNPC members and take into account the RIFs listed in Table 3.17 simultaneously. However, even this is not sufficient because it would only provide a snapshot for the period depicted, April 1996. The question is whether there is a general trend towards rewarding or punishing particular states, parties etc. Thus, several cross sections over several time periods are required.

To address these issues I will take five cross sections at times that represent the composition of the parliament and cabinet after the elections in 1996, 1998, 2001 and 2004. I will also include the data for the period after the last LNPC reshuffle in 2007.

Before I continue I need to explain several aspects of the data. The data are taken from the yearly Hansard for the first parliamentary session of the year. Thus, the data represent the makeup of the LNPC in parliament and cabinet at that time for each year. For example, the 1996 data show the situation at the first parliamentary session in April 1996 which followed the election of March 1996. The problem is that several elections took place in the middle of the year and therefore the changes in the makeup of parliament are not manifested in the data until the following year. This means that the changes that took place in the October 1998 election, for example, are not reflected in the data until the first session for 1999. The same situation exists for the elections in 
November 2001 and October 2004. This means that, in order to get cross sections that represent the situation as it existed after the elections over the period, it is necessary to use the data from 1996, 1999, 2002 and 2005. Along with the 2007 cross section, which represents the final reshuffle before the 2007 election, these data represent the five cross sections. Analysis of these should capture any patterns in the way cabinet posts were awarded, if any.

In order to demonstrate the structure of the data, it is worthwhile considering the data for two particular individuals in the cohort. Table 3.18 shows the data for Tony Abbott and Judy Troeth. These two individuals were selected from the cohort of 192 LNPC parliamentarians who were in parliament over the period 1996-2007 in order to provide an insight into the nature of the dataset.

Table 3.18: Data for Logistic Regression -Abbott and Troeth 1996 - 2007

\begin{tabular}{|llcccccccccccccc|}
\hline Year & Name & Sen & Fem & Vic & NSW & Qld & Tas & SA & WA & ACT & NT & NP & Age & Exp & CM \\
\hline 1996 & Abbott, AJ & 0 & 0 & 0 & 1 & 0 & 0 & 0 & 0 & 0 & 0 & 0 & 38.5 & 2.1 & 0 \\
1999 & Abbott, AJ & 0 & 0 & 0 & 1 & 0 & 0 & 0 & 0 & 0 & 0 & 0 & 41.3 & 4.9 & 0 \\
2002 & Abbott, AJ & 0 & 0 & 0 & 1 & 0 & 0 & 0 & 0 & 0 & 0 & 0 & 44.3 & 7.9 & 1 \\
2005 & Abbott, AJ & 0 & 0 & 0 & 1 & 0 & 0 & 0 & 0 & 0 & 0 & 0 & 47.3 & 10.9 & 1 \\
2007 & Abbott, AJ & 0 & 0 & 0 & 1 & 0 & 0 & 0 & 0 & 0 & 0 & 0 & 49.3 & 12.9 & 1 \\
1996 & Troeth, J & 1 & 1 & 1 & 0 & 0 & 0 & 0 & 0 & 0 & 0 & 0 & 55.8 & 2.8 & 0 \\
1999 & Troeth, J & 1 & 1 & 1 & 0 & 0 & 0 & 0 & 0 & 0 & 0 & 0 & 58.5 & 5.6 & 0 \\
2002 & Troeth, J & 1 & 1 & 1 & 0 & 0 & 0 & 0 & 0 & 0 & 0 & 0 & 61.5 & 8.6 & 0 \\
2005 & Troeth, J & 1 & 1 & 1 & 0 & 0 & 0 & 0 & 0 & 0 & 0 & 0 & 64.5 & 11.6 & 0 \\
2007 & Troeth, J & 1 & 1 & 1 & 0 & 0 & 0 & 0 & 0 & 0 & 0 & 0 & 66.5 & 13.6 & 0 \\
\hline
\end{tabular}

All variables other than age and experience are binary variables which take the value of 1 if the RIF applies to the individual and 0 if it does not. For example, Table 3.18 shows that for the Senate variable, Abbott receives a 0 and Troeth a 1 . Similarly Troeth receives a value of 1 for the variables Fem (Female) and Vic (Victoria) because she is a female representing the State of Victoria. By the same logic, Abbott receives a 1 
for NSW because he representing an electorate in NSW. Both Abbott and Troeth receive a 0 for NP (National Party) as they both belong to the Liberal Party. The age and parliamentary experience columns depict their age and years of parliamentary experience respectively for the given years. Finally, the CM column shows the CM status for both parliamentarians at the time the cross section was taken. Abbott was promoted to $\mathrm{CM}$ in 2000 and remained a $\mathrm{CM}$ for the duration of the period so the value for CM is coded as 0 for 1996 and 1999 and thereafter he receives a coding of 1 . Troeth did not become a CM in the years concerned so receives a coding of 0 for all years.

All 192 individuals who were members of the LNPC for the period 1996 to 2007 were coded using these same principles. Individuals who were members of the LNPC at any stage but subsequently became independents were included in the analysis only for as long as they were in the LNPC. Similarly, individuals who changed party, state or house had their coding changed in the appropriate years.

The data from all five cross sections illustrates the long-term structure of the parliament as well as that of the cabinet for the period 1996-2007. Table 3.19 summarises the data.

Table 3.19: LNPC Representational Data - Pooled Cross-sections

\begin{tabular}{|l|cccccccccccccc|}
\cline { 2 - 12 } \multicolumn{1}{c|}{} & $\mathrm{n}$ & Senate & Female & Vic & NSW & Qld & Tas & SA & WA & ACT & NT & NP & Av' Age & Av' Exp' \\
\hline Parliament & 611 & 181 & 126 & 122 & 165 & 132 & 32 & 74 & 72 & 5 & 9 & 91 & 50.9 & 8.7 \\
Non-CMs & 527 & 159 & 116 & 103 & 133 & 123 & 30 & 57 & 67 & 5 & 9 & 76 & 50.8 & 7.9 \\
CMs & 84 & 22 & 10 & 19 & 32 & 9 & 2 & 17 & 5 & 0 & 0 & 15 & 51.7 & 14.0 \\
Parl' Prop' & & $30 \%$ & $21 \%$ & $20 \%$ & $27 \%$ & $22 \%$ & $5 \%$ & $12 \%$ & $12 \%$ & $1 \%$ & $1 \%$ & $15 \%$ & n/a & n/a \\
Cab' Prop' & & $26 \%$ & $12 \%$ & $23 \%$ & $38 \%$ & $11 \%$ & $2 \%$ & $20 \%$ & $6 \%$ & $0 \%$ & $0 \%$ & $18 \%$ & n/a & n/a \\
\hline
\end{tabular}

The pooled data involving 192 individuals provides 611 observations of "events" over the five cross sections. There were 527 non-CM "events" while there 
were $84 \mathrm{CM}$ "events". This shows that the overall probability of a cabinet appointment event was $14 \%(84 / 611)$. The next step is to consider how the probability of appointment for each different RIF can also be calculated. Consider, for example, the Parliamentary Proportion figure for the Senate which shows that over the five cross sections, the Senate made up $181 / 611=30 \%$ of parliament. In comparison, the Senate cabinet proportion was only $22 / 84=26 \%$, demonstrating that a senator was marginally less likely to be appointed to cabinet than the parliamentary proportion of senators suggests should have been the case. Females were systematically under-represented in cabinet with female representation in parliament overall at $21 \%(126 / 611)$ but only $12 \%$ $(10 / 84)$ were selected for cabinet. Using this method of cross sectional analysis it is possible to see whether each RIF was over of under-represented in cabinet.

On the face of it, deviations from perfectly mirrored representation can affect the probability of an individual becoming a CM. For example, it is possible that, given the under-representation of WA and the over-representation of SA, a parliamentarian from SA should have a higher probability of being selected than an individual from WA. In fact, what is required is a systematic analysis of how all the RIFs affect the probability of appointment to cabinet simultaneously. This needs to be done because descriptive data are not enough to determine the underlying associations.

Consider, for example, two phenomena that are clear from the cross sectional data: the under-representation of females and a positive effect on the probability of cabinet appointment of a member having more experience. It might be supposed that these phenomena are independent. However, it is also possible that they are linked. The average experience of females in the five cross section sample is 7.7 years. This is less than the non-CM average of 7.9 and very significantly less than the CM average 
experience of 14. Thus, independently of any possible gender bias against women it is important to take into account fact that there was only a small pool of experienced women to draw from. This means that, to some extent, the under-representation of women in cabinet may be due to women being relatively inexperienced in comparison to men. This kind of observation can only be made if a method of analysing all the RIFS simultaneously is used. Similarly, the under-representation of one state may take place due to some other factor such as underrepresentation of members from the Senate or National Party. It will not be possible to tease out these possibilities unless we look at the influence of each individual factor on $\mathrm{CM}$ appointment while holding all other factors constant. In other words it is necessary to simultaneously take into account all the variables as presented in Table 3.19. The way to do this is to use logistic regression.

In order to examine the influence of the RIFS on selection for CM positions I used logistic regression with a repeated measures design. The repeated measures design was required because many of the individuals in the cohort are measured repeatedly in the 5 cross sections. As such there is variation both between and among individuals and both these variations need to be accounted for.

Two models were created. The only difference between the two is the reference category for the states. Model 1 uses Victoria as the excluded category while Model 2 uses NSW. The variables included were all the variables that have been discussed in relation to RIFs including age and experience. Age squared and experience squared were also included to capture any non-linear effects of these variables. It should be noted that in both models the ACT and the NT were excluded because there were no CMs from these regions in the years under consideration. The parameter estimates of the models are presented in Table 3.20. 
Table 3.20: Parameter Estimates for Multivariate Analysis of LNPC RIFs

\begin{tabular}{|c|c|c|}
\hline & Model 1 & Model 2 \\
\hline Senate & -.339 & -.405 \\
\hline NP & -.333 & -.265 \\
\hline Female & -.712 & -.687 \\
\hline NSW & $.924 *$ & \\
\hline Vic & & -.729 \\
\hline QLD & -.606 & $-1.424^{* *}$ \\
\hline Tas & -.379 & -1.138 \\
\hline SA & .335 & -.443 \\
\hline WA & -.461 & -1.241 \\
\hline Age & $.800^{* * *}$ & $.798^{* \star *}$ \\
\hline AgeSq & $-.008^{* * *}$ & $-.008^{* * *}$ \\
\hline Exp & $.322^{* \star *}$ & $.314^{* \star *}$ \\
\hline ExpSq & $-.005 *$ & -.005 * \\
\hline $\mathrm{n}$ & 611 & 611 \\
\hline True Positives & 21 & 22 \\
\hline False Positives & 17 & 16 \\
\hline True Negatives & 510 & 511 \\
\hline False Negatives & 63 & 62 \\
\hline
\end{tabular}


In Model 1 only age and experience are significant. Age is significantly $(\mathrm{p}<.01)$ positively associated with $\mathrm{CM}$ while age squared is significantly $(\mathrm{p}<.01)$ negatively associated with CM. In essence this means that there is a negative quadratic relationship between age and $\mathrm{CM}$ such that the odds of appointment to cabinet rise up to age 47 and thereafter decline. The significant $(\mathrm{p}<.01)$ positive coefficient for experience along with the borderline significant $(\mathrm{p}<.1)$ coefficient for experience squared indicates that there is a borderline significant negative quadratic relationship between experience and $\mathrm{CM}$ such that the odds of appointment rise for the first 31 years of experience and then decline. There is a borderline $(\mathrm{p}<.1)$ positive association between NSW and cabinet appointment. In this model Victoria is the excluded state so the positive coefficient for NSW indicates that there was some evidence that, in comparison to Victoria, there was a greater probability of becoming a CM if a member was from NSW.

In Model 2 NSW is the (excluded) reference category for the states. The age and experience variables and their squares are as for Model 1 . The only other variable with a significant coefficient is Queensland: Queensland is significantly $(\mathrm{p}<.05)$ negatively associated with $\mathrm{CM}$ appointment. A possible reason for the negative association between QLD and CM in the second model is that, as we saw in section 2 there was under-representation of Queensland and significant over-representation of NSW.

The conclusion overall is that there are some statistically significant influences of the LNPC RIFs on appointment to cabinet. However, I wish to turn now to the question of how many actual cabinet appointments the models explain. The literature emphasises the role of RIFs in the explanation of cabinet appointments. In Models 1 and 2 I have used the variables that are commonly cited as being important so we would expect that, as well as some statistical significance, a reasonable proportion of the actual 
appointments would be correctly classified by the model. Despite the finding of a statistically significant influence of age and experience in both models, and of QLD representation vis-a-vis NSW in Model 2, the actual classification accuracies of the models are low. ${ }^{6}$

The ability of the model to classify individuals into the CMs and non-CMs can be determined by considering the overall accuracy. ${ }^{7}$ This is calculated by taking the proportion of true classifications (True Positives and True Negatives ) over all classifications:

$$
\text { Accuracy }=(\mathrm{TP}+\mathrm{TN}) /(\mathrm{TP}+\mathrm{TN}+\mathrm{FP}+\mathrm{FN})
$$

A second set of measures is the Sensitivity and the Specificity of the model. The Sensitivity is the ability of the model to classify those who are actually positive cases (CMs) as positive cases. It is calculated by taking the Number of True Positives and dividing by the number of True Positives and False Negatives:

$$
\text { Sensitivity }=\mathrm{TP} /(\mathrm{TP}+\mathrm{FN})
$$

The Specificity is the ability of the model to classify those who are actually negative cases (non-CMs) as negative cases. It is calculated by taking the Number of True Negatives and dividing by the number of True Negatives and False Positives:

\footnotetext{
${ }^{6}$ In reporting the performance of regression models it is customary to report $r^{2}$ values in some form. It should be noted that this is a repeated measures design and therefore includes variance both between and within subjects. As such a meaningful $r^{2}$ value cannot be calculated.

${ }^{7}$ Cutpoints for all classification models in this thesis $=0.5$.
} 


\section{Specificity $=\mathrm{TN} /(\mathrm{TN}+\mathrm{FP})$}

Sensitivity and specificity measure two different aspects of the classification accuracy of the model. To take account of the overall classification accuracy we need to consider a global measure of the extent to which the predicted classification is similar to the actual classification. One measure which provides this information is Cohen's Kappa which measures the "agreement" of the predicted classification with the actual classification. The Kappa takes a value of -1 if there is complete disagreement, 0 if there is no agreement (that is, if the two sets of classifications are randomly associated) and 1 if there is perfect agreement.

With measures of the accuracy, sensitivity, specificity and kappa, it is possible to assess the classification accuracy of the models. These can be compared with the baseline accuracy which is the "accuracy" which would occur if we assumed that no parliamentarian would become a CM. Figures for the two models are as follow: 
Table 3.21: Accuracy Metrics for LNPC Models

\begin{tabular}{|l|cc|}
\cline { 2 - 3 } \multicolumn{1}{c|}{} & Model 1 & Model 2 \\
\hline Accuracy & 0.87 & 0.87 \\
Baseline Accuracy & 0.86 & 0.86 \\
Sensitivity & 0.25 & 0.26 \\
Specificity & 0.97 & 0.97 \\
Kappa & $0.28 *$ & $0.30 *$ \\
\hline
\end{tabular}

The overall accuracy of each model is $87 \%$ which seems to indicate that the models are efficient. However, this is due to the fact that the vast majority of the cases $(86 \%)$ are classified correctly simply due to the balance of the CM and non-CM categories. That is, $86 \%$ of the events are non-CM events and we would get all of these "correct" if we did not have a model but just assumed that there would be no CM events. In other words, we would get $86 \%$ accuracy simply by saying that no given individual would become a CM. The idea of using the model is that it should add to this baseline level of accuracy. However, the models add only a marginal increase in accuracy from $86 \%$ to $87 \%$. In other words, despite including a vast amount of information which, according to the literature, is useful in explaining cabinet appointments, the models only provide a very marginal increase in the ability to explain cabinet appointments. It should be noted that an accuracy of $87 \%$ would be a good result if the sensitivity were significantly higher. However, this is not the case. The 
sensitivity is only $25 \%$ indicating that the accuracy of the model comes from the baseline accuracy.

However, there is evidence that the models classify well beyond what we would expect by chance alone. The Kappa of .28 $(\mathrm{p}<.01)$ for Model 1 and $.30(\mathrm{p}<.01)$ for Model 2 show that there is a positive correlation between the predicted and actual classification for both models. Thus the variables in the model are able to add some information beyond mere chance.

The next question is how well the model explains individual CM events. The sensitivity of .25 for Model 1 indicates that Model 1 can correctly classify $25 \%$ of the CM "events". That is, of the $84 \mathrm{CM}$ events, the model can identify 21 . This leaves 63 unexplained. Similarly, Model 2 can classify $26 \%$ of the $84 \mathrm{CM}$ events which is effectively 21, the same as model 2 .

To summarise the discussion of the accuracy of the models in classifying CMs it is possible to say that the models definitely add to the classification accuracy over and above what would be achieved by chance alone. However, the model leaves a large number of CM events unexplained. Furthermore, the high level of correct classifications of the non-CM events (97\%) is largely due to the default baseline accuracy which is an artefact of the high proportion of non-CM events in the dataset.

A second study was undertaken, this time with data from the ALP in opposition. I pointed out above that the problem with the ALP data is that for most of the study period the shadow ministry was not divided into a shadow cabinet and a shadow outer ministry. However, in 2005 and 2006 the ministry was so divided so it was possible to run a similar analysis to that undertaken for the LNPC. However, it should be stated that the sample size is very much smaller for the ALP study so the results need to be 
interpreted cautiously. In fact, the sample size falls below the threshold requirement of 10 positive events per independent variable. Nevertheless the analysis yields some observations that partially overlap with the findings from the LNPC model.

As with the LNPC models, two models were created each with one of the two main regional areas, NSW and Victoria, as the excluded regional category. There were no ministerial appointments from the ACT or the NT so these regions were eliminated from the analysis. As with the LNPC models, a repeated measures design was used.

One main point of difference between the LNPC and the ALP scenario is that, unlike the LNPC, the ALP does not consist of two parties. However, it does contain several factions. In order to represent these, three basic categories were created: the Left faction; the Right faction; and a faction representing those that remained including those who identified with the centre-left and the independents. ${ }^{8}$ In the models the Right faction was the excluded category.

Parameter estimates for both models are provided in Table 3.22.

${ }^{8}$ It should be noted that the information as to the factional memberships of ALP parliamentarians is not available from public sources. The data for this section of the analysis was assembled with the assistance of several individuals with a knowledge of ALP factional memberships, particularly John Nethercote and Jane O’Dwyer. 
Table 3.22: Parameter Estimates - ALP Multivariate Analysis

\begin{tabular}{|c|c|c|}
\hline & Model 1 & Model 2 \\
\hline Senate & -.700 & -.585 \\
\hline Female & .189 & .177 \\
\hline NSW & -.565 & \\
\hline Vic & & 1.092 \\
\hline QLD & -.567 & .304 \\
\hline Tas & -.462 & .281 \\
\hline SA & 1.875 & 2.613 * \\
\hline WA & .913 & $1.727^{\star *}$ \\
\hline Left & -.607 & -.529 \\
\hline $\mathrm{Cl}$ & -.702 & -.606 \\
\hline Age & 1.070 & .932 \\
\hline AgeSq & $-.013 *$ & -.012 \\
\hline Exp & $.740^{* * *}$ & $.768^{\star \star \star}$ \\
\hline ExpSq & $-.021 * *$ & $-.022 * *$ \\
\hline$n$ & 175 & 175 \\
\hline True Positives & 7 & 9 \\
\hline False Positives & 9 & 10 \\
\hline True Negatives & 130 & 129 \\
\hline False Negatives & 29 & 27 \\
\hline
\end{tabular}

The broad conclusions for the ALP models are as for the LNPC models except that neither of the age variables is significant in the ALP models, although age squared 
is borderline significant $(\mathrm{p}<.1)$ in Model 1. In both ALP models, experience is positively and significantly $(\mathrm{p}<.01)$ associated with cabinet appointment while experience squared is negatively significantly $(\mathrm{p}<.05)$ associated with cabinet appointment. Thus, the same quadratic relationship between experience and executive appointment that occurs in the LNPC Model 1 is evident in the ALP models. However, years of parliamentary experience beyond which the probability of appointment falls in the ALP models is 19 which is much lower than the inflection point for experience in the LNPC models of 31 . This difference may be due to there being very big differences in the appointment dynamics in government as opposed to opposition. Furthermore, the ALP data includes the entire shadow ministry rather than just the senior members of the ministry and this may have an effect on the results.

In ALP Model 2 the parameter WA has a significant $(\mathrm{p}<.05)$ positive coefficient and indicating that coming from WA increases the odds of a shadow cabinet appointment. Similarly there is a borderline significant $(\mathrm{p}<.1)$ positive effect of coming from SA. In this Model the excluded regional variable is NSW. This means that the states of origin parameters in Model 2 are effectively compared with NSW. Thus, the positive coefficients for WA and SA indicate that, relative to NSW, there is an increase in the odds of being appointed to cabinet of coming from WA and SA.

The classification accuracy of the ALP models is comparable to the classification accuracy of the LNPC models in that only a small proportion of the cabinet appointments are explained by the models. 
Table 3.23: Accuracy Metrics for ALP Models

\begin{tabular}{|l|cc|}
\cline { 2 - 3 } \multicolumn{1}{l|}{} & Model 1 & Model 2 \\
\hline Accuracy & 0.78 & 0.79 \\
Baseline Accuracy & 0.79 & 0.79 \\
Sensitivity & 0.19 & 0.25 \\
Specificity & 0.93 & 0.93 \\
Kappa & $0.16^{*}$ & $0.21^{* *}$ \\
\hline
\end{tabular}

$$
* \mathrm{p}<.05 ; * * \mathrm{p}<.01
$$

The overall accuracy of Model 1 and Model 2 are .78 and .79 respectively. Given that the baseline accuracy is .79 there does not seem to be an improvement on what we would get by merely saying no individual will become a shadow $\mathrm{CM}$ in the ALP. However, there is some evidence that the models are able to classify beyond mere chance. The Kappas for Model 1 and 2 are $.16(p<.05)$ and $.21(p<.01)$. However, their magnitudes indicate that the classification accuracy is not greatly above the value of 0 (no agreement) and does not come close to 1 (complete agreement).

The sensitivity of .19 for Model 1 indicates that $19 \%$ of shadow ALP ministers are classified correctly while the sensitivity of .25 for Model 2 indicates that $25 \%$ of CMs are correctly classified. The high specificity values, as explained above, are due to the high proportion of shadow non-CMs in the sample. The conclusions from the classification performance of the ALP models are similar to those of the LNPC models: the models do not enable us to explain the majority of shadow cabinet appointments. 
In short, the ALP RIF models, like the LNPC RIF models, have a classification accuracy beyond mere chance but overall leave the vast majority of $\mathrm{CM}$ appointment events unexplained. Unlike the LNPC models, in the ALP models neither age nor age squared have significant influence however experience and experience squared do. There is some indication that coming from SA and WA in comparison to NSW is beneficial for an appointment to the ALP shadow ministry. It should be noted that a direct comparison between the ALP and LNPC models may not be warranted because the study group is different in each case. Furthermore, the dynamics of appointment to the front bench in opposition may be unlike the dynamics of appointment to the frontbench in government. Finally, the ALP RIF model is constructed with a small sample size relative to the number of independent variables and this could affect the results.

\section{Summary of Section 3.4.1}

In this section I have used logistic regression to test the hypothesis that RIFs explain cabinet appointments. The analyses were run for the LNPC in government using cross-section data for five post-reshuffle period 1996-2007. For the ALP the analyses were run for the years 2005-2006. The findings were that age and cabinet appointment are related in a significant negative quadratic relationship in the LNPC, with a maximum at age 47. In the ALP models there is no such relationship between age and CM. However, the relationship between age squared and shadow cabinet appointment age is significant at the borderline level in ALP Model 1. In both the LNPC and the ALP there is a negative quadratic relationship between experience and cabinet appointment. However, the number of years of experience at which the maximum 
probability of appointment occurs in the LNPC is 31 which is higher than the age at which the maximum probability occurs in the ALP of 19. This difference may reflect different dynamics of appointment in government as opposed to opposition. Of the other representational variables there is some evidence from the LNPC Model 2 that coming from Qld in comparison to NSW reduces a parliamentarian's chances of cabinet appointment. There is borderline evidence from LNPC Model 1 that coming from NSW is positively associated with CM appointment. There is evidence from the ALP model 2 that an ALP parliamentarian coming from WA and SA in comparison to NSW has increased chance of shadow cabinet appointment. Beyond these no other variables are significant.

Of considerable moment is the finding that no model explains actual cabinet appointments to any great degree. The model with the highest sensitivity is LNPC model 2 which has a sensitivity of .26 . Thus, the best model leaves $74 \%$ of the cabinet appointments unexplained. In short, there is very little evidence that the representational variables can be used to explain cabinet appointments in the LNPC over the period 1996-2007 or shadow cabinet appointments in the ALP over 2005-2006. Thus, despite the fact that leaders in general attempt to mirror the structure of parliament in their cabinets, the RIFs have little influence on the probability of an individual being appointed to cabinet. In the next section I will attempt to explain why this might be.

\section{Section 3.4.2: Explanation of the Results}

How can the coefficients for most of the RIFs in both parties be non-significant when much of the literature states that RIFs affect cabinet appointments? Furthermore, 
how can it be that the RIFs explain very few actual cabinet appointments? As we saw in Section 2 there is a plethora of discussion as to who should be demoted and who should be promoted on the basis of the representation of states, parties, gender etc. However, the regression analysis tells a different story. The analysis shows that the influence of most RIFs is not statistically significant and that the effect on actual appointments is weak. How can we reconcile these two opposing viewpoints?

The answer is that the leaders are good enough at mirroring the representational structure of the parliament in their cabinets that the statistical effect of most RIFs on cabinet appointment is eliminated. A good way to conceptualise the situation is to consider the probability of selection in a virtual parliament. Consider a parliamentary party with 120 members from which the leader has to select a cabinet of 12. The probability of being a CM for any individual is $1 / 10$. Let us now divide the party into three factions (we could use states, gender or any other representational factor other than age or experience as the concept is exactly the same). Faction A has 30 members, Faction B has 20 members and Faction $\mathrm{C}$ has 70 members. The leader needs to maintain factional balance in each of the factions so she must ensure that the 12 members of cabinet are drawn from each faction in proportion to the faction's numbers. Thus three members are drawn from Faction A, 2 from faction B and 7 from faction C. What is an individual's probability of being CM for each faction? For faction A the probability is $3 / 30=1 / 10$; for faction $\mathrm{B}$ the probability is $2 / 20=1 / 10$, and for faction $\mathrm{C}$ the probability is $7 / 70=1 / 10$. For all factions, the probability of being selected to become a member of Cabinet is $1 / 10$, the same as the probability of being a $\mathrm{CM}$ for a member of the parliamentary party without taking into account factions. In other words, if the leader draws CMs from the factions in the same proportion as their numerical 
representation in parliament, being a member of any faction does not alter the probability of being a CM no matter how numerous its members or "powerful" it is relative to the other factions.

This explains why the coefficients for the RIFs except age and experience and some smaller states are not significant; Leaders tend to draw CMs from the various RIFs, reasonably closely to their numerical representation in parliament. They don't do this in relation to age, experience, Queensland vis-à-vis NSW and possibly NSW vis-àvis Victoria in the LNPC; nor do they do this in relation to experience, SA or WA vis-àvis NSW in the ALP. For the other RIFs, they do mirror in cabinet the representation in parliament so there is no statistical effect of these other RIFs on cabinet appointments.

\section{Summary of Section 3.4}

I have examined the factors that are usually cited as being important for explaining cabinet appointments. I looked at the RIFs that are usually cited and found that in both the ALP and the LNPC there was a positive quadratic relationship between experience and cabinet appointment and between age and cabinet appointment in the LNPC. There was a significant negative effect of coming from QLD in comparison to NSW in the LNPC and a significant positive effect of coming from WA and SA in the ALP. No other variables were significant. Furthermore, in both the LNPC and the ALP I demonstrated that the explanatory power of both models was small. The two LNPC models explained only 25\% (Model 1) and 26\% (Model 2) of the cabinet appointments while the ALP model explained 19\% (Model 1) and 25\% (Model 2). I explained the lack of statistical effect of RIFs by pointing out that the RIFs do not affect the 
probability of an individual being selected if the leader draws CMs from the various RIFs according to the parliamentary makeup of the RIFs.

I can therefore conclude that there is little evidence for the RIFs explaining cabinet appointments.

\section{Summary of Chapter 3}

The focus of this chapter has been the RIFs that are commonly cited in the Australian literature as being important for determining $\mathrm{CM}$ appointments. They are important for the current thesis because if cabinet appointments are made on the basis of these factors then, according to the standard argument, they should have an effect on the probability of an individual becoming a CM. With this in mind I examined the RIFs and their relation to cabinet appointments in the case of the Howard LNPC government 1996-2007.

The first stage of the process was to descriptively examine the RIFs. This involved looking at the media debate over 1996-2007 and the relationship between the actual and expected number of CMs for the RIFs under investigation. The general finding here is that the media debate provides some indication of the pressures the leader was under to represent the various RIFs. There are generally four different scenarios for the various RIFs: chronic under-representation (as with females); chronic over-representation (as with NSW); variation between over and under-representation (as with the Senate) and; close to perfect representation (as with the National Party). In the case of age and experience there is more leeway, and there is some evidence of a 
tradeoff between experience and age such that the leader seems to have attempted to get a relatively experienced cabinet but to occasionally infuse it with "new blood".

The next stage in the process was to examine the RIFs in a multivariate setting. This was done using a repeated measures design logistic regression analysis. In the case of the LNPC there is evidence of a negative quadratic effect of age, experience, and borderline evidence that coming from NSW in comparison to Victoria is a positive influence on CM. There is also evidence of a negative influence of coming from Queensland in comparison to Victoria. In the case of the ALP in opposition there is good evidence of a negative quadratic relationship between experience and shadow CM appointment. There is also borderline evidence of a non-linear relationship between age and appointments as the squared term for age was negative and significant at the $\mathrm{p}<.1$ level in Model 1. However, in neither of the models was the age variable significant. There was also evidence that coming from WA and SA as opposed to Victoria has a positive influence. There is no evidence of the other RIFS having an influence on CM.

I went on to assess the classification accuracy of the models. The conclusion was that the classification accuracy did not explain the vast bulk of CM appointments. My overall conclusion was that the RIFS are not as important in determining cabinet appointments as the literature suggests.

My next task was to try to explain why the RIFs, apart from a few exceptions, are not statistically linked to cabinet appointments despite the obvious efforts the leader made to appoint CMs from cabinet in proportion to the various RIF proportions in parliament. I explained this by pointing out that if the cabinet directly mirrors parliament as a whole then the statistical effect of the RIFs will be eliminated. 
The Selection of Cabinet Ministers in the Australian Federal Parliament

Having failed to explain the vast bulk of cabinet appointments using RIFs I will now turn to methods based more on individual factors. 


\section{Chapter 4: Towards a Method of Measuring Ministerial Ability}

\section{Section 4.1: Introduction}

The findings from the previous chapter enable us to say that the RIFs commonly referred to in the literature and the public debate are not able to explain the vast majority of cabinet appointments. This leaves us with three possibilities.

The first is that there are other representational variables that we have not discovered which explain cabinet appointments. This is unlikely because given that the leader is under intense scrutiny, particularly from the popular press, it would seem unlikely that there could be another set of variables which the leader was taking into account.

A second possibility is that individuals are selected for cabinet roles on the basis of random assignment. That is, the leader randomly selects individuals and, subject to the need to make her cabinet representative of all the competing RIFs, there is no other identifiable selection criterion. In other words, it is possible that there is no selection on the basis of either RIFs or individual talents and abilities and that the references to these in the literature are merely post hoc anecdotal accounts. This would mean that those who engage in discussions of ministerial ability are falling foul of the "narrative fallacy" (Taleb 2008: p62). This phenomenon is based on the human need for some kind of explanatory narrative to account for complex events, the actual causes of which we were not able to discern prior to the event but which, after the event, become "obvious". 
It is a third possibility that I wish to explore: that there are individual differences in the abilities of ministers. If this account is true then it may still not be possible to identify what these differences are. Perhaps if we were to administer a battery of personality tests to cabinet ministers and a control group of non-ministers we might be in a good position to identify what the differences are. As it is, even if we operate under the assumption that there is a difference between cabinet ministers and non-cabinet ministers we still have to find variables that tap into these difference. This is the essential subject matter of this chapter - how do we identify a set of independent variables that can be used to determine the differences between CMs and non-CMs? Primarily this will involve looking at the rather ephemeral concept of ministerial ability. The literature often refers to ministerial talent but stops short at trying to assess or measure it. In this chapter I will take steps to try to come up with a way of identifying individuals who have ministerial ability.

One of the most obvious places to look for differences in individual abilities is education. The education one receives is a very good indication of the abilities one has. It is highly unlikely that an expert in classical languages will lack verbal ability. Similarly it is unlikely that a scholar doing pioneering work in topology will lack spatial skills. Thus, education is a primary source of information as to the specific skills an individual has.

Another source of information about individual abilities is the way an individual uses language. We saw in Chapter 2 that Rose (1975) points out that most of the skills required of a minister are based on verbal ability. Cohen (1990) makes a claim about what an aspiring minister must do and, on inspection, most of these activities are 
verbally oriented. We also saw that the skills that were salient in enabling Howard and Rudd to rise to senior ministerial roles were verbally based. It therefore seems that a good place to start looking for a method of identifying ministerial ability is to look at the speech behaviour of parliamentarians. As I will show in this chapter, differences in the ways individuals use language can be used to determine cognitive and psychological differences.

Another set of characteristics that will be examined are biographical variables. These are not specifically markers of cognitive style but may be important in distinguishing between $\mathrm{CMs}$ and non-CMs for other reasons. Age at the time of entering parliament will be used because the idea of there being a relationship between age and appointment to high political office is a recurring motif in the literature. We also have direct evidence from the modelling in the last chapter that age is likely to be important. I will also include gender in the selection of independent variables. Finally, the circumstances in which the first speech was delivered needs to be taken into consideration. While this is not a biographical variable, there is some evidence that those whose party is in opposition tend to use language that is different from those whose party is in government (Hirst, Riabinin and Graham 2010). Therefore I include a dummy variable for this purpose in case this phenomenon is important.

The next question that needs to be addressed is where to draw this data from. In the case of educational and biographical data this is not difficult as there is detailed information on the qualifications, dates of service and dates of birth of parliamentarians in the Parliamentary Handbook of the Commonwealth of Australia (1968-2008). However, there is a major issue in terms of finding speech samples. One might think 
that because there is a record of parliamentarians speech in the form of Hansard this would not be a problem. In fact, there are problems with gaining representative speech samples that can be meaningfully compared. The highly prepared speech of a minister may not be as representative as a more spontaneous speech. Another problem is getting a sample of speeches from the range of individuals under study. Certainly it is possible to get speech samples of the CMs. However, many backbenchers say little during their entire parliamentary careers. My solution to these problems rests on recognising that there is one type of parliamentary speech that is very similar for all parliamentarians and is delivered by all parliamentarians in essentially the same circumstances - the maiden speech. My source for speeches will therefore be the first official parliamentary speech of each parliamentarian. As I will explain in detail below, this source has various advantages for extracting information about the speaker's cognitive style over other speeches delivered in a parliamentarian's career. I will use this source to examine what neophyte parliamentarians think is important and, more importantly, I will get an indication of how they think. The idea here is that a snapshot at this time is an indication of overall cognitive style. It is a contention of this thesis that cognitive style is the fundamental factor that determines whether or not a parliamentarian becomes a CM.

Having identified the maiden speech as the text source, the next issue is how precisely to analyse the text. In order to determine the most appropriate method I will review a number of different text analysis methods. I will show that there are a number of text analysis methods that have been applied in a number of domains including political speeches, all of which have some merit. I divide the text analysis methods reviewed in this chapter into two basic categories: those that are based on some a priori 
idea about what kinds of linguistic phenomena are of interest - the "content analysis" methods, and those that are based purely on the distribution of words in the text - the "text" analysis methods. Both have merit and I will explain why I have decided to use content analysis rather than text analysis.

Thus, this chapter is intended to address the following issues:

1) We need to recognise that the RIFs do not explain the vast majority of cabinet appointments and therefore it is possible that it is individual qualities that play an important role in determining cabinet appointments.

2) Methods of determining some measure of individual qualities needs to be derived. One method is to use the educational backgrounds of parliamentarians to determine cognitive orientations. Another method is to use speech samples to isolate the way individuals reveal cognitive style in their speech. Finally, a number of biographical variables will be included on the assumption that these can reveal cognitive characteristics.

3) Determining the educational background is a straightforward procedure which simply requires collecting data about what qualifications parliamentarians have. This is also the means by which biographical data will be sourced.

4) Determining the verbal characteristics of parliamentarians is significantly more involved and requires two steps. The first is the identification of a representative speech sample for each parliamentarian. It is contended that the maiden speech is ideal for this purposes. The second is to determine a method of analysing speech. It is contended that content analysis is the most appropriate way of doing this. 
By following these steps I should be able to develop a set of independent variables based on the educational background and verbal behaviour of parliamentarians. These independent variables can subsequently be used to see if there is a significant difference in the verbal style of cabinet ministers and noncabinet ministers.

\section{Section 4.2: Education as a Marker of Cognitive Style}

We have seen in chapter 2 that Kerby (2009) found, in the Canadian context, a positive relationship between having a university education and the "risk" of becoming a CM. Having a legal background was also positively associated with increased probability of becoming a CM. O'Malley (2006) demonstrated that a tertiary education was significantly associated with the odds of appointment to cabinet in Ireland. Kam et al (2010) found that Oxbridge education was positively associated with appointment to the UK cabinet and Dewan et al (2007) found that Oxbridge education reduced the risk of de-selection. Thus there are good precedents for the idea that education may be linked with decisions about the kinds of individuals who will function well in cabinet.

Education can be used as a means of coding for a number of inherent characteristics of parliamentarians. Berlinski, Dewan and Dowding, for example, consider that public school or Oxbridge education could be a means of capturing characteristics such as acquired skills, latent ability or access to social networks. (Berlinski, Dewan and Dowding 2012: 79). In this thesis I wish to emphasise the importance of education as a marker of cognitive thinking styles. Thus, the specific 
subject area pursued by a parliamentarian is what I need to code for. The idea here is that a particular type of education is likely to be linked to a particular way of looking at the world. This is not to posit a causal relationship between the two. I am not asserting that a particular type of personality or cognitive style is likely to be attracted to a particular type of education. Nor am I asserting the reverse - that a particular type of education is likely to have an effect on the cognitive orientation of an individual, although both these scenarios are compatible with the idea that the kind of education one has is a good maker of cognitive style.

The idea that there is a link between the type of education pursued by an individual and their personality style is by no means a new idea. Lievens, Coetsier, De Fruyt and De Maeseneer (2002) found that medical students were more likely than other students to score highly on extroversion and agreeableness; Boone, van Olffen and Roijakkers (2004) found that individuals with a high internal locus of control were more likely to select subject areas for study that were more challenging and uncertain and led to more unstructured future careers in comparison to individuals with a low internal locus of control; Frey and Meier (2003) used data on contributions to social funds and found that students of political economy are more generous than students of business economics; McLain and Christiansen (1970) found that students training to be English teachers tended to be more extroverted, independent and emotional than other students; Trautwein and Lüdtke (2007) found that final year high school students who score highly on certainty beliefs (that is, they see scientific theories and findings as correct, true and stable and believe there is a "right" answer to all questions) were more likely to enrol in applied areas such as engineering and business while those low on the certainty 
of knowledge scale were more likely to enrol in pure and "soft science" areas such as the social sciences and humanities. Interestingly, the study found that when the cohort was followed up two years later and had enrolled in their chosen fields of study, the differences in certainty beliefs were more pronounced indicating that there was a socialisation process at work on top of the self-selection process.

Thus, there is good reason to believe that the education a parliamentarian pursues is a good marker of other cognitive characteristics. The specific psychological characteristics that each type of education might represent may be difficult to determine. Furthermore, it is possible that despite education being a good marker of psychological characteristics, the characteristics that they pick out may not be those that distinguish between CMs and non-CMs. Nevertheless, education is a good place to start.

From the literature, it would seem that an appropriate starting point for coding for education would be to flag particular types of education. It is therefore proposed that binary variables be provided for 1) Legal education, 2) Arts/Humanities education, 3) Economics/Business 4) Teacher Education, 5) Science/Technical Education, 6) Medical Education. Coding for these variables accounts for 96 of the 97 individuals with a tertiary education in the sample of 134 used for modelling in Chapter 6.

\section{Summary of Section 4.2}

In this section I have given an overview of the reasons for including some measure of education. Education is likely to be a very good marker of cognitive style and therefore it is likely to provide the kind of marker that may be useful in 
distinguishing between CMs and non-CMs. To this end six dummy variables will be investigated to determine whether they are associated with the likelihood of being appointed to cabinet.

In the next section I will continue the attempt to isolate parliamentarians' individual cognitive differences by focusing on variables associated with linguistic behaviour.

\section{Section 4.3: Verbal Behaviour as a Marker of Cognitive Style}

In this section I wish to examine how language use might be used to tap into cognitive style. Again, the underlying assumption here is that there are cognitive differences between CMs and non-CMs. If there are no such cognitive differences then it is unlikely that cognitive differences as revealed by language use will be useful in distinguishing between CMs and non-CMs. However, an examination of the reasons why some parliamentarians are appointed to cabinet while most are not requires that we look for differences between them and a plausible place to look for cognitive differences is in the way language is used.

In the remainder of this section I would like to take two steps towards analysing the language of parliamentarians. The first is to determine the source for the samples of speech. I will argue that the maiden speech is an ideal such source. The second is to determine how the sample maiden speeches should be analysed in such a way as to generate independent variables. I will argue that the ideal way to do this is to use content analysis. 


\section{Section 4.3.1: Maiden Speeches as a Source for Speech Behaviour}

Maiden speeches were used to analyse Australian parliamentarians by Pickering (1996) who used them to compare the incoming LNPC MPs in 1996 with those of 1975. Pickering held that the maiden speech “...provides an important window into the minds of those who have sought and achieved office on behalf of the coalition" (Pickering 1996: 96). The basis of comparison was the difference in content between the incoming 36 LNPC MPs after the Federal election of 1996 on the one hand and that of the 33 incoming LNPC parliamentarians in December 1975 on the other. One of the significant differences Pickering found was the differing emphasis placed on small business and the family by the different cohorts. Small business received 100 mentions in 36 speeches from the 1996 cohort compared with 8 mentions in the 33 speeches from the 1975 cohort, indicating that small business became significantly more important in 1996 compared with 1975 (Pickering 1996: 106). Another difference was the rate of mentions of the family. The family was mentioned on average four times per speech by the 1996 cohort but not at all by the 1975 cohort.

Power and Beradone (1998) compared the first speeches of a random sample of 5 men and 5 women in the House of Representatives of the 38th parliament. The idea behind the study was that both the style and content of women's speeches differ from men's and therefore this should be detectable in maiden speeches. The assumption is based on Power and Beradone's observation that previous research into women's speech "....indicate[s] that women seek confirmation more from the other speaker, are more precise in their speech and speak less than men do, but they speak of attitudes, 
beliefs and concerns more than men do"(Power and Beradone 1998: 4). The main findings of the study of parliamentary speeches were that women acknowledge support from others more than men do, women disclose more personal information than men, and women focus more than men on topics and issues relating to the three broad categories of family/spouse/children, crime/police/violence, and gender equity (Power and Beradone 1998: 9).

Maiden speeches will be used in the current thesis because, it is contended, they are able to provide linguistic clues to the cognitive makeup of parliamentarians. The idea is that there may be a cognitive style that is associated with cabinet membership and this can be extracted from the speech acts of parliamentarians. The maiden speeches of parliamentarians are a good source for these speech acts because the speech acts all occur in a similar manner, format and context.

In House of Representatives Practice the first speech is defined as being the first speech delivered in the House, notwithstanding that the member may have previously served in the Senate or a State parliament. The convention is that the first speech, which is not to exceed 20 minutes, is heard without interruption and that the speech not be unduly provocative. The speech of a new member is usually made in the Address in Reply debate of a new parliament following a general election. Members elected at a by-election usually give their speech in debate on Appropriation bills. The rules of relevance are suspended in relation to a first speech such that the member need not confine the content of their speech to the subject matter of the debate at hand (Department of the House of Representatives 2005: 141-142). As such, a speech is the opportunity for the new member to introduce themselves to the parliament and make a 
general statement of their aims and intentions. Odgers' Australian Senate Practice defines the first speech in the Senate in essentially similar terms (Department of the Senate 2008: 210).

From the guidelines set out above it is clear that the topics of maiden speeches are intended to be general. This is certainly what inspection of the speeches reveals. Most speeches include a biographical sketch of the parliamentarian and reference to the characteristics of her electorate. Most speeches also cover general economic issues as well as specific economic issues that affect the parliamentarian's electorate. Most speeches also cover in detail issues that interest the parliamentarian. Finally, many speeches include sections on thanking people who have helped the parliamentarian get into parliament. This kind of broad spectrum of topics that have been chosen by the parliamentarian is what is needed to compare parliamentarians. To see why this is important consider a speech by a parliamentarian representing her party's position on a specific concrete area such as taxation policy and a speech by another parliamentarian representing her party's position on a more abstract specific area such as human rights. If we were to compare these we might conclude that the first parliamentarian was more concrete in outlook while the latter was more abstract. In fact, it is the subject matter that is leading to the distinction not the cognitive style of the parliamentarian. In order to avoid this problem we need general speeches and the maiden speech is likely to be significantly more general than any other speech a parliamentarian will make in her parliamentary career. Thus, the maiden speech is ideal for getting a speech sample that shows how the parliamentarian addresses a relatively broad spectrum of subjects. 
It should be stated at this point that there is no suggestion that there might be a causal connection between the speech and the subsequent career trajectory. Rather, the maiden speech is being taken as a marker of cognitive characteristics. Because it is essentially on topics of the parliamentarian's own choosing, the maiden speech is likely to be highly indicative of what the parliamentarian considers important. As such it is likely to be indicative of what the parliamentarian thinks about and, more importantly, how the parliamentarian thinks. The maiden speech therefore instantiates a general set of psychological/cognitive characteristics of the individual and it is contended that these characteristics are related to a parliamentarian's chances of being appointed to cabinet. Thus, it makes no sense to say that a minister might change the content of her maiden speech in an attempt to change her career trajectory. A good analogy here is that of a blood test is used to assess the risk of a heart attack. There is not a causal relationship between having high blood pressure and having a heart attack. However, such a marker is indicative of a syndrome, the presence of which increases the risk of having a heart attack. Similarly, it is contended that the presence of certain verbal characteristics as revealed in maiden speeches does not cause selection to cabinet. However, they may be related to a cognitive "syndrome", the presence of which significantly increases the "risk" of being selected for a CM role.

One other issue of importance is whether the maiden speech consists of the parliamentarian's own thoughts. The issue here is that many high profile political leaders have speeches written for them and therefore the texts may not reflect the cognitive characteristics of the "speaker". The "ghost writer" problem has been given careful consideration in the literature. Winter (1987) explained why presidential 
inaugural addresses, usually written by a speechwriter, could be reliably used as a basis for content analytical assessments of individual presidents even though the presidents are unlikely to have written them. There are two reasons why, according to Winter, the prepared speech can be relied on as a marker of what the speaker think. Firstly, a good speech writer will produce words and images that the "client" will feel comfortable with. Secondly, the client will spend considerable time reviewing and vetting the text (Winter 1987: 198).

Support for this contention of Winter's comes from Ballard (1983) who found that the spontaneous speech utterances of a selection of Canadian prime Ministers had the same level of linguistic complexity as prepared speeches. This supports the idea that speech writers and adapt to their client's style and that the client will adapt the speechwriter's words to his own style. However in contrast to the findings of Ballard, Dille and Young (2000) found in an analysis of the speeches of presidents Carter and Clinton that there was a difference in the complexity of spontaneous and prepared speech, with spontaneous speech being more complex. Their explanation was that speech writers tend to reduce the complexity of speech for mass consumption. Thus, there is evidence for both sides of the ghost writer argument.

Fortunately, this problem is not as great in the current situation is it is with speeches from high profile politicians. The ghost writer issue emerged because the texts being used were known to have been written by others because the individuals under study were high profile leaders such as presidents. Such individuals have the resources available to have speeches written for them. But maiden speeches in the Australian federal parliament are typically given by low profile newly elected members of 
parliament. Such individuals tend to have very limited resources and are therefore very unlikely to have personal speechwriters. What this means is that, although there will certainly be parliamentarians who have had their speeches written for them, the vast majority will not and therefore, in general, the speeches are likely to represent the ideas and cognitive style of the parliamentarians delivering them.

\section{Section 4.3.2: Deriving Independent Variables from Texts}

The decision to use maiden speeches as a source of independent variables raises the question as to the manner in which the speeches are to be analysed. Clearly, the text of the speech needs to be analysed in some systematic way. In this section I will briefly review several methods of reducing texts to variables that can be used in statistical modelling. The basic requirement here is that the texts need to be broken down into some kind of numerical data. The question is what kind of variables will be most useful? Various text and content analysis methods could be used so the important issue to address is which methods are most likely to tap into individual markers of cognitive style. I will argue in this section that two specific forms of content analysis will be the appropriate way to proceed.

\section{Content Analysis versus Text Analysis}

There are two broad approaches to analysing text. The traditional approach is content analysis which focuses on analysing texts by looking for some kind of pre- 
determined content. The other approach is text analysis which treats the words in text inductively as data independent of the semantic content of the text.

A good example of a method of content analysis is the study by Power and Beradone (1998). This study involves a content analysis of five maiden speeches of men and five of women of the $38^{\text {th }}$ parliament. As stated above, they found that women acknowledge support from others more than men do, disclose more personal information than men, focus more than men on topics and issues relating to the family, crime and gender equity (Power and Beradone 1998, p. 9). This is essentially a content analysis because their starting point is that there is a particular content that distinguishes women's from men's texts. Consider their finding that women acknowledge support more than men do. In order to ascertain this it is necessary to find statements in which the speaker expresses gratitude. Thus, the number of words devoted to "thanking" in women's speeches is compared with that of men. Similarly, the finding that women mention issues about crime, the family and gender equity requires that a particular selection of words is sought in each of these categories. In short, there is a search for particular content.

Power and Beradone's (1998) study is in stark contrast to the approach used in an archetypal text analytical technique, that of Laver, Benoit and Gary (2003) who “...present a new way of extracting policy positions from political texts that treats texts not as discourses to be understood and interpreted but rather, as data in the form of words" (Laver et al 2003: 312). The approach they use is to focus on word frequencies in texts. The starting point is to examine a sample of texts, the authors of which are known to have a particular ideological orientation. The particular words and their 
relative frequencies that distinguish between these political orientations are then derived from the texts. By comparing scoring "virgin" texts on the basis of the word frequencies derived from the training sample it is possible to derive the ideological position of the virgin texts. The idea here is that the relative frequencies of the words in the reference sample is a signature of ideological orientation. It should be noted that there is no reference to meaning, semantics or content. The process requires no interpretation. However, it should be noted that the selection of reference texts and their scoring on ideological position can be considered to an extent an interpretative exercise (Laver et al 2003: 314).

Lowe, Benoit, Mikhaylov and Laver (2011) describe a content analytical approach to the same problem of determining the political orientation of texts. The method used in this study is described as "traditional manual content analysis" (Lowe et al 2011: 124). The political orientation of texts is based the count of 13 "left" and 13 "right" categories of content. That is, there are 13 categories of typically "right" policy content and 13 categories of typically "left" policy content. The coder looks for this content and the tallied scores for each of these categories provide the basis for positioning a given text on a left-right scale. The important difference between this approach and that of Laver et al (2003) is that the construction of the scale in the former case is dependent on coding specifically identified content whereas the latter involves no such search for content but relies on the distributions of words in the archetypically "left" and "right" texts.

One way of looking at the difference between content analysis and text analysis is to say that content analysis tends to be deductive while text analysis is inductive. 
Content analysis starts with an assumption about what should be in particular kinds of document and then goes about looking for it. Text analysis makes no assumptions about what should be present or absent in different kinds of documents but instead takes what it finds and uses these findings as a basis for making distinctions between kinds of documents (Laver et al 2003: 314).

Between the two extremes of the Power and Beradone (1998) approach and that of Laver et al (2003) there are methods that adopt elements of each. In the following review of the literature it is not intended to try to classify the various approaches into content analysis and text analysis. Rather, the attempt is made to give an overview of the kinds of analysis that have been undertaken. At the end of the section I will explain why, for the purposes of tapping into cognitive differences, a method that is more content analytic (deductive) should be preferred over the more text analytic (inductive) one.

House, Spangler and Woycke (1991) analysed the inaugural speeches of 31 presidents in order to derive a number of psychological constructs. Their hypothesis was that presidents' scores on these psychological constructs should be related to subsequent assessments of the presidents' charisma and achievements. Their approach was heavily deductive. For example they assumed that the number of times the word "not" was mentioned in the text divided by the number of words in the text gave a measure of the construct "Activity Inhibition", which is a measure of the extent to which an individual is willing to use "...power to achieve institutional or social goals rather than personal goals" (House, Spangler and Woycke 1991, p365). Using the texts to generate measures for Activity Inhibition, and three other psychological constructs, they found some 
support for their hypothesis that each of the constructs were related to various measures of charisma and greatness. The interesting point of this from the perspective of the current thesis is that they were able to extract from the inaugural speeches personality elements that were shown to be related to the subsequent career performance of presidents. This supports the idea that speeches in a politician's career contain elements that mark their psychological and cognitive style.

In a similar vein to House Spengler and Woycke's study, Emrich, Brower, Feldman and Garland (2001) analysed US presidents' inaugural speeches to determine whether those that used more imagery were perceived as having higher levels of charisma and greatness. According to Emrich et al (2001), certain categories of words are more evocative than others. Thus, using a phrase such as "I have a dream" is somehow more evocative than a phrase such as "I have an idea", and this should mean that listeners perceive those who use more evocative phases as being more charismatic and "great". In order to score each speech for evocativeness they used Martindale's (1975, cited in Emrich et al 2001: 530) 2900 word Regressive Imagery Dictionary. This dictionary lists words in different categories which fall into two broad categories of words: those that are evocative of physical sensations on the one hand and those that are conceptual on the other. The general hypothesis was supported. Those presidents who used more image-based speech were considered by historians to be "greater" and scored higher on various measures of charisma.

The Emrich et al (2001) study like the House et al (1991) study shows how information about the underlying characteristics of individuals can be derived "at a distance" by using speeches. The main difference between the two studies is that the 
data extracted from the speeches in the House et al (1991) study were psychological constructs whereas the data extracted in the Emrich et al (2001) study were of a propensity to use a particular kind of language. The important point is whether extracting linguistic proxies for psychological constructs or general linguistic markers of cognitive style, speeches can be used as a source of useful information about individuals.

There is tradition in the content analysis literature of attempting to identify traits that can be used to explain the behaviour of leaders in office. A good example of this is Herman's (2005) Leadership Trait Analysis (LTA). This framework uses insights from cognitive psychology to derive seven constructs that measure the "traits" of need for power, ethnocentrism, locus of control, conceptual complexity, self-confidence, distrust of others, and task/interpersonal emphasis. The idea is that these traits can be used to explain why particular leaders took particular courses of action while in office. The interesting aspect of the approach for the current thesis is that the scores on these traits are all derived using "at a distance" methods: the scores are entirely derived from the public speech acts of leaders. For example, conceptual complexity is measured by creating an index based on the frequency with which they use words associated with high or low levels of complex thinking. According to the theory, the conceptually complex person sees the world in a nuanced rather than black and white way. The speech acts of leaders are used to identify their level of conceptual complexity, the assumption being that the way a leader speaks reflects the way she processes information about the external world. This profile can then be used to explain their behaviour in office. The measure is calculated by dividing the number of words 
denoting certainty by the number of words denoting tentativeness. The use of tentative words to qualify statements, such as "probably" and "likely", indicate a higher level of cognitive complexity than words such as "certainly" and "definitely".

Dyson (2009) applied this technique to responses to foreign policy questions in the House of Commons by post-1945 British prime ministers and found that Margaret Thatcher had the lowest conceptual complexity of the post 1945 prime ministers. Dyson claims that Thatcher's low level of conceptual complexity was evident in her propensity to see the world in binary "us and them" terms. Dyson points out that Thatcher's colleagues and biographers found a tendency toward black-and-white thinking to be one of the foremost characteristics of her leadership. Anthony King (1985: 132, cited in Dyson 2009: 38) notes "a disposition to see the political world as divided into friends and enemies, goodies and baddies".

A concept similar to conceptual complexity is integrative complexity (Suedfeld and Rank, 1976; Suedfeld and Tetlock, 1977; Tetlock, 1983; Tetlock, Hannum and Micheletti, 1984). As with Herman's (2005) approach, the basic idea behind these concepts is that individuals differ in the way they process information, come to conclusions, and make decisions.

LTA and integrative complexity can be considered to be within the content analysis tradition because the approach is to look for particular content. In the case of conceptual complexity the content under investigation is complexity of information processing. 
Purpura and Hillard (2006) use a system akin to that of Laver et al (2003) in that they use individual words to classify texts. Their aim was to automate the classification of legislative bills according to the 20 major topics and 226 sub-topics of the Policy Agendas Program. A given bill can be classified into one major topic and one sub-topic. The idea of using word frequencies is that certain types of bill will contain certain types of words: a document containing the high frequencies of the words "international" and "trade", for example, is likely to belong to the major topic category of Foreign Trade. Similarly, a document containing high frequencies of the words "export" and "subsidy" is likely to fit into the sub-topic Tariff and Export Restrictions. In the procedure each word in a document was weighted according to the number of occurrences divided by the number of all other words. A "training sample" of bills that had already been classified provided the word frequency signatures for each of the topic and sub-topics. The algorithm compares the word frequency scores of un-classified bills against the word frequency scores of the classified bills. Clearly, this method is inductive in that the schema for classifying bills is taken as given by the word frequencies. There is no specific content that the classification scheme relies on other than the distribution of words in the texts.

The above review covers only a small fraction of the growing number of articles on content analysis, and text analysis. Due to the availability of texts in the form of 'blogs' and "tweets" methods of extracting data in the form of opinion mining and sentiment analysis are developing at a great rate. The common element to all of these is the reduction of text to some form that can be used for further analysis. 
The question we are left with is which method should be used in the current application? The answer, I submit, is that I need to select a method that is appropriate to the task. Strictly speaking, I am not trying to classify texts, I am trying to classify individuals. The basis on which I am trying to classify individuals is their cognitive profile. As such, the ideal method of breaking down the speeches should be one that enables me to track the cognitive style of individuals. This means that I will need to use some form of content analysis. I am looking for some kind of cognitive difference between CMs and non-CMs so I will need to break each speech down into some proxy for cognitive style. In other words I need to look for content related to cognitive style.

There are two content analysis methods I wish to use. One is based on research into psycholinguistics, the other has become the industry standard for text analysis in psychology and related disciplines - Linguistic Inquiry and Word Count (LIWC).

\section{Psycholinguistic Content Analysis}

This method of content analysis is based on Paivio Yuille and Madison's (1968) and Clarke and Paivio's (2004) word norms. The idea is to score each speech on the 32 psycholinguistic variables under consideration in these studies.

The Paivio Yuille and Madison (1968) and Clarke and Paivio (2004) (PYMCP) word norms are based on a sample of 925 nouns. For each of these words, 32 linguistic and psycholinguistic variables were derived. Many of these are structural and include such measures as the number of letters and number of syllables. The more interesting from a cognitive style point of view are those variables that were derived from subjects' responses to the words. For each word, subjects were asked to answer 
questions on a number of psycholinguistic dimensions. For example, meaningfulness was derived by asking subjects, for each word, how many associated words they could think of in 30 seconds. Similarly, the age of acquisition was derived by asking subjects at what age they estimate they learnt each of the 925 words. The result is that there are 32 variables for each of the 925 words that measure structural and psycholinguistic properties. This means that for each word there is a comprehensive set of variables that tap into the nature of the word and how it is processed by subjects.

The idea of scoring each speech on these 32 variables was that the psycholinguistic characteristics measured by the variables may enable us to tap into differences in the cognitive style of parliamentarians. For example, one of the 32 psycholinguistic variables is the age of acquisition which measures the average age of acquisition of the 925 words across the cohort of subjects used in the study. The idea is that simpler more concrete words are acquired at an earlier age and the AOA measure should provide insight into various aspects of the way language is used by individuals with different cognitive styles. My use of this variable is based on the idea that a parliamentarian whose speech includes a lot of words with a high age of acquisition could be considered to be using language that differs on some cognitive dimension from that of a parliamentarian who uses a lot of words with a lower age of acquisition. Given that there is a strong verbal emphasis in the selection of parliamentarians it is conceivable that such variables may have the key to distinguishing between those who become CMs and those who do not. 
To explain how the scoring of the speeches was done I will use the "ease of definitions" (Def) variable. All 32 variables were used by me to score the speeches in the same way.

Before I begin my explanation it is worthwhile explaining precisely what Def is a measure of. The PYMCP Def scores for each of the words in the 925 word sample were derived by asking subjects to score how easy it would be to explain the meaning of the word on a scale of 1 to 7 , with 7 being the easiest. Out of the sample of 925 words the word that was easiest to define was "baby" ( the hardest to define was "gadfly" (score $=1.92$ ). Over the 925 words, the average score was 5.14. No individual words scored precisely the average of 5.14 however words with in this range were "vessel" (5.13), "warmth" (5.13), "alimony" (5.17) and "caravan" (5.17).

To use the raw Def scores to score speeches, the first stage was to determine, for each speech, which of the 925 words in the PYMCP sample were present. The average Def score for each speech could then be calculated. Consider for example the sentence

"The baby ridiculed the gadfly’s caravan",

In this sentence the words "the" and "ridiculed" are not in the 925 word sample so they are ignored. The words "baby", "gadfly", and "caravan" are in the sample with scores of $6.79,1.92$, and 5.17 respectively. As the sentence contains three words from the sample, the "Def" score for the sentence is calculated as follows:

$$
(6.79+1.92+5.17) / 3=4.6 \text {. }
$$


If the word "baby" had appeared twice, as in the sentence

"The baby ridiculed the baby gadfly's caravan"

the score for the word "baby" is included twice so the calculation is

$(6.79+6.79+1.92+5.17) / 4=5.17$.

In this way we get a proxy for the average ease of definitions of words used in each speech. It is only a proxy because it is based on a 925 word sample. The speeches were scored on all 32 psycholinguistic variables in the same way as described above of ease of definition.

As we will see, the psycholinguistic variables are prominent in the modelling process. We will see that speeches that score high on the presence of concrete words are those that tend to be from non-CMs.

\section{Content Analysis with LIWC}

LIWC uses 68 predefined dictionaries to create 68 linguistic categories. As such it is in the content analysis tradition in that the method only searches for what the researcher is looking for. That is, it is not inductive like the Laver et al (2003) and Purpura and Hilliard (2006) methods.

The word categories used are based common behavioural and cognitive processes. They include Negative Emotion, Affect, Leisure, Work, Family, Social Activities and Psychological Processes. The idea here is that the list of 68 categories is 
common to all individuals. That is, the categories are not designed to isolate characteristics associated with specific psychological constructs of proclivities. The categories were derived from a list of words associated with each category. For example, the Psychological Processes category was populated with words developed from the Positive Affect Negative Affect Scale (Watson, Clarke and Tellegen, 1988, cited in Pennebaker et al 2007), Roget's Thesaurus, as well as standard English dictionaries. From these sources the list of words associated with "Psychological Processes" was developed.

The utility of LIWC in text analysis has been demonstrated across a substantial number of domains. Tausczik and Pennebaker (2010) list 121 studies using LIWC for text analysis since 2001 when the first version of the software became commercially available. These include applications to political discourse. LIWC was used to analyse television interviews with Democrat presidential candidates in the 2000 and 2004 election (Slatcher et al 2006). It was found that Kerry and Edward used similar rates of positive emotion words whereas Kerry used higher rates of Negative emotion words. A comparison between Kerry and Gore found that they had very similar linguistic styles. In particular they had very similar levels of pronoun usage and Insight and Cognitive words. Edwards' interviews were statistically significantly different from both Kerry and Gore on these measures. Hirst Riabinin and Graham (2010) analysed the Hansard of the Canadian Parliament in two periods over which the government had changed. They found that the party in government uses more positive emotion words while the party in opposition uses more negative emotion words. Yu, Kaufman and Diermeier (2008) used LIWC to determine whether it was possible to use text analysis to classify opinions on 
topics in congressional debates as "for" or "against" the motion under discussion. The idea here was that it should be possible to determine whether a speaker supports or opposes a topic under discussion on the basis of markers such as positive and negative emotion. They found that most Congressional debate involves very low levels of sentiment. Thus, they concluded that using sentiment-laden adjectives was not sufficient for opinion classification in political speech. Niederhoffer and Pennebaker (2002) used LIWC to analyze the official transcripts of the Watergate tapes. They were looking for evidence that in dyadic conversation the words of one speaker will co-vary with the words of the other. The idea behind this is that the words used by the first speaker prime the second speaker to use particular words. This "synchrony" is the verbal equivalent of physical synchrony in which interlocutors will mirror each other's body language. They found support for the language synchrony hypothesis at both the turn-by-turn level and the overall conversational level.

It seems that LIWC may be a good way of analysing text for the purposes of extracting cognitive "signatures" of the author. I will therefore use LIWC to break down the maiden speeches of parliamentarians in the hope that within the 68 linguistic variables there are some variables that tap into the cognitive style of parliamentarians.

\section{Summary of Section 4.3}

I began this section by giving an overview of the reasons for using maiden speeches as a means of determining the cognitive characteristics of parliamentarians. The maiden speech is ideal for this because it is delivered under controlled conditions 
and because it covers general topics of interest to the individual. As such it should provide a highly individual snapshot of how parliamentarians use language and this should give an insight into the cognitive characteristics of the speakers. There is unlikely to be a problem with ghost writing given that the neophyte parliamentarian is likely to write her own speech.

The next issue I dealt with was how the maiden speeches of parliamentarians should be broken down in order to derive a set of independent variables that are most likely to tap into the cognitive style of parliamentarians. I surveyed a number of content analysis and text analysis methods. I decided that, because I am trying to categorise individuals rather than texts it was more appropriate to use content analysis rather than text analysis. The idea here being that I am looking for some kind of marker of cognitive style rather than classifying speeches. I explained that one way of doing this would be to use the psycholinguistic variables derived from the PYMCP word norms to score speeches. I then discussed LIWC which has been used in a variety of settings. It has been shown to be useful for extracting useful psychological information from texts in a number of settings.

In the next section I will consider how Garrad (2003) used the LIWC categories to analyse the application essays of Airforce trainees to determine which applicants would be more likely to complete their courses. The point of this is to demonstrate that the LIWC categories are efficient at analysing texts in a situation where the task is to distinguish between the cognitive characteristics of individuals. As this application is very similar to what I am engaged in with this thesis this should provide a good 
example of how useful LIWC should be for classifying parliamentarians into CMs and non-CMs

\section{Section 4.5: Linguistic Inquiry and Word Count and Personnel Selection}

Garrad used the application essay written by trainees in the Royal Australian Air Force to assess the likelihood of the applicant successfully completing training courses leading to the positions of Pilot, Air Defence Officer and Air Traffic Controller. Applicants for these courses completed a 20 minute writing task which required the applicants to "...discuss their motivation for joining the RAAF in the occupational capacity for which they had applied, their expectations of adjustments that they will be required to make, and the nature of the officer role and any relevant experiences they may have" (Garrad 2003: 70). Using an earlier (2001) version of LIWC than the version used in this thesis (2007), Garrad converted the essays to 72 text categories using the LIWC dictionaries. As there were far more categories (variables) than could be of practical use in standard linear modelling, a procedure for exclusion of categories was adopted from Pennebaker and King (1999). Text categories that had mean usage levels below $0.5 \%$ of the total text were excluded. Secondly, text categories that substantially overlapped with other categories were excluded. Thus, Affect was removed because it overlapped Positive Emotions and Negative Emotions. Thirdly, variables that did not meet at least 0.5 on Kaiser's Measure of Sample Adequacy were removed. Additionally, the categories of Pronoun and Present were removed as variance proportions suggested that there was considerable overlap between these variables and others. Finally, variables that did not relate to the specific content of words, such as variables relating to 
punctuation and word length, were removed. After the exclusions, 23 variables remained. These were used as dependent variables in logistic regression models. The dependent variable in the models consisted of a binary coding of 1 for successful completion of the training course and 0 for unsuccessful completion.

Models for each of the three categories of applicants, Pilot, Air Defence Officer and Air Traffic Controller, were created separately. As a first stage in the modelling process the various psychometric scores used by the Air Force to select trainees for the three training courses were introduced as a block of independent variables. The second block of independent variables consisted of the LIWC variables. These were entered in a backward stepwise procedure.

In the case of the Pilot model, of the 23 candidate variables introduced in the stepwise procedure, four were selected: Pronouns (e.g.; "he", "she", "they"), Present (present tense verbs), Insight (e.g.; "think", "know", "consider") and Negations (e.g.; "not", "not", "never") were found to significantly add to classification accuracy. In the case of the Air Defence Officer model, of the 23 variables introduced in the stepwise procedure, four were selected. Positive Emotions, (e.g.; "happy", "good", "like"), Discrepancies (e.g.; "should”, “would”, “could”), Tentative (e.g.; "maybe”, "perhaps", "guess") and Achievement (e.g.; "try", "goal", "win") were found to significantly add to classification accuracy. In the case of the Air Traffic Controller model, of the 23 variables introduced in the stepwise procedure, six were selected: Negations, Inhibition (e.g.; "block", “constrain", “stop”), Tentative, School (e.g.; “class", "student", “teacher”), Job (e.g.; “employ”, "boss", “work”), and Leisure (e.g.; "house”, "TV”, 
"music"). In this model, however, the inclusion of the linguistic variables did not increase classification accuracy.

In the case of the Air Defence officer model, the inclusion of the LIWC variables improved the Nagelkerke Pseudo $\mathrm{R}^{2}$ by 0.19 and improved model fit with $\chi^{2}$ moving from $7.09, \mathrm{df}=2, \mathrm{p}<.003$ to $22.52, \mathrm{df}=6, \mathrm{p}<00$. The classification accuracy improved from $71.29 \%$ to $77.23 \% .^{1}$ Similar results were found for the Pilot model with overall classification accuracy rising from $61.75 \%$ to $63.38 \%$. The result for Air traffic Controllers was mixed. The non-LIWC variables consisted of an interview rating and various psychometric variables. Neither the psychometric nor interview variables were significant. The addition of the LIWC text variables added to the ability of the model to detect failures (increased the specificity) but, simultaneously, decreased the ability of the model to detect passes (decreased the sensitivity). Thus, the overall accuracy of the model was not improved.

The conclusion was that, in the case of Air Defence Officers and Pilots, there is a clear influence of text variables on the ability to detect potential successful candidates. In the case of Air Traffic Controllers, there is not a good overall improvement in the classification accuracy when the text variables are added. It should be noted that, in the Air Traffic Controllers model even the psychometric and interview data failed to be able to distinguish between completers and non-completers. Garrad (2003) attributes this to the range problem. That is, the range of dependent variables is already highly restricted because the selection processes prior to selection for the Air Traffic Control course has

\footnotetext{
${ }^{1}$ It should be noted that classification accuracies referred to in this section are the in-sample classification accuracies. Out-of-sample accuracy cannot be assessed as a holdout sample was not used.
} 
already highly selected the cohort of candidates (Garrad 2003, p158). Thus, according to Garrad the failure of the text data to improve the accuracy of the model is due to sample problems rather than any problems inherent in the methodology. It should be noted that this does not seem to be explain the lack of performance of the model. The Air Defence Officers and Pilots had also been "pre-selected" yet there does not seem to have been a range problem with these models.

It is important to note that the text variables that improved the accuracy of the models in the above scenario were not selected on the basis of theory. There were 23 candidates for inclusion in the model and backward stepwise regression was used to "select" the LIWC variables. This is more akin to data mining than traditional theoretically based research. The only "theory" used here was the assumption that somehow, the way people use language is indicative of underlying characteristics which need not be explicitly enumerated in order to be of use in making classifications.

One shortfall of the method described here is that independent holdout samples were not used to test the models. This means that the models may have overfitted the data and that the patterns detected in the training data may not be generalizable to "unseen" data.

\section{Summary of Section 4.5}

In this section I have given a brief overview of a method of personnel selection which uses, among other variables, a selection of LIWC variables generated from a common verbal task. This is essentially what I aim to do with parliamentarians. 
Garrad's (2003) study can be seen as very similar to the task I intend to undertake with parliamentarians and the fact that he was able to increase the accuracy of two of the three classification models by including LIWC variables suggests that LIWC variables may tap into some kind of cognitive variables useful for distinguishing between people of differing abilities. Whether these variables will be useful in distinguishing between CMs and non-CMs remains to be seen.

\section{Chapter 4 Summary and Conclusion}

In this chapter I have considered three sets of variables that are likely to be useful in distinguishing between CMs and non-CMs. The variables are educational, biographical and linguistic. The biographical variables are relatively straightforward and are likely to be useful in the classification task because they have been found to be useful in previous research. The other two sets of variables, education and linguistic behaviour, have also been found to be useful in previous research. This may be because they directly tap into the cognitive style of individuals. In relation to education I discussed a number of studies which have shown that students in particular disciplines have cognitive styles that differ from students in other disciplines. I came to no conclusion as to the direction of cause because the important element of education as a marker is the cognitive style that accompanies it, not its aetiology. I decided on 6 different educational variables that cover a range of cognitive styles. These will be included as potential independent variables in classification models designed to classify parliamentarians into CMs and non-CMs. Having decided on the educational variables to examine I turned to question of how to use the language of parliamentarians to tap 
into their cognitive style. This procedure involved two steps 1) deciding on an appropriate speech sample and 2) deciding how to analyse the speech sample. I decided that the maiden speech would be a good choice of speech sample because it is delivered in controlled conditions and covers general subjects that reflect parliamentarians' personal interests rather than specific party or policy related issues. It is also highly likely to be written by the parliamentarian himself. In deciding on the method of analysing the speech sample I reviewed a number of content analysis and text analysis methods. As I am looking for cognitive content I decided on two content analysis methods rather than the more inductive text analysis methods. I decided to use a psycholinguistic method as well as LIWC to analyse the speeches. The psycholinguistic method scores speeches using 32 variables derived from sample of 925 nouns. LIWC is a content analysis method derived from common cognitive and language categories.

Having decided on the method of deriving the educational, biographical and linguistic variables I then provided an example of an actual classification task using psychometric and linguistic variables. Garrad's (2003) study has several parallels with the project I am undertaking and it was therefore instructive to find that the LIWC variables used in Garrad's study increased the classification accuracy of two of the three models used for personnel classification tasks.

In the next chapter I will discuss how to approach the issue of how to use the independent variables I have decided on in an actual modelling situation. There are 68 LIWC variables and 32 psycholinguistic variables, 6 educational variables and 3 biographical variables to investigate. To include all 109 of these in a standard regression model would require a sample size larger than that provided by all the parliamentarians 
who have sat in the Australian federal parliament since federation. However, each variable is potentially able to add to the ability of the model to classify parliamentarians into CMs and non-CMs; thus it would be unwise to discard any particular variable without a good reason. Therefore, I need to consider a method for selecting the variables. I will argue that the most appropriate approach is to use methods derived from data mining to select the "features" (independent variables). I will also argue that the correct approach to use is to create a model using a "committee" classifier. An important aspect of the procedure will be the creation of models using "training" data and testing them on holdout samples. 


\section{Chapter 5: An Approach to Modelling using Data Mining}

\section{Section 5.1: Introduction}

The first research question of this thesis asks what the characteristics are of those parliamentarians who become CMs. We have seen that the representational approach accounts for only a small proportion of cabinet appointments. Thus, I have turned to looking at individual characteristics to see if there is a better way to explain cabinet appointments. In particular, I wish to see whether there are cognitive characteristics that differentiate between parliamentarians who become CMs and those that do not. In the last chapter I considered the kinds of variables that can be used to tap into the individual cognitive characteristics of parliamentarians. It was determined that there are three types of variables that could be used to do so: educational, linguistic and biographical variables. The upshot of this is that there are 109 variables that can be used in the analysis.

The purpose of this chapter is to explain my decision to use data mining to analyse the data. This is an important issue because, as I will explain, data mining maximises the probability of finding variables that might be useful in distinguishing between CMs and non-CMs. Furthermore, data mining methods reduce the probability that the final model is overfitted which can result in a model that seems to perform well but in fact merely "learns" the noise in the data and is unable to generalise. This is a possible flaw in the approach used by Garrad (2003). 
The first part of the chapter will consider the nature of data mining by contrasting it with traditional hypothesis testing. I will then go on to consider a number of issues that must be considered in approaching an analytical exercise using data mining. These include the selection of "features" (independent variables), ${ }^{1}$ validating the model, validation metrics, interpreting the model and the advantage of using a "committee" of models rather than a single model.

\section{Section 5.2: Traditional Statistics and Data Mining}

One of the best ways to highlight the difference between data mining (DM) and traditional hypothesis testing (THT) is to consider their different approaches to variable selection. There are 109 independent variables to choose from in constructing the model. How do we select the variables that are to be used to differentiate between CMs and non-CMs? I need to make a choice between the "dust bowl empiricism" (Miner 2007: 8) of DM and the rational theorising of THT to determine which variables should be included. Let us consider the case for each.

\section{Theory Driven Hypothesis Testing}

Traditional hypothesis testing involves making a hypothesis about the relationship between two variables, and testing for this relationship. If the relationship is statistically significant the hypothesis is not rejected. If the relationship is not statistically significant the hypothesis is rejected. This method of developing theory is variables.

${ }^{1}$ In data mining the terms "features" and "dimensions" are used to describe independent 
the cornerstone of scientific method. However, in the current thesis we have a problem which hypothesis testing is not suited to deal with - the selection of a small number of variables out of a possible field of 109 to enable us to solve a classification problem. Let us consider why it is difficult to use THT is such a situation.

The first reason is not so much a methodological problem as a lack of coherent theory in leadership theory upon which to derive hypotheses. With hypothesis testing we need a theoretical basis for choosing variables. It is contended that this condition does not hold for the field of leadership studies. The area of leadership study has been highly infused with theoretical debates and yet has not delivered any consistent or empirically supported means of determining what the characteristics are that lead to some people rising to the top of the pyramid while the rest do not. This is not to say that the individual studies of leaders do not provide an insight into their personalities and reasons why they undertook particular courses of action. Dyson's (2009) account of Thatcher's lack of complexity, for example, provides an excellent account of why she behaved in office as she did; Winter's (1987) analysis of the motive profiles of American presidents gives us great insight into the forces driving presidential behaviour; Walter's (1970) analysis of Gough Whitlam gives us a unique interpretation of possibly the most charismatic politician in Australia's history. The problem with these accounts for the present purpose is that they tell us about leaders but they don't tell us what differentiates leaders from non-leaders. If we are to use a theory-driven approach to selecting variables then we need to have some idea of the characteristics of leaders that differentiates them from non-leaders. 
One area where we might expect some insight as to the important variables to consider is behavioural science. However, there seems to be few insights that might guide our choice of variables from this source. As early as 1959 it was stated (Bennis 1959: 259) that "[o]f all the hazy and confounding areas in social psychology, leadership theory undoubtedly contends for top nomination”. By 2009, Prafka (2009: 41) showed that little had changed:

The field of leadership is presently in a state of ferment and confusion (Yukl 1989). Most of the theories are beset with conceptual weaknesses and lack strong empirical support (Bass, 2000; Northouse, 2004; Stogdill, 1974).

(references cited in Prafka 2009:41)

The lack of robust theoretical or empirical reasoning in the literature means that there is little to aid in the selection of independent variables out of the 109 that are in contention.

It could be argued that in fact there are some good a priori reasons for selecting certain variables, notwithstanding the lack of consensus in the literature. The problem here is that if a variable is chosen on the grounds of some theoretical reason it will not necessarily be good at discriminating between two classes in a classification model. In other words, there may be a theoretical reason for selecting a variable and it may even be statistically significant but a classification procedure needs to use variables that are 
not only significant but which had the ability to classify effectively. I demonstrated this problem in Chapter 3 in which I created several models to test the significance of several variables. A small number of these were statistically significant yet the model itself was unable to classify more than a handful of cabinet appointment events.

I would like to provide the following example of how THT could lead to the selection of statistically significant but inefficient variables from the dataset under consideration. One branch of the leadership theory states that individuals who lack humility may be less likely to become leaders (Morris, Botheridge and Urbanski 2005, p1332). The idea is that a lack of humility reduces the chances that you will listen to the ideas of others. A traditional hypothesis testing approach would be to look at the variables on offer in order to see whether there is a variable that could operationalise humility or a lack thereof. The one that seems to do this well, from an a priori point of view is the LIWC variable "I" or first person pronouns (FPP) which include "I", "me", and "my". Several other researchers have used FPP as a proxy for self-obsession, selfimportance and self-focus (Raskin and Shaw 1988; Fast and Funder 2010; Holtzman, Vazire and Mehl 2010). The traditional hypothesis testing approach would therefore be to include this variable in the candidate variables in a multivariate model. However, although the FPP does have a significant $(\mathrm{p}<.05)$ negative association with $\mathrm{CM}$, there are other candidate variables that have a much higher discriminative power than it. Including the FPP in the model when there are other variables that are likely to have higher discriminative power could result in overfitting which will mean that the model is less able to discriminate between $\mathrm{CMs}$ and non-CMs than a more "data-driven" model. 
Given the above discussion it is contended that a more empirical approach should be used to choose the variables out of the 109 that are in contention. One such strategy is data mining. Let us now consider the case for data mining.

\section{Data Mining}

Data mining is the process of looking for patterns associated with a phenomenon of interest. An essential element of data mining is that "nuggets" of knowledge are derived from large amounts of raw data, much of which is not relevant to the problem at hand (Han and Kamber 2006: 5). Importantly, the selection of explanatory variables is driven by how well the variables predict the dependent variable. This is in contrast to traditional statistical approaches which attempt to posit a hypothesis as to why particular independent variables might be associated with the dependent variable and then go on to test the hypothesis. In data mining there is more emphasis placed on classification accuracy while theory development follows the discovery of relationships in the data. The important point is that the discovery of the relationship in the data comes first. This essentially eliminates the problems associated with selecting variables by a priori means because it is the data that "select" the variables.

To illustrate how classification problems are approached using data mining it is worthwhile considering a particular military application - how to identify the most effective military recruiters. Halstead, Goerger and McGinnis (2006) describe a system that is designed to select, from the pool of available NCOs, those who will be best at recruiting civilians into the army. The idea here is that some NCOs have better "sales" skills than others and these are the individuals who should be deployed in the 
recruitment tasks as they will tend to sign up more recruits. The system compares the recruitment rates of NCOs who have been engaged in the recruitment process and attempts to discover the identifying variables of those who are able to sign up high numbers of recruits compared with those who are less able to do so. The independent variables used were responses to psychological test banks and biographical data such as age and gender. Using this method the system was able to relatively accurately rank individuals in terms of their ability to sign up recruits using only the test bank and biographical data. The idea is that if you are looking for a recruiter there is a set of test bank and biographical characteristics that you should look for.

The description of this system sounds similar to a system that might have been constructed using traditional statistics. However, the important point is that the independent variables or "features" were not selected using some a priori assumption about what makes a good recruiter: they were selected by mining the available data. The test bank and biographical data yielded 260 features and in order to create a model that was able to classify efficiently, the number of features had to be significantly reduced, otherwise the "noise" in the data might overwhelm any signal. Thus, it was important that only those features that were able to add to the classification efficiency of the model were included. For this reason data mining was employed. Algorithms were used to trawl through the data to find what the relationship was, if any, between each of the 260 features and the ability of an NCO to sign up recruits. The result was that 36 features out of the possible 260 were found to be predictive of the ability to recruit (Halstead, Goerger and McGinnis 2006: 26). 
To put this in the context of the current thesis, in the same way that test bank and biographical data were used to classify recruiters in Halstead, Goerger and McGinnis (2006), I use biographical, educational and linguistic variables to trawl for differences between those who become CMs and those that do not. In this way I avoid having to make a subjective or theory-based selection of the variables from the 109 candidates.

The major benefit of this approach is that it is more likely than hypothesis testing to find variables that are significantly related to the dependent variable, even those we might not have thought to consider. This is the basis of the term "mining" in that the underlying assumption is that there are "nuggets" of information in the mass of data and the process of mining will enable such nuggets to be discovered.

\section{Summary of Section 5.2}

In this section I have discussed why a hypothesis testing approach to the problem of selecting variables is unlikely to result in the selection of appropriate independent variables. The first reason I mention in relation to this issue is not a failure of the statistical methods but a lack of theoretical basis in the leadership research on which to select variables. My second objection is that even if we did have a good basis for selecting variables, theory driven selection of variables emphasises statistical significance rather than discriminant power. Related to this problem is that using theory can lead to the rejection of variables that are not obviously associated with the dependent variable but which might be useful. A data mining approach avoids the 
problems associated with a theory-driven hypothesis testing approach because it is the data that are used to select the variables.

While data mining solves the major problems associated with theory driven hypothesis testing it raises other issues. In the next section I will outline the major issues and explain how they can be addressed.

\section{Section 5.3: Data Mining Issues}

We saw in the last section that data mining solves the problem of how to select predictive variables. In essence, the process is data driven. That is, those independent variables that are best at performing the classification task are identified directly rather than by hypothesising about putative relationships with the dependent variable. In this section I propose to address four issues that arise with data mining. The first is the actual approach to selecting the most appropriate independent variables. We need to address the actual procedure by which independent variables will be selected. The second issue to be addressed is how to validate the model created. In hypothesis-testing a model is assessed by various means including whether the variables explain more of the variance than a model without the variables; how much of the variance is explained by the model; and whether the independent variables lead to significant differences. In data mining a model is chosen purely and simply on the basis of its classification accuracy. In this section we will review validation methods as well as the metrics used to measure validation accuracy. The third issue I wish to address is how to interpret the model. In hypothesis-testing we begin with a theoretical stance and the analysis either 
supports the stance or does not. In data mining there is no such theoretical stance prior to the construction of the model. This means that the interpretation needs to be undertaken posterior to the creation of the model. This is not always possible because of the "black box nature of many data mining techniques. However, I will argue that data mining can proceed with more transparent models which enable interpretation. Finally I would like to introduce the idea of "committee" models. In data mining and machine learning it has been found that using one model for classification is not as effective as using several models and averaging the results. I will explain how this approach can be used in the current thesis.

\section{Feature Selection}

Data mining methods are designed to find patterns in data. Although this seems similar to what we would do in traditional hypothesis testing it is very different for the fundamental reason that we do not begin with any hypothesis. We simply allow the algorithms to find the relevant patterns. This means that we can find patterns we would not otherwise have considered. The fact that we use algorithms to search for patterns means that we are able to explore vast amounts of data. Prior to the period in which computer power was easily accessible this was not a practical possibility. It is now possible to analyse extremely large databases with little more than a standard desktop computer. This means that such fields as text analysis and genetic research can be conducted using tens of thousands of independent variables in the search for predictors of the phenomena under investigation. However, given the large number of possible predictive variables it is important to narrow down the field early in the modelling 
process so that only the most powerful are included in the modelling process. Otherwise, a large number of ineffective models could be created. As Foreman (2003: 1289) states "...no degree of clever induction can make up for a lack of predictive signal in the input features". The predictors selected will become the independent variables used to predict and explain the phenomenon under examination. The question is how do we find the best predictors? The answer is that we adopt a method that has been used in a field where the search for predictors out of a vast field of potential candidate predictors has been an on-going issue - genetic research. This field in particular has provided the impetus for many of the advances in data mining, including providing methods of selecting a small subset of independent variables from huge set of potential independent variables.

Typically, genetic research involves a sample size significantly smaller than the number of independent variables. For example, Ultsch and Kämpf (2004) give an example of a data set consisting of 72 leukaemia patients and 7192 variables. There are two types of leukaemia represented in the data set, acute lymphoblastic leukaemia and acute myeloid leukaemia. As the treatment for each type is different it is important to be able to distinguish between them. The authors therefore used data mining techniques to distinguish each type on the basis of their genetic characteristics. The problem is that there were 7192 gene expressions associated with these 72 cases. Each of these 7192 gene expressions is a potential marker of the disease. Furthermore, particular clusters are likely to be involved. Similarly Nguyen (2005) reports on a method for calculating the survival times for patients with B-cell lymphoma in which the survival times for 40 patients was available and the independent variables consisted of expression values for 
5622 genes. These examples highlight the necessity of eliminating the "uninteresting" variables to find the potentially "interesting" variables. This has been described as the "curse of dimensionality" (Friedman 1994). Much of the literature in the field of data mining is devoted to narrowing down a large number of potential independent variables to a manageable set of independent variables.

Possibly the most common method used to identify good potential predictors is simple correlation (May, Dandy and Maier 2005: 34). The idea here is that independent variables that are correlated with the dependent variable are likely to be useful in predicting the dependent variable (Guyon and Elisseeff 2003: 1161). Ideally, a selection of variables that are correlated with the dependent variable but not correlated with themselves will be chosen. Independent variables that are correlated with each other are likely to be measuring closely related phenomena and, as such, some are likely to be redundant when all are included together.

Related to correlation is the use of t-tests for the differences of means. The standard t-test for the significance of the differences between the means of two different classes simply compares the means of the two classes under consideration on the basis of the variable being assessed. Thus, for a given variable ' $v$ ' we would compare the mean value of ' $v$ ' for the non-CM class with that of the CM class. We then check for unequal variances as between the two classes using an F-test. If the variances are equal we use Student's t-test to determine the p-value of the difference. If the variances are not equal we use Welch's t-test. We then rank each variable on p-values. Those with the lowest p-value are likely to be the most useful. 
Another method of variable ranking is to test each variable's univariate ability to classify the dependent variable. This method assesses variables on the very characteristic they will be called upon to perform - classification (Guyon and Elisseeff 2003: 1161). This method has been found to be useful in selecting independent variables in text analysis. The idea is that variables that are able to contribute to the classification of the dependent variable need to be identified. We therefore create a univariate model using logistic regression or any other induction method and assess its classification accuracy. If we iteratively go through the independent variables to see which individual independent variables perform best as univariate predictors at classifying the two classes then we will get a good idea of which variables are likely to perform well in a multivariate classification model. The selection of variables is based on the classification accuracy of each univariate classification model. That is, variables are ranked on the basis of their classification accuracy in univariate models. Clearly, the problem of redundancy is likely to be an issue here. It is always possible that combining the best such predictors will result in a model that is not as good as the univariate predictor performance indicated it would be. The essence of model building is that variables often behave differently when combined with other variables. Nevertheless, the idea of ranking each variable on its performance as a single variable classifier has been found to provide a good way of identifying potentially good predictors (Bowden et al., 2006; Raghuraj 2008).

The basic algorithm that will be used in this thesis the t-test for differences in means. The reason for this is that this is possibly the simplest available. As we will see, using this method to filter out the variables that are unlikely to be useful will leave a 
smaller set of independent variables that have a high degree of discriminant power. If this method was found to be unable to yield a set of predictors that were likely to be useful then I would be warranted in using some other more complex method. However, as we will see, this is not the case.

Thus, t-tests will be used to filter the vast majority of the variables out of contention leaving a small group of variables. Using the t-test criterion I will reduce the number of variables from 109 to $3-8$ over the course of creating several models. For each model I will use a test for redundancy to further reduce the number of variables. I will then use these as the basis for the final modelling.

Before leaving the issue of reducing the number of variables to be considered, it is worthwhile considering whether the approach advocated is wasteful. Thus, it might be possible to use a method such as principal components analysis or factor analysis to create a synthetic scale based on all the text variables. The idea here is that by "filtering" out the variables that seem to have little connection with the dependent variable we may be losing information that could contribute to classification accuracy. Thus, there is a potential gain by using all the variables in some way.

Principal components analysis works by assessing the correlations between independent variables and distilling the common correlations into a number of uncorrelated components. Thus, a large number of variables can be reduced to a smaller number of variables which theoretically contain the "important" information. Similarly, factor analysis reduces a large number of variables to a smaller number of putative underlying common "factors" by assessing the commonalities between variables. 
These methods and their variants have been used in data mining. However, they are not as common as filter methods (Luyckx and Daelemans 2011: 38). Furthermore, where they have been used, the results indicate that they do not increase classification accuracy. In Skott (2005) dimension reduction using a PCA based on a "bottleneck network" was not as effective as using individual variables identified as being associated with the dependent variable. Lam and Lee (1999) found that PCA resulted in a slight albeit insignificant reduction in classification accuracy of text documents in comparison with using individual word based strategies. Similarly, in a study that specifically uses LIWC, Liu et al (2012) found that PCA did not increase classification accuracy over the use of the top ten individually selected variables. Kramer and Rodden (2008) used a factor analysis of LIWC data derived from blogs. The factor structure revealed 5 factors but this provided "mixed results" when this was used in an attempt to create five clusters of writing types (2008: 1128). Beyond text analysis, Hall and Holmes (2003) experimented with six variable selection methods as well as PCA on fifteen different datasets from science, medicine and engineering. PCA was found to be the least efficient data reduction method in terms of classification accuracy.

A possible reason why PCA and FA do not increase classification accuracy is that they select independent variables that covary amongst themselves without reference to the dependent variable (Tian 2009: 10). They work by focusing on the independent variables and the search for associations is not "supervised" by reference to the dependent variable. This " unsupervised" approach means the procedure may result in the exclusion of variables that may have low variance relative to the other variables but which are highly correlated with the dependent variable . Cunningham (2008) makes 
essentially the same point in stating that in unsupervised methods (such as PCA and FA) the object of the exercise is not as well defined as when the features are selected directly in relation to the dependent variable] and "...consequently it is a much less explored area" (Cunningham 2008: 100). Cunningham points out that where the data is unlabelled (that is, there is no dependent variable) then PCA can be used. Where the data are labelled, then the appropriate method is some form of feature selection (Cunningham 2008: 111).

Beyond unsupervised methods, it may be possible to develop some kind of synthetic measure based on an a priori idea of what may be a reasonable combination of linguistic variables. The major problem with this is that it makes the assumption that we can make some kind of hypothesis about what the important variables might be. This is precisely the kind of hypothesising that we wish to avoid: the data mining approach is designed to let the data speak for itself. Certainly there is the possibility that, by not making any attempt to include variables that we think are sensibly associated with the dependent variable we may exclude some important variable(s). However, there is also the possibility that we could simply add noise. The procedure advocated in this thesis of applying a "filter" to remove the variables unlikely to provide information is prominent in text analysis (Luyckx and Daelemans 2011: 38). This is largely because it has been found to be effective. 


\section{Validating the Model}

The purpose of a classification model is classification. Ideally, a model should be assessed entirely on whether it is able to classify a holdout sample at an acceptable level of accuracy. The reason for the dependence on a holdout sample is that a holdout sample indicates how the model is likely to perform on data the model has not been "trained" on. Such a test is determines whether the rules generated by the model are generalisable to a sample wider than that which was used to generate the model. In this section I will outline various methods of validating the ability of a model to do this.

According to many data mining researchers, the best method of validation in data mining is holdout-sample validation (Ransohoff 2004). Holdout sample validation (HOV) is where a portion of the data is separated from the data used for training the model and used only for testing the model. The idea here, as stated above, is that the true test of the model is its ability to classify a sample that the model has not "seen". If the holdout sample is referred to for any purpose other than testing the classification accuracy of models then there is a danger that information may flow from the holdout sample to the training sample thus invalidating the independence of the holdout sample (Ransohoff 2004: 310).

The main problem here is that I will need to split the data in such a way that there is enough data in the training sample for any regularities to be detected and, at the same time, ensure that the holdout sample is large enough to provide a statistically significant classification result (Fielding and Bell 1997: 39). A correct classification of $70 \%$ of a holdout sample of $\mathrm{n}=10$ is not statistically significant. However the same rate of accuracy for a holdout sample of size $n=100$ is statistically significant. The problem 
is that a holdout sample of sufficient size to get statistical significance may not be viable with a small number of cases given that we need the majority of cases to build the model. As we will see in the following chapter, in the parliamentary sample to be used for model building we have 134 cases. This gives us very little data for both model building and testing. With large sample sizes it is possible to create a holdout sample using $50 \%$ of the cases. However, with a sample size of 134 this would leave only 67 cases to create a model with.

Another problem that is often mentioned in relation to using HOV is that there is always the possibility that the holdout sample, notwithstanding that it should be a random selection from the data, may not representative of the sample as a whole. This is particularly a problem with small holdout samples. By chance alone a holdout sample may contain a large number of outliers that are very difficult or very easy to classify. Furthermore, the estimation sample may contain outliers such that the parameters do not reflect the sample as a whole. These problems can affect our decision to accept or reject the model. Azuaje (2010) goes so far as to say that the holdout method results in “...highly biased and inexact estimates...independently of the prediction model or algorithm applied (Azuaje 2010: 39).

Given the problems associated with holdout samples several alternatives have been suggested. One standard solution to the problem of holdout sample creation is to use k-fold cross validation. In the 10 -fold variant, the data is divided into 10 equal sized "folds". The fold 1 is held out and the model is estimated using the remaining nine of the folds. The classification accuracy of this classifier is tested on fold 1 . This procedure is repeated ten times so that each fold is held out once and tested on a classifier 
estimated using the remaining 9 folds. The average classification accuracy over all 10 folds is the 10 fold cross validation accuracy. It will be noted that each time the model is trained, it is then tested on a sample that has been held out from the data used to train the model. As such the procedure gives a good indication of how well the model will classify an actual holdout sample.

Any number of folds up to the number of cases in the sample can be used in this process. However, 10-fold-cross validation is considered by some to be the most reliable method (Witten and Frank 2005: 150).

Other researchers have found that Leave One Out Validation (LOOV) is a better estimate of classification accuracy (Kohavi 1995; Ambroise and McLachlan 2002). This variant works by creating a number of folds equivalent to the number of cases. In the first iteration, one case is held out and the model is constructed using the remaining cases. This model is then used to classify the one case held out. The held out case is then returned to the rest of the data and another case is selected to be held out while the model is trained on the other cases. This process continues until each case has been used as the holdout once. Thus, if there are 90 cases there will be 90 models each predicting one held out case each time. The average accuracy of the individually held out cases is taken to be the classification accuracy of the model constructed using the selected variables on unseen data.

LOOCV is considered to provide an unbiased estimate of error rate (Kohavi 1995; Ambroise and McLachlan 2002; Cawley and Talbot 2006). Furthermore, LOOCV is better for use in small sample sizes than 10 -fold $\mathrm{CV}$. The reason for this is that in 
LOOCV a smaller number of cases is held out of each fold than is the case for 10-Fold CV. Consider for example, a situation in which there are 90 cases and the model is tested using LOOCV. For each iteration, the model is trained on 89 cases and tested on 1 and this is repeated 90 times. With 10 fold CV the model would be trained on 81 cases and tested on 9 and this is repeated 10 times. In the first case the classifier has a greater number of cases (89) to generalise from so is more likely to form a stable decision rule (Cawley and Talbot 2006: 2351).

A method that represents a kind of hybrid of CV and HOV is Monte Carlo crossvalidation which uses a random splitting of the data into training and test sets (Picard and Cook 1984). This method has been shown to give a better estimate of the actual classification accuracy than LOOCV (Xu, Liang and Du 2004; Shao 1993; Efron 1986). Furthermore, this method addresses the possibility that a given holdout sample is not representative of the data as a whole. Monte Carlo cross-validation (MCCV) is identical, in its first stage, to using the pure holdout sample method in that a random sample is taken to create a holdout sample while the variable selection and model building is conducted on the estimation (training) sample which consists of the remaining cases. The holdout sample is used for testing the classification accuracy of the models created using the estimation sample. So far this is identical to the standard holdout method. However, the procedure is repeated several times with different randomly generated holdout samples and the accuracy is taken as the average classification accuracy of these models.

The main problem with MCCV, is that it does not test models with different variables. MCCV and other methods that use 'bootstrap' re-sampling consist of 
retesting with different samples but the same selection of independent variables is used. Re-sampling methods assume that some initial selection of variables is the optimum selection and then random re-sampling is undertaken to test the ability of this selection of variables to classify accurately. This is a limitation because there may be a slightly different selection of variables that would classify better. Furthermore, averaging across a high number re-sampled errors may not necessarily improve accuracy greatly because the errors of each individual iteration are likely to be highly correlated.

Ideally, we need a method that minimises the disadvantages with all of the methods discussed while retaining their advantages. My solution is to create five completely independent models with five independently generated holdout samples for testing. The validated models will be form the basis of a "committee". Importantly, the selection of variables will take place independently each time the process is repeated and each model is tested on a different independent holdout sample.

Thus, the procedure will be as follows: I will create an initial model by randomly splitting the 134 cases into a $1 / 5(n=27)$ holdout sample and a 4/5 $(n=107)$ estimation sample. As we shall see this $1 / 5-4 / 5$ split will provide a sufficient sample for model building and a large enough holdout sample to provide statistically significant results. The variables will be selected and the model built using the estimation sample. The model will then be tested on the holdout sample. This procedure will then be repeated four times. The process will begin each time with the full set of 134 cases. These will be split using random process into a training group $(\mathrm{n}=107)$ and a testing group $(\mathrm{n}=27)$. That is, rather than basing the modelling on the classification accuracy of one sample of $1 / 5$ of the data I will conduct the exercise five times so that five 
independent holdout samples are used to estimate the accuracy of the models. Thus, across the five models the test sample $(5 * 27)$ will be effectively the same size as the training sample. This is similar to the standard methods of testing in data mining such as LOOCV and k-Fold CV in which the test sample is the same size as the training sample. As we will see the five independent model building exercises will provide models that lead to similar conclusions with classification accuracies of more than $70 \%$.Furthermore, as I will demonstrate in the discussion on committee models below, the use of the committee system has been identified as a highly effective means of maximising classification accuracy particularly where the errors of each model are diverse. The diversity of models means that errors are unlikely to be correlated and this means that only a small number of committee members is required to improve classification accuracy.

One issue that should be addressed is why many hundreds of iterations of the model building process is not advocated in data mining. With modern computing power it is possible to run create many models based on different subdivisions of the data and yet the standard methods discussed above rely on a test set that is some kind of variation on the training set and of the same size. Thus, in LOOCV, the number of test samples is equivalent to the number of training samples. Similarly, in $\mathrm{k}-$ fold $\mathrm{CV}$, the $\mathrm{k}$ folds are created by dividing the test set into $\mathrm{k}$ samples of size $\mathrm{n} / \mathrm{k}$. Thus, with $10-$ fold $\mathrm{CV}$ and a data set of $n=134$, 10 samples of approximate size 134/10 would be used for testing. As with these methods I create a five holdout samples across the five committee models such that the total size of the holdout sample used for testing is $5 * 27=135$ which is effectively the same size as the training sample. The question is, given that computing 
power is not an issue, is there a significant benefit in creating many more models (ie, using a greater number of test samples) than is advocated in the standard data mining approach?

The answer is that there is no significant advantage in generating more models once a test sample is used that effectively replicates the training sample. Generating additional models results in models that are less dissimilar and that therefore add less information. Let us consider the theory behind this by considering the two related methods of validation used in data mining - '632 Bootstrap' and its extension the '632 Bootstrap +'. The sampling method used in these procedures is similar to the method I have used to generate holdout samples in that it uses sampling with replacement. However, unlike the method I advocate, these procedures use multiple repetitions of the bootstrap sampling procedure to validate the model. It is my contention that using five holdout samples is a more effective validation method.

The '632 Bootstrap' and '632 Bootstrap +' methods use a "bootstrap" sample which is sampling with replacement of the data set. Essentially, for a data set of $n, n$ random samples are chosen with replacement to derive a test set of $\mathrm{n}$ (Witten and Frank 2005: 152). Because the sampling takes place with replacement, there is a probability that some of the cases that occur in the test set will occur more than once. In such a bootstrap sample where the test set and the training set are equivalent in size, (eg: bootstrap sample $=134$ and training sample $=134$ ), there is a .632 probability that an individual case will occur twice in the bootstrap sample (Witten and Frank 2005: 152. If a larger bootstrap sample were taken such that the bootstrap sample $>n$, the probability that individual cases will recur rises such that as the bootstrap sample rises beyond $\mathrm{n}$, 
the probability of a repetition of a single cases converges on 1 . Where many times $\mathrm{n}$ is used as a bootstrap sample there will be many repetitions of cases so the information gained from the additional sample size falls away. The testing done on the one bootstrap sample (bootstrap sample $=\mathrm{n}$ ) provides more diversity than any extension to $\mathrm{x} * \mathrm{n}$ because going beyond $\mathrm{n}$ involves a repetition of cases that have already been tested. Thus resampling the data set so that the test set is many multiples of the training set does not increase the information gained significantly.

Let us put this theory into the context of the current situation. If a bootstrap sample twice the size of the training sample were taken (that is, if I had made ten models rather than 5 such that there were in total ten random holdout samples of 27) the probability of a repetition of a given case in the bootstrap sample of $270(2 * 135)$ converges on 1 for all cases. Thus, the incremental value of increasing the bootstrap sample (creating more models) begins to decline because the same cases begin to appear in each of the individual holdout samples. The question is, would producing more models, and thus increasing the bootstrap sample, increase accuracy? The answer would have to be that most likely it would but not significantly. The maximum diversity has already been achieved in the creation of the first five models and any subsequent model(s) will be more similar to the existing models than the existing models have to each other.

The above discussion explains why data mining in general and the approach I have used in particular uses a test set that is effectively the same size as the training set even though computing power allows for the creating of many more models tested over many divisions of the data. However, where a committee approach is used, there is 
another benefit of using only those models created from a replication of the training data. The reason is that, as explained above, the models created with a test set that is $1 *$ $\mathrm{n}$ are more diverse than the models created with $1 \mathrm{X} * \mathrm{n}$. In a committee setting, such diversity is an advantage.

The theoretical argument from diversity states that, where models are diverse, only a small number need be included in the ensemble. I will discuss the theoretical reasons for this below. At this point it suffices to say that there is empirical evidence supporting this view. The empirical evidence bears this out. In Elder and Abbott (1997) only six committee members were used. A similar approach was used by Zhou et al (2001) which used five committee ('ensemble')members, The reason why only a small number of committee numbers was required in these cases was that the models were diverse. Diversity leads to low correlation between the errors of each model which means that combining only a few such committee members significantly improves classification accuracy. In general, increasing the number of diverse committee members beyond 10 is unlikely to be of benefit (Hansen and Salamon 1990; Agrafiotis et al 2002). Russell and Adam (1984) found that including all available models was not as effective as including only the best 3-5.

In the current thesis, the diversity of the models used in the committee is achieved by the fact that 1) different random partitions of the data are used and 2) there are several different combinations of variables across the models used in the committee. The evidence that diversity actually exists across the committee models is that the classification accuracies of the models used in the committee are variable, ranging from $74 \%-85.19 \%$. This diversity of model accuracy is a very good indication that the 
errors are not highly correlated. Thus, although it is possible that using a vastly increased number of models would increase the overall performance of the committee, such improvement is unlikely to be significant because any subsequent models are likely to have errors that are correlated with the initial models.

So far I have discussed accuracy in abstract terms. Thus, we need to be more specific about how accuracy will be assessed: we need to consider the validation metrics. I have already alluded to this issue by pointing out that a $70 \%$ classification accuracy across two different sample sizes of $n=10$ and $n=100$ can result in very different assessments of statistical significance. As such, it is important to use a measure of classification accuracy that includes an assessment of the statistical significance of the classification accuracy. For this purpose I will adopt Cohen's Kappa discussed in Chapter 3. The advantage of this measure is that it provides an assessment of overall accuracy and test of the significance of the measure. A result that is significant at the $\mathrm{p}<.05$ level can be taken as a result that is beyond what would occur by chance alone.

The Calculation of Cohen's Kappa is as follows:

$$
\mathrm{K}=(\mathrm{P}(\mathrm{A})-\mathrm{P}(\mathrm{E})) /(1-\mathrm{P}(\mathrm{E}))
$$

where $\mathrm{P}(\mathrm{A})$ is the proportion of times that the predicted agrees with the actual and $\mathrm{P}(\mathrm{E})$ is the proportion of times that we would expect agreement by chance alone. This metric compensates for the fact that some hits will occur by chance alone. It evaluates the proportion of correctly classified instances relative to the number of instances that would have occurred by chance alone. In contrast to the raw accuracy rate, which calculates accuracy over both classes, the kappa calculates the accuracy rate over each 
class separately and then aggregates the results (Galar et al 2011: 1766). Kappa varies from -1 , where there is complete disagreement between the actual and predicted classes to 1 where there is complete agreement between actual and predicted classes. A score of 0 would indicate that the classifier randomly assigns cases to classes.

Another metric that needs to be considered is the sensitivity. As we saw in chapter 3 this measures the extent to which the model can correctly identify true positives:

Sensitivity $=$ True Positives $/$ (True Positives + False Positives $)$

The complement of the Sensitivity is the Specificity which measures the extent to which the model identifies that the negative cases are indeed negative:

Specificity $=$ True Negatives $/($ True Negatives + False Negatives $)$

With accuracy, sensitivity, specificity and Cohen's Kappa we can come to a good overall assessment of how well the model is able to classify the holdout sample as a whole and provide a statistical test for the significance of this as well providing a measure of how well the model classifies the true positives and true negatives.

\section{Interpreting the Output - Prediction versus Explanation}

One of the strengths of data mining is that it finds patterns in the data that enable us to make predictions. Models are assessed on the basis of their ability to correctly classify. The problem is that in data mining there is a limited tradition of explanation. Data mining and machine learning emphasise classification accuracy over and beyond 
any attempt to explain the reasons for the classifications. This is why "black box" methods such as artificial neural networks (ANNs) and support vector machines (SVMs) are well established in the data mining community even though they cannot be interrogated in any way analogous to the procedure of looking at the parameter estimates of a logistic equation. The lack of transparency of such methods is no bar to their being used to make accurate predictions. However, the lack of transparency is a bar to explaining their predictions.

This is not to say that it is impossible to examine the likely effects of the important independent variables in a black box classification model. If a certain set of independent variables has been found to be useful in a classification task then this is good evidence that those variables are the ones that are likely to be importantly associated with the phenomenon under investigation. As such the identification of a group of potential signal-bearing variables is a good first step in explaining what is going on. Isolating interesting variables means that these variables can be further investigated. However, it is true to say that black box methods do not give any real explanation of the causal direction or importance of variables. Certainly "sensitivity" analyses can be conducted by perturbing inputs randomly and observing the effect on the dependent variable but this is an artificial method of determining the importance of a variable.

One solution is to use a method that is transparent. Fortunately there is a method which is highly transparent and has been shown to be close to ANNs in terms of classification accuracy on many classification tasks - logistic regression (Sargent 2001; Dreiseitl and Ohno-Machado 2002). This method gives a readily interpretable means of 
determining the relationship between the independent and dependent variables. There can be problems in interpreting the coefficient when the coefficient is not significant. Furthermore, the size of the coefficients can be subject to bias if the sample size is too small. However, these problems are less severe than the problems of interpreting more opaque methods. Thus, because the problem of transparency is tractable, logistic regression will be used rather than the more opaque methods such as ANNs and SVMs in this study.

\section{“Committee" Models}

In traditional statistics we tend to try to find one particular model to apply to a given situation. In data mining the attitude is more akin to Box's idea that “...[a]ll models are wrong, but some are useful" (Box 1979: 212). In data mining, a model is only considered useful if it is good at classifying. Thus, it is not surprising that there has arisen a method in data mining which assumes that there is no sense in relying on one model when several may prove to be better at the classification task. Data miners have found that one way to increase the classification accuracy of a data set is to use the available data to create a number of models and use this "committee" of models to make predictions by averaging the results for each individual model (Dietterich 2000).

The committee method results in increased classification accuracy if the constituent models are diverse and each is able to classify at a rate better than chance alone (Dietterich 2000: 2). The diversity requirement is due to the fact that averaging a number of models that produce exactly the same classifications will not result in a better outcome. It has been found that "[c]ombining outputs of multiple classifiers into an 
ensemble (committee) output is one of the most important techniques for improving classification accuracy" (Verikas et al 2010: 6957). The important issue here is that each classification model needs to be different. That is, each of the models needs to classify a given set of input data slightly differently, otherwise there is no point in using the committee system. There are several ways of creating different models with the same basic dataset: we can use the same data but different induction methods, different subsections of the data and the same induction methods, different combinations of variables, or any combination of these. Intuitively this is equivalent to the idea that the errors of one committee member can be "corrected" by the other committee members if the committee members assess individual cases differently and each committee member has a greater than $50 \%$ chance of being right. This is closely related to Condorcet's jury theorem which states that:

If each voter has a probability $\mathrm{p}$ of being correct and the probability of a majority of voters being correct is $\mathrm{M}$, then $\mathrm{p}>$ 0.5 implies $\mathrm{M}>\mathrm{p}$. In the limit, $\mathrm{M}$ approaches 1 , for all $\mathrm{p}>0.5$, as the number of voters approaches infinity (Zenobi and Cunningham 2001:2).

In the current thesis I will be creating five separate classification models. The same basic data consisting of 134 cases and 109 variables will be used but the holdout samples (and, by construction, the estimation samples) for each will be randomly generated. Thus, each of the classifiers will be generated using a different training sample and tested on a different holdout sample. There will be some variation in the variables and classification accuracies as between the models. The use of different 
subsamples for training and testing is one of the most common ways of introducing diversity into the system (Zenobi and Cunningham 2001:3, Cunningham 2007: 4). Thus, the models should fulfil the diversity requirement. Importantly, they will all produce classification accuracies beyond mere chance. This means that combining the results of all five models will result in a more accurate estimate of classification accuracy than using any one model.

One of the advantages of combining the results by using a committee system can be readily seen if we consider Azuaje's objection that the holdout sample method can lead to biased results as there is no way of telling if the holdout sample is an accurate reflection of the data as a whole (Azuaje 2010: 39). If I were creating one model and testing it on one holdout sample this would be a concern. There is always the possibility that the holdout sample is particularly easy or particularly hard to classify and we might mistakenly accept or reject the model accordingly. With one holdout sample we cannot determine whether this is the case. However, I will create five models and test them on five different and independent holdout samples. There is a certain probability that one of these is not representative of the data as a whole and is either an unusually easy sample to classify or an unusually difficult sample to classify. However, the probability that all are unrepresentative is very low. By combining all five results we get a very good idea of the "unbiased" out-of-sample classification rate for the committee of models.

Let us consider, then, how the creation and interpretation of the committee takes place. Let us assume that each of the five models M1, M2, M3, M4 and M5 has been trained and tested on 5 different divisions of the data into training and testing samples 
are described above. Let us also assume that the models have the independent variables and classification accuracies as depicted in Table 5.1.

Table 5.1: Hypothetical Committee Models

\begin{tabular}{|c|ccccc|}
\cline { 2 - 6 } \multicolumn{1}{c|}{} & $\mathrm{M} 1$ & $\mathrm{M} 2$ & $\mathrm{M} 3$ & $\mathrm{M} 4$ & $\mathrm{M} 5$ \\
\hline Ind' Variables & $\mathrm{a}, \mathrm{b}, \mathrm{c}$ & $\mathrm{b}, \mathrm{c}$ & $\mathrm{a}, \mathrm{b}$ & $\mathrm{a}, \mathrm{c}$ & $\mathrm{a}, \mathrm{b}, \mathrm{c}$ \\
Accuracy & $70 \%$ & $75 \%$ & $80 \%$ & $55 \%$ & $70 \%$ \\
Kappa & 0.51 & 0.53 & 0.55 & 0.12 & 0.51 \\
$\mathrm{p}$ & $<.01$ & $<.01$ & $<.01$ & $\mathrm{~ns}$ & $<.01$ \\
\hline
\end{tabular}

For models M1, M2, M3 and M5 the classification accuracies are all significant at the $\mathrm{p}<.01$ level. Model M4 has a non-significant classification accuracy. M5 seems to be redundant in that it has the same classification accuracy and the same variables as another model in the committee (M1). However, if each of these models was created with a different subset of the data this may be sufficient provide diversity as between the two models. Thus, we would be inclined to use models M1, M2, M3 and M5 in our committee.

Using the committee of M1, M2, M3 and M5 is equivalent to saying that each model has a hypothesis. The hypothesis of M1 and M5 is that the independent variables $\mathrm{a}, \mathrm{b}$ and $\mathrm{c}$ are related to the dependent variable. Assuming that they do not have identical coefficients for these variables (which is a reasonable assumption given that they have been created with different subdivisions of the data) they will give slightly different weightings to the variables and as such provide slightly different "opinions" as to whether the "case" should be classified as a 0 or as a 1. M2 has a different 
hypothesis: that $\mathrm{b}$ and $\mathrm{c}$ are related to the dependent variable and its "opinion" on any given case will be based on this hypothesis. Finally, the hypotheses and opinions of M3 are based on variables a and b. The "true" hypothesis might be none of these. However, the holdout sample classification accuracies indicate that the given hypotheses are good practical approximations. Furthermore, trying to find which of these is closer to the "true" hypothesis involves a risk that the one model chosen is actually the least correct. Thus, the solution is to average the results. We have evidence that using all four should yield an average classification accuracy on unseen data of $73.5 \%$ $((70 \%+70 \%+75 \%+80 \%) / 4)$. Thus, for any new case we could run the data through all three models and average the results and we could be $73.5 \%$ confident that the classification accuracy of the committee is correct.

A final issue in relation to committee classification is the interpretation of the ensemble. There is no single model to rely on for interpretation. However, there are regularities that can be used to interpret how the variables are related to the dependent variable. For example, in the committee members chosen from Table 5.1 the variables a and $\mathrm{c}$ are in three of the committee models and variable $\mathrm{b}$ is in all four models. Thus, we would conclude that variable $b$ is the most important variable because it is in all four models while variables a and $\mathrm{c}$ are less important. Thus we have a starting point for explaining the phenomenon under investigation in that we can determine which are the most important variables.

I will show in the next Chapter that this method of interpretation can yield a good method of interpreting the variables. In four of the models, having a legal qualification occurs and is positively associated with $\mathrm{CM}$. The age of entering 
parliament (Parlage) is in four models and is negatively associated with CM. In three of the models three different measures of language concreteness occur and are negatively associated with CM. Thus, the interpretation of the committee is that having a legal qualification is positively associated with $\mathrm{CM}$ while higher age at the time of entering parliament and higher levels of concrete speech are negatively associated with CM.

\section{Summary of Section 5.3}

In this section I have discussed three issues that need to be addressed in data mining. The first is feature selection. I have pointed out that in data mining the researcher needs to select a small subset of variables from the large pool of candidate variables. I explained that I will use t-tests to narrow down the selection from 109 variables to $3-8$ in the course of creating 5 models. I will then narrow this down further by addressing such issues as redundancy. The second issue I addressed was validation. I pointed out that in data mining the validity of the model is determined by the ability of the model to classify "unseen" data. Two common ways of doing this are to use a holdout sample and to use k-fold cross validation. Both of these methods are valid but have their own limitations. A method that addresses the limitations of both is to use a committee of five models. Each model will be created using a random split of the data into training and test sets. This approach has the advantage that it uses the data splitting methods used in Monte Carlo cross validation but has the advantage that several completely separate models are used to estimate classification accuracy. I then went on to review a number of metrics that will be used to assess the classification accuracy of the holdout/cross validated samples. These were accuracy, sensitivity, 
specificity and Cohen's Kappa. The next issue I addressed was the issue of interpretation of the model created using data mining techniques. Some induction methods used in data mining make it difficult to interpret the relationships between the independent variables and the dependent variables. I argued that this would not be a major issue because it is possible to use logistic regression. This method has been shown to be comparable to more sophisticated methods in some data mining applications while not suffering from the "black box" phenomenon. The final issue I addressed was the idea of using a "committee" of models rather than one model. I explained how this approach can result in greater efficiency than using one model and I also explained how using the committee method was no bar to deriving an interpretation of the relationship between the independent variables and the dependent variable.

\section{Summary of Chapter 5}

In this Chapter I have explained why I am using a data mining approach rather than a hypothesis testing approach in analysing the data. The reason is partly because there is no reliable theoretical basis in leadership research upon which to base the selection of variables. A selection of variables based on theory runs the risk of choosing variables that are not the best predictors of the dependent variable. As such, the hypothesis testing approach seems inappropriate. An alternative approach has been advocated: data mining. This involves a more rigorous method of model building because the search for predictor variables involves a comprehensive search through a large amount of data. I explained that there are issues that need to be addressed in the design of the data mining procedure. Feature selection is one such issue and I explained 
that I would be using t-test and tests for redundancy to narrow down the field of variables. I then discussed validation procedures and pointed out that I would use a committee method based on several models, each of which is created using a random splitting of the data into training and test sets. Monte Carlo cross validation. I also explained how the raw validation figures would be reported using accuracy, sensitivity, specificity and Cohen's Kappa so that we could determine the statistical validity of any given model's classification accuracy. I discussed how it is possible to interpret the results because the induction method used will be the relatively transparent logistic regression. Finally I explained how the use of the committee method of model design could be of benefit.

Having explained how the data will be analysed the next chapter deals with the actual modelling of the data. 


\section{Chapter 6: Modelling Factors Associated with Cabinet Appointment}

\section{Section 6.1: Introduction}

In Chapter 4 I explained that I would use educational, biographical and text based variables in an analysis of the difference between CMs and non-CMs. I explained that these kinds of variables are likely to tap into the characteristics that distinguish between these two classes. In Chapter 5 I explained that the modelling method I would use to find the important variables would be data mining. I explained that traditional hypothesis testing would be inappropriate given the large number of potential independent variables that need to be investigated.

In this chapter I will put these ideas into practice. The purpose of this chapter is to create a committee classifier that can be used to determine the characteristics that are associated with being appointed to cabinet. Essentially this involves determining the difference between CMs and non-CMs. The model will be assessed, not on traditional measures such as the overall goodness of fit but on the accuracy of the prediction of holdout samples. A model that is able to predict out-of-sample is highly likely to include the variables that are important in the phenomenon under investigation. In short, if the model can predict out-of-sample then we can be reasonably sure that we have detected the variables that are involved in distinguishing between CMs and non-CMs. We can then go on in Chapters 7-9 to use the insights developed from the model to 
come up with plausible explanations as to why these variables are associated with the dependent variable.

In the next section I will present an overview of the study design. I will also describe the cohort from which the sample is drawn. Finally, I will provide a preview of the major findings of the chapter.

\section{Section 6.2: Study Design, Sample and Preview of the Findings}

The basic aim is to use data available at the beginning of a parliamentarian's career to predict the likelihood that she will become a cabinet minister.

The cohort under examination here is the parliamentarians who were in parliament at any time over the period from the first session of parliament in April 1996 to the first session of parliament in February 2008. Using these parliamentarians as a basis I wish to determine whether there are differences between those who become CMs and those who do not. In order to do this I will compare CMs and non-CMs on the basis of a number of biographical, educational and linguistic characteristics. These characteristics will be taken from the information available on the parliamentarian at the time they give their first speech in parliament. Thus, the design of the study is prospective. Unlike the cross-sectional approach used in Chapter 3 I wish to compare individuals rather than events. In the regression analysis in Chapter 3 the unit of analysis was the cabinet appointment "event". Thus, an individual being appointed to a cabinet position was considered an event. But in the current situation I wish to use individuals as the unit of analysis. That is, I wish to determine whether there is 
something about individuals that leads to them becoming CMs. To do this I will create a study design that compares individuals who became CMs with individuals who did not. As such, the study is effectively a case-control design. In order to do this I need to define the dependent variable. That is, I need to define what I mean by a CM and, more problematically, what I mean by a non-CM.

A CM is simply an individual who has been appointed to cabinet at any stage in their parliamentary career. This is essentially a matter of public record. In the cohort of parliamentarians over the period April 1996 - February 2008, there is a number of parliamentarians who were CMs in previous governments but were not CMs in the period 1996- 2008. However, for the purposes of the study they are defined as CMs. Peter Morris, for example, was an ALP parliamentarian from December 1972 - August 1998 but was first appointed CM in the Hawke ministry in September 1988. Similarly, Ian Sinclair was an LNPC parliamentarian from November 1963 - November 1998 but was first appointed CM in the Holt/McEwen ministry in October 1967. Neither of these parliamentarians were CMs during the period under investigation (1996-2007) However, for the purposes of this study they are defined as CMs because they were CMs at some point in their careers. At the other end of the spectrum are the newly appointed ALP CMs who assumed office after the election of November 2007. As at the first session of parliament in 2008 these individuals were defined as CMs because they had been appointed after the 2007 election.

It is worth noting that even the CM classification I have adopted may not be as transparent as it seems even though it seems to be merely a matter of inspecting the public record. This is because there is always the possibility that one or more CM jobs 
were allocated on the basis of nepotism, favouritism or political expediency. Such individuals will not have objective characteristics that set them apart from non-CMs. Blewett gives the example of Stewart West who was "[e]levated to the cabinet in the first Hawke ministry as a token representative of the left...[He] was neither quick on the uptake nor a notably dynamic minister" (Blewett 1999: 20). This individual is not in the cohort under consideration but the example indicates that this kind of thing does occur. If we are looking for characteristics that differentiate CMs from non-CMs then having a large number of individuals who may not have actually possessed the differentiating characteristics has the potential to make the task difficult. As with the sampling in general there is no way of eliminating the possibility of these types of errors. Another anomaly occurred in the case of Duncan Kerr who was a the Minister for Justice (a JM position) in the Keating administration from 1993 - 1996. This includes a three week period as "caretaker" Attorney General when the position was vacant and Keating was waiting for the outcome of a by-election which the intended future Attorney General Michael Lavarch was contesting. Lavarch won the by-election and became Attorney General and Kerr reverted to his role as Minister for Justice. The question is, should we classify Kerr as a CM given that "at some time in his career" he had been a CM. As it is I have classified him as a non-CM (JM). This makes some sense because he was not an official member of cabinet and was not sworn in. However, the examples reveal that even a seemingly transparent definition such as CM can present difficulties.

The basic definition of a non-CM is a parliamentarian who was a backbencher (BB), Junior Minister (JM) or Parliamentary Secretary (PS). However, there is a complication with this definition. We need to be able to observe an individual's whole 
parliamentary career in order to define them as a non-CM. The reason for this is that if an individual is still in parliament, it is still possible that he could become a $\mathrm{CM}$ at some time in the future. Clearly this is not a problem for the CMs who are still in parliament as they are definable as CMs. With the non-CMs it is a problem because they may not have reached the highest office of their career. As we will see, the sample will need to be adjusted so that we only include as non-CMs those individuals whose entire career we can observe. I will explain this in more detail in the section on the sample design.

Another issue I will need to consider in the design of the sample is how to deal with backbenchers (BBs) who were in parliament for only a short period. The issue here is that some $\mathrm{BBs}$ are in parliament for less time than it takes to become a $\mathrm{CM}$ and, having remained on the backbench, have not been selected for any ministerial role whether CM, Junior Minister (JM) or Parliamentary Secretary (PS). These individuals may have had the potential to rise beyond the backbench but they are removed by the electorate before they have come to the attention of the selectors or before they have served enough time to be granted a senior position. For example, the shortest length of time in parliament served by a BB in the cohort was eight months served by Leonie Short. If she had had the ability to become a CM it is unlikely that this would have been revealed in this time. On the other hand, she may have only had the ability to remain on the backbench or to attain a role in the outer ministry as a JM or PS. Furthermore, she was a member of the ALP which was in opposition at the time she was in parliament so even if she had been seen to have talent she would not have had the opportunity to be appointed to cabinet. At the other extreme we have the case of John Watson who accumulated 29 years in parliament which includes 16 years, accumulated over several 
changes of government, in which his party was in government. Thus, during the 16 years in which he was in parliament and his party was in government he had ample opportunity to become a CM but was not selected. The two extremes of Leonie Short and John Watson illustrate the fact that it is only those BBs who had enough opportunity to become a CM but were not appointed should be classified as non-CMs. Classifying the short stay BBs, such as Leonie Short, as non-CMs would seem to run the risk of classifying as a non-CMs persons who may have had the potential to become a CM but were removed by the electorate before being able to do so. My solution is to include in the sample only those BBs who had sufficient time in parliament while their party was in power. I will explain this in greater detail in the section on sample design.

The next stage in the process of developing the model will be to explain the derivation of the data used as independent variables. There are 9 biographical and educational variables and 100 linguistic variables. In the case of the biographical and educational variables I will define these in the section on the sample data below. In the case of the linguistic variables it is not feasible to explain the derivation of all these due to their number. Furthermore, many are irrelevant for the purposes of constructing the model. The data mining process will identify the several important linguistic variables and I will then address the issue as to what each represents.

The final stage in the process is the creation of the actual models. I will show that of the 109 variables, fewer than ten in total are of potential interest. I will go on to use data mining techniques to determine which of these are the most useful in differentiating between CMs and non-CMs. It will become clear that there are several variables that are particularly useful. 
One of the variables that I find to be important is having a legal education. This replicates similar findings in the literature. Kerby (2009), for example, found that possessing a legal qualification is associated with cabinet appointment in the Canadian parliament. Another variable that I find to be important is the age of first entry to parliament (Parlage). This replicates the finding in a number of different settings. Kerby (2009) found that after age 42 an individual's chances of being appointed to cabinet fall. Buck (1963) and King (1981) found a similar age related phenomenon. Kam et al (2010) found that age is negatively associated with cabinet appointment. My finding that the age of entry to parliament is negatively associated with a parliamentarian's likelihood of becoming a $\mathrm{CM}$ is consistent with these findings. In Chapters 7 and $8 \mathrm{I}$ will derive plausible explanations as to why legal qualification and age have this relationship with $\mathrm{CM}$.

As well as the legal and age variables there are several linguistic variables that are important in the selection of CMs. These variables seem to be related to the concreteness of language. I will show that those parliamentarians who use language that is relatively non-concrete (i.e., abstract) are have a greater likelihood of becoming CMs. This is the first time this observation has been made. In Chapter 8 I will derive a plausible explanation as to why this relationship exists.

Thus, by the end of this chapter I will have solved the problem I wished to address - the characteristics of those who become CMs. I will have identified a small number of variables that explain who became a $\mathrm{CM}$ in approximately $70 \%$ of the cases in the sample derived from the cohort of ALP and LNPC parliamentarians from the period 1996-2008. 


\section{Summary of Section 6.2}

In this section I have discussed the procedure by which I intend to address the identification of the characteristics associated with becoming a CM. The basic approach will be to use data available at the start of parliamentarians' parliamentary careers to build a committee classifier that can predict who will become a CM. I have defined the dependent variable: $\mathrm{CMs}$ are those who have been a $\mathrm{CM}$ at some time in their parliamentary careers. Non-CMs are those who were not appointed to cabinet over their entire parliamentary careers. I have pointed out that this means we must be able to observe the entire parliamentary career of those we define as non-CMs. That is, we need to consider how to deal with those who were still in parliament after the first session of parliament in 2008. I have also alluded to the problem of defining BBs in term of their opportunity to become CMs. I have pointed out that the sampling procedure will involve removing those BBs who did not have the opportunity to become CMs. I then addressed the issue of data. The biographical and educational variables will be defined in the section below. Given that there are 100 linguistic variables I will discuss only those that are found by data mining techniques to be important in the final modelling process. We will see that of the 109 variables, only a small number is potentially of interest - four linguistic and three educational/biographical. A further screening process will reveal that of these, five variables can be used in a committee modelling procedure to correctly classify $78 \%$ of the cases in holdout samples.

In the next section I will turn to the development of the sample from the total cohort of ALP and LNPC parliamentarians in parliament over the period 1996-2008. I 
will use the sampling methods discussed above to reduce the initial cohort of 384 to a sample of 134.

\section{Section 6.3: The Sample}

The cohort was drawn from those ALP and LNPC parliamentarians who were in parliament at any time from the first session of Parliament in 1996 to the first session of parliament in 2008. Only ALP and LNPC members were included because in the Australian Federal context these are the only parties from which ministers are drawn. The definitions of cabinet minister (CM), junior minister (JM), parliamentary secretary (PS) and backbencher (BB) are based on the highest office achieved by the parliamentarian over their parliamentary career using information available at the first session of parliament in 2008. The resulting cohort consists of 205 LNPC parliamentarians and 179 ALP parliamentarians making a total of 384.

The breakdown of the 384 parliamentarians by party/LNPC and ministerial rank is given in Table 6.1. Data on each of the individuals in the cohort are given in Appendix 2. Of the 205 LNPC parliamentarians, 112 were BBs, 26 PSs, 33 JMs and 34 CMs. Of the ALP parliamentarians, 111 were BBs, 16 were PSs, 18 were JMs and 34 were CMs. 
Table 6.1: Cohort by Party and Ministerial Rank

\begin{tabular}{|l|c|c|c|}
\cline { 2 - 4 } \multicolumn{1}{c|}{} & LNPC & ALP & Total \\
\hline BB & 112 & 111 & 223 \\
PS & 26 & 16 & 42 \\
JM & 33 & 18 & 51 \\
CM & 34 & 34 & 68 \\
& & 179 & 384 \\
\hline
\end{tabular}

The idea is to use the $68 \mathrm{CMs}$ as the study group and create a control group of non-CMs from the remaining parliamentarians. However, as I mentioned above, we cannot use all of these parliamentarians in the control group.

The first problem to consider is that there is a difficulty classifying those BBs, PSs and JMs who were still in parliament at the February 2008 session. These may go on to become CMs and they are therefore difficult to classify. In contrast, the CMs who were in parliament in the first session of 2008 are not difficult to classify because they have already reached, at some stage in their career, the highest point. Thus, the problem is, how do we classify parliamentarians who have never been CMs but who still have the opportunity to become CMs because they were still in parliament in February 2008 ? The answer is that we need to remove them. We cannot observe whether or not they will go on to become CMs so we cannot classify them as CMs or non-CMs. Removing the BBs, PSs and JMs who were in parliament in the first session of parliament in 2008 (including those who were newly elected and re-elected at the November 2007 election) results in the sample shown in Table 6.2. 
Table 6.2: Sample without BBs, PSs and JMs in Parliament at February '08

\begin{tabular}{|l|c|c|c|}
\cline { 2 - 4 } \multicolumn{1}{c|}{} & LNPC & ALP & Total \\
\hline BB & 57 & 46 & 103 \\
PS & 12 & 3 & 15 \\
CM & 14 & 7 & 21 \\
& 34 & 34 & 68 \\
\multicolumn{1}{|l|}{ Total } & 117 & 90 & 207 \\
\hline
\end{tabular}

The result is that we have a cohort of $68 \mathrm{CMs}$ who were in parliament at February 2008 or who had served in parliament at some time over the period 1996 2007, and a control group of non-CMs whose career had come to an end by February 2008. In short, we have a study group who are clearly definable as CMs and a control group of individuals who did not become CMs over their entire parliamentary careers and are thus classifiable as non-CMs.

With this reduced sample there is still a problem. Within the sample of BBs there are individuals who did not have enough time in parliament to become CMs. These are the individuals who may have had the ability to become CMs but were removed by the electorate before they had sufficient time in parliament to demonstrate $\mathrm{CM}$ ability. A related problem is that some backbenchers may have spent some or all of their parliamentary experience in opposition. Such individuals may not have had the opportunity to be appointed to cabinet merely because their party was not in power. An individual whose party was in opposition for the duration of their time in parliament had no chance of being elevated to cabinet. They might have had the ability to be a CM had their party been in power but, due to electoral preferences, they were unable to become 
CMs. ${ }^{1}$ Including in the control group the short stay BBs and the BBs who spent most of their careers in opposition would run the risk of including individuals who had a high probability of becoming CMs given other circumstances. This is something we wish to avoid and although we cannot eliminate the possibility of including such individuals in the sample, there are steps we can take to minimise the probability of this occurring.

The solution I have decided on to deal with these problems is to exclude those backbenchers who did not have sufficient "in-government" experience to become CMs. Here, in-government experience includes the total amount of time in parliament during which their party was in government. Thus, a BB who has two years of experience as a BB while his party is in government followed by ten years when his party was in opposition and another three years of experience as a BB while his party is in government will have 15 years of total parliamentary experience of which $2+3=5$ was in-government experience.

With the concept of in-government experience we can now go on to consider how much in-government experience a BB needs to reveal executive potential. The idea here is that when a position in cabinet arises there will be a search for potential candidates. Possibly the first to be considered will be those who are already in the ministry. However, there are situations when BBs are directly appointed to cabinet but a BB's party has to be in power in order for such an opportunity to arise. Thus, ingovernment experience rather than total parliamentary experience is the important factor. Therefore, of the 103 backbenchers in the sample in Table 6.2 I wish to remove

\footnotetext{
${ }^{1}$ One possible solution would be to factor in membership of the shadow cabinet here. However, as we have seen, the ALP tended not to divide the ministry into inner and outer shadow ministries which makes this infeasible in the current situation. Furthermore, the dynamics of promotions and appointments in opposition may not be comparable to what occurs when in power.
} 
those who possibly had potential but did not have sufficient in-government experience to demonstrate it. The question is, how do we determine how long is sufficient time to reveal ministerial potential? In order to determine this, we must consider how much ingovernment experience CMs had on average before they were appointed to cabinet. This will give us a good indication of the amount of time required for a parliamentarian who has potential to actually reveal that potential.

For the sample of $68 \mathrm{CMs}$, the average amount of in-government experience these individuals had before being appointed to cabinet was 3 years with a standard deviation of 3.5 years. The problem here, however, is that this includes a number of CMs who were appointed without any in-government experience. Typically, these individuals were senior members of the party when in opposition and, upon the party winning government, these individuals became CMs due to having demonstrated cabinet potential while in opposition. These individuals were not "waiting in the wings" to be called upon to enter cabinet while their party was in power. Including these individuals in the calculation underestimates the amount of in-government experience an individual must accumulate in order to be appointed to cabinet. If we exclude the CMs who were appointed with no in-government experience we find that the amount of in-government experience accumulated by $\mathrm{CMs}$ on average before they were appointed was 5.5 years with a standard deviation of 3.0 years $(n=37)$.

We can now say that an individual who has not become a CM within $5.5+3.0$ years $=8.5$ years in-government experience is very unlikely to do so. The most likely explanation for their lack of success is that there was always someone else who was seen as better able to do the job. This is not to say that using this criterion will ensure 
that all BBs in the control group lacked the qualities to become CMs. No sampling method can claim to be so efficient. What I am suggesting is that this is a method of reducing the probability that, on average, the $\mathrm{BBs}$ in the sample had the qualities required to become CMs. It should also be stated that there is nothing absolute about this decision rule. The point is that some trade-off is required between a decision rule that is too strict and one that is too lenient. Too strict a rule will mean that the sample of BBs will be reduced to the point that there will not be a sufficient representation of BBs. Too lenient a decision rule and the risk is that there will be included in the control group individuals who actually had the talent to become CMs. The decision rule of 8.5 years is merely an empirically derived attempt to balance these two considerations.

Removing from the sample those BBs who had less than 8.5 years ingovernment experience results in the number of BBs falling to 30. The breakdown of the distribution of parliamentarians with this reduced number of BBs is given in table 6.3 .

Table 6.3: Final Modelling Sample

\begin{tabular}{|l|c|c|c|}
\cline { 2 - 4 } \multicolumn{1}{c|}{} & LNPC & ALP & Total \\
\hline BB & 16 & 14 & 30 \\
PS & 12 & 3 & 15 \\
JM & 14 & 7 & 21 \\
CM & 34 & 34 & 68 \\
$\quad$ Total & 76 & 58 & 134 \\
\hline
\end{tabular}


The remaining sample consists of $68 \mathrm{CMs}$ (including CMs who were still in parliament in the first session of 2008) and 66 BBs, JMs and PSs whose careers had ended by the first session of parliament in 2008 .

This sample of 134 should provide a good basis for the analysis. The control group consists of 66 individuals who were not selected for cabinet positions during their entire careers. The BBs, because we have selected them on the basis of their ingovernment experience, had sufficient time to prove themselves during their careers and yet had not been selected. In the case of the JMs and PSs, these individuals are also likely to be good non-CM exemplars because during their parliamentary careers they did not rise further than the junior ministry. In other words, they had come to the attention of the selectors at some time but during the appointments and re-shuffles it was always judged that there was someone who was more appropriately suited to cabinet than the career JMs and PSs. Conceptually, it is always possible that, as with the BBs, given more time some might have been appointed to cabinet. Furthermore, in extraordinary circumstances such as war or other national emergency, it is possible that these individuals might have been elevated to cabinet. However, the point is that, because they rose no higher during their careers, on average this group represents individuals who were judged as being less capable of $\mathrm{CM}$ appointment. Thus, as a group, the BBs, PSs and JMs in the sample should provide a good set of non-CM exemplars.

It should be added that the two adjustments to the sample are unlikely to introduce any systematic bias. The idea with the deletions is to maximise the extent to which the control group of non-CMs actually does represent non-CMs. Given the 
reasoning upon which the deletions were made there does not seem to be any basis on which it could be said that systematic bias was introduced.

\section{Summary of Section 6.3}

In this section I have explained the sampling technique for the modelling sample. The basic cohort consists of those members of the ALP and LNPC in parliament over the period March 1996 to February 2008. Of these 384, I removed any BBs, PSs and JMs who were still in parliament in the first session of parliament in February 2008. The reason for this is that we could not tell, from the information available at February 2008 whether or not they would eventually become CMs. Another alteration to the basic cohort was that I also removed those who were backbenchers and who had less than 8.5 years in-government experience. These were removed because it is important to include only those backbenchers who had sufficient time to prove themselves and yet who failed to do so. With these adjustments to the sample the control group consists of 66 non-CMs and the study group consists of 68 CMs.

Having explained the sampling method I will turn, in the next section, to the data. I will explain the coding for the binary dependent variable and 109 independent variables. 


\section{Section 6.4: The Data.}

In this section I will explain the coding for the dependent and independent variables. In the case of the independent variables I will restrict a full explanation to the biographical and educational variables as well as the small handful of linguistic variables that become important in the modelling. It is not useful to describe in detail the 100 linguistic variables as many of them turn out to be relevant in the modelling process.

\section{The Dependent Variable - CM}

The dependent variable for the modelling is quite straightforward: using information available at the first session of parliament in February 2008, a parliamentarian who had been selected to be a cabinet minister at any time in their career is scored as 1 . Non-CM controls were scored as 0 . The definition of non-CM is as discussed in section 6.3 Briefly, it consists of BBs, PSs, and JMs whose whole career we are able to observe (that is, whose career had ended) by the first session of parliament in February 2008. Furthermore, the definition of a BB is a BB who had ended their career by February 2008 and who had more than 8.5 years of in-government experience. It should be noted that the restriction of 8.5 in-government experience was not placed on PSs and JMs. The reason for this was that, being active members of the ministry, their abilities were on display to the selectorate and therefore it is likely that, had they displayed executive potential, they would have been promoted. The BBs were not involved in ministerial activities and therefore did not have the opportunity to display their talent or lack thereof. 


\section{The Educational and Biographical Independent Variables}

Parlage - This is the age in years of the parliamentarian at the time they entered federal parliament for the first time. For the vast majority of parliamentarians there was one time of entry and the age at this date was used. Where an individual entered federal parliament, lost her seat and then regained it in a subsequent period, the age at the time of the initial entry to parliament is used. Where an individual moved from state parliament to federal parliament the age at entry to federal parliament is used. Where an individual moved from one house to another, the age at the time of entering the first house was used.

InPower - This is a dummy representing whether the parliamentarian's party was in power when the parliamentarian delivered her first speech. The idea here is that individuals in opposition have been found to use slightly different language in comparison with those in government (Hirst et al 2010). This variable is designed to capture this effect. A parliamentarian whose party was in power when they delivered their speech is coded as 1 while if they were in opposition when the speech was delivered the coding is 0 .

Female - This is a dummy variable taking a value of 1 if the parliamentarian is a female and 0 if not.

The remaining variables are educational. This data is drawn from the various editions of the Parliamentary Handbook of the Commonwealth of Australia (19682008) as well as the online editions (www.aph.gov.au). The education coded for is the education acquired by an individual before entering parliament. The idea is to attempt to 
capture the cognitive style of parliamentarians as represented by educational background.

There are six binary variables for tertiary education:

Law - Individuals who were academically qualified to practice law are coded as 1 with the others coded 0 . This variable represents the qualification so an individual who has acquired the qualification but has not practised as a lawyer is still coded as 1 . The qualifications included in this category are B.Juris, LLB, LLM and the diploma qualifications leading to admission to practise through the Legal Practitioners Admissions board and its predecessors. Where a qualification is not stated but it was stated that an individual was a legal practitioner prior to entry to parliament they receive a coding of 1 .

Arts - Individuals with the following qualifications were coded as 1: BA, MA, BASocWk.

ECon - Individuals with the following economics qualifications were coded as 1: B.Ec, B.Com, B.Bus, MBA, M.Ec, BSc (Econ).

$E d u$ - Individuals with any education qualification that qualified them to teach in a state or territory school system were coded as 1. Qualifications included were DipEd, B.Ed, M.Ed, Dip. T, Cert. T.

SciEngSurv - Individuals with the following Science, Engineering or Surveying qualifications were coded as 1: BSc, MSc, BE, BSurv. 
Med - Individuals with the following medical qualifications were coded as 1 : MBBS, BMBS. Where a qualification is not stated but it was stated that an individual was a medical practitioner prior to entry to parliament they received a coding of 1 .

\section{The Linguistic Independent Variables}

The linguistic independent variables consist of two sets of variables. One set comes from Linguistic Inquiry and Word Count (LIWC). Variables from LIWC constitute 68 of the 100 linguistic variables. The remaining 32 are derived from the Paivio Yuille and Madigan (1968) and Clarke and Paivio (2004) psycholinguistic word norms.

Linguistic Enquiry and Word Count variables consist of 68 continuous variables as described in previous chapters. They are derived by running maiden speeches through the LIWC software using the LIWC dictionary version LIWC2007_English100131.

Paivio Yuille and Madigan (1968) and Clarke and Paivio (2004) (PYMCP) Word Norms are used to create 32 continuous psycholinguistic variables. In section 4.3.2 of Chapter 4 I gave an example of how the ease of definition (Def) variable is calculated. All the psycholinguistic variables are calculated in a similar way using a sample of 925 words originally developed by Paivio Yuille and Madigan (1968) with additional variables for the 925 words measured by Clarke and Paivio (2004). Essentially, each of the 925 words is given a value on 32 psycholinguistic variables. My scoring of the speeches used this data to give a score for each speech on all 32 variables. 
Of the 100 linguistic variables only 5 survive the filtering process. They are Img, (imagability) Con (concreteness), Conav (context availability), AOA (age of acquisition) and Def (ease of definition). Def has been discussed above. I will now discuss the remaining four variables.

Img is derived from the Paivio Yuille and Madigan (1968) norms for a sample of 925 nouns. Imagability scores for each word were derived by asking subjects the following question in relation to each of the words:

Nouns differ in their capacity to arouse mental images of things or events. Some words arouse a sensory experience such as a mental picture or sound, very quickly and easily, whereas others may do so only with difficulty (i.e., after a long delay) or not at all. The purpose of this experiment is to rate a list of words as to the ease or difficulty with which they arouse mental images. Any word which...[]...arouses a mental image (i.e., a mental picture or sound, or other sensory experience) very quickly and easily should be given a high imagery rating; any word that arouses a mental image with difficulty or not at all should be given a low imagery rating (Paivio Yuille and Madigan 1968: 4, italics in original).

Subjects were asked to rate each word on a score of 1 (low) - 7 (high).

Scores for Con (concreteness) were derived in the same way as those for Img except that the question was as follows: 
Any word that refers to objects, materials or persons should receive a high concreteness rating; any word that refers to an abstract concept that cannot be experienced by the senses should receive a high abstractness rating,... (Paivio Yuille and Madigan 1968:5; italics in original).

Subjects were asked to rate each word on a score of 1 (low) -7 (high)

In the case of Conav (context availability), the following instructions were given:

Think of a context for each word and then rate how easy it was to think of a context on a scale of 1 to 7 , where 1 means "very hard to think of a context" and 7 means "very easy to think of a context." For example, it may be easy to think of a context for the words "baseball" and "repentance" (e.g., the World Series or a Church) and they should receive high ratings of 6 or 7. It may be harder to think of a context for the words "inversion" and "sloop," although eventually contexts might come to mind (e.g., a smog inversion in a large city or sailing on a lake). Such words should receive low ratings of 1 or 2 . Rate words of intermediate ease of context availability between these extremes (Clarke and Paivio 2004: 381).

Subjects were asked to rate each word on a score of $1-7$. 
In the case of AOA (Age of acquisition), subjects were given the following instructions:

Use the following scale $[1-7]$ to rate the words in the booklet on their AGE OF ACQUISITION — that is, on how old you were when you learned to understand and use the words. Words that you learned early in childhood get high ratings. Words that you learned later in childhood get low ratings (Clarke and Paivio 2004: 381).

The concept that links these five variables is concreteness or some closely associated phenomenon. The variable Con measures concreteness directly while the variables Img and Conav measure concepts related to concreteness. Clearly, the ability to derive an image associated with an object is likely to be associated with the extent to which a sensory "image" can be imagined, thus explaining the connection between concreteness and Img. It has been suggested that Conav is a more reliable measure of the actual concept of concreteness than Con (Schwanenfugel and Schoben 1983, cited in Wiemer-Hastings, Krug and Xu 2001: 1135). The idea here is that it is easier to think of a context for concrete objects than for abstract objects. The variable Def is not a direct measure of concreteness but measures something closely related to concreteness. Abstract words are more difficult to define than concrete words (Clarke and Paivio 1991: 160). The word "car", for example, is easier to define than the word "justice". This explains why, as we will see below, the scores for Def are highly correlated with the other measures for concreteness. I will return to this issue in Chapter 8 where I will explain how the Dual Coding Theory (Clarke and Paivio 1991) links the ease of 
definition of a word (Def) to the extent to which the definition is stored using nonsemantic images associated with the word. Finally, the variable AOA is linked to concreteness in that "... words acquired early in life tend to be short, concrete and common" (Morrison, Ellis and Quinlan 1992:706).

Of the five linguistic variables, only three - Img, Con and Def - survive the filtering processes involved in model building. Two of these (Img and Def) are direct measures of concreteness while the remaining variable, Def, can be taken as a close proxy for concreteness. This is not to say that there is not some ambiguity with the concept of concreteness itself. In a factor analysis of the 925 words (Clarke and Paivio 2004), there is evidence that concreteness is not a unitary concept in that there is some difference in the way that the various measures of concreteness load on to different factors. $\operatorname{Img}, \quad \operatorname{Img} 2^{2}$ and Con load on the same factor ('Imagery/Concreteness') however Conav and Img2, as well as Def, load on a different factor ('Familiarity/Context availability'). This suggests that concreteness may not be reducible to a single phenomenon. However, the important point for the current analysis is that there are good reasons for saying that Con and Img are closely related to concreteness while Def is a proxy for concreteness.

\section{Summary of Section 6.4}

${ }^{2} \operatorname{Img}$ and Img2 are identical in terms of the sample of 925 words and the stimulus question used to generate the scores. The difference is that the data for Img was gathered from the studies undertaken in 1968 (Paivio, Yuille and Madigan 1968) with the 1968 cohort of subjects while the data for Img 2 was gathered in 2001-2002 from different subjects (Clarke and Paivio 2004). The two measures have a correlation of .803 (Clarke and Paivio 2004: 375). 
In this section I have described how the variables to be used in the analysis have been derived. The dependent variable is a binary variable taking the value of 1 if the parliamentarian was a $\mathrm{CM}$ and 0 if not. The biographical data consist of 2 binary variables and one continuous variable. The educational variables consist of 6 binary variables. The linguistic data are from two sources. The first consist of 68 continuous LIWC variables; the second consists of 32 continuous psycholinguistic variables. Both sets of linguistic data were derived by running the first speeches of the 134 parliamentarians in the sample through the relevant software. Of the 100 linguistic variables, we will see that only five survive the initial filtering process and only three appear in the final models. These variables are linked in that they are measures of concreteness.

The data for the five "important" variables described in this section for the modelling sample of 134 parliamentarians is provided in Appendix 3.

\section{Section 6.5: The Modelling Process}

In this section I will go through the procedure for creating Model 1 of the 5 Model committee. The creation of the other 4 models in the committee follows the same procedure. Full details of the model creation process for the other 4 models are in Appendix 3.

I will select, from the 109 candidates, a group of variables that are most likely to be useful in distinguishing between CMs and non-CMs. In order to identify the variables most likely to provide such a signal I will use a variable selection method 
based on the standard t-test for the difference of means. I will demonstrate that there are seven variables out of the 109 that are likely to be useful predictors of CM. This set of variables will be used to create a "naïve" model consisting of all seven variables. I will then use a test of redundancy to create a "reduced" model which has the redundant variables removed. This reduced model consists of four variables. I will then use these four variables to create 10 models by using all possible combinations of the 4 variables. The "optimum" model will be the model that has the highest out-of-sample classification accuracy.

\section{Division of the data into training and test Sets}

The first stage in this process involves dividing the 134 cases into training and test sets. One of the most salient differences between traditional statistics and data mining is that data mining uses out-of-sample classification accuracy to validate models. I have chosen to use an external holdout sample to test the accuracy of the models. Thus, the first stage of the modelling process is to split the 134 cases into an estimation (training) sample and a holdout sample. The training set will be used for all analysis while the test set will be used for testing models.

The difficulty here is to split the data in such a way as to provide enough of a training sample to enable regularities to be extracted from while providing a holdout sample of sufficient size to provide statistical significance. There is no ideal split between training and testing sample size. Where the sample size is large it is possible to use a 50-50 split. Such a split with a small sample size would result in a training sample that was not large enough to build a viable model with. At the other extreme, having a very small test sample can mean that the classification accuracy of the test sample is 
meaningless. Ransohoff gives an example of a published study which uses a training sample of 24 and a holdout sample of 6 (Chang et al 2003, cited in Ransohoff 2004: 310). Ransohoff points out that even if the classification accuracy of a holdout sample of $n=6$ was beyond chance the error variance is likely to be such that the same result may not occur with a different sample.

Given these considerations the strategy I have decided on is to use a 80-20 split. This provides 107 cases for training which should be adequate for a small number of independent variables without running into the problem of overfitting. The holdout sample of 27 is close to the standard sample size of 30 and therefore can be seen as reasonable for the purposes of statistical significance.

The holdout sample was created using stratified random sampling (Witten and Frank 2005: 149). That is, the cases to include in the holdout sample were randomly selected but the proportion of CMs and non-CMs was set up to reflect the distribution of CMs and non-CMs in the data set as a whole. As there were slightly more that $50 \%$ in the $\mathrm{CM}$ class $(\mathrm{CMs}=68 / 134=51 \%)$, the holdout sample was designed to have slightly more than 50\% CMs. Thus, in each holdout sample of 27, 13 were non-CMs and 14 were CMs.

Having thus split the 134 cases into holdout and training samples, the analysis of variables was conducted on the training sample only. The holdout sample was used only to test the models after they had been constructed. If the model can classify the holdout sample at a probability level beyond mere chance there is a lower probability that the model has merely "learnt" ungeneralisable patterns in the training sample. 


\section{Initial Screening of Variables}

Using the 107 cases of the training sample, the first stage of data screening involved scanning all 109 variables for possible associations with the dependent variable CM. The aim here is to find the variables most likely to provide a signal which can be used to predict the dependent variable. There is a large number of variables and we should therefore be aware that some of them will be associated with CM by chance alone. As such we should be stricter than we would normally be with our decision criterion. Thus, in tests of statistical significance in relation to the selection of variables we should apply the $\mathrm{p}<.01$ level of significance rather than the $\mathrm{p}<.05$ level. The reason for this is that in a group of 109 variables approximately $.05 * 109=5$ will be associated with CM appointment by chance alone. However, only 1 will be associated by chance alone at the $1 \%$ level. Thus, if we find more than one variable that is significantly associated with CM appointment we can be reasonably sure that there is some signal beyond the noise in the data.

For each of the 109 variables a t-test was conducted to see if there was a significant difference between the mean values for CMs and non-CMs. ${ }^{3}$ Variables were then ranked according to their p-values on the t-tests. Figure 6.1 depicts this ranking. The lowest $\mathrm{p}$-values are at the bottom left and it is clear from the p-values that the vast majority of variables is unlikely to be useful. Only 7 are associated with CM appointment at the $\mathrm{p}<.01$ level with an additional 8 associated at the $\mathrm{p}<.05$ level.

\footnotetext{
${ }^{3}$ F-tests were used to determine whether the populations had equal variances. Where this was not the case Welsh's t-test was applied.
} 
Figure 6.1: Ranking of 109 Variables on the Basis of T-tests

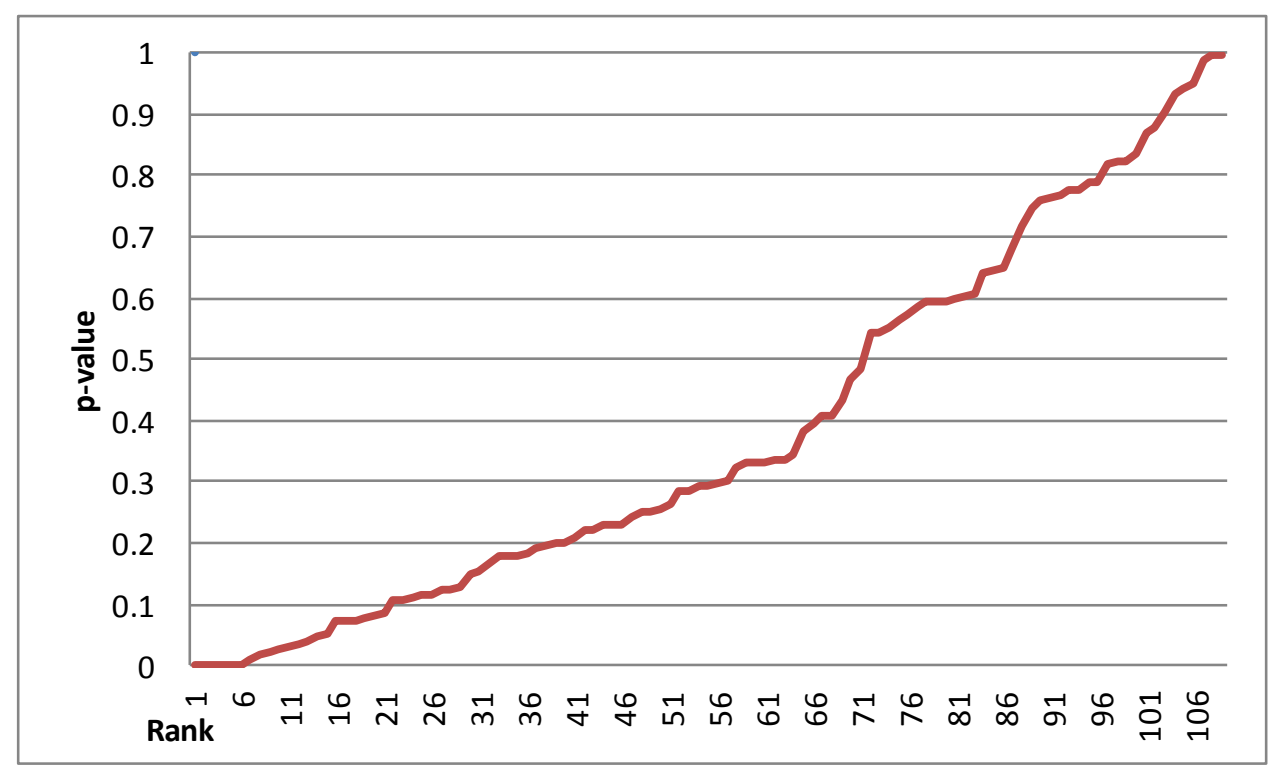

Ninety four of the variables are unrelated to $\mathrm{CM}$ on the basis of t-tests. This is not to suggest that it is impossible that they could provide information from which to detect a signal in the data. Searches based on non-linear and discontinuous relationships could yield useful variables. Furthermore, interactions between variables could provide data that would be useful information. However, the number of such possibilities is extremely large. For example, the number of possible two variable interactions is $n(n-$ 1)/2. With 109 variables the number of possible interaction terms is 5886 . Thus, it is computationally and possibly methodologically more prudent to look at simple relationships as a first step. If I had been unable to find any significant relationships using t-tests it would have been useful to move on to more complicated searches. However, given that I have found 7 potentially useful variables I proceeded with these.

The seven variables that were associated with $\mathrm{CM}$ appointment at the $\mathrm{p}<.01$ level are listed in table 6.4. 
Table 6.4: Variables with $p<.01$ on Tests of Differences in Means

\begin{tabular}{|c|c|c|c|c|}
\hline & $\begin{array}{c}\text { Mean } \\
\text { Non-CMs }\end{array}$ & $\begin{array}{c}\text { Mean } \\
\text { CMs }\end{array}$ & $p$-value & Description \\
\hline Law & 0.11 & 0.52 & 0.000 & Binary Variable: 1 = legal qualification, $0=$ no legal qualification \\
\hline $\mathrm{CON}^{*}$ & 0.41 & -0.36 & 0.000 & Concreteness \\
\hline ParlAge & 42.74 & 37.87 & 0.000 & Age of first entry to Federal Parliament \\
\hline IMG* & 0.37 & -0.33 & 0.000 & Imagability. A measure of concreteness \\
\hline DEF* & 0.28 & -0.37 & 0.001 & Ease of definitions \\
\hline Arts & 0.25 & 0.56 & 0.001 & Binary Variable: 1 = Arts qualification, $0=$ no Arts qualification \\
\hline CONAV* & 0.24 & -0.26 & 0.009 & Context availability. A measure of concreteness \\
\hline
\end{tabular}

*The values given for these variables are converted to z-scores to aid interpretation. The original values are on a scale of $1-7$

Having selected the variables the next stage is to create a "naive model" using all 7 variables.

\section{The Nä̈ve Model}

This model consists of the variables Law, Con, Parlage, Img, Def, Arts and Conav. I have called it naïve because there has been no attempt to eliminate variables based on further tests. Using these 7 variables the classification performance using holdout sample $1(n=27)$ was as follows: Accuracy $=66.67 \%$; Sensitivity $=50.00 \%$; Specificity $=84.62 \% ;$ Kappa $=.3415(\mathrm{p}=.057){ }^{4}$

The strength of this model is that it identifies the non-CMs at a rate of $84.62 \%$ which is well beyond what we would expect by chance. However, it is not able to detect CMs, given that it has a sensitivity of only $50 \%$. The overall measure of the ability to classify correctly (on a scale of $0=$ random classification to $1=$ perfect agreement) is .3415 and this is at borderline significance $(\mathrm{p}=.057)$.

\footnotetext{
${ }^{4}$ The data used for training and testing this model as well as the 4 other models created using different holdout samples are presented in Appendix 3.
} 
What this indicates is that either there is not a sufficient signal in the data to enable a more accurate classification rate to take place or there is redundancy in the model. In the latter case, the inclusion of variables that carry similar information may have resulted in the degradation the ability of the model to generalise. I will now address this issue. We will find that the removal of redundant variables can increase the classification accuracy of the model.

\section{Redundancy}

A problem contributing to the lack of a model's ability to generalise is the inclusion of redundant variables in a model. This can be a problem with both traditional methods such as logistic regression as well as with more sophisticated methods. Gabrilovich and Markovitch (2004), for example, provide an example of how redundancy can degrade the performance of support vector machines, possibly the most sophisticated induction method currently in use.

It is possible that there is considerable redundancy in the selection of variables because I have used a univariate test for each variable. That is, I have selected variables using an individual test for each variable. The problem here is that although each variable is individually significantly associated with the dependent variable, we need to consider their intercorrelations. As mentioned earlier, there are several variables that are linked in that they are measuring concreteness or a closely related concept. If they are measuring similar phenomena then including more than one in any one model is likely to result in redundancy and this can add noise to the model (Gibbs, Morgan, Maier, Dandy, Holmes and Nixon 2003: 791). The extent to which potential redundancy is 
present becomes evident if we consider the correlations between variables. Table 6.6 shows the intercorrelations of the variables in the model.

Table 6.6: Inter-correlations between $\mathrm{CM}$ and 7 Independent Variables

\begin{tabular}{|c|c|c|c|c|c|c|c|c|}
\hline & $\operatorname{CH}\{1\}$ & $\operatorname{Law}\{1\}$ & $\operatorname{Arts}\{1\}$ & ParlAge & IMG & CON & CONAU & DEF \\
\hline $\operatorname{CM}\{1\}$ & 1.0000 & 0.4352 & 0.3164 & -0.3400 & -0.3399 & -0.3729 & -0.2500 & -0.3266 \\
\hline $\operatorname{Law}\{1\}$ & 0.4352 & 1.0000 & 0.4232 & -0.1867 & -0.3347 & -0.3828 & -0.2303 & -0.3363 \\
\hline $\operatorname{Arts}\{1\}$ & 0.3164 & 0.4232 & 1.0000 & -0.1334 & -0.2873 & -0.3070 & -0.2090 & -0.2688 \\
\hline Parlage & -0.3400 & -0.1867 & -0.1334 & 1.0905 & 0.2843 & 0.2449 & 0.1836 & อ. 1382 \\
\hline I Hitg & -0.3399 & -0.3347 & -0.2873 & 0.2843 & 1.0900 & 179 & 0.7 & 0.7442 \\
\hline CON & -0.3729 & -6.3828 & -0.3970 & b. 2449 & 0.9179 & 1.0005 & 0.5985 & 0.7113 \\
\hline CONAU & -0.2500 & -0.2303 & -0.2590 & 0.1836 & 0.7579 & (0.5985 & 1.0900 & 6.7193 \\
\hline DEF & -6.3266 & -0.3363 & -0.2688 & b.1382 & 0.7442 & 6.7113 & b.7193 & 1.0000 \\
\hline
\end{tabular}

The correlation between Img and the other three linguistic variables varies from a high of .92 (Con) to a low of .74 (Def). In comparison, Img is correlated with the dependent variable, CM, at -.34. In other words, Img is more correlated with the other linguistic variables than it is with the dependent variable. The same situation obtains for the other three linguistic variables. Thus, there is a classic case of redundancy in that the four linguistic variables are effectively measuring similar things and with such high levels of redundancy it is unlikely that they are collectively adding more signal than noise. This indicates that the model can be improved by removing one or more of them.

The procedure here is to create four models, each of which has all three independent variables Law, Parlage and Arts but only one of Img, Con, Conav or Def. Table 6.7 shows the holdout sample classification accuracy for each of these four models. 
Table 6.7: Holdout Sample Classification Accuracy - Four Models

\begin{tabular}{|lcccc|}
\hline \multicolumn{1}{|c}{ Variables } & Accuracy & Sensitivity & Specificity & Kappa \\
Law, Parlage, Arts, IMG & 74.07 & 78.57 & 69.23 & $0.48^{*}$ \\
Law, Parlage, Arts, CON & 66.67 & 64.29 & 69.23 & 0.33 \\
Law, Parlage, Arts, CONAV & 74.07 & 71.43 & 76.92 & $0.48^{*}$ \\
Law, Parlage, Arts, DEF & 62.96 & 42.86 & 84.62 & 0.27 \\
\hline
\end{tabular}

$* \mathrm{p}<.05$

The models that include Img and Conav have equal highest accuracy at $74.07 \%$. This means that we still have to make a decision about which of the two out of Img and Conav to continue with in the further analysis of the variables. Where the accuracy is identical the next criterion is to look at the actual Kappa values. The Kappa for the model including Img is .4793 while that for the model including Conav is .4822 . Thus, it is the latter we should continue with.

\section{The Optimum Model}

The redundancy test has resulted in a reduced model consisting of Law, Parlage, Arts and Conav. I would now like to explore all possibilities of the four variables we have isolated. The procedure here is quite straightforward: the 10 possible combinations of the four variables is used to create 10 models. It is then a simple procedure to use the holdout sample to assess which is the best model. Table 6.9 lists the model variables, their classification accuracy and their Kappas. 
Table 6.8: Accuracy of Models Created with Law, Arts, Parlage and Conav

\begin{tabular}{|l|ccc|cc|}
\hline \multicolumn{1}{|c|}{ Variables } & Accuracy & Sensitivity & Specificity & Kappa & p \\
\hline Law, Parlage & 74.07 & 64.29 & 84.62 & 0.49 & 0.0098 \\
Law, Parlage, Conav & 74.07 & 71.43 & 76.92 & 0.48 & 0.0120 \\
Arts, Conav, Law & 70.37 & 64.29 & 76.92 & 0.41 & 0.0313 \\
Law, Conav & 66.67 & 50.00 & 84.62 & 0.34 & 0.0566 \\
Law, Parlage, Arts & 66.67 & 64.29 & 69.23 & 0.33 & 0.0816 \\
Parlage, Arts, Conav & 62.96 & 57.14 & 69.23 & 0.26 & 0.1682 \\
Law,Arts & 59.26 & 35.71 & 84.62 & 0.20 & 0.2284 \\
Parlage, Conav & 59.26 & 57.14 & 61.54 & 0.19 & 0.3317 \\
Parlage, Arts & 55.56 & 57.14 & 53.85 & 0.11 & 0.5680 \\
Arts, Conav & 51.85 & 50.00 & 53.85 & 0.04 & 0.8416 \\
\hline
\end{tabular}

On the criterion of holdout sample performance it is clear that a model consisting of Law and Parlage is the best performer. The holdout sample accuracy is $74 \%$ with a sensitivity of $64 \%$ and a specificity of $85 \%$. The Kappa of .49 indicates that, on a scale of random agreement $=0$ and complete agreement $=1$, there is agreement of .49 between actual and predicted classifications. This classification accuracy is likely to occur by chance in only one out of 100 random classifications $(\mathrm{p}=.0098)$.

Parameter estimates for the model are presented in Table 6.9. There is a significant $(\mathrm{p}<.01)$ positive association between Law and CM and a significant $(\mathrm{p}<.01)$ negative association between Parlage and CM.

Table 6.9: Parameter Estimates of Model 1

\begin{tabular}{|c|c|c|c|c|c|}
\hline Uariable & Parameter & Std. Error & Pr. Chi Sq. & Lower C.I. & Upper C.I . \\
\hline Law & & & & & \\
\hline 1 & 2.0719 & 0.537 & 0.0501 & 1.020 & 3.12 \\
\hline ParlAge & -0.0999 & 0.034 & 0. 0037 & -0.167 & -0.032 \\
\hline Constant & 3.4524 & 1.394 & 0. 0133 & 0.720 & 6.185 \\
\hline
\end{tabular}




\section{Summary of Section 6.5}

In this section I have described the modelling process. The first stage involved the division of the 134 cases into an estimation group $(n=107)$ and a holdout sample $(n$ $=27)$. Using the estimation group of 107 cases I undertook an initial screening of variables using t-tests. From this I created a naïve model consisting of 7 variables.. This model had an accuracy of $66 \%$. The next stage was to reduce the 7 variable model by eliminating any redundant variables. A correlation matrix was used to identify variables that were more correlated with each other than with the dependent variable. On this basis it was found that the four linguistic variables were good candidates for removal given that they were correlated with each other more than with the dependent variable. Thus, I decided to remove three of these. To determine which to remove I ranked the linguistic variables according to how they performed individually in models along with the other variables Law, Parlage and Arts. That is, I constructed four new models, each of which included Law, Parlage and Arts and one only of the linguistic variables. On this basis the model containing Conav was found to have the highest accuracy so it was retained while the other 3 were discarded. This reduced model (Law, Parlage, Arts and Conav) had a holdout sample classification accuracy of $74 \%$. The final stage of the model creation process was to attempt to find an optimum model by searching through the fifteen possible combinations of these four variables. The resulting model consisted of two variables, Law and Parlage. I then went on to look at the parameter estimates of these variables. Law is positively associated with $\mathrm{CM}$ while Parlage is negatively associated with CM. 


\section{Section 6.6: The Committee}

In the previous section I detailed the construction of Model 1 of the committee of models. The model building process was repeated with four other randomly generated holdout $(n=27)$ and estimation $(n=107)$ groups. Data used to construct these models are presented in Appendix 3. The summary results for all five models are displayed in Table 6.9.

Table 6.9: Summary Classification Results for 5 Models

\begin{tabular}{|c|l|ccc|c|}
\hline Model & \multicolumn{1}{|c|}{ Model Variables } & Accuracy & Sensitivity & Specificity & Kappa \\
\cline { 2 - 6 } 1 & Law, Parlage & 74.07 & 64.29 & 84.62 & 0.49 \\
2 & Law, Parlage, IMG & 85.19 & 78.57 & 92.31 & 0.70 \\
3 & Parlage, CON & 77.78 & 71.43 & 84.62 & 0.56 \\
4 & Law, Parlage & 81.48 & 78.57 & 84.62 & 0.63 \\
5 & Law, DEF & 74.07 & 64.29 & 84.62 & 0.49 \\
\hline \multicolumn{2}{|l}{ Average } & 78.52 & 71.43 & 86.16 & 0.57 \\
\hline
\end{tabular}

The highest classification accuracy is achieved by Model 2 with an accuracy of $85 \%$ and a Kappa of .70. The lowest accuracy in the committee is $74 \%$ with a Kappa of .49 which is achieved by both Models 1 and 5. The average accuracy of all 5 models is $78 \%$ with a Kappa of 57 . The temptation is to select the model with the highest accuracy rate, Model 2. However, as discussed above, this model may achieve this high level of accuracy due to a serendipitously easily classified holdout sample. Similarly, if we were to reject the two lowest scoring models, Model 1 and Model 5, on the grounds that they do not perform as well as the others in the committee, we may be making a mistake because they may, by chance, have difficult holdout samples to classify. It will be recalled that Azuaje (2010: 39) objected to the holdout sample method because the a given holdout sample could be biased. However, we do not have one holdout sample but 
five. Thus, the solution here is that we do not choose any individual model. Instead, we choose all of them. That is, we should use the decisions of the entire committee. The average accuracy rate of the committee of $78 \%$ is likely to represent the realistic error rate of the "hypothesis" that the variables in the models are related to the dependent variable in the way depicted by the committee.

The question we must now consider is what the important variables are. Various metrics for determining variable importance have been considered in the data mining literature. The issue is important in data mining because many induction methods are "black-boxes" which do not allow direct inspection of the relationship between the independent variables and the dependent variable as is possible with logistic regression. Thus, a popular method of assessing the importance of variables in black-box methods is determining the influence of the variable on the model's classification accuracy (Baxter, Gawler and Ang 2007: 22). The method here is to assess how well the model classifies when each of the variables is removed individually. Variables are then ranked according to the effect they have on the classification accuracy. The data mining community is in the process of determining new ways of measuring variable importance (van der Laan 2006). However, in the current situation, because logistic regression is transparent it is possible to rely on a fairly standard set of measures.

The first method I would like to use is the intuitively appealing idea that the number of times a variable is used by the committee is a good indication of the importance of a variable. On a raw count of the variables in the committee, Law and Parlage are the most prominent, appearing in four of the five models. Thus, there is little doubt that these variables are important in the committee's decisions. The two measures 
of concreteness, Con and Img appear in one model each, while the proxy for concreteness, Def, also appears in one model, indicating that concreteness is the third most important concept given that some measure of concreteness appears in three of the models.

A second measure of the importance of variables is available by inspection of the odds ratios and statistical significance for each of the variables in each of the models. Table 6.11 shows the odds ratios for the variables in each of the five models. As a further indication of the importance of each variable, those variables that are significant at the $\mathrm{p}<.01$ level in the respective models are in bold while those that are not in bold are significant at the $\mathrm{p}<.05$ level.

Table 6.11: Odds Ratios for Variables in 5 Models

\begin{tabular}{|c|ccccc|}
\cline { 2 - 6 } \multicolumn{1}{c|}{ Model } & Law & Parlage & Con & IMG & Def \\
\hline 1 & $\mathbf{7 . 9 4}$ & $\mathbf{0 . 9 0}$ & & & \\
2 & 4.28 & $\mathbf{0 . 9 1}$ & & 0.59 & \\
3 & & 0.93 & 0.56 & & \\
4 & 6.72 & 0.93 & & & \\
5 & 4.29 & & & & 0.60 \\
\hline Average & 5.81 & 0.92 & 0.56 & 0.59 & 0.60 \\
\hline
\end{tabular}

Clearly, Law is the most important variable given that the average odds ratio for the five models is 5.81. Furthermore, this variable is significant at the $p<.01$ level in each of the four models in which it appears. The average odds ratio for Parlage is .92 and in two of the models in which it appears it is significant at the $p<.01$ level while in the remaining two models it is significant at the $\mathrm{p}<.05$ level. The two measures of concreteness, Con and Img have odds ratios of .56 and .59 respectively while the proxy 
for concreteness, Def, has an odds ratio of .60. All three of Con, Img and Def are significant at the .05 level in the models in which they appear.

Given that Parlage appears in four of the models and is significant at the $p<.01$ level in two it is reasonable to say that it is the second most important variable. However, it should be noted that, on the basis of odds ratios, the linguistic variables are more influential than Parlage in that the average odds ratio for Parlage is .92 while the odds ratios for the linguistic variables are .56 for Con, .59 for Img and .6 for Def. If we going on the basis of odds ratios alone there we might conclude that Con is more influential than Parlage followed by Img and and Def. In short, while it is clear that Law is the most important variable in the committee there is some room for interpretation as to whether Parlage or the variables associated with concreteness should be considered the second most important.

\section{Summary of Section 6.6}

In this section I have considered the interpretation of the committee. The committee consists of five models, each constructed according to the same procedure but using different holdout and estimation samples. There are five variables in the committee: Law, Parlage, Con, Img and Def. Law and Parlage are the most important, occurring in four models. The three linguistic variables occur in one model each. Two of the variables, Con and Img, are closely related measures of concreteness. The remaining variable, Def, is a close proxy for concreteness. Thus, the three "concepts" 
that are used in the "decisions" of the committee could be said to be Law, Parlage and concreteness of language.

\section{Summary of Chapter 6}

The purpose of this chapter was to create a committee of models that could be used to isolate the characteristics associated with $\mathrm{CM}$. The first stage of this process was the creation of a sample to be used in the analysis. This is an important stage as the selection of the control group was not a straightforward task. The sample had to be adjusted to remove BBs, PSs and JMs whose careers could not be fully observed. Furthermore, BBs who had only spent a short term in parliament or who had spent large portions of their careers in opposition had to be removed. The remaining sample provided 66 non-CMs and $68 \mathrm{CMs}$ for analysis. Having defined the sample I turned to a description of the data. I described the 6 educational variables and three biographical variables. I did not explain in detail all the linguistic variables but pointed out that 68 were derived from the LIWC analysis of maiden speeches and 32 were derived from psycholinguistic analyses of maiden speeches. I explained the derivation of the five linguistic variables that would survive the initial variable screening process. The next stage of the analysis was to create 5 different models using 5 different holdout and estimation groups. For each model the same procedure was followed but in the exposition above only the creation of the first model was described. I explained the split of the sample of 134 cases into an estimation sample of 107 and a holdout sample of 27. The subsequent analysis took place using the training sample with the testing sample used only for testing models. The training sample was used to rank the 109 variables in 
terms of their performance on t-tests. By doing this 7 variables were isolated as being potentially useful. A naïve model was then constructed using these variables. This model was able to classify out-of-sample with an accuracy of $66 \%$. Reducing the number of variables by eliminating the redundant variables yielded a model with four variables which had a classification accuracy of $74 \%$. Further optimising the mix of variables resulted in the creation of the "optimum" model which was selected to be Model 1 of the committee. This had a slightly better accuracy than the 4 variable model and was more parsimonious, consisting of only Law and Parlage. I then explained how this model building procedure was repeated four times and that the committee of models results in a classification accuracy of $78 \%$. The most important variable in the committee is Law. There is some room for interpretation as to which is the more important of Parlage or the three linguistic measures of concreteness.

Having isolated the variables associated with CM I can say that the purpose of the chapter has been fulfilled. The first research question has been addressed in that the characteristics associated with CM have been identified. It is now necessary to turn to the second research question: why are these characteristics associated with CM? In order to answer this I will need to turn to the wider research on these characteristics. I will demonstrate that there are good theoretical reasons why Law, Parlage, Con, Img and Def are associated with CM. 


\section{Chapter 7: Legal Qualification}

\section{Section 7.1: Introduction}

Having a legal qualification is the most important predictor in the committee of models. There is a strong influence of legal education on the likelihood of a parliamentarian becoming a CM. I will show in the following sections that there are good reasons why this should be. I will cover several ideas about the relationship between legal training, the cognitive habits of lawyers and specific skills associated with legal training.

I will begin the analysis with a review of the perception of the high proportion of lawyers in politics as it appears in the popular media. This is a useful exercise because it shows that the public is aware that the selection of CMs is possibly linked to legal training. Although there is no statement by the leaders that this might be the case it is interesting to note that the issue emerges in the media.

I will then discuss the reasons why there might be a relationship between $\mathrm{CM}$ and legal training. The first consideration is whether there may be similarity bias. That is, whether there is a large number of legally trained individuals (LTIs) who do the selecting and they tend to pick people like themselves. I use a simple statistical analysis to show that this is not the case. I then consider the findings from US congress which show that there is a long-standing association between having a legal qualification and attaining positions on the more prestigious and influential committees. I discuss several reasons why this might be. I then turn to possible cognitive explanations for the 
advantage lawyers have when it comes to promotions in the legislature. I use Christiansen's (2006) idea that legal training gives individuals an ability to summarise information efficiently. I argue that this could not account for the advantage because other professions instil similar skills in their students. I then turn to the empirical studies on the relationship between legal training and the development of specific cognitive skills. There are two particular skills associated with legal training that have been identified in the literature. I end the chapter with an analysis of how these skills could be of benefit to an aspiring CM.

\section{Section 7.2: The Media Perception}

In November 1998 Tim O'Dwyer wrote an article for the Australian observing that front benches tend to be heavily weighted in favour of lawyers and the legally trained. His feeling was that he would rather the "country [were] governed by the law, not by lawyers" (O’Dwyer 1998). He points out that the cabinet and outer ministry are "swamped" by lawyers with 19 out of 30 ministers being legally trained and 11 out of 17 in the cabinet being legally trained. O'Dwyer points out that the ALP shadow ministry, by contrast had only 9 LTIs in its shadow ministry of 30 .

O'Dwyer states that he agrees with Edward DeBono's contention that the overrepresentation of LTIs in parliament was likely to lead to a lack of new ideas because the logical legal thinking was too rigid to allow the exploration of "new possibilities or outcomes". In a later article on the same issue O'Dwyer (2003) makes the point as follows: 
Concern about too many lawyers in government is based partly on De Bono's invitation for all problem solvers to move beyond old style thinking and partly on a personal suspicion that once you have been to law school, studied the classic cases about carbolic smoke balls, snails in bottles and wagon mounds, learned a little black-letter-parliament-made-law, written legal assignments, mooted and passed law exams, you will have acquired the lawyer's mindset De Bono sees as "analysis and judgment, fine tuning and juggling of existing concepts".

The idea here is that the subtle analysis of "existing concepts" leads to a mindset that is not attuned to new ideas.

However, O’Dwyer departs from the argument about what might be good for the country and goes on to point out that there is an advantage to a prospective parliamentarian in having legal training. He quotes MP Joe Hockey who states that the analysis of legislation and policy that lawyers must do is similar to what parliamentarians must do. He also quotes Senator Amanda Vanstone who says that they law gives people a sense of "fairness and equity" as well as the ability to "marshal[...] the arguments one way or the other."

There are several ideas here in relation to the perception that lawyers bring a particular way of thinking to politics. The first is the rigidity of thinking. There is a concern that lawyers are not trained to think beyond a certain repertoire of cognitive skills and this, according to DeBono and O'Dwyer, is likely to be detrimental to 
government. Interestingly there is some substance to O'Dwyer and DeBono's concern about the lawyer's mindset. In the section below on the cognitive habits of those with legal training we will see that there are differences in the way LTIs process information: lawyers tend to view the notion of causality quite differently to non-LTIs and this tendency is not just in relation to legal issues but flows into their interpretation of the external world.

Another strand in the argument is that there are strengths developed by those who study law in relation to arguing and presenting arguments. It makes intuitive sense that the adversarial legal training may be be useful in the adversarial parliament. Furthermore, the ability to marshal arguments quickly and persuasively in a courtroom setting is likely to be of use to a parliamentarian who must do essentially the same thing in parliament, with the media and amongst her constituents.

There is a perception, at least on the part of Vanstone, that the law gives individuals a sense of fairness and equity. There is no empirical evidence to support this. However, Perez (2010) conducted a laboratory study of "inequity aversion" amongst first year student lawyers and teachers. The aim of the study was to determine whether there was a difference in the extent to which lawyers as opposed to teachers were willing to adopt a remuneration strategy for a group which could have resulted in some members of the group being remunerated better than others. One of the findings was that first year lawyers who planned a career in public law were more likely to be averse to inequity than those lawyers who were planning a career in private practice. This suggests, contra Vanstone, that it is the ideology of the individual rather than the training that influences attitudes to fairness and equity. 
O'Dwyer's observations and those of his interlocutors are interesting because they provide an intuitive overview of some of the themes that, as we will see, recur in the literature in relation to LTIs in politics. The perception that there are more lawyers at the executive level than at the backbench level is certainly apposite. The modelling results given in the last chapter indicate that there is an advantage to having a legal qualification for an individual who wishes to rise through the legislature. Furthermore, as we will see below, the advantage that a legal training bestows on a legislator who is aiming for high office is confirmed in studies of US legislatures. Finally, the intuition that there is a lawyer's mindset has some merit and I will review the empirical literature on this in the section on legal thinking.

\section{Summary of Section 7.2}

In this section I have provided an overview of the perception of the role of lawyers in parliament. I reviewed two articles by Tim O’Dwyer (1998; 2003) and found that there was a perception that: i) there were too many lawyers in parliament: ii) the over-representation of lawyers may give rise to overly rigid thinking: iii) there is a mindset associated with legal training: and iv) there are some advantages in a legal training for an aspiring parliamentarian. The importance of these observations is that they show that there is a public perception that there is a link between legal training and attaining high political office. Thus, the modelling seems to confirm what people suspect. Furthermore, the public perception that there are ways of thinking and skills that are bestowed by legal training is interesting in that it demonstrates that there is an intuitive idea that lawyers think differently. Thus, the media discussion is an apt prelude 
to the analysis in this chapter which is intended to determine the differences between the cognitive habits of lawyers and non-lawyers.

Before proceeding to this analysis, however, I must consider an opposing idea. In the next section I will address the idea of similarity bias in the selection of lawyers. That is, I will consider whether there is a bias in the Australian federal system of LTIs appointing LTIs to cabinet. We will see that the similarity bias explanation for the prevalence of lawyers in parliament is not strongly supported.

\section{Section 7.3: Similarity Bias and the Selection of Legally Trained Individuals}

In order to explain the prevalence of LTIs in cabinet I need to consider the possibility of similarity bias (Byrne 1971). Similarity bias theory essentially states that people are likely to find people who are like them to be more agreeable than those who are not like them. Many of those who are instrumental in making cabinet selection decisions are themselves legally trained so this is a plausible explanation for the importance of legal training in cabinet selection. We saw very good evidence for this perception in the articles of O'Dwyer $(1998 ; 2003)$ who asserts that the legally trained Howard had a preference for selecting legally trained CMs. If this is a pervasive influence in the selection of CMs across leaders then it could account for the association between having a legal training and becoming a CM.

The similarity effect occurs where an individual observes similarities in others and, on this basis, develops positive affect towards them. The similarity can be based on self-categorisation, in which an individual identifies with a particular category, such as 
race or gender and views others in that category favourably (Jackson et al 1991; Turner 1987). An alternative explanation for similarity bias is social identity theory which explains the attraction to a group in terms of the positive feeling associated with belonging to the group (Tajfel 1982). On this account, the group membership provides a basis for belonging in that it provides a medium for creating the "ingroup" and “outgroups" (Dustin and Davis 1970; Brewer 1979). A positive feeling is generated by being part of the ingroup and identifying members of the outgroup as the "other".

In the case of $\mathrm{CM}$ selection, the basis on which any putative similarity effect would be based is legal training. If we can find evidence of a systematic bias of LTI leaders appointing LTIs to cabinet then we have some support for the explanation based on similarity bias. Alternatively, if we find that non-LTI leaders appoint LTIs at a similar rate as non-LTI leaders then the argument would lose support.

The vast majority of CMs in the LNPC sample were appointed by LTIs. In fact, of the $34 \mathrm{CMs}$ in the LNPC sample, excluding himself, Howard appointed 32. The legally trained Ian Sinclair was initially appointed by the legally trained Holt while Howard himself was appointed by the non-legally trained Fraser. The remaining LNPC CMs were first appointed by Howard and it is therefore possible that the LNPC sample reflects Howard's similarity bias. Howard studied law at Sydney University in the late 1950 and graduated in 1961. He then practised law until becoming a member of the House of Representatives in 1973. As we have seen from O’Dwyer $(1998 ; 2003)$ there is a perception that Howard had a penchant for appointing LTIs to cabinet. 
In contrast, a great proportion of the ALP CMs were appointed by non-LTIs. ${ }^{5}$ In the ALP sample of $34 \mathrm{CMs}$, two of the three leaders responsible for making cabinet appointments were not legally trained. The non-legally trained Rudd made 17 of the 34 ALP CM appointments with the non-legally trained Keating appointing 7 while the legally trained Hawke appointed 9. Thus, only 9 out of 34 were appointed by a legally trained leader. ${ }^{6}$ Table 7.2 summarises the situation for both the LNPC and the ALP.

\footnotetext{
${ }^{5}$ In the ALP, the caucus traditionally selects the individuals who will be in the ministry but the leader allocates the portfolios. As such the leader selects who will be in cabinet.

${ }^{6}$ Rudd himself is excluded from the numbers here as he first became a CM when he became prime minister. Thus, he was not appointed to cabinet by another leader.
} 
Table 7.2: CM Appointer and Appointee Legal Training Status

\begin{tabular}{|c|c|c|c|c|c|c|c|}
\hline \multicolumn{4}{|c|}{ LNPC } & \multicolumn{4}{|c|}{ ALP } \\
\hline Cabinet Minister & $\begin{array}{c}\text { CM Legally } \\
\text { trained }\end{array}$ & $\begin{array}{c}\text { First } \\
\text { Appointed } \\
\text { to Cabinet } \\
\text { by: }\end{array}$ & $\begin{array}{c}\text { Appointer } \\
\text { Legally } \\
\text { Trained }\end{array}$ & Cabinet Minister & $\begin{array}{l}\text { CM Legally } \\
\text { trained }\end{array}$ & $\begin{array}{c}\text { First } \\
\text { Appointed } \\
\text { to Cabinet } \\
\text { by: }\end{array}$ & $\begin{array}{c}\text { Appointer } \\
\text { Legally } \\
\text { Trained }\end{array}$ \\
\hline AbbottA & Yes & Howard & Yes & AlbaneseA & No & Rudd & No \\
\hline AlstonR & Yes & Howard & Yes & BaldwinP & No & Keating & No \\
\hline AndersonJ & No & Howard & Yes & Beasleyk & No & Hawke & Yes \\
\hline AndrewsK & Yes & Howard & Yes & BolkusN & Yes & Hawke & Yes \\
\hline BishopJl & Yes & Howard & Yes & BreretonL & No & Keating & No \\
\hline BroughM & No & Howard & Yes & BurkeAT & Yes & Rudd & No \\
\hline CampbellIG & No & Howard & Yes & Carrk & No & Rudd & No \\
\hline CoonanH & Yes & Howard & Yes & CollinsRL & No & Keating & No \\
\hline CostelloP & Yes & Howard & Yes & Conroys & No & Rudd & No \\
\hline DownerA & No & Howard & Yes & CookP & No & Hawke & Yes \\
\hline FaheyJ & Yes & Howard & Yes & Creans & Yes & Hawke & Yes \\
\hline FischerT & No & Howard & Yes & EvansC & No & Rudd & No \\
\hline HillRM & Yes & Howard & Yes & EvansG & Yes & Hawke & Yes \\
\hline HockeyJ & Yes & Howard & Yes & FaulknerJP & No & Keating & No \\
\hline HowardJ & Yes & Fraser & No & FergusonM & No & Rudd & No \\
\hline KempD & Yes & Howard & Yes & FitzgibbonJ & No & Rudd & No \\
\hline MacfarlanelE & No & Howard & Yes & GarrettP & Yes & Rudd & No \\
\hline McGauranP & Yes & Howard & Yes & GillardJ & Yes & Rudd & No \\
\hline McLachlanIM & No & Howard & Yes & HoldingC & Yes & Hawke & Yes \\
\hline MinchinN & Yes & Howard & Yes & LawrenceC & No & Keating & No \\
\hline Moorej & No & Howard & Yes & LeeM & No & Keating & No \\
\hline NelsonB & No & Howard & Yes & LudwigJ & Yes & Rudd & No \\
\hline NewmanJM & Yes & Howard & Yes & MacklinJ & No & Rudd & No \\
\hline PattersonK & No & Howard & Yes & McClellandR & Yes & Rudd & No \\
\hline ReithP & Yes & Howard & Yes & McMullanRF & No & Keating & No \\
\hline RuddockP & Yes & Howard & Yes & MorrisP & No & Hawke & Yes \\
\hline SharpJR & No & Howard & Yes & RayR & No & Hawke & Yes \\
\hline Sinclairl & Yes & Holt & Yes & RoxonN & Yes & Rudd & No \\
\hline TrussW & No & Howard & Yes & RuddK & No & $\mathrm{n} / \mathrm{a}$ & $\mathrm{n} / \mathrm{a}$ \\
\hline TurnbullM & Yes & Howard & Yes & SmithSF & Yes & Rudd & No \\
\hline VaileM & No & Howard & Yes & SwanW & No & Rudd & No \\
\hline VanstoneA & Yes & Howard & Yes & TannerL & Yes & Rudd & No \\
\hline WillamsDR & Yes & Howard & Yes & WillisR & No & Hawke & Yes \\
\hline WooldridgeMRL & No & Howard & Yes & WongP & Yes & Rudd & No \\
\hline
\end{tabular}

Source: Data drawn from Parliamentary Handbook of the Commonwealth of Australia, www.aph.gov.au. 
It is difficult to determine whether there was bias in Howard's selection of LTIs. Certainly he selected LTIs at a high rate: $56.25 \%$ of his appointments were of LTIs. However, this is only marginally more than Rudd's LTI appointment rate of 53\%. These rates are higher than those for Hawke (40\%) and Keating (0\%). Thus, it is possible that both Howard and Rudd had a bias towards LTIs. However this would reduce the strength of the similarity bias argument because Rudd was not legally trained while Hawke was.

To assess whether there is similarity bias across the sample we need to take into account the legal education status of the leader who appointed the CM and see if there is a difference in the rate of appointment of LTIs for legally trained leaders as opposed to that of non-legally trained leaders. The way to do this is to conduct a t-test. Those with legal training are coded as 1 while those without legal training are coded as 0 . If the average "legal training score" of the group of individuals appointed by an appointee with legal training is significantly greater than the average "legal training score" of the group of individuals appointed by those without legal training then we will suspect similarity bias.

For the non-legally trained leaders (Fraser, Rudd, and Keating) $40 \%$ of the appointees were legally trained $(n=25)$ while for the legally trained appointers (Howard, Holt and Hawke), 55\% of appointees had legal training $(\mathrm{n}=42)$. This difference is not statistically significant $(p>.1)$. We can conclude that there is no statistical support for the idea that LTIs are selected due to similarity bias. 


\section{Summary of Section 7.3}

In this section I have addressed the idea that the high proportion of LTIs in Cabinets is due to similarity bias. Legally trained Howard did seem to appoint a large number of legally trained cabinet ministers, more so than any other leader. $56 \%$ of the CMs he appointed were legally trained. However, non-legally trained Rudd was not far behind at $53 \%$. Furthermore, t-tests show that those appointers who are legally trained do not show a statistically significant bias towards appointing CMs with legal training. Thus, we cannot rely on similarity bias to account for the fact that a large number of LTIs become CMs.

In the next section I will begin turn to alternative explanations for the association between legal training and CM appointment. I will examine the issue of the relationship between legal education and high political office in the context of the evidence from the US. We will see that in both US Federal and State arenas there is evidence that a legal education confers on an individual an advantage in rising through the legislature.

\section{Section 7.4: Findings from USA Congress}

A significant literature on the differences between lawyers and non-lawyers exists in relation to the US congress. Lawyers have an advantage in being appointed to influential congressional committees and tend to rise to more senior positions than nonlawyers. Miller (1995) notes that LTIs tend to arrive at the legislature at earlier ages than non-legally trained legislators and, once there, are more likely to hold key positions 
(Miller 1995: 86). Lawyers in USA legislatures have always been over-represented in the most important committees and have held a disproportionately high number of chairmanships of such committees (Eulau and Sprague 1964: 118; Blaustein and Porter 1954: 97, both cited in Miller 1995: 86). There are three general strands of thought as to the reasons for this prevalence: i) lawyers have specific technical skills that are useful for a legislator: ii) lawyers perceive their role as representatives differently to nonlawyers: and iii) individuals who are politically ambitious may, as an element of their ambition, pursue a legal education as part of the process of attaining high political office, thus creating an association between high political office and legal education.

\section{Technical Skills}

As might be expected, one area in which lawyers have an advantage is with the drafting of legislation (Miller 1995: 77). Legally trained members of the legislature are particularly useful in detecting technical defects in bills. Non-lawyers are more likely to defer to the judgment of their lawyer colleagues on such legal matters (Blaustein and Porter 1954: 99-100, cited in Miller 1995: 77). Non-lawyers are also more likely than lawyers to want to leave the consideration of constitutional issues to courts. Furthermore, the technical aspects of lawmaking are more likely to be attended to by lawyers than non-lawyers (Morgan 1966, 156-57, 366, 343-44, cited in Miller 1995: 77). According to Miller, "[t]hese differences are subtle, but extremely important" (Miller 1995: 77).

Polsby (1990, cited in Miller 1995: 78) points out that one of the subtle ways in which the legislative process is differentially influenced by the technical aspect of the 
law is via the highly legally oriented committee system. Committees "hold hearings", "witnesses" "testify" at these and their comments are "on the record" while one senior member is "counsel" to the committee. Because the language and general context of these activities are based on legal protocols, lawyers are in their element in such an environment. Thus, lawyers are at home in the engine-room of legislation - the congressional committee (Miller 1995: 78).

In short, the skills and general approach that are important in the legislative process are more likely to be exhibited by LTIs. It is plausible that individuals who demonstrate the ability to actively participate in the legislative process are those who will attract the attention of the people responsible for making senior appointments. It should be noted that Australian federal parliamentary committees are similar to congressional committees in respect of their legal environment and as such the observation that US lawyers are "at home" in the legislative committee is extendable to the Australian context. Thus, it is possible that individuals with a legal background are able to participate in drafting, developing and scrutinising legislation to a greater extent than non-LTIs. This could give them an advantage in that they are seen as making a positive contribution from the time they enter parliament.

Because lawyers have a knowledge of the law, non-lawyers are more likely to defer to them on technical aspects of law making (Blaustein and Porter, 1954: 99, cited in Miller 1995: 87). This deference leads to them being seen as leaders. According to Miller "[n]onlawyers in the legislature often defer to lawyers because lawyers are thought to hold more expertise on many legislative questions and because lawyers are 
stereotyped as better leaders" (Miller 1995: 87). Thus, there is likely to be a connection between technical skill in the law and being perceived to be more "leader-like".

\section{Role Perceptions}

A difference between lawyers and non-lawyers in their attitude to constituents has been noted in the research. Miller (1995) adopts the idea of the legislator as one of three kinds of representative: 'the delegate', who consults with his constituents and follows their instructions, irrespective of his own views; 'the trustee', who acts according to his conscience, principles and convictions without concern for their constituent's opinions but always with their best interests in mind, and; 'the politico', who combines elements of both the delegate and the trustee (Miller, 1995: 91). According to Miller's conclusions from interviews with members of the Ohio, Maryland and North Carolina legislatures, lawyers were much more likely than non-lawyers to see themselves as trustees and politicos than delegates. That is, they were much more likely to use their own judgment on political issues than merely follow the dictates of their constituents. Miller holds that this may be because the traditional role of the lawyer is to take instructions from a client but proceed using knowledge that far surpasses the client's and therefore supersedes the ability of the client to give relevant instructions: "Just as a lawyer is hired because he or she has more knowledge or expertise than the client, the lawyer legislator does not feel constrained to accept instructions from his or her less informed constituents" (Miller 1995: 94). This way of thinking can be linked to the way a leader thinks in that the typical leader takes advice from those around her but makes a final decision based on her own perception of what should be done. As such it 
is possible to see how an individual who behaves this way in relation to their constituency has an outlook more aligned to leading than following. It is conceivable that this kind of outlook will be seen by others as instantiating "leader-like" qualities.

The problem with this explanation is that the definition of a profession usually includes the idea that the professional has greater knowledge than his or her employer and therefore, on technical issues may not take the position of the employer. This is the classic agency situation in which the agent has greater information than the principal and will therefore make a decision that is not always that which the principal would make. Thus, we would expect to find a similar advantage for professionals who are in the habit of engaging in an agency relationship with their clients such as medical professionals and economic and financial consultants. However we do not find this relationship: in the modelling in Chapter 6 only a legal education was found to be predictive of CM appointment.

A second problem with this argument is that this difference in role perceptions may not be pervasive. A more recent study is Eakins' (2006) study of the Ohio legislature which finds that both lawyer-legislators and non-lawyer-legislators are likely to identify with the politico role. Although this study is based on only one legislature and Miller's (1995) study is of three, it seems that there may have been a change in the perception of the role of the legislator in the decade that separates these studies. 


\section{Ambition}

Eulau and Sprague (1964) pointed out that lawyers in state legislatures were more likely than non-lawyers to desire running for higher political office. They state that "[i]nsofar as the state legislature serves as a proving ground for politicians, it appears that lawyers move on to other political offices not by predestination, but by force of forethought" (Eulau and Sprague 1964: 80, cited in Miller 1995: 90). Supporting this idea is the observation made above that lawyers tend to join the legislature at earlier ages than non-lawyers (Miller 1995: 86). This may indicate that they have an intention to be politicians at an early stage in their lives and choose to study law because it is seen as a good background for public life. Similarly, in a study of the Ohio state legislature by Eakins (2006), found that ambition and an early desire to be in politics are more prevalent in lawyers than non-lawyers. On this account, the ambition causes both the study of law and the ability to rise through the system, leading to the positive association between the latter two variables.

It should be noted that the idea that Law is a measure of ambition is not supported by the modelling. I have effectively controlled for ambition by including Parlage in four of the five committee models. The findings of Buck (1963) and King (1981) support the idea that the age of entry to the legislature is a good proxy for ambition, the idea being that the more ambitious the individual the earlier they will want to begin their career. I will return to this issue in Chapter 8 . The important point at this stage is that if Parlage is a proxy for ambition then, given that it is present in four of the models and is significant at the $\mathrm{p}<.01$ level in two and $\mathrm{p}<.05$ level of the remaining two, ambition is already controlled for. Furthermore, in the models in which both Law and 
Parlage are present, the legal education binary variable is still very powerful and significant. Thus, ambition is unlikely to be the reason for the strength of the legal variable.

\section{Summary of Section 7.4}

The above research shows three general strands of thought as to why LTIs should have an advantage in achieving high political office. The idea that there are specific technical skills that skills that LTIs bring to parliament is very plausible given that the function of the legislature is to produce legislation - the very subject matter that lawyers are experts in. Due to their greater technical skill they tend to be deferred to by other non-lawyer legislators and this makes them seem more like natural leaders. The role perception argument is less convincing. The assertion is that, because they do not merely blindly follow instructions of their clients without their own judgement, this makes them more like leaders. However, most professions entail taking a similar agency role, yet only law has the advantage in the legislature. Furthermore, there is recent evidence that there has been a change in recent years towards the more consultative politico away from the more autonomous trustee by both lawyers and non-lawyers. Finally, the issue of ambition seems apposite. Those who see a clear path to political office via the legislature from an early age would plausibly see a legal training as part of the process. Thus, an association would occur between legal training and ambition. However, given that this may be controlled for in the model, the ambition explanation is not supported. 
Thus, of the three explanations, skill sets, role perception and ambition, the explanation based on skill sets is the most persuasive.

In the next section I will review the literature on a specific set of cognitive skills that lawyers learn. We will see that there is a plausible reason for accepting that lawyers do use a particular way of organising information. However, it will be argued that many other professionals use similar skills and therefore it is difficult to assume that the skills discussed should give LTIs the advantage they have in the legislature.

\section{Section 7.5: Cognitive Skill - "Chunking" and the Case Brief}

It is possible that the mode of thinking that LTIs learn during their training is akin to the work undertaken by a CM and LTIs are therefore better able to demonstrate the required skills. The ideas from O'Dwyer's $(1998 ; 2003)$ articles show that there is a perception that the skills LTIs have in organising information and presenting arguments are what sets them apart in the legislature. The question is: what is the nature of the skills that sets lawyers apart?

If the ability to quickly and efficiently organise information is what marks LTIs apart then it is worthwhile looking at how lawyers are trained to organise information. Such an analysis has been made by Christensen (2006) who describes how high achieving individuals who first enrol in law find it very difficult to adapt to the kind of thinking required to understand legal argument. These students perform well on verbal ability tests and yet have considerable difficulty in their first encounter with legal reasoning. By the end of their first year most students have acquired the skill. According 
to Christensen, the successful students learn how to condense a large amount of information using the "case brief". The case brief is a schema used for the purpose of categorizing information contained in legal opinions. It is a method of organizing information in such a way that the general pattern of the case is retained but the short term memory is not swamped with the details.

An essential aspect of the case brief is that it facilitates "chunking" Expert knowledge involves chunking information into rational "chunks" of information such that, once allocated to a rational category, the information takes up less space in working memory. This frees up more space for the "challenging task of actually thinking about the material" (Christiansen 2006: 18). Experts tend to be able to solve problems in their domain significantly more easily than non experts largely because they have chunked a lot of the ways of thinking about problems in such a way that the information held in the chunks can be easily retrieved and applied to the problem at hand. Blasi (1995, cited in Christiansen 2006: 18) uses the example of the phrase WYSIWYG/P6/QWERTY/AS400. ${ }^{7}$ This 27 symbol phrase is difficult for a noncomputer literate person to remember, let alone think about. But a computer literate person sees this as only 4 concepts or chunks and can immediately begin the process of analyzing what it is saying.

This is a plausible explanation as to why LTIs are more likely to become CMs. In political life there are many situations that require an ability to quickly master the basics of a subject area and then move on to actually debating about the concepts. The

\footnotetext{
${ }^{7}$ WYSIWYG = "What you see [on the computer screen] is what you get [on the printout]; QWERTY = Standard Keyboard layout; P6 = A post Pentium processor; AS400 = A mid-range model IBM computer (Blasi 1995, ff: 343).
} 
problem with this explanation, however, is that, as Christensen points out, experts in general tend to engage in chunking in their own domains (Christensen 2006: 18). Professionals in all fields tend to be able to quickly assess problems in their own domains because they have a good understanding of the overall picture due to their ability to apply schemas from their own fields of expertise to problems that arise. In medical diagnosis, for example, a clinician takes into account a broad spread of information including the qualitative information from the patient and data from tests but the procedure undertaken is not iterative. That is, the clinician does not evaluate each possible diagnosis against the data available. Instead they use heuristics derived from training and experience (Ericsson and Lehman 1996). In particular, they tend to begin anticipating likely scenarios before they get all the data. This means that they already limit the amount of information processing they need to do. Chess players have been found to do exactly the same kind of thing such that the best moves are already determined early within each assessment of a move (de Groot 1946/1978, cited in Ericsson and Lehman 1996: 275). In other words, they perceive the situation without needing to iteratively work through a large number of possibilities. The latter course of action would be prohibitively cognitively expensive and thus, for a human, as opposed to a computer, it makes more sense to rely on global heuristics. The important point here is that all professionals tend to do this in their own domain. The case brief is the LTI's version of the same phenomenon.

Thus, we cannot explain the advantage that LTIs have in the legislature by saying that they have a more efficient method of processing information than others 
because the evidence is that most professionals would possess an analogous skill yet they do not have the same advantage as the LTIs in the legislature.

\section{Summary of Section 7.5}

In this section I looked at whether there was a distinctive way that lawyers are taught to organise information and whether this could account for their advantage in parliament. I considered the case brief as the paradigm way that lawyers are taught to organise information. The case brief is a way of isolating the essential information so that the legal principals can be applied. The idea is that the cognitive load of holding the information can be minimised so that the analytical apparatus can be put to work. The problem with ascribing to this the advantage that lawyers have in the legislature is that all professionals have this ability in their own domain but they do not have the same advantage that lawyers have in the legislature. Thus, it does not seem reasonable to assume that the way lawyers are taught to organise legal information is what gives them the advantage in the legislature.

In the next section I will continue with the analysis of the cognitive skills that lawyers have by looking at observations from empirical studies of the way lawyers reason.

\section{Section 7.6: Observations from Empirical Studies}


The empirical evidence is that there are cognitive characteristics that lawyers have to a greater extent than non-lawyers. These are a tendency to rely on counterfactual reasoning and a lack of probabilistic skills. Each of these could conceivably be of benefit to an aspiring $\mathrm{CM}$.

Lehman, Lempert and Nisbett (1988) looked at whether postgraduate training in law, psychology, medicine and chemistry has an influence on the ability to use different types of reasoning. The types of reasoning were statistical (e.g., the idea of regression to the mean in large groups), methodological (e.g., the ability to use the concepts such as control groups and self-selection to determine whether causal processes were at work), conditional (e.g., the ability to use the material conditional " $p$ if and only if $q$ " in a complex setting) and verbal (e.g. the ability to detect analogies and evaluate arguments) (Lehman Lempert and Nisbett 1988: 435). The procedure was to use cross sectional and longitudinal designs to determine whether there was a change in any of the reasoning skills as subjects were inculcated with the ways of thinking in their chosen discipline. Students' scores from each of the subject areas when they first began their studies were not significantly different except that law students had a slight advantage in verbal reasoning.

The results showed that, on tests of verbal reasoning, only medical students showed an increase in both the cross section and longitudinal studies. On tests of statistical and methodological reasoning, there were "dramatic" improvements over the three year period of psychology and medical students in both the cross sectional and longitudinal studies. There was no increase in statistical or methodological reasoning scores for chemistry students in either the cross sectional or the longitudinal studies. On 
tests of conditional reasoning, students in law, medicine and psychology increased their scores in the longitudinal but not the cross sectional study. Chemistry students did not improve in either the longitudinal or the cross sectional study. The conclusion to be drawn is that the probabilistic disciplines of medicine and psychology develop statistical reasoning while chemistry, being non-probabilistic and law being non-scientific, did not develop these skills. Furthermore, psychology, law and medicine all teach rule based systems in which conditionals are employed and thus these groups' conditional reasoning improved.

Thus, the major observation is that legal training is not associated with any benefits over and above those conferred to medical and psychology students in relation to verbal or conditional reasoning. However, there is a big difference in statistical reasoning. Legal training does not confer any training in the analysis of "variability or uncertainty in causal relations" and therefore does not confer the ability to apply the statistical or methodological rules of the probabilistic sciences.

In short, LTIs tend to have naïve notions of cause. They do, however, develop high level conditional reasoning skills over the course of their training but this does not set them apart from others because Psychology and medical students also develop conditional reasoning skills over the course of their training. As such the increase in conditional reasoning skills cannot be seen as a skill that sets lawyers apart. If we are looking for a difference between CMs and non-CMs, the clue to be derived from the above discussion is that lawyers are likely to lack probabilistic thinking skills. It seems to be incongruous that a lack of skill could be an advantage. However, I will explain this finding in subsequent sections. 
Amsel, Langer and Loutzenhiser (1991) were critical of the Lehman et al's (1988) conclusion that causal reasoning is not developed in legal training. They cite the fact that there is a large body of research in law on the nature of causality and in particular in the law of torts (Amsel et al 1991: 226). They argue that Lehman et al (1988) used a conception of cause that was more associated with social science training than general causal explanation and therefore did not tap into a general conception of cause. To address the issue using a more general conception of cause, Amsel et al (1991) looked at whether the training and experience of lawyers leads to them solving problems by using a different set of causal schemas in comparison to psychologists and "novices". The procedure was to see how lawyers, as compared with other groups, evaluated a statement by a protagonist that a series of events is causally related rather than coincidental (Amsel et al 1991: 237). In particular, they were asked to evaluate an explanation as to why a TV image became clear after the TV was kicked. There were three basic schemas examined: the mechanical, in which causal explanations are given in standard mechanical terms by pointing out physical chains of cause (such as the possibility that kicking the TV re-connected some wires); the covariance explanation in which causal explanations are couched in terms of the observation that particular types of causes are usually associated with events and can therefore be taken as causing an event in a given case (thus, kicking the TV usually clears the picture therefore the two are casually connected), and; counterfactual in which the explanation for a cause relies on the idea that had an event not preceded a subsequent event, the subsequent event would not have occurred (had the TV not been kicked the picture would have remained fuzzy). The idea under investigation was that there would be differences in the way 
psychologists, lawyers and "novices" (adult policemen and undergraduates - those untrained in law or social sciences) prefer to explain cause.

For all groups except the psychologists, mechanism was the most convincing evidence for cause. For psychologists, covariation was the most convincing explanation. For all groups, except lawyers, the counterfactual explanation was the least preferred explanation. Lawyers chose counterfactual explanations as often as they chose covariance explanations. In short, lawyers considered counterfactual explanations to be as acceptable as covariance explanations while the other groups gave very little support to counterfactual explanations. The authors explain that this is possibly related to exposure of lawyers to the "but-for" reasoning test used in legal causal reasoning (Amsel et al 1991: 236). This type of reasoning proceeds by positing causal efficacy to event $e$ in the circumstance that "but for" the occurrence of event $e$, the outcome would not have occurred.

\section{Summary of Section 7.6}

Drawing together the findings of the two studies we can see that there are good reasons for thinking that lawyers may be "different". Firstly, we can say that they do not tend to use statistical or methodological reasoning skills well. Lehman et al (1988) found that law students did not improve in the kinds of causal reasoning used in the sciences whereas psychology and medicine students did. Secondly, Amsel et al (1991) showed that although lawyers, as with other groups, used mechanistic reasoning more than any other method, their preference for counterfactual causal explanations was 
greater than that for other groups. In sum, training in law is associated with a preference for counterfactual causal explanations and seems not to be associated with any benefit in probabilistic thinking.

The question remains, how do these two cognitive habits assist individuals in becoming CMs? In the next section I will consider how each of these characteristics could conceivably be of benefit to an aspiring CM.

\section{Section 7.7: The Value of Skills Derived from Legal Training}

In the last section I reported on two ways of thinking that have been found to be peculiar to those with legal training. LTIs tend to be more prone than other groups to use counterfactual reasoning, and relatively unskilled in the use of probabilistic reasoning.

In this section I will explain how each of these is likely to be of use to a parliamentarian who wishes to become a CM.

\section{Counterfactual Reasoning}

The evidence is that lawyers tend to use counterfactual reasoning more than others. This can be useful because counterfactual reasoning has been found to stimulate the ability of the individual to come up with solutions that she might otherwise not have devised. 
Galinsky and Moskowitz (2000) found that generating counterfactual thinking can improve the performance of individuals in problem solving. The basic finding was that counterfactual thinking primes individuals to consider alternatives (Galinsky and Moskowitz 2000: 385). In this study, the conception of a counterfactual situation used was that of an event which "almost" didn't happen. The idea here is that counterfactual thinking is stimulated where some counterfactual event is proximate in that it "almost" happened. Missing an aeroplane by five minutes is more likely to stimulate ideas about "what might have been" than missing it by 6 hours. Thus, the counterfactual scenarios used in the study involved priming with a story of an event that "almost" happened. In particular, it consisted of an individual who changes seats at a concert and as a result wins a lottery, the prize for which is a trip to Hawaii. In the negative version the person with whom the individual swaps wins the trip. Thus, in the first case she "almost" loses the trip while in the second she "almost" wins. The control scenarios were both positive and negative but did not involve outcomes that almost did not occur. Instead, the events were very distal. For example, the change in seats involved a swap to the other side of the auditorium. Thus, the non-counterfactual scenarios involved situations that did not involve "almost" winning or losing.

After being primed with the counterfactual/ non-counterfactual negative/nonnegative primes, subjects were asked to complete the Duncker candle problem in which subjects are presented with a candle, matches and a box of thumbtacks and asked to attach the candle to a cardboard wall in such a way that the candle does not drip on the floor. The solution requires the subject to realise that the box can be emptied and stuck to the wall with thumbtacks and used as a shelf to hold the candle in place. Those 
participants who were primed with the both the negative and positive counterfactual solved the problem at a significantly $(\mathrm{p}<.001)$ higher rate than those who were primed with a non-counterfactual. Similar results were found for the time taken to complete the task. For those who completed the task, those who were primed with the counterfactual took significantly $(\mathrm{p}<.01)$ less time $($ Mean $=6.89$ minutes $)$ than those who were primed with a non-counterfactual (Mean $=9.65$ minutes). The authors point out that there is no logical connection between almost winning or losing trips to Hawaii due to relocating in an arena and finding an alternative function for a box (Galinsky and Moskowitz 2000: 393). They contend that reading the counterfactual scenario makes one aware of the outcome and an alternative and thus primes an individual to think of alternative uses for the thumbtack box.

In a second experiment the idea was to test whether the counterfactual thinking can hinder solving a particular type of problem. The problem here was a variation of the Wason card sorting test. Subjects were presented with the rule that travellers who wish to enter the country, as opposed to merely pass through in transit, need to have been inoculated against cholera. Each traveller has a health card. On one side of their health card their travelling status is revealed (Entering or Transit) and on the other is a statement of the inoculations the individual has had. The participant is presented with the health cards of four individuals. On the desk the participant can see the following information from the health cards of four individuals:

A: $\quad$ Transit 

B: $\quad$ Entering
C: Innoculations: Cholera and Hepatitis
D: Innoculations: Typhoid

On the other side of the A and B cards is the inoculation status and on the other side of the $\mathrm{C}$ and $\mathrm{D}$ cards is the travel status. The question is what are the cards that need to be turned over to check that each of these individuals, A, B, C and D, has the required permission? The first card is irrelevant because the individual is not trying to enter. The second card must be turned over to check if the individual has been inoculated against cholera. The third card is irrelevant because whether they are entering or not they have permission to enter because they have been inoculated against cholera. The fourth needs to be turned over to check whether they wish to enter the country. Thus, only the second and fourth cards need to be turned over.

The point about this test is that, unlike the Duncker test a counterfactual scenario is detrimental. There are two cards that need to be examined and that is the only solution. Thus, considering alternatives may actually confuse individuals. This is, in fact, what was found: priming with a counterfactual scenario (identical to that in experiment 1 described above) significantly reduced the ability of participants to solve the card test ( $\mathrm{p}<.01)$ (Galinsky and Moskowitz 2000: 397).

A third experiment tested the idea that exposure to counterfactuals would reduce confirmation bias in a trait hypothesis-testing situation. The starting point here is the 
observation that when subjects are told an individual has a particular personality trait, upon being asked to determine if this is in fact the case, subjects tend to look for evidence to confirm the hypothesis rather than disconfirm it and to neglect evidence that disconfirms it (Snyder and Swann 1978; Pyszczynski and Greenberg 1987, cited in Galinsky and Moskowitz 200: 398). This is because subjects tend to use a few simple heuristics to arrive at conclusions (Trope and Liberman 1996: 242, Sherman and Corty 1984, cited in Galinsky and Moskowitz 2000: 398). Exposing subjects to counterfactuals should, according to the theory, open individuals up to alternative possibilities and therefore encourage them to entertain a disconfirming hypothesis. The priming materials for this experiment were as for the first two experiments. Subjects were then told an individual had been tested and was an extrovert. They were shown a description of an extrovert and then asked to select a 12 interview questions from a selection of 25 to determine whether the individual was an extrovert. Ten of the questions were hypothesis confirming, ten were hypothesis disconfirming and five were indeterminate. As expected, those primed with the counterfactual scenario asked significantly $(\mathrm{p}<.05)$ more introvert (hypothesis disconfirming) questions and significantly $(\mathrm{p}<.04)$ fewer extrovert (hypothesis confirming) questions than those primed with the non-counterfactual scenario. No significant differences were found with the indeterminate questions. Thus, those who were primed with the counterfactual scenario were more likely to consider alternatives instead of falling foul of confirmation bias.

The experiments of Galinski and Moskowitz (2000) show that there is good evidence that counterfactual thinking can affect the way individuals process 
information. My contention here is that LTIs, because they have a higher level of baseline propensity to use counterfactual reasoning, will be like the individuals who are primed to think counterfactually. That is, they may have a more permanently primed propensity to use counterfactual thinking due to their training. This tendency may, according to the Galinsky and Moskowitz (2000), result in the generation of alternatives which those who do not engage in counterfactual thinking, may not be willing or able to countenance. In the political environment the range of problems an individual is called upon to consider is great. From the practical issue of electoral success to issues of international importance, a CM is called upon to confront a wide variety of problems. It is conceivable that an individual who is able to consider a larger range of options will be at an advantage and will be seen by those who are involved in the selection process to have the ability to generate potential solutions to problems.

However, the Gallinsky and Moskowitz (2000) study also found that on problems associated with the strict application of rules, such as the Wason test, as opposed to open ended problems such as the Duncker test, those primed with counterfactual thinking are likely to do worse than those who are not so primed. Thus, there is a potential disbenefit associated with counterfactual thinking. This implies that those who engage in counterfactual thinking will have a disadvantage on tasks involving closed problems. The Galinsky and Moskowitz (2000) study showed that there was a disbenefit of counterfactual thinking in the conditional permission task. The reason for this is that alternatives are not possible and are likely to divert subjects from the correct response. We might expect, therefore, that lawyers would be diverted from the correct procedure when dealing with these types of closed logical problems and would be 
therefore less effective at them. Thus, lawyers, with their higher than average baseline propensity to use counterfactual thinking should also have a disadvantage in relation to those who have a lower propensity to use counterfactual reasoning, such as nonLawyers.

One way of answering this objection is to point out that legal training, as well as medical and psychology training, involves training students to look at closed logical problems in a particular way. The Amsel et al (1991) study showed that all groups except chemistry students improved their conditional reasoning skills, and the conditional permission/obligation type of scenario is exactly the type of activity that lawyers excel in. What this suggests is that where the situation calls for closed logical thinking, notwithstanding that they may be professionally primed to think counterfactually, lawyers will not be diverted from strictly logical way of thinking because their ability to solve closed rule based problems is a separate skill which they learn and master. In other words, lawyers have the best of both worlds in that, due to their increased proclivity to entertain counterfactual reasoning, they are able to generate alternatives in the types of scenario in which this is beneficial, as shown in experiments 1 and 3 of the Galinsky and Moscowitz (2000) study, but are not disadvantaged by this proclivity when solving logical problems such as that in experiment 2 because, like medical and psychology students, they are trained to recognise these situations and apply the appropriate reasoning.

In sum, there is a plausible explanation for the benefit associated with counterfactual reasoning, particularly in the case of lawyers. Counterfactual reasoning leads to the generation of more ideas in an open ended problem situation and therefore 
is associated with success in such problems. However, in closed rule-based problems counterfactual reasoning is generally associated with poorer performance. Lawyers, by their training, have a higher propensity to engage in counterfactual reasoning and therefore may be more likely to generate novel solutions than non-legally trained parliamentarians. However, they may be less prone to distraction in closed rule-based problems due to their specific training in these types of problems.

\section{Lack of Probabilistic Reasoning Skill}

We usually consider the possession of any skill to be a positive attribute. However, in certain contexts it is actually a disadvantage to have certain skills, or at least, to reveal them if you do have them. I would like to make the case in this section for the idea that a potential CM who does not demonstrate probabilistic reasoning skills is in a better position to rise through the ranks than an individual who does. The reason for this is that probabilistic thinking tends not to provide the kind of thinking that political leaders, the media, parliamentary colleagues or the electorate prefer. It is my contention that leaders tend to prefer ideas that are clear cut and easily sold. The probabilistic reasoning used by scientists used to explain causal processes is quite different from the legal notions of cause. However, I will attempt to demonstrate that this works to the advantage of parliamentarians aspiring to become CMs because it creates a vision of certainty. Scientific thinking is better described as reducing uncertainty than creating certainty and political leaders and the electorate require the impression of certainty. Therefore, individuals who can provide this will be favoured. 
The starting point for this analysis is the division between the scientific concept of cause and the lawyer's. The modern scientific notion of causation is based on inference. Where two phenomena are seen to be connected a causal hypothesis for this connection is posited. This hypothesis is subject to falsification and as more sophisticated experimental methods become available the posited hypothesis is put under further scrutiny (Culhane 1997: 188). This process is therefore based on uncertainty in that hypotheses are never considered certain but simply less uncertain than their predecessors.

Let us now consider the judicial notion of cause. Basically, the legal demand is for the explanation for an event. The legal system requires a statement of what caused certain events with near certainty (Berger and Solan, 2008: 851). In many cases a purely mechanistic explanation is quite appropriate because the events are closely related. Thus, the but-for test would seem to be an ideal way of explaining causation in a simple case of assault where an injury would not have occurred "but for" the contact by the assailant. However, the judicial procedure is to attempt to apply these types of reasoning to complex situations such as toxic torts (Culhane 1997: 190). Here, the causal chains are notoriously difficult to determine. Nevertheless, the legal system requires a method of determining whether given events produced given outcomes. The use of simplified definitions of cause are therefore an essential part of the legal process.

Exemplifying this phenomenon is the situation in Australia in which the phrase "common sense causation" has been used as a basis for legal decision making (Stapleton 2010: 468). This has been described in the following terms: “...in some cases what the court means by this slippery term is simply the permission to infer facts from 
common experience" (Stapleton 2010: 469). In short, phenomena that are actually the result of complex causal chains are simplified in legal reasoning so that the legal question as to whether one event caused another can be given a straightforward answer. The emphasis is on whether or not the facts can be proved. This is very much at odds with the scientific notion of cause.

Let us now consider a leader who wishes to select a parliamentarian to take up the role of $\mathrm{CM}$ in a given portfolio. The new $\mathrm{CM}$ will need to be able to quickly and efficiently explain reasons for policy decisions to cabinet colleagues, the media, the public, the electorate and to the leader herself. What kinds of explanations do these stakeholders require? The answer seems to be that they require answers that convey a notion of certainty that inferential explanation cannot provide. Moreover, the appearance of uncertainty in the portrayal of the facts by the CM will undermine the credibility of the CM (and their government) in the eyes of the public. Oreskes and Conway (2010) point out how tobacco industry executives used this strategy to undermine the claims of scientists that there was a link between smoking and lung cancer:

Doubt is crucial to science - in the version we call curiosity or healthy scepticism, it drives science forward - but it also makes science vulnerable to misrepresentation, because it is easy to take uncertainties out of context and create the impression that everything is unresolved. This was the tobacco industry's key insight: that you could use normal scientific uncertainty to undermine the status of actual scientific knowledge....'Doubt is 
our product," ran the infamous memo written by one tobacco industry executive in 1969, "since it is the best means of competing with the "body of fact" that exists in the minds of the general public" (Oreskes and Conway 2010: 34).

A CM who presents information based on inferential reasoning opens himself up to exactly the same kind of undermining that the tobacco industry undertook. Interest groups, political opponents and journalists can use the uncertainty inherent in an inferential exposition to attack both the speaker and the speaker's message if the speaker couches the debate in inferential terms. Thus, the kind of individual who communicates using such ideas will not be as effective in cabinet as an individual who is trained to give the appearance of certainty.

This conclusion is supported by the observations on the effects of different types of education. There is no association between having a scientific background and being a CM. The results for t-tests for differences in group means for those with science engineering or surveying degrees $(n=8)$, economics degrees $(n=24)$, or medical degrees $(n=5)$ show that there is no association between having an education that fosters inferential thinking and being a CM. The same result occurs if we add these categories together to get a bigger sample size $(n=37)$. What this indicates is that those who think inferentially are no more likely to become CMs than any other parliamentarian. However, those who have law degrees $($ mean $=.48)$ are significantly $(\mathrm{p}<.001)$ more 
likely to be CMs than non CMs $($ mean $=.12) .{ }^{8}$ The same results hold for another group that tends to be non-probabilistically oriented - the arts qualified individuals. For such individuals the mean for the possession of an arts qualification amongst CMs (.53) is significantly $(\mathrm{p}<.01)$ higher than that for non-CMs $($ mean $=.29)$.

We can see that a legal training actively encourages individuals to generate simplified ideas of causation and, by extension, scientific explanation. This observation coheres well with the observation made above in relation to the Lehman et al (1988) study which found that law students did not improve in their methodological and statistical reasoning skills. Thus, it is a substantial benefit for an aspiring CM to be legally trained because he is already primed for the kind of thinking he is likely to be called upon to produce. There is little need to subvert a desire to consider nuances of probabilistic explanation if your training has already reduced this proclivity.

Thus, the LTI's lack of probabilistic reasoning skills can be seen as a positive benefit in the accession to cabinet. The kind of reasoning required in explaining policy to the media, public, journalists, the leader of your party and cabinet colleagues is already inculcated into the mindset of the LTI.

\section{Summary of Section 7.7}

In this section I have considered how specific skills that are imparted to the legally trained may be of use to the aspiring CM. These are a proclivity to engage in

\footnotetext{
${ }^{8}$ These results differ slightly from the results reported in the discussion of the modelling in Chapter 6. The reason for this is that the results in Chapter 6 were based on the training sample $(n=107)$ while the results here are based on the full sample of 134).
} 
counterfactual reasoning and a lack of probabilistic reasoning skills. I considered how these might be of use for a parliamentarian who wishes to become a CM. The proclivity for using counterfactual reasoning is beneficial because it encourages individuals to consider more options in open-ended problems than they would otherwise consider and, in the case of lawyers and others who experience improvements in their conditional reasoning skills, does not distract them from the correct solution in closed, rule-based problems. Finally, the lack of probabilistic reasoning skills is of benefit because it reduces the element of uncertainty in expositions. A parliamentarian who phrases things in terms of certainty is less likely to be undermined by opponents who can exploit the uncertainty inherent in the exposition of those using more probabilistic explanations.

\section{Summary of Chapter 7}

In this chapter I have addressed the issue of how legal training could be of benefit to parliamentarians who aspire to cabinet appointment. I started the chapter by pointing out that statistically there is a significant advantage for an individual who wants to become a $\mathrm{CM}$ if she has a legal education. I followed this observation by noting that there is a perception in the media that there is a bias towards LTIs in cabinet. The media debate gave a suggestion that similarity bias may be responsible for this to some extent but then went on to point out that there are more practical benefits for a parliamentarian who has a legal education. I then addressed the issue of similarity bias. I found that there was some evidence of similarity bias in the case of Howard in that he had a higher tendency to appoint LTIs than any other appointer. However, there was no statistical evidence that legally trained appointers tend to appoint legally trained CMs. 
Given the benefit to the parliamentarian aspiring to a $\mathrm{CM}$ appointment of legal education I looked at some of the research that has come from the US on this issue. The research shows that there is a significant advantage in having a legal education for a legislator who aspires to high office. My reading of the research led me to conclude that this is due to the technical expertise of lawyers which is of benefit in drafting legislation and because others defer to them in this process. I followed this with an attempt to isolate a particular way of thinking associated with legal reasoning. I looked at the possibility that the skill learnt via the case report - "chunking" - might give lawyers an advantage in parliament. I concluded that many professionals have a way of thinking that is akin to this and therefore this is unlikely to be the explanation for the lawyer's advantage. The next step was to look at the empirical research and it is here that a good explanation for the benefit of legal training becomes clear. I found that counterfactual reasoning and a lack of probabilistic reasoning skills are cognitive habits imparted to the legally trained. I then explained how these can all be useful for a parliamentarian to high office.

As we have seen, there is recognition in both the media and academic debate of the greater likelihood of the legally trained reaching high political office in comparison with their non-legally trained colleagues. Much of the debate has focused on the practical benefits of having a knowledge of the law for an individual who wants to have significant input into creating law. There has been empirical research on the differences in the way lawyers think, however these ideas have not been applied to the issue of why legally trained legislators have an advantage. In this chapter I have addressed this issue in detail and have developed a plausible explanation as to why the legally trained should 
have an advantage in the legislature. The cognitive skills and habits imparted by legal training can be seen to be beneficial for an individual working in the parliamentary environment. This is because parliament requires a particular way of thinking which allows for some creative input via the generation of novel ideas, but requires the impression of certainty and therefore downplays probabilistic reasoning. I have shown that these ways of thinking are imparted by legal education. Certainly there are other factors at play such as that others defer to the legally trained on legislative matters and this gives the legally trained a "leader-like" aura. However, it seems that the habits of mind associated with legal training are likely to be the reason why they have an advantage in the legislature. 


\section{Chapter 8: Parlage and the Dynamics of Ambition}

\section{Section 8.1: Introduction}

The variable Parlage represents the age of parliamentarians at entry to parliament. It appears in four of the committee models and is negatively associated with CM. It is significant at the $p<.01$ level in two of the models of at the $p<.05$ level in the remaining two. This is good evidence that the younger an individual is when they enter parliament the more likely they are to be appointed to cabinet in their subsequent career. This is consistent with the findings of several others in other legislatures. Buck (1963) pointed out in an aptly titled article, The Early Start Toward Cabinet 1918-55, that in the UK House of commons, "[m]inisterial aspirants seize an early opportunity to begin their advance in the official hierarchy, and in most cases they have also begun their career in the Commons at a relatively early age" (Buck 1963: 629). Schlesinger (1966: 176) noted that "[t]he younger a man is when he enters politics, the greater the range of his ambitions and the likelihood of his developing a career commitment to politics". In this chapter I will show that there is good evidence that it is not age per se that is the important factor but ambition. I will examine the idea that ambition is the important factor and Parlage taps into ambition. Ambitious individuals both enter parliament at an earlier age and are more assiduous in pursuing opportunities as they arise. This, I contend, is part of the reason for the negative association between Parlage and CM. I also consider another phenomenon that links age and ambition. I look at the idea that the desire to progress to higher levels of office, "progressive ambition", declines at a certain age. Essentially, individuals who have not achieved their goals by the average age at 
which such goals are achieved tend to become less assiduous in pursuing promotion. I support this contention by surveying the literature to look for evidence that ambition declines with age whereas few of the other qualities associated with age decline sufficiently to explain the fall in promotional prospects. I conclude that the best explanation for this is that there is a fall in the ambition of individuals over time and it is this subjective state of mind that results in the reduction of chances of future promotion. I will provide a good example of this from the Australian political literature later in the chapter.

\section{Section 8.2: Overview of Age at Entry to Parliament}

Parlage is the age at entry to parliament. The descriptive data for Parlage is presented in Table 8.1. The average age at entry of CMs for the model sample $(n=68)$ is 38 and the standard deviation is 6 . For non-CMs $(n=66)$, the average is 43 with a standard deviation of 7 . Thus, CMs were on average five years younger than non-CMs on entry to parliament.

Table 8.1: Descriptive Data for Parlage - Age at Entry To Parliament

\begin{tabular}{|lccccc|}
\hline & Average & Stdev & Min & Max & N \\
CMs & 38 & 6 & 27 & 54 & 68 \\
Non-CMs & 43 & 7 & 28 & 58 & 66 \\
Total Sample & 40 & 7 & 27 & 58 & 134 \\
\hline
\end{tabular}

\section{Summary of Section 8.2}


In this section I have provided a brief overview of Parlage. I have presented descriptive data and pointed out that Parlage is negatively associated with $\mathrm{CM}$

In the next section I will survey some of the literature on the relationship between age and senior appointment in other legislatures. It will become apparent that a negative relationship between age and accession to high political office is well established in the literature.

\section{Section 8.3: Age and Leadership in General}

As mentioned earlier, Buck (1963) points out that those who enter parliament at an earlier age are more likely to become CMs than those who entered at a later age. He puts this down to ambition. King (1981) also notes that those who enter the UK parliament at an earlier age are more likely to become cabinet ministers. His explanation is that there is a passion and drive in the "career politician" which results in both a desire to enter politics at an earlier age and greater ambition for high political office. Such individuals are "...eager for office and promotion and, if they are offered them, will accept with alacrity" (King 1981: 282). In this section I would like to establish two propositions. The first is that the literature in general supports a negative association between age and the probability of promotion. The second is that a number of standard reasons given for this association are not plausible. That is, there are no declines in ability as a person ages that map the decline in the likelihood of appointment. I will therefore conclude that several explanations for the decline in the probability of promotion are not plausible. 


\section{Age and the Probability of Promotion}

There are two types of studies that look at the relationship between age and the likelihood of promotion. The first is prospective. These look at the relationship between the age at entry to parliament and the likelihood of achieving high office in the future. The findings of these studies are very similar to the finding that Parlage is negatively associated with CM. Two studies that use this prospective approach are Buck (1963) and King (1981). These studies find a negative association between the age at entry and the probability of future accession to high office.

The second set of models is based on cross sectional analysis such as Kam et al (2010) and O'Malley (2006). Kam et al (2010) in their model of cabinet appointment show that there is a significant $(\mathrm{p}<.01)$ negative association between age and the probability of being appointed to cabinet. Each additional year of age decreases the probability of appointment by 6\%. O’Malley (2006) used a cross sectional approach and found a negative association between age and cabinet appointment but this association is not significant. This is explained by O'Malley by pointing out that in the small pool of the Irish parliament, experience is more important than age because in the small pool and with a low level of parliamentary turnover, appointments tend to be made on the basis of how well known an individual is (O'Malley 2006: 331). Thus, in the "small pool" situation of the Irish parliament experience in parliament is more important than age. In the judicial sphere, Blaines i Vidal and Leaver (2010) found that the relationship between age and promotion to higher office in the English judiciary was a negative quadratic with a peak at the age of 50 (Blaines i Vidal and Leaver 2010: 586). Finally, 
it should be recalled that the relationship between age and the probability of being a CM in the LNPC RIF model in Chapter 3 was a negative quadratic with a peak at the age of 47.

The general conclusion from both the prospective and cross sectional literature is that there is a negative association between age and promotion. Where quadratic terms are included the form of the relationship is a negative quadratic. In the one case where no association was found between age and CM (O'Malley 2006) there were institutional factors that explained this. There are no studies that show a positive association between age and promotion to senior political office.

It is the contention of this chapter that ambition is the reason for the negative association between age and accession to high office. However, before embarking on an analysis of ambition it is necessary to consider other alternatives. There is a stream of the literature that examines the relationship between age and leadership and I would like to consider a number of these explanations. I will show that the explanations are implausible in the current context.

\section{Age and Leadership Ability}

There is some empirical evidence that the effectiveness of a leader peaks in the mid-40s. Simonton (1984) conducted an historiometric analysis of 25 absolute monarchs between the middle ages and the Napoleonic era. The idea here was that, because the monarchs were absolute, any beneficial or detrimental effects of their leadership style would be directly reflected in the condition of their kingdoms. If there are effects of age on the ability to govern then this should be measurable by tracking the state of the kingdom as the monarch ages. Simonton (1984) found that the older a 
leader, the less likely a country is to invade another and the less likely they are to gain territory if they do invade. Furthermore, the older the monarch, the less likely the army is to be victorious in any engagement. There are also changes in diplomatic relationships as a monarch ages: the number of international treaties declines as the age of the monarch increases. There are more domestic disturbances in the monarch's country amongst his people as she ages. Militarily, the optimum age for success in battle is a negative quadratic with a peak at 42 . Here, success includes maximising territorial gains as well as a minimising loss of territory via negotiated settlements. In sum, on many measures of leadership ability there is a negative association with age.

In a similar analysis of British monarchs from 1066 to 1811, Simonton (1998) calculated the effects of age and "experience" - the number of years on the throne - on 17 criteria relating to the condition of the nation. Age was found to have a negative quadratic association with: i) civil disturbances initiated by the aristocracy: and ii) volume of legislation and number of reforms. Thus, there was an inverted $u$ function and an optimum age for each of these two activities. For aristocratic disturbances, the peak age was 43, indicating that legislation and reforms likely to upset entrenched interests begin to fall after this age (Simonton 1998: 315). The peak ages for legislation and reforms were 44.8 years and 42.3 years respectively (Simonton 1998: 316).

Thus, the empirical literature on political leadership and age suggests that the important turning point occurs in the fifth decade. The basic findings are that actual leader effectiveness tends to decline at some point during the 40s. This is not to suggest that a leader cannot contribute for some time after this age. However, there is a steady decline on a number of measures of leadership. 
How plausible is this as an explanation for the negative association found between age and future promotion in the prospective studies? To examine this we have to consider a cohort of individuals who, after acquiring the required experience in parliament, are assessed on their leadership ability. Those who are older than the average age at which selection decisions are made are likely to be assessed as having passed their peak. Using the data from the modelling sample it can be shown that this is an implausible scenario. Let us consider that the average age at which CMs arrive in parliament is 38 while the average age at which non-CMs arrive in parliament is 43 . Thus, there is an average difference of 5 years. Let us now consider the average age at which CMs are appointed. Table 8.2 shows that the average age at which LNPC CMs arrived in parliament was 38.5 years and these parliamentarians were appointed to cabinet, nine years later at the age of 48. The figures for the ALP CMs are not statistically significantly different. They tend to arrive in parliament at the age of 37.6 and are, on average, appointed to cabinet nine years later at the age of 46.3

Table 8.2: Age at Entry (Parlage) and Age at Appointment for CMs

\begin{tabular}{|lccccc|}
\hline & Mean & Stdev & Min & Max & $\mathrm{n}$ \\
LNPC: & & & & & \\
Age at Entry (Parlage) & 38.5 & 7.3 & 27.3 & 53.5 & 34 \\
Age at Appointment & 48.0 & 6.6 & 38.3 & 59.5 & 34 \\
ALP: & & & & & \\
Age at Entry (Parlage) & 37.6 & 5.1 & 27.7 & 53.5 & 34 \\
Age at Appointment & 46.3 & 5.9 & 36.0 & 56.8 & 34 \\
\hline
\end{tabular}


Let us see how the "leadership decline" theory fits with these observations. At the time that the CMs are being appointed to cabinet, their non-CM colleagues are approximately 5 years older than they are. Thus, on average they would be approximately 51-2. The leadership decline theory holds that there is a peak in the leadership ability sometime in the 40s. Theoretically, therefore, the leadership decline theory fits with this scenario. Of those who have done on average a 9 year "apprenticeship", those who are 51-2 will have begun to decline in leadership ability while their colleagues who are 5 years youngers will not.

The first problem with this scenario is that the decline in leadership in the Simonton $(1984 ; 1998)$ studies cited was noted in active leaders. Potential CMs have not been engaged in actual leadership roles so they cannot be assessed on their actual ability to govern. Thus, the idea that potential CMs are being assessed in terms of whether they have peaked in terms of leadership ability seems unlikely. A second problem is that the leadership decline theory simply states that there is a peak in leadership ability but there is no suggestion that the decline is precipitous. In order for the leadership decline theory to apply the selectorate needs to be able to discern subtle differences in the leadership potential of the pool of potential CMs from the pool of parliamentarians and to be able to discern that those at around the age of 47 have not suffered a decline in their leadership potential while those at the age of 51-2 have. This is implausible as the differences would have to be discernible between individuals who do not differ greatly in age. The negative quadratics in the Simonton (1984: 98) studies cited above were derived by looking at the careers of monarch over their entire lives. The idea that it is possible to discern significant differences between individuals who are not greatly dispersed around the peak is unlikely. 
We can conclude that the leadership decline theory does not explain the negative association between age and future accession to cabinet.

\section{Survival Value of Information}

Evolutionary explanations relate leadership to survival value. The idea here is that information vital for survival will confer leadership status on individuals. As it is older individuals with more experience who will hold this information leadership status comes to be associated with age (van Vugt, Johnson, Kaiser and O'Gorman 2008, p276). This explanation supports a generally positive association between leadership and age. Reynolds et al (2006) found using agent based modelling of hunter gatherer societies that the "fixed order" feeding rule in which the older more experienced members of the group were fed first was the most stable survival strategy for the group. The idea here is that the information held by the older individuals is of value and preserving it helps preserve the group.

As an explanation this certainly makes sense. However it does not explain why there should be a negative association between age and CM. The evidence is that knowledge and experience continue to grow well into middle age and do not decline until much later. Crystalised intelligence tends to be stable until old age (Horne and Cattel 1967; Schaie 1983; Roring and Charness 2007). If holding information has survival value and this is the explanation for the relationship between age and leadership we would expect the prospects of promotion to track the ongoing accumulation of knowledge. However, this does not occur. If it did then we would expect that age would be positively associated with CM. This would occur throughout the parliamentary career so that younger parliamentarians would be ranked lower in 
terms of wisdom and knowledge on the basis of their age. After a certain amount of experience had been acquired (from Table 8.2 it would seem that the "required" experience is 9 years) those who were older would be seen as the most appropriate CMs. In fact, we see the reverse. Furthermore, in none of the studies on cabinet appointment cited above is age positively associated with cabinet appointment. Kam et al (2010) show a significant $(\mathrm{p}<.01)$ negative association between cabinet appointment and age, an association we would not see if there were an information-based advantage of age. Furthermore, the LNPC RIF models developed in Chapter 3 showed a negative quadratic association between age and being a $\mathrm{CM}$ with a peak at 47 , well before the declines associated with age-related cognitive decline would be manifested. Thus, we would be unwise to consider the age-related accumulation of knowledge to be associated with the political appointment dynamics.

\section{Testosterone}

Another strand of the literature links age and leadership via variations in testosterone levels. Both men and women have higher levels of testosterone at younger ages and this may have an influence on behaviour which is noted by selectors who may reward aggressive moves to rise up the political ladder. As an individual's behaviour changes over time due to lowered levels of testosterone selectors may be less willing to award promotions due to the individuals lowered ambition. Horowitz et al (2005) used leader's age as a proxy for testosterone levels in a study of age and the initiation of military conflict. One of the hypotheses was that younger men would be more likely to initiate hostilities than older men. Their findings were that the reverse was the case with older male leaders more likely to initiate hostilities than younger men. 
A related testosterone-based argument is that younger individuals may be more willing to attack an older individual's position due to their perception that the older individual's aggression and risk-taking propensity is lower than their own. Bak and Palmer (2010) found support for this in that they found older rather than younger US presidents were more likely to be in office at the time of a targeted military attack on the US.

Applying this explanation to the current problem we can imagine that a group of younger individuals may be more likely to offer themselves as candidates for cabinet positions if they perceive that the incumbents are significantly older than they are. Younger individuals may be less likely to defer to older individuals on the basis of seniority or age. The effect of this would be that on average the pool of potential replacements is always younger than the pool of incumbents.

The main problem with explanations based on testosterone is that testosterone levels fall over the course of life with a peak at 15-22 (Ellison et al 2002). Thus, it is difficult to see how a difference in the age of non-CMs as opposed to CMs of five years could account for the differences in promotional prospects at midlife when both groups' testosterone levels have fallen significantly. Like the leadership decline theory the testosterone explanation seems to fit with the data but the actual size of the effect is likely to be very small.

\section{General Declines Associated with Age}

There is a strand of literature that deals with the general decline in the physical and cognitive performance of individuals in middle age. However, the fall in performance tends to be gradual over many years with many declines beginning in the 
early thirties. As mentioned above levels of testosterone peak in the mid to late teens. One other factor that declines is "fluid" intelligence - general reasoning ability including the ability to take in and make sense of novel information (Horne 1978; Schaie 1983; Roring and Charness 2007). Fluid intelligence peaks in the late teens early 20s. It is possible that the decline in these abilities may be what is responsible for the fall in leadership ability and performance. The problem here is that the decline in cognitive abilities is far slower than the decline in the prospects of promotion. The decline in cognitive abilities takes place over decades and it is unlikely that a decline in cognitive abilities of a 47 year old as opposed to a 52 year old would be discernible. Thus, it seems unlikely that the change in cognitive abilities could be responsible for the advantage that an individual has who arrives in parliament earlier than their older colleagues.

\section{Summary of Section 8.3}

In this section I have given an overview of the literature on the relationship between age and promotion to high office. It has become clear that most studies find a negative association between age and senior appointment while one study, O'Malley (2006) finds a non-statistically significant negative association. Where there is an explanation for the negative association it is couched in terms of ambition as in Buck (1963), King (1981) and Schlesinger (1966). I then examined some possible alternative reasons for this negative association between age and the prospects for promotion. I looked at arguments based on changes in general leadership ability as age increases, information changes associated with increased age, changes in testosterone in later life and general cognitive declines associated with age. None of these provided plausible 
explanations for the general negative association between age and promotion noted in the literature and in the Australian federal data.

In the sections that follow I will consider the case that ambition is the driving force that affects the probability of promotion and the reason that age is associated with promotional prospects is that age is associated with ambition.

\section{Section 8.4: Ambition}

In this section I will identify two respects in which age and ambition are likely to be related. The first is associated with Parlage in that it relates the baseline level of ambition to the age at which a parliamentarian enters parliament. The second is related to changes in ambition over time. This is a more contentious discussion because my evidence for its presence in the Australian context is based on tangential data. However, these two effects demonstrate that there is a clear case for saying that age and ambition are related.

I will begin the section with a discussion of ambition in general. I will then point out that there is good evidence from the literature that age and ambition are negatively associated, and I will show that this can explain why age and political promotion are negatively associated.

\section{Definitions of Ambition}

The idea that ambition itself could play an important part in the career of a legislator was extensively discussed by Schlesinger (1966) who identified three types of ambition: discrete, static and progressive. Discrete ambition is where the legislator has a specific goal or office to achieve and when this is achieved the legislator is content to 
voluntarily leave office. Static ambition is where the legislator is content to remain in the current office. Progressive ambition is where the legislator has a desire to seek higher office. Two other types of ambition are generally referred to in the literature. Fox and Lawless $(2004 ; 2005)$ refer to "nascent ambition" as the ambition of an individual to one day enter a political contest. They use the term "expressed ambition" to describe the state of the individual who has actually entered into a political race. One form of ambition that has not been extensively examined in the literature is intrainstitutional ambition (Herrick and Moore 1993). This is the desire to reach higher office in the one institution. The other five types of ambition usually refer to ambition to reach office in a forum of which the individual is not yet a member. Progressive ambition, for example, usually refers to the ambition of a state member to enter the federal arena. Intra institutional ambition refers to the desire to reach higher office in the one institution. Thus, a backbencher who desires to become a CM exhibits intrainstitutional ambition. It is a matter of definition as to whether this could also be described as progressive ambition.

As well as trying to identify different types of ambition, those who have looked at the concept of ambition acknowledge that ambition can change over the course of a career and can differ between individuals. Schlesinger, for example, pointed out that "[a]n ambition theory need not assume that office goals are constant in their intensity and direction for the same individual or for different individuals. As a man does or does not progress in his career the possibilities change, and if he is reasonable, so will his ambitions" (Schlesinger 1966, 9). 


\section{Empirical Measures of Ambition}

Buck (1963), King (1991) and Schelisinger (1966) emphasise the importance of age in relation to ambition. In these accounts, age at entry to parliament is a proxy for ambition. The idea here is that the ambitious are 1) more likely to enter parliament at an early age and 2) are more likely to "seize" opportunities as they arise. Thus, age at the time of entry to parliament is a good way of capturing ambitiousness without needing a direct measure of ambition.

The factor that is said to drive both the desire to enter politics early and the eventual accession to high office is ambition. This is a plausible account. However, it would be useful if we had some empirical evidence that ambition was in fact related to the early entry to parliament and the desire to seek higher office. Fortunately there is such evidence. Fox and Lawless (2005) undertook a study of "nascent" political ambition using data from the Citizen Political Ambition study (Fox and Lawless 2005: 647). The idea here is that nascent political ambition gives rise to "expressive" political ambition, which is the actual running as a candidate (Fox and Lawless 2005: 647). The methodology involved drawing a national sample of 6800 individuals from the areas that supply the vast majority of political candidates: law, business, education and political/community activism. Sample design intended to redress the gender imbalance in these professions resulted in a final sample of 3765 (Fox and Lawless 2004: 267). Respondents were given a questionnaire designed to capture details of sociodemographic backgrounds, family arrangements, political outlook and experience and their perceptions of, and intentions to, run for office. One of the findings from the study was that age was significantly $(\mathrm{p}<.01)$ negatively associated with the ambition to run for 
any office at all such as local, school board, council, state or federal. Age was also significantly negatively associated with the ambition to run for higher office such as federal.

Other studies in different settings find essentially the same phenomenon. Gaddie (2004), found that among office-holding national political convention delegates, those who were younger were more likely to express a desire to achieve higher office than those who were over 55 (Gaddie 2004, cited in Fox and Lawless 2005: 647). Gallagher (2009) found of a negative association between political ambition in line with her initial hypothesis. In her words, she “...[e]xpect[ed] that younger individuals who are perhaps more willing to endure the rigors of politics and who have less time invested in a particular career path will prove to be more ambitious than older individuals who are further advanced in their careers" (Gallagher 2009: 8).

The importance of the studies that find a negative association between age and ambition is that it strengthens the idea that age can be used to tap into ambition. In the absence of a direct measure of ambition it can be said that age is a good approximation.

Thus, it is clear that the interpretation of Parlage as being related to ambition seems justified in the light of the literature. The literature that examines the negative relationship between the age of entry to parliament and prospective success (Buck 1963; Schelisinger 1966; King 1981) imputes a higher degree of ambitiousness to younger entrants. In this respect age is being used as a proxy for ambition. I am essentially making a similar contention in that I am contending that Parlage is a proxy for ambition. The studies that examine ambition directly and find a negative association between ambition and age (Fox and Lawless 2005; Gaddie 2004; Gallagher 2009) show that 
using age as a proxy for ambition is empirically supportable. In short, interpreting Parlage as a way of tapping into ambition is a justifiable strategy.

\section{Changes in Ambition}

There is evidence that as age increases ambition declines. Schlesinger (1966) argues that ambition and opportunity are inter-related and both decline as a politician ages (Schlesinger 1966, cited in Hain 1974: 642). Hain (1974) undertook a study of legislators for the states of California, New Jersey, Ohio, and Tennessee and found evidence that both ambition and opportunity decline as a legislator approaches the age of 50. Using data from interviews of $94 \%$ of the incumbents, Hain found that the mean age of those who had a desire to reach a higher position was 44.3 years while those who did not aspire to a higher position were aged on average 54.1 years (Hain 1974: 266). Thus, there was a decrease in ambition as age increased. Furthermore, there was no influence of experience. That is, prior legislative experience was not related to the change in ambition indicating that the important factor was the relationship between age and ambition. Following up in the years after the initial interviews, it was found, as expected, that the actual rates of advancement followed this pattern. The mean age of legislators initially interviewed who subsequently advanced was 43.3 at the time of the interview while the mean age of those who did not advance was 50.6 years (Hain 1974, p271). The conclusion Hain comes to is that the opportunities for advancement fall as a legislator approaches 50 and his expectations also fall. This clearly supports Schlesinger's view. However, neither Hain nor Schlesinger attempts to disentangle the relationship between the decline in ambition and the decline in opportunity. The 
problem with using ambition in combination with opportunity as an explanation for a fall in promotional prospects as age increases is that the relationship between ambition and opportunity is difficult to unravel. The drop in ambition may be due to the realisation that opportunities (offers of higher positions) have begun to diminish. Alternatively, the fall in ambition may be a cause of the fall in the promotional prospects with the individual not following up opportunities that present themselves.

Brace (1984) included age and age squared in a logistic regression analysis of risk and ambition. The binary variable here was seeking higher office as opposed to merely seeking re-election to the house in which they were serving. The idea was that the relatively old and the relatively young were less likely to pursue higher office as opposed to merely seek re-election. Brace found a negative quadratic effect with the age of 43 being the age at which an individual was most likely to seek higher office. Brace's study supports the ideas of Schlesinger and Hain (1974) that age and ambition are negatively associated (Brace 1974: 568) and supports the general idea that age can be used as a proxy for ambition.

Kiewiet and Zeng (1993) found a negative association between the desire to seek higher office and age. The average age of those retiring from the US House of Representatives was 59.6 years while the average age of those seeking re-election was 51.4 years, and those seeking higher office was 46.6 years (Kiewiet and Zeng 1993: 934). Their explanation for the decline in ambitiousness was that younger members have typically served fewer terms than older members and thus had less to lose by going for a more risky alternative.

The studies cited show that there is a decline in the ambition of members of various forums. The decline effect seems to be related to the age at which subjects 
perceive they should have achieved certain goals. In other words, the decline effect is likely to be related to the age of achieving high status in specific domains. It has been well documented that in different domains, high status is achieved at different ages. Simonton (2007) used a linear regression approach in determining the peak age of output of authors of a variety of literary styles. Conceptualist poets do their best work at the age of 28. Conceptualist novelists do their best work at 33.5. The ages at which experimental poets and novelists produce their best work are 38.9 and 44.2 respectively (Simonton 2007: 136). Similarly, Simonton (1985) found that eminent psychologists produce their best work at the age of approximately 40. Levin and Stephan (1991) used a pooled regression model and found that there were differences in the peak age for output of different types of scientists. For example, solid-state/condensed matter physicists tended to have their peak publication output at 45 years while geophysicists peak at age 59 years. (Levin and Stephan 1991: 122-125). Blanes i Vidal and Leaver (2010: 46) found a negative quadratic association between age and promotion in the English judiciary with a peak at age 50. Similar patterns occur in the field of leadership. Lehman (1947) surveyed political, military, economic and political leaders and found that for each field of leadership there were different average ages of serving leaders. Popes tended to be older while the youngest were hereditary rulers of England, France, Germany and Italy (Lehman 1947: 354).

The importance of there being specific milestones in different spheres of leadership is that this may be the reason for the decline effect. It is conceivable that the decline effect is due to the realisation by the individual that they have not achieved certain mileposts in their career at the time when their peers have done so and this causes a fall in their aspirations due to a realisation that they may not achieve their 
desired goals. This would explain why, as Brace (1984), Hain (1974), and Kiewiet and Zeng (1993) stress, ambition tends to decline at a specific age in various domains. The idea here is that, in each of the forums in which these three studies were conducted, there was an age at which the successful high office seekers should have attained their goals. Those who had not achieved these offices would perceive that they had "missed the boat" and would suffer a decrease in ambition.

It is worthwhile examining whether there is a similar decline effect at play in the Australian federal context. The presence of such an effect would strengthen the idea underlying the interpretation of Parlage in that it shows that there is a close relationship between age and ambition.

Let us consider how the decline effect might work in the Australian federal system. We have seen from Table 8.2 that, on average, it takes 9 years after entry to parliament to be appointed to cabinet. We have also seen that the average age of appointment to cabinet is 47 years. Thus, the average CM enters parliament at the age of 38 years and, after 9 years is appointed to cabinet. In order to establish a decline effect we would need to find evidence that non-CMs suffer a decline in ambition after the age of 47 years, the average age at which high office is achieved in the forum under discussion. If they are older than the age of 47 years they are likely to feel that they have "missed the boat " and lower their aspirations accordingly. The question is, do we have evidence of this?

We have two sources indicating that the late 40s are an important turning point. The first is biographical. The second is quantitative and is based on the quadratic relationship between age and the probability of being a $\mathrm{CM}$ at a given cross section in 
time that we found in Chapter 3 using data from the LNPC in government for the period 1996-2007.

The biographical accounts of the careers of Petro Georgiou and Malcolm Turnbull are good examples of the phenomenon in question. Georgiou's case gives a good indication that, at 50, an Australian federal parliamentarian may consider that, if he has not been appointed to a senior position, he is not likely to be. Petro Georgiou is interesting because he is one of the few Australian federal parliamentarians to refuse an offer of a promotion. He entered parliament at the age of 47 in 1994 when the LNPC was in opposition. In 1996 the LNPC was returned to power and in 1997 at the age of 50 he was offered the position of parliamentary secretary. He is reputed to have said to Howard "I'm too old and ugly for that" (Gordon 2005). The implication was that he aspired to a more senior position. However, he was never subsequently offered another senior position and remained a backbencher until he left parliament in 2010. The point of this is that it indicates that there may be a perception on the part of parliamentarians that 50 is the age at which a parliamentarian should be a $\mathrm{CM}$ and if you have not achieved this there is no point continuing in the effort to achieve a senior position.

Turnbull is an excellent counterexample because he is the exception that proves the rule. He was older than Georgiou when he entered parliament and yet his ambition had not declined. Turnbull entered parliament at the age of 50, was offered a role of parliamentary secretary at the age of 51 which he accepted and was a cabinet minister by the age of 52. Clearly, the junior position of parliamentary secretary was not a role he felt he was "too old and ugly" for. Instead, he seized the opportunity. The point of this comparison is that Turnbull, although he entered parliament relatively late, was known for his drive and ambition. Crabb (2009) in an aptly titled essay on Turnbull, 
Stop at Nothing: The Life and Times of Malcolm Turnbull, points out that he was described by one associate as a "force of nature" (Crabb 2009: 7). He seems to have been driven by the urge to engage in politics from an early age given that his first attempt to enter parliament was in 1981 at the age of 26 . Failing this he went on to a number of high profile corporate and legal positions until his entry to parliament in 2004.

Georgiou represents the archetypal individual who instantiates the decline effect. He perceived himself to be too old to accept a junior position, expecting at age 50 to be offered a senior position. Having not secured such a role he effectively gave up. The important point is that his ambition declined. Turnbull provides a good counterexample because he represents the individual whose ambition did not decline and, not surprisingly, attained the goal of high office. Turnbull demonstrates that the decline effect is not due to age but to ambition. On this account age is merely a proxy for ambition and as age increases, ambition has a tendency to fall. Age is a proximate measure of ambition rather than an absolute measure of ambition and this is demonstrated by the counterexample of Turnbull whose ambition was not substantially diminished by age. The point is, however, that Georgiou's response represents the usual response to the situation of not achieving high office. Hence, his example seems to be the kind of thinking that underlies the decline effect.

As well as this biographical account of the decline effect there is some evidence that the probability of being a CM declines after the age of 47. In the LNPC RIF model developed in Chapter 3 using cross sectional data, one of the factors considered was age. Both age and age squared were included in the model and the coefficients were .799 and -.008 respectively, with both significant at the $\mathrm{p}<.01$ level. These coefficients 
essentially distil the effect of age on the probability of being a $\mathrm{CM}$ at a given cross section of time. They form a negative quadratic with a peak at the age of $47 .^{9}$ In other words, the cross sectional analysis in Chapter 3 shows that the age at which a parliamentarian is most likely to be a CM is 47 . Older individuals are less likely to be CMs at a given point in time. It should be stressed that being a $\mathrm{CM}$ at a given point in time is conceptually different from the age at first appointment, which, from Table 8.2, is also 47. Nevertheless, the quadratic relationship between age and the probability of being a $\mathrm{CM}$ shows that there is a plausible connection between age and ambition in that after the age of 47 parliamentarians may feel that they are unlikely to accede to cabinet if they have not done so by this age. Conceivably, they therefore lower their aspirations. That is, their ambition declines. Like Georgiou, they are therefore less likely to be appointed to such roles. The reason they would feel that way after the age of 47 is that they would compare themselves with those who have made it to cabinet and either unconsciously or after doing the calculations themselves, would come to the conclusion that those who have made it to cabinet did so by the age of 47 .

This discussion of the decline affect has provided further support for the idea that it is not unreasonable to see Parlage as tapping into ambition. There is some evidence that the decline effect is at work in the Australian federal parliament. After an average of 9 years of "apprenticeship", those who are beyond the age of 47 may lower their aspirations and therefore, by their own loss of ambition reduce their chances of attaining high office.

\footnotetext{
${ }^{9}$ It should be noted that the inflection point of 47 is not merely an artefact of the average age of appointment being 47. These coefficients were generated using a cross sectional analysis of the cohort of LNPC members over the period 1996-2007. Table 3.19 in Chapter 3 shows that the average age of CMs in this analysis was 51.7 while that of parliamentarians as a whole was 50.8
} 


\section{Summary of Section 8.4}

In this section I have explored the idea of ambition and its relationship to age. In particular my concern was to see how Parlage might tap into ambition. My first step was to consider how others had conceived of ambition and to see how ambition had been measured in the literature. In general, age at the time of entry to parliament is negatively associated with ambition. Furthermore, direct measures of ambition seem to show a negative associated with age. I took this to be a good justification for interpreting Parlage as tapping into ambition. I then went on to consider the literature on changes in ambition. The empirical literature shows that there is a generally negative association between age and ambition. I discussed this in terms of there being an age comparison on the part of those who are unsuccessful in their bid for higher office with those who were successful. I determined that there is evidence for this in the Australian federal parliament. I concluded that this gives further justification for seeing Parlage as a way of tapping into the dynamics of ambition.

\section{Summary of Chapter 8}

In this chapter I have examined whether it is justifiable to interpret Parlage as a means of tapping into ambition. I began with an overview of Parlage and determined that it is negatively linearly associated with $\mathrm{CM}$ and that there is an average 5 year age difference in the Parlage of CMs as opposed to non-CMs. I then went on to examine the 
relationship between age and the probability of achieving high office in a number of settings and found that the relationship was in general negative. I examined a number of reasons unrelated to ambition that could explain this and found that these explanations were implausible. I determined that ambition was the most plausible reason for the age related negative association with $\mathrm{CM}$. Examining the literature I found that there is general agreement that age and ambition are negatively associated. In particular I found that there was support for the idea that the more ambitious parliamentarians enter parliament earlier and their ambitiousness is manifested in a more assiduous pursuit of promotion opportunities as they arise. I went on to look at how ambition might change over time. I found that in the Australian federal parliament there is evidence that after the late 40s a parliamentarian who has not become a CM will suffer a decline in ambition. I was able to link this with Parlage in that those who enter parliament at a later date will, by the time they have acquired sufficient experience to be appointed to cabinet, tend to be older than the age by which most CMs are appointed. They therefore lower their aspirations. I also gave two biographical examples indicating that it is ambition not age per se that is the important factor. Finally, I offered an explanation for the decline effect using the insights gained from the models developed in Chapter 3.

In the next chapter I turn to the explanation of the final variables to be considered Con, Img and Def and the concept that they instantiate - concreteness. 


\section{Chapter 9: Abstract versus Concrete Thinking and Cabinet Selection}

\section{Section 9.1: Introduction}

In the chapter on modelling I noted that there is a set of linguistic variables which were significantly correlated with CM. Three models had such variables. One model contained the variable Con (concreteness), another contained Img (Imagability) and another contained Def (Ease of Definition). I have pointed out that these variables tap into linguistic concreteness. That is, these variables measure a form of linguistic behaviour characterised by the use of terms that are easily representable using sensory images. Thus, the contention is that the less concrete the language of a parliamentarian the more likely she is to become a CM. I will discuss possible reasons why this association should exist. That is, I will examine whether concreteness is a proxy for some other quality that is of benefit to those aspiring to higher political office. I will then test for the association between concreteness and the existence of this higher order quality by selecting two individuals, one of whom displays high levels of concreteness in their first speech, the other of whom displays low levels of concreteness. I will show that the two members of this dyad demonstrate cognitive differences that are plausibly linked to the differences in the concreteness of the language used.

Before continuing I should point out that throughout this chapter I will use the terms concrete and abstract as antonyms representing the two extremes of the same phenomenon. The concreteness measures I refer to represent continua so any discussion of concreteness is also a discussion of abstractness. It is important to make this point 
because much of the literature phrases the debate from the point of view of abstractness and by making this point explicit here I should be able to avoid any ambiguity as to what is meant by abstractness as opposed to concreteness in the exposition.

In the next section I will discuss what is meant by concreteness in the specific case of the variables in question and link this with the discussion of concreteness in the literature in general.

\section{Section 9.2: What is Concreteness?}

Concreteness, in linguistic terms, is the extent to which the object represented by a word can be represented to the senses. Thus, the word "horse" is concrete in that it is not difficult to conjure up a visual image of a horse. However, the word "unreality" is more difficult to imagine. One requires information beyond that available to the senses in order to conceptualise such an abstract concept.

As mentioned in Chapter 4, the psycholinguistic measure of concreteness used in this thesis is derived from a group of 925 common nouns (Paivio, Yuille and Madigan 1968). The measure of Concreteness (Con), which is arguably the variable that most directly measures the concept in question, was derived for the 925 nouns by asking subjects to rate each word on the basis of the question: "Any word that refers to objects, materials or persons should receive a high concreteness rating; any word that refers to an abstract concept that cannot be experienced by the senses should receive a high abstractness rating,...” (Paivio Yuille and Madigan 1968: 5; italics in original). 
We can get a sense of what this represents by pointing out that the two words with the lowest concreteness score in the 925 word sample are "hope" and "unreality", both scoring 1.18. Words with the highest score (7) are concrete objects and consist of such words as "accordion", "car" and "window". The average concreteness score in the 925 word sample is 4.97 ( $\mathrm{sd}=1.87)$. Words in this range include peacemaker (4.97) and combustion (4.98). The average score for the parliamentary speech sample is $4.19(\mathrm{sd}=$ .38) indicating that the average speech uses words slightly less concrete than the average concreteness of the 925 noun sample.

Other measures of concreteness have been used and are referred to in the literature. All tend to be related by the concept of sensory perception in that the easier the word is to represent to the senses, the more concrete it is. Much of the conceptual work on the importance of concreteness in language has been based on the Linguistic Category Model (Semin and Fiedler 1988). In this model, measures of concreteness abstraction are based on four categories of words of ascending levels or abstraction. The four categories, in descending levels of concreteness, are descriptive action verbs, interpretative action verbs, state verbs and adjectives. Descriptive action verbs are words that describe a direct perceptible event such as "kicked" in "Mary kicked the ball'. Interpretative action verbs are words that go beyond description and interpret an event such as "helped" in 'Mary helped the child'. State verbs describe states rather than events such as "loves" in 'Mary loves john'. Adjectives describe dispositions rather than states such as "honest" in 'Mary is honest' (Maas, Salvi, Arcuri, and Semin 1989: 982). The link between the concept of concreteness here and the general linguistic concept of 
concreteness is that tangible words and concepts are more concrete while the more interpretative words and concepts are more abstract.

One issue we need to address is the extent to which the three variables Con, Img and Def are tapping into the same basic concept of concreteness. There is good evidence that Con and Img are closely related. Def, on the other hand, is not a direct measure of concreteness. Nevertheless, the connection between Def and concreteness is established. Reynolds and Paivio (1968, cited in Clarke and Paivio 1991: 159) found that, when orally defining words subjects tended to utter dysfluencies and hesitate more with abstract words than with concrete words. O’Neill (1972, cited in Clarke and Paivio 1991: 159) used a sample of 277 nouns and found that when subjects rated them on ease of definition the scores were correlated with scores of .70 with rated imagery and .64 with rated concreteness. The results for the 925 sample (Clarke and Paivio 2004) are essentially the same. The theoretical reason for the connection between imagery/concreteness and the ease of definition is that there is more to determining the meaning of a word than verbal processes. The Dual Coding Theory (DCT) holds that the meaning of a word is represented in an image-based non-verbal network of associations as well as a verbal network (Clarke and Paivio 1991: 153). Thus any attempt to define a word will involve drawing on both the verbal and non-verbal networks. A highly concrete word has a strong representation in the non-verbal network as well as the verbal network. A highly abstract word has a less rich set of semantic associations in the non-verbal coding system and is therefore more difficult to define.

The predictions of DCT were substantiated in an fMRI study which found that the visuospatial processing regions of the brain tend to be more active when a subject is 
reading or hearing high imagery-based sentences as opposed to low imagery based sentences while the semantic processing regions showed greater activation during the comprehension of low-imagery sentences (Just, Newman McEleny and Carpenter 2004: 112). In short, the link between Def and concreteness is via the DCT. It is therefore justifiable to interpret Def as being a measure of concreteness similar to Con and Img.

\section{Summary of Section 9.2}

I have presented a discussion of concreteness both in terms of the variable Con and in more broad terms. Concreteness in general is related to the extent to which an object or concept can be represented to the senses. I then went on to a more contentious issue: whether Def can be considered as tapping into concreteness. On the face of it Def does not directly measure the extent to which an object or concept can be represented to the senses. However, it is clearly tapping into something closely related to concreteness. This is evident from the correlations between Def and the various measures of concreteness. Furthermore, the findings of DCT support the idea that there is likely to be a link between the lexical task of defining a word and the non-verbal process of drawing on imagery to do so.

In the next section I will begin the analysis of the role of concreteness in the selection of CMs. I will begin by providing an overview of plausible explanations as to why concreteness might be related to the selection of CMs. 


\section{Section 9.3: Some Effects of Differing Levels of Abstraction}

I have found that those who use relatively abstract language are more likely to become CMs. My contention is that the level of abstraction of language is a marker of the level of abstraction of the mindset of the speaker. In this section I will provide an overview of the literature on abstraction and thinking style. In general, the more abstract and individual's thinking, the better at generalising, planning, and making assessments based on the gist of a situation without her needing or wanting to know the details. In short, abstract thinking is associated with the kinds of skills one would expect in big picture thinking (Liberman and Trope 2008: 1202). Concrete thinking is associated with attention to fine detail, a procedural mindset and a propensity to hold off making any kind of judgment without a full knowledge of the facts and circumstances. Thus, concrete mindsets are associated with a technical way of thinking. Importantly, there are circumstances in which one type of thinking is better than another. Reacting to immediate surroundings in a crisis situation requires highly concrete thinking whereas planning for possible future contingencies requires abstract thinking skills. Most individuals tend to be able to inhabit each mindset to some extent as the circumstances require. The important point for the analysis of $\mathrm{CMs}$ is that there is a difference in the baseline concreteness of individuals and this has an effect on their way of looking at the world and interacting with it.

In this section I will review several phenomena associated with the level of abstraction in an individual's way of looking at the world. There is a vast amount of research on this relationship and any of the issues I have selected are indicative only of the scope of the field. 
Hendrick (1979) used a standard measure of abstractness orientation to divide a group of subjects into a high abstractness group and a high concreteness group. Given the same group problem-solving task, the high concrete group took almost twice as long as the high abstract group to complete the task. Pacini and Epstein (1999) found that concrete thinking underlies the ratio-bias phenomenon. This phenomenon is characterised by a tendency to interpret the probability of an unlikely event as being higher than it really is due to it being expressed in larger rather than smaller numbers. Thus, 10 out of 100 would be considered by a concrete thinker to be more likely than 1 out of 10. The concrete thinker's holistic processing strategy is to associate greater quantity with greater probability. The abstract thinker, on the other hand, is more likely to process the actual meaning of the ratios.

The above examples show that there are advantages in abstract thinking. However there are also disadvantages. One such disadvantage is that abstract thinkers tend to be less capable of persuasion. The reason for this is that concrete words portray vividness and are therefore more memorable (Martindale 1986). The more concrete a word, the easier it is to conjure up a sense associated with a word and the greater its impact. Thus, the more concrete the message the more persuasive (Forgas 2007). However, the extent to which the persuasion is successful depends on the match between the imminence of the issue and the concreteness (Kim, Rao and Lee 2009). That is, a concrete argument is more persuasive in a decision that is closer in time while an abstract argument is more persuasive where there is a longer time to consider the issues. Thus, explaining to people why they should vote will be more persuasive when 
the election is temporally distant but explaining how to vote is more persuasive when the election is temporally proximate (Kim, Rao and Lee 2009, p877). Given that there is a positive relationship between concreteness and persuasiveness and that there is a negative relationship between concreteness and $\mathrm{CM}$ we could infer that CMs are not chosen on the basis of their skills in persuasion. It is possible that it is set of some other skills that are associated with concreteness which CMs are chosen for. That is, there may be a set of cognitive characteristics that are characterised by abstract thinking and it is these that determine whether a parliamentarian is more likely to be a CM. I will examine this possibility further in the section on the psychological level of construal below.

\section{Summary of Section 9.3}

In this section I have presented a brief selective overview of the kinds of psychological phenomena associated with the level of abstraction of thinking. I discussed some evidence that abstract thinkers may be better at team based problem solving. I mentioned evidence that a common error - the ratio bias phenomenon - may be due to a concrete thinking style. Finally, I looked at the relationship between persuasion and concreteness, concluding that concreteness is associated with persuasiveness. I pointed out that the negative association between $\mathrm{CM}$ and abstractness indicates that CMs may not be selected for their powers of persuasion. I concluded that concreteness may be a marker for some other set of characteristics that are related to the cognitive requirements of CMs. 
In the next section I wish to consider is a strand of the research on abstraction that seems to encapsulate a broad variety of cognitive phenomena, possibly including the phenomena referred to in this section. I am referring here to the research on the psychological level of construal (Liberman and Trope 2008). This way of looking at the issue provides a comprehensive account of how variations in thinking abstraction can have a powerful influence on the way an individual perceives the world and interacts with it.

\section{Section 9.4: Concreteness as a Marker of the Level of Construal}

In the previous section I discussed concreteness as a phenomenon in itself. That is, I examined a number of phenomena that have been associated with concreteness. However, there is a way of conceptualising concrete thinking such that many of these phenomena are subsumed as well as a range of other cognitive phenomena. I am referring here to the idea that the level of abstraction in language may be a marker for the extent to which the speaker is focused on the proximal rather than the distal. The "psychological level of construal" (PLC) indicates the extent to which an individual uses concepts and ideas that are proximal rather than distal in physical, psychological, temporal and social senses. Individuals who conceptualise the world in terms of the here-and-now have a low PLC while those whose focus is on distant times, places and people have a high PLC (Liberman and Trope 2008). The importance of this in the current discussion is that, given there is a strong relationship between concreteness and the PLC, the indication is that CMs, with low levels of concreteness, have a high level of PLC in comparison with the more concrete non-CMs. 
The importance of the level of construal on influencing an individual's world outlook is illustrated by Liberman and Trope in the following words:

"Human history is associated with expanding horizonstraversing greater spatial distances (e.g., discovering new continents, space travel); forming larger social groups (families versus cities versus states versus global institutions); planning and investing in the more distant future; and reaching farther back into the past. Human development in the first years of life involves acquiring the ability to plan for the more distant future, to consider possibilities that are not present, and to consider the perspective of more distant people..." (Liberman and Trope 2008, p1202).

There has been some research on PLC and political leaders. A relationship between level of construal and charisma was identified by Shamir, Arthur, and House (1994) who found that those leaders who were considered more charismatic tended to have more distal than proximate goals in their speeches.

A higher level of temporal construal - that is, a greater temporal distance - tends to influence an individual's emphasis of ends versus means. In a study by Day and Bartels (2008, cited in Trope, Liberman and Wakslak, 2007, p85), participants were asked to judge the similarity of such activities as "going to the dentist", "getting a tattoo", and "joining a health club". When described in the distant future, the first and 
the third were found to be more similar in that they were both good for the health. That is, the ends were emphasised. When described in the very near future the first and the second were found to be more similar as they both involved sitting in a chair. That is, the means were emphasised.

Similarly, greater temporal distance will tend to lead to people using traits to characterise behavior rather than situational constraints (Nussbaum, Tope and Liberman 2003 cited in Trope Liberman and Wakslak, 2007). Thus, where the priming story involves a man who is described as temporarily upset (a situational constraint) and who deals with it by getting drunk, subjects will be more likely to judge the fact that he resorted to alcohol as evidence that he was temporarily upset. However, where the same event is set in the temporally distal future (one year hence) subjects are more likely to attribute the resorting to alcohol as indicative of an underlying propensity to drink. In short, the greater the temporal distance, the more likely subjects will attribute behaviour to general dispositions rather than context-based reactions to immediate stimuli.

The importance of the PLC to the current issue is that it seems likely that the base level of construal differs among individuals and those who become CMs may have a more distal level of construal. Concreteness is associated with a proximate level of construal: as the level of construal becomes more distal the details become more abstract and general (Liberman and Trope 2008, p1203). The implication is therefore that CMs have a higher psychological level of construal.

Before I continue with this discussion it is important to point out that much of the research in this area has been based on studies of state rather than trait. That is, 
experiments have in general involved manipulating the level of construal by changing such things as the future versus present orientation of priming questions. In the parliamentary speech sample it is more likely we are tapping trait characteristics than state characteristics as the state of the individuals is largely controlled in that the maiden speeches are given in very similar circumstances. Thus, I am claiming that those individuals who are initially elected to federal Parliament are likely to reveal their trait level of construal in the controlled conditions of delivering a first speech. I am implicitly assuming that individuals differ in their baseline PLC and that the model has picked up a relationship between the level of construal and the probability of becoming a CM. This is in contrast to much of the literature on the PLC in which it is the state that is manipulated. However, there is no reason to think that the observations made in relation to the state might not be extrapolated to trait level.

Why should a high PLC be beneficial to a potential CM? Trope and Liberman point out that " $[\mathrm{t}]$ he use of high-level, abstract construals to represent psychologically distal objects is...[]...indispensable for effective functioning in many domains: for developing object constancy, orienting in space, planning the future, learning from the past, relating to and understanding other people, and for considering alternative outcomes and courses of action" (Trope and Liberman 2010, p441).

One advantage of a higher PLC significantly pertinent to political office is that it can give rise to a broader search for alternative solutions. The reason for this is that it enables a comparison of alternatives that are not strictly "alignable' (Malkoc, Zauberman, and Ulu, 2005, cited in Trope and Liberman 2010, p453). Objects are alignable if they share concrete attributes. Thus, the selection of one residential 
apartment compared to another could be based on similar concrete attributes such as price, location and size. Even at a low level of construal this can be done with ease as the trade-off requires a simple comparison of the concrete variables. However, moving to a house is not strictly alignable with selecting an apartment because there are different concrete attributes associated with each alternative. This means that that it requires a higher level of construal to compare living in a house with living in an apartment. In order to compare these two alternatives an individual must be able to make an abstract comparison of qualities that are not commensurable. For example, being close to the city in an apartment is not directly comparable to living in a house which has the benefit of having a garden. The overall satisfaction of both these options cannot be measured on the same terms as is possible when measuring a single concrete variable such as price. The point of this is that individuals with a trait of low level of construal will tend to stick to options that are comparable on concrete variables and will not bother to countenance options beyond easily comparable options. However, individuals with a higher level of construal are more likely to be able to countenance a greater number of possible alternatives because they are willing to make the abstract jump and compare alternatives on criteria that are not commensurable. Malkoc, Zauberman, and Ulu (2005, cited in Trope and Liberman 2010: 453) tested this idea using perceptions of the quality of potato chips which were to be given out at either the end of the session (temporally proximal - low level construal) or at the end of a six month period (temporally distal - high level construal). The two brands had 12 attributes, 4 of which were common between the two brands, 4 of which were alignable attributes, and 4 of which were non-alignable attributes. As predicted by the theory, in 
the more temporally distal condition, more weight was given to non-alignable qualities than in the temporally proximal condition.

The importance of this is that an individual with a higher base PLC is likely to come up with a greater number of possibilities. In a political party it can be seen that those in senior positions would need to have this ability. The ministers need to be able to weigh up a number of different solutions presented to him. Those who can weigh up many different alternative solutions to problems will be more likely to decide on a solution that is optimal and would have a greater ability of coming up with solutions that more people agree with than an individual without this ability. The latter will be able to consider fewer possibilities because he is restricted to solutions that have alignable qualities.

Another characteristic that varies according to the PLC is the extent to which individuals are willing to mitigate their own ideological positions, with higher levels of construal being associated with lower mitigation. Those who mitigate their ideological outlook can be seen to have deserted their ideals and this reflects negatively on them as potential leaders. This idea was tested by priming individuals with a proximal cue to see if they are more likely to consider short term deviations from their long term ideological position (Ledgerwood et al 2008, cited in Trope and Liberman 2010: 544). In this study subjects were initially assessed on an ideological scale in order to determine their likely support for a policy on immigration, the assumption being that conservatives were less likely than liberals to support immigration. Subjects then read about the policy and were told it was due to be implemented next week/next year. They also had a discussion partner who expressed agreement/disagreement with the policy. Subjects then reported 
their voting intention privately. The finding was that the subject's voting intention deviated from their ideological position and toward their discussion partner's to a greater extent when the policy was due to be implemented in the near future as opposed to the distant future. When the policy was due to be implemented in the distant future subjects' voting intentions were less swayed by interaction with the discussion partner and the subject's voting intention was influenced more by their ideological position. A plausible implication of this is that those with a higher base PLC will be less likely to compromise their long term ideological position.

This is likely to be seen to be a strongly positive characteristic. Those who do compromise their position are likely to weaken their standing in the eyes of their colleagues. A good example of this is Costello's reaction to Hewson's decision to tone down the LNPC's economic policy after the party lost the election in 1993, the ostensible reason for the toning down being that the public did not like the policy:

The worst thing a conviction politician can do is give up his convictions. After the 1993 election defeat Hewson announced he was no longer in favour of a GST. This damaged his one great strength: his economic credibility. He gave away his chief equity. He had always said that the Fightback! Program was necessary for the economy and he would not compromise on it. His appeal had been: 'I'm the tough economic leader for these tough economic times. I have the tough - but right -economic program.' He now saw that Fightback! was not necessary after 
all and he dumped it. He abandoned his whole raison d'etre. He could not remake himself as a populist (Costello 2008, p58-9).

Thus, a parliamentarian who has a high PLC will tend to be seen as less likely to sacrifice their " raison d'etre". It should be noted that this can lead, in extreme cases, to intransigence which can be a negative aspect of the high level of construal. However, the point is that in the eyes of the selectors, being willing to "flip-flop" may be seen as a greater sin than intransigence.

\section{Summary of Section 9.4}

It is the contention of this section that the measure of concreteness that distinguishes CMs and non-CMs may be tapping into differences in PLC. A higher PLC has been shown to be associated with a range of habits of mind that are likely to be associated with the kinds of phenomena that distinguish $\mathrm{CMs}$ from non-CMs. The general picture is that those with a high PLC are more likely to engage in long term planning and will tend to have a better idea of the "big picture" than those with a lower PLC. Having pointed out these general benefits associated with a higher PLC I discussed two specific benefits that are likely to be associated with accession to cabinet: those with a higher PLC are better able to develop alternative strategies in problem solving scenarios; furthermore, those who have a higher PLC are more likely to have more stable overarching perceptions of the "big picture" and are therefore less likely to deviate from their long term ideological position. This means that they maintain their credibility. 
In order to examine the idea that CMs have higher PLCs than non-CMs I will examine the speeches of two individuals with vastly different measures of concreteness. I will show in the next section that the PLC explanation is plausible given the differences in the ways of thinking exhibited by the two individuals concerned.

\section{Section 9.5: Case Studies from the Speech Sample}

In this section I intend to look for evidence of variations in the PLC of two parliamentarians who differ in their scores on concreteness. The argument here is that, given the relationship between concreteness and the PLC I discussed in the previous section, if the variables Con, Img and Def are measuring concreteness, then those who score high on these variables should demonstrate a low level of PLC while those that score low on these variables should score high on PLC.

To create a dyad I added together the scores for Con, Img and Def (CID) to get a single index. I then ordered the whole sample $(n=134)$ on the basis of this index. The dyad consists of the highest scorer De-Anne Kelly $(\mathrm{z}$ score $=2.68)$ and the lowest scorer Simon Crean $(\mathrm{z}$ score $=2)$. As these parliamentarians are 4.68 standard deviations apart on the variables I have associated with concreteness then, according to the PLC theory, we should see differences in their PLC with Crean demonstrating a higher PLC and Kelly demonstrating a lower PLC. I will attempt to determine their differing perceptions by examining their first speeches. 


\section{De-Ann Kelly's Speech}

Kelly's speech displays a number of characteristics of low PLC. In particular this is demonstrated by a high level of self-references and the lack of an over-arching set of ideas tying together her observations.

A good indicator of the level of psychological construal of individuals is the extent to which they are self-focused:

Psychological distance is egocentric: Its reference point is the self in the here and now, and the different ways in which an object might be removed from that point—in time, in space, in social distance, and in hypotheticality-constitute different distance dimensions. Transcending the self in the here and now entails mental construal, and the farther removed an object is from direct experience, the higher (more abstract) the level of construal of that object (Trope and Liberman 2010, p440).

A good proxy for the level of self-focus is the extent to which an individual selfrefers. This can be examined using the LIWC "I" variable which measures the rate of use of the words "I", "me", "mine", "my" and "myself". The "I" use in the speech sample $(n=134)$ is positively correlated with the concreteness $($ Con $)$ of speeches $(r=$ $.29, \mathrm{p}<.01)$. This is an important observation because it underscores the extent to which a concrete mindset tends to focus the individual on the immediate present. There is nothing more present to the individual than the self and as such those who tend to be 
concrete thinkers tend to focus on themselves and those in their immediate surroundings. The upshot of this is that concrete thinkers tend to miss the big picture.

A salient aspect of Kelly's speech is the relatively high number of uses of "I" terms: the z score for Kelly's "I" use is $1.77(\mathrm{q}=.038)$ indicating that she is in the top $4 \%$ for "I" use. ${ }^{1}$ This is the first indication that she is likely to have a low level of construal. She is likely to be focused on herself and her immediate environment. By definition this means that she is less focused on the big picture.

The relative lack of awareness of the big picture in the case of Kelly is evident in that she tends to base most of her thinking around her electorate. While this is an admirable quality for a parliamentarian it is not for a CM. A CM needs to see that the factors affecting their own electorate are likely to be part of a complex interaction of factors and that general nationally based policy prescriptions may be preferable to thinking at the local level. Let us consider the following extract:

I would like to pause for a moment and tell you some of the difficulties that face the industries in [the electorate of] Dawson. Our beef industry has now seen a dramatic fall in prices of 20 per cent. Soon that will be 30 per cent. I am also concerned about access for tourists to the mighty Whitsundays. If you have not had a holiday in North Queensland, do yourself a favour and come to the Whitsunday [islands]. It is absolutely

${ }^{1}$ The measure used here is $q$ rather than $\mathrm{p}$ because we wish to derive the probability that the observed z-score deviates from average by chance alone. This is equivalent to a one tailed t-test. The use of a one tailed test is appropriate given that we are looking for a difference in one direction. The hypothesis is that those with a low levels of PLC use are likely to have a score on 'I' use significantly above the mean. 
magnificent there. But we have a difficulty because [tourists on the islands] do not have access to the tourist areas in Dawson. That is something that I have pledged to rectify while I am the federal member (Australia, House of Representatives, Debates 1996: 193).

This extract indicates that Kelly is certainly aware of the issues in her own electorate. However, it is interesting to note that, given that Australian beef is sold on the international market, she sees the fall in beef prices as being a problem in her electorate rather than as a national problem. Furthermore, her concern for the local tourism industry, again admirable, is centred on a highly local and specific problem. A more global approach might be to derive policies that increase tourism in general and this could conceivably lead to benefits at both the national and local level.

Another interesting observation about the above extract is that Kelly mentions several problems fleetingly without an overarching vision or comprehensive approach to addressing problems. There are several ways of connecting beef prices and tourism. Both, for example, are related to the strength of the Australian dollar. But Kelly does not try to make connections. Instead, she lists issues that are connected with her local concerns. In the paragraph following the one quoted she engages in the same listing process with the lack of water storage and the "over-analysis" of the sugar industry by bureaucrats, devoting one sentence to the former and three to the latter. Both of these are certainly significant local concerns but their cursory treatment suggests a lack of global thinking. Kelly's approach to her vision for the nation takes a similar form: 
I would now like to mention a little about my view of how you do not build a nation and then what I believe does need to be done. You cannot build a nation by dividing its people with special privileges. You cannot build a nation by pitting the weak against the strong. Competition is sometimes exploitation. You cannot pit the metropolitan city against the regional centre or the country town. You cannot pit the chain store against the corner store. You cannot pit the international commodity traders against the small family farmer. You cannot build a nation by substituting the disorderly love and discipline of family life for the cold, structured care of the state. You cannot build a nation by substituting kindness and respect for life with the sterile computer-generated use-by date for human life (Australia, House of Representatives, Debates 1996: 194-5).

This sequential, fluid enumeration of contextualised, detailed, local, unstructured observations is archetypically low level construal (Trope, Liberman and Wakslak 2007, p83).

So far I have pointed out that Kelly exemplifies a low level construal in that she lacks an overarching vision. However, it should be noted that there are places in her speech where Kelly does make more abstract, general and national statements. For example: 
The national interest is what we should be concerning ourselves with, because the nation is not just a public, which is those who are living now. A nation is those who have defended and worked for our great country. It is those who are yet unborn. A nation is a contract between past, present and future Australians (Australia, House of Representatives, Debates 1996: 194).

Here the concerns are national rather than local and relatively abstract in that, echoing Burke's idea of society being a contract between the living, dead and unborn (Burke 2001: 143), she sees the nation as a set of relationships. In another paragraph Kelly refers to the temporally distal future and asks what the nation will be like in years to come. However, the important point is that the vast majority of her speech is local, contextualised and contains details but little global thought connecting the details.

\section{Simon Crean's Speech}

Kelly's speech is in stark contrast to that of Simon Crean, the parliamentarian with the lowest score on the Con, Img Def (CID) index in the sample. Crean shows an outward orientation away from narrow concerns and towards the bigger picture of the national stage. He also has a coherent overarching vision. Both of these characteristics are typical of a higher level of construal.

As we would expect from a low scorer on concreteness, Crean uses "I" terms less than Kelly: his $\mathrm{z}$ score on this variable is .14 which is not significantly different 
from average. His orientation is outward rather than inward: he mentions his electorate by name only 8 times in comparison to Kelly's 19 times.

One of the most significant differences between the speeches of Kelly and Crean is that, as mentioned above, Kelly tends to provide lists of desirable features of a political and social system while Crean, on the other hand, explains what he thinks needs to be done. While Kelly's unstructured listing lacks an overarching concept linking them together, Crean provides a linked set of ideas based on the role of the trade union movement:

A strong proactive and independent trade union movement is a bellwether of a strong democracy. In these dramatic and historic times, as we observe with humility and intense admiration the efforts of the men and women of the countries of eastern Europe to seize their destinies and overturn totalitarianism in favour of democracy, it is no mere detail or unintended consequence that those people are establishing free trade unions as an initial step...[T]he trade union movement is nothing at all if not concerned with the promotion and protection of individual rights and freedoms. This is the very bedrock principle of trade unionism. It is the essence of naivety to ignore the fact that in a democracy it is through collective means that such rights and freedoms are protected. Without the capacity for collective action in its democratic forms, whether through trade union organisation or indeed the Parliament, then individual rights are 
at risk and the aspirations of individuals will remain unfulfilled (Australia, House of Representatives, Debates 1990: 747).

This is a cohesive statement rather than an unstructured list. Here and throughout his speech, Crean uses the idea that the trade union movement can perform a number of roles associated with democratic and social goals to tie together his ideas. Kelly changes the subject under discussion almost every paragraph but there is no unifying idea to tie the disparate ideas together while Crean has an overarching notion that the trade union movement can be used as a unifying principle in tying together the disparate issues that he mentions. This is typical of a high level of construal:

"[h]igh level construals entail constructing abstract conceptualizations of information about objects and events. They apply to a broad array of examples and selectively include relevant and exclude irrelevant features of those objects and events. High-level construals, therefore, capture the superordinate, central features of an object or event, and abstracting these high-level, immutable features conveys the general meaning of the event. Low-level construals, alternatively, consist of subordinate, incidental features. In lowlevel construals, events and objects are unique and specific" (Fujita et al 2006, p5). 


\section{Discussion}

The two case studies presented above indicate that there is a specific set of intellectual habits associated with concrete versus abstract thinking. The low level of construal of Kelly is exemplified by the extent to which her ambit of reference is based around herself while Crean's high level of construal is demonstrated by the extent to which he is outwardly focused. Furthermore, the low level construal of Kelly is demonstrated by the lack of an overarching set of ideas that tie together her perceptions while Crean's high level of construal is demonstrated by the extent to which he connects individual observations to the "bigger picture".

Let us now consider a hypothetical discussion between two senior party members as to whom a CM position should be allocated. There are two candidates. One is like Kelley with local, unstructured views on policy while the other is like Crean with an outward orientation and a coherent set of ideas underlying his policy prescriptions. It seems clear that individuals wishing to maximise the political talent in cabinet would do better to appoint an individual such as Crean rather than Kelly. This is, in effect what did occur, with Crean being appointed to the junior ministry on his arrival in the HOR in 1990 and appointed to cabinet 14 months later. He remained in cabinet until the Labor party lost power in 1996. He was then re-appointed to cabinet when the Labor party regained power in 2007 and remains there at the time of writing (December 2011). Kelly, on the other hand held the role of parliamentary secretary in the Howard government (1996-2007) from October 2003 until October 2004 when she was appointed to a junior ministerial role. In September 2006 she was demoted to 
parliamentary secretary, a position she held until the end of the Howard government in November 2007.

There are a number of characteristics we usually associate with leadership, such as having a "vision" of the future rather than being concerned with merely day-to-day issues. It seems that the selectors in the case of Kelly and Crean were likely to have perceived that Kelly did not have the required abilities while Crean did. Their respective abilities are revealed in their speeches and it is highly plausible that their way of seeing the world became apparent to the selectors in their respective parties. Crean with his high PLC was deemed to be leadership material while Kelly, with her low level of psychological construal was not.

\section{Summary of Section 9.5}

The starting point of this section is the idea that we can use concreteness, as measured by the PYMCP word norms, to tap into the PLC of parliamentarians. This is very plausible given that the PLC is strongly linked to the level of concreteness of thinking: those with a low PLC tend to have a concrete way of thinking such that the immediate environment is emphasised while the reverse is the case for those with a high PLC. Thus, two individuals with opposing levels of concreteness should demonstrate opposing levels of psychological level of construal. Using the two most extreme cases in the sample I have compared the most concrete Kelly with the least concrete Crean. Two salient aspects emerge from this comparison. Kelly has a highly proximal focus and lacks an overarching set of ideas while Crean has a distal focus and has a well 
developed sense of the "big picture". Thus, there is support for the ideas that the three variables Con, Img and Def tap into concreteness and for the idea that concreteness is negatively associated with CM because concreteness is associated with PLC. Having made these observations I went on to suggest that the selectors would be likely to perceive this difference in world view in their day to day dealings with the two individuals involved. I pointed out that the high level of construal of Crean gave him a way of looking at the world that marked him as being able to see the world as a CM should while Kelly's low level of construal marked her as a non-CM.

\section{Chapter 9 Summary and Conclusion}

In this Chapter I have discussed the notion of concreteness and the way it relates to the selection of CMs. I began by pointing out that there is a negative association between $\mathrm{CM}$ and concreteness. I then surveyed some of the general research on the relationship between concreteness and thinking styles. I pointed out that there is research linking abstract thinking with the ability to solve management problems in a team. I also looked at research linking abstract thinking with the ability to process abstract concepts as opposed to concrete thinking which relies on holistic processes. I further linked this with the idea that abstract thinkers are less likely to fall foul of the ratio bias phenomenon. I also looked briefly at the relationship between concreteness and persuasion commenting on the fact that persuasion and concreteness are positively linked. I made the point that, as concreteness and becoming a cabinet minister are negatively linked it was very likely that CMs are not chosen on the basis of their persuasion skills. This led to the idea that concreteness may be a marker for a set of 
cognitive skills. In other words, it may be that the low level of concreteness of CMs is associated with a set of cognitive skills and it is these that CMs are selected for. This led to a discussion of the psychological level of construal. Those with a high PLC are more likely to think in global, distal and general terms. Their way of perceiving the world is abstract rather than concrete. As such their language is relatively abstract. I contended that this is what is tapped into with the scores on concreteness as measured by Con, Img and Def. I examined this idea by looking at two individuals who score at opposite ends of the spectrum on and index made of these measures. As expected, Kelly, with her high score on concreteness demonstrated a lower level of construal while Crean, with his low score demonstrated a high level of psychological construal. As those habits of mind associated with a high level of CM are those that we would normally associate with the ability to function as a leader it seems apt that Crean was selected for a CM role while Kelly was not.

Thus, in this chapter I have developed a plausible explanation as to why Con Img and Def are related to being appointed as a CM. These variables tap into the psychological level of construal via concreteness. These variables are therefore markers for those characteristics we would normally associated with the ability to plan, assess individuals and subordinates, make global judgments and assess information in a global way.

I have now explained how the three characteristics identified as associated with CM appointment, Law, Parlage, and the three measures of concreteness, are likely to be linked to CM appoitment. I have therefore fulfilled the second research question of the 
thesis. In the next Chapter I will summarise the findings, suggest some applications and point out some possibilities for future research. 


\section{Chapter 10: Thesis Summary and Conclusion}

\section{Section 10.1: Introduction}

In this thesis I have examined two related questions. This first is the question of who is likely to become a $\mathrm{CM}$ in the Australian federal Parliament. The second is the question of why those who become CMs are successful. In other words, I have isolated a set of characteristics of those who become CMs and I have explained why these characteristics are efficacious in assisting a parliamentarian to become a CM. In this chapter I intend to recapitulate the main findings of the thesis and to make some general observations on the findings as well as to suggest how these findings might inform future related research.

\section{Section 10.2: Thesis Summary}

I began my analysis in Chapter 2 where I surveyed the general threads in the literature on ministerial selection in parliamentary systems, with particular emphasis on the Australian and UK parliaments. The general trend, in both the qualitative and the quantitative literature is that there are two general sets of factors that are used to analyse why certain individuals become ministers. The first set of factors can be described as representational and institutional factors (RIFs). These are factors that the selectors take into account when deciding how representational the cabinet should be in relation to the various interests that need to be represented as well as taking into account any 
institutional constraints. In general these are not peculiar to the individual in that numerous individuals might instantiate any particular representational factor. The RIFs usually cited as being important in the Australian literature are gender, geographical area represented, house (upper or lower), party (if in LNPC), and faction (in the ALP). Two other factors that can be considered representational are age and experience. However, these are often "represented" in cabinet differently than the representation in parliament. The second set of factors can be considered to be personal factors. These factors enter into the ministerial selection calculus in a different way to the RIFs in that the selectorate looks for these characteristics to judge whether the individual in question has the appropriate characteristics to be a CM. Such factors cited in the literature include education, loyalty to the party or leader and parliamentary performance. It has been suggested that electoral performance is also an individual factor in that individuals with the ability to engender electoral success demonstrate a valuable political skill.

In chapter 3 I attempted to examine the validity of the claims that RIFs are important in the Australian Federal context. I began the chapter by considering the public debate and found that there is significant support in the mainstream press for the idea that a particular set of RIFs is important in the selection of CMs. These are gender, state/territory represented, party (only an issue in the LNPC in which members are drawn from the two constituent parties), faction (only an issue in the ALP where CMs are drawn from three basic factional groupings), house (HOR or Senate), age and parliamentary experience. In order determine whether these factors influence an individual parliamentarian's probability of being selected to be a CM I modelled the CM selection process for the LNPC in government (1996-2007) and the ALP in 
opposition (2005-6) using these RIFs as independent variables. In the case of the LNPC I found that age and experience and some states are statistically significant but overall the variables did not greatly contribute to classification accuracy. In the case of the ALP I found that experience is statistically significant as well as some states but the ALP models in general, as with the LNPC models, performed poorly on actual classification accuracy. The important finding was that the models with RIFs could explain only a very small proportion of cabinet appointments. This is despite the fact that an enormous amount of effort is expended by party leaders to ensure representational balance in regard to most of these factors. I was able to explain this apparent paradox by pointing out that RIFs, other than age and experience and a small number of states, have no statistical influence on the probability of an individual being selected because the leader is under pressure to make the cabinet representative and thus has little leeway to bias the cabinet towards or away from the parliamentary representation of interests. Where the leader does not make the cabinet representative there is a statistical advantage/disadvantage for an individual who instantiates a representational factor which the leader over-represents/underrepresents.

Having found that the RIFs explain only a small proportion of appointments I turned in Chapter 4 to an analysis of the more personal factors. I decided to use education and speech as a way to do this because these are very personal markers of personality and cognitive characteristics. I also included 3 biographical variables in the analysis. For the education variables I coded for 6 categories that represented the vast majority of qualifications in parliament. For the speech analysis I chose to use the first or maiden speech in federal parliament because this is delivered in a controlled situation 
for all members and therefore provides a relatively comparable speech sample. I surveyed a number of text analysis methods and chose to use LIWC because it has been shown to be effective in psychological applications. I also used the PYMCP word norms to score the speeches as these psycholinguistic variables tap into the way individuals process information.

Having explained the reasons for the selection of various independent variables in Chapter 4 I turned to the issue of the modelling method in Chapter 5.

Chapter 5 was devoted to the exposition of how I would use data mining rather than traditional hypothesis testing to analyse the data. I explained why hypothesis testing was not appropriate in the specific circumstances of the problem. In particular I pointed out that there is a lack of consistent theory in the leadership literature from which to derive hypotheses. I then explained that if we were to try to derive theoretical reasons for why particular variables were related to the dependent variable we might, paradoxically, find that there was a statistically significant relationship but that the relationship was not strong enough to add discriminatory power to the model. I therefore advocated the use of data mining. The impetus for this decision was that the selection of variables would be based on their potential discriminatory power rather than on some a priori assumption. Furthermore, if conducted rigorously, the data mining method is more likely to be able to identify the important variables because so many variables are considered. I then went on to discuss several issues associated with data mining. I pointed out that the "committee" classifier was appropriate given the problems associated with using a single model with a single holdout sample. The committee method involved creating five models using five different training and testing groups. 
Each model was slightly different but was independently efficient at classifying a random holdout group. The results for each model are averaged and the results of the committee of models is more likely to be accurate than any individual model. The interpretation of the models involves looking at all the variables in the five constituent models. For each individual model the same creation process was used. I discussed how feature selection would need to be done in such a way as to identify the best possible predictors. I decided on the use of t-tests for the initial screening and used tests for redundancy to reduce the number of variables in the models created. I then discussed validation of the model, pointing out that the ultimate measure of accuracy is the classification accuracy and this necessitates testing on holdout samples. I explained how the data was to be divided into training and testing sets for this purpose. Central to using classification accuracy as a criterion for assessing models is the discussion of how classification accuracy is to be measured and for this purpose I discussed the use of accuracy, sensitivity, specificity and kappa. Finally, I discussed the issue of how to interpret the models created using the selected variables. I explained that logistic regression would provide a relatively transparent view of the important variables in the models.

In Chapter 6 I described the actual model creation process. I defined the cohort as those parliamentarians in parliament at any time between April 1996 and February 2008. I defined the dependent variable as a binary consisting of a coding of 1 if the individual was appointed to cabinet at some time in their career and 0 if not. Importantly, the definition of a non-CM is dependent on us being able to observe the entire career of the non-CM so those whose careers had not ended at February 2008 
were removed from the sample. Furthermore, those BBs who did not have sufficient ingovernment experience (8.5years) to reveal their executive potential were removed from the sample. The independent variables consisted of 6 binary educational variables, two binary biographical variables, one continuous biographical variable and 100 continuous linguistic variables derived from the parliamentarians' first speeches. I then created five different models. For each model, the creation process involved the reduction of this large set of variables into a small subset of "interesting" variables. Using t-tests I identified variables significant at the $\mathrm{p}<.01$ level. These were used to create a naïve model. By looking at inter-correlations it was found that the linguistic variables were more correlated with each other than with $\mathrm{CM}$ so I removed the redundant variables. The variables in the reduced model were then used to create a number of simpler models based on all possible combinations of the variables in the reduced model. I used the holdout sample to test each of these models. The best 'optimum' model that was created using this method was used as a member of a committee of models. Using five models created using the same process I created a five member committee of models and determined that the characteristics associated with CM are Law (positively), Parlage (negatively) and the use of concrete language (negatively). I had therefore isolated the characteristics associated with $\mathrm{CM}$. The next stage in the process was to explain why these might be associated with CM.

In Chapter 7 I began explaining why having a legal qualification should be associated with CM. There is a perception in the popular press that the two are related and I gave an example of how O'Dwyer $(1998 ; 2003)$ made the observation that lawyers tend to have skills that could be useful in parliament. I also noted his impression that 
Howard may have chosen legally trained individuals preferentially. In order to examine whether similarity bias was behind the selection of LTIs I conducted t-tests for the difference of means as between the legally trained and the non-legally trained leaders to see whether the former preferentially chose LTIs to be CMs. I found no evidence for this across the sample. The next stage in the analysis was to look at the US research on the relationship between legal training and high political office. The main findings are that there are technical benefits associated with legal training and that these benefits assist in the legislator's rise though the legislature. There was also some indication that legally trained individuals are more likely to perceive their roles less in terms of representing their constituents and that this gives them a different outlook compared to the non-legally trained. However, this evidence was equivocal and furthermore, this principal-agent explanation could equally apply to other professions. I then looked at the concept of "chunking" in relation to legal training on the ground that there may be a method of summarising information that is taught to law students that gives them an advantage. The "case brief" was found to facilitate this procedure. However, there is evidence that all experts use a similar method of solving complex problems so I argued that this was not a good explanation. My final step was to look at the empirical studies on the differences between those with legal training and those without. I found that there is good evidence that the legally trained differ from the non-legally trained in that they are more likely to use counterfactual reasoning and are less likely to be adept in probabilistic thinking than the non-legally trained. I argued that these two cognitive habits would be potentially of benefit to a parliamentarian. Counter factual thinking was found to be beneficial in stimulating the creative production of ideas while a non- 
probabilistic cognitive orientation is of benefit to a parliamentarian because it allows them to communicate in a non-ambiguous way.

In Chapter 8 I addressed the negative relationship between Parlage and CM. I explained this in terms of ambition. An individual who enters parliament at a young age can be seen to be more politically ambitious than an individual who enters at a later age. This ambitiousness is manifested in a greater assiduousness in taking opportunities as they arise. I also examined ambition in terms of the phenomenon of the decline in ambition that seems to take place in a number of forums. The idea here is that individuals who do not achieve their goals by the average age at which such goals are usually achieved tend to lower their aspirations. I explained how this force may be at work in the Australian system such that an individual who enters parliament after the age of 38 is more likely to lower their aspirations by the age of 47 if they have not been appointed to cabinet given that this is the average age at which CMs are appointed and that there is an average 9 year "waiting period" for a cabinet appointment. Parliamentarians who enter before the age of 38 are less likely to lower their aspirations after the expiration of the "waiting period" because, on average, they will not have reached the age of 47 . I also addressed the reason why there should be a negative relationship between age and appointment to higher political office. This is a motif in the political literature. I looked at a number of possible explanations for this including the idea that cognitive abilities decline and that testosterone declines. I did not consider these types of argument convincing because the pattern of change in the chances of promotion is quite different from the changes that take place in cognitive ability and testosterone as an individual ages. The most convincing argument is that it is ambition 
that declines and this has an effect on the probability of appointment after the middle of the fifth decade.

In Chapter 9 I addressed the negative association between concrete language use and CM. I determined that the three variables isolated in the model building procedure were likely to be measuring concreteness of language or something very similar. I then went on to consider some of the literature on the influence of differing levels of concreteness on cognitive phenomena. I found that the literature supports the idea of a link. In particular, abstract thinking is related to a greater ability to solve team-based problems. Concrete thinking is also possibly behind the ratio-bias phenomenon. Finally, concrete language is more persuasive than abstract language. Thus, there is likely to be a set of cognitive habits which are positively associated with abstractness and which account for the appointment to cabinet of CMs. In order to explore this possibility I turned to the research on the psychological level of construal. This theoretical framework links abstract thought with the extent to which an individual has a focus on the distal rather than the proximate. I gave examples of how those with a distal level of construal would be at an advantage in being able to assess differing alternatives that had non-alignable factors while those with a more concrete level of construal would have difficulty doing so. Finally, I looked at how those with an abstract mindset may be more likely to stick to their long term ideological outlook than those with a short-term mindset. I argued that those with a concrete mindset are more likely to depart from their stated ideological stance and this is detrimental in political circles as it demonstrates that such individuals may be unreliable in their commitment to their ideology. In the final section of Chapter 9 I compared the highest scorer on concreteness in the sample 
with the lowest scorer on the assumption that these two individuals would differ also in terms of their PLC. This assumption was borne out in that De-Anne Kelly, the highest scorer on a composite measure of concreteness (Con, Img and Def), had the characteristics of low level construal such as a focus on herself and her electorate and she lacked an overarching set of ideas tying her observations together. The lowest scorer on concreteness (Simon Crean) exhibited the opposite. His high PLC was evidence by a high degree of outward orientation and a coherent set of ideas linked by an overarching way of providing coherence to his observations.

In essence, Chapter 6 answers the first research question in that it is this chapter which identifies the factors associated with $\mathrm{CM}$ while chapters 7,8 and 9 answer the second research question in that they provide explanations as to why these factors should be associated with CM.

In the next section I will address some general ideas that emerge from the research I have undertaken

\section{Section 10.3: CM Selection may be a Species of Personnel Selection.}

By demonstrating that there are three variables that can classify parliamentarians into CMs and no-CMs with approximately $78 \%$ accuracy I have essentially shown that $\mathrm{CM}$ selection can be considered as transparent as analytical selection methods such as those used to determine the suitability of individuals for higher level training in the airforce (Garrad 2003). In this section I would like to explore the possibility that much of the discussion of ephemeral qualities such as "leadership" may be reducible to 
measurable characteristics and that the notion of "leadership" is at best a useful shorthand for these characteristics and at worst a reification of ephemeral notions of what makes a "leader".

What is being proposed here is that the way CMs are selected is much like the way any individual is selected for promotion. Those who are doing the selecting need to ensure that they select individuals with the right qualities. One way of doing this is by observation over a long period to see how individuals perform at lower levels. We can see how parliamentarians enter parliament and are assessed by their colleagues, in the case of the ALP and by their leader, in the case of the LNPC. Those that show that they are able to handle the demands of parliamentary life are given a promotion, possibly to the role of parliamentary secretary or junior minister. This puts them under more pressure to perform and also more scrutiny. Those that are able to perform at this level are then likely to be promoted further. At all stages they are under scrutiny and those that do very well at each subsequent level are likely to be promoted. This is the standard way of being promoted in any bureaucracy. The words written over one hundred years ago in a quite different context describe the same phenomenon:

When I was a lad I served a term

As office boy to an Attorney's firm

I cleaned the windows and I swept the floor

And I polished up the handle of the big front door $\ldots[] \ldots$

As office boy I made such a mark

That they gave me the post of a junior clerk 
I served the writs with a smile so bland

And I copied all the letters in a big round hand

$\ldots[] \ldots$

In serving writs I made such a name

That an articled clerk I soon became

I wore clean collars and a brand-new suit

For the pass examination at the Institute

$\ldots[] \ldots$

Of legal knowledge I acquired such a grip

That they took me into the partnership

.......(Gilbert and Sullivan 1878, from H.M.S. Pinafore)

What I am suggesting is that, as with Sir Joseph in HMS Pinafore, CMs are selected by observation of how well they do at each level. There are no characteristics that are mandatory. Instead, members of the selectorate observe individuals over time to determine how well the individual is able to do the lower level jobs leading up to CM. An individual may have failings in one sphere but is able to make up for them in another. The selectors will note the strengths and weaknesses and make an overall assessment of an individual's ability to perform at higher levels. In short, my contention is that there is no need for reference to a quality called leadership because the process of $\mathrm{CM}$ selection is reducible to a personnel selection process.

The important point is that if CM appointment is reducible to a species of personnel selection then, like other personnel selection methods, it should be amenable 
to analysis in terms of measurable characteristics. This is essentially what I have demonstrated in this thesis. I have demonstrated that it is possible to reduce the process of $\mathrm{CM}$ selection to a number of variables which, conceivably, could take the place of the long period of observation usually required to identify CMs.

Although the idea that this kind of "talent identification" may seem heretical to traditionalists it has been applied in many contexts. To illustrate how this might operate in another context I would like to use the example of talent identification in sport. In recent years talent identification methods have been used to determine which school aged children are likely to go on to become professional athletes. One example is Pienaar et al (1998) who took anthropometric and motor measurements of the top three teams in the South African under 11 rugby cohort. They used non-rugby playing boys of the same age as controls and developed a regression model in which four motor skills and four anthopometric measures were the dependent variables. Applying this model to a broader out-of-sample cohort of players in the under 11 league they were able to classify players as back or forward players with an accuracy of $88 \%$. The variables that were important in the discriminant equations were 7 metre passing accuracy, sprint time, flexed arm hang, vertical jump, femur width, arm correction, calf correction and stature/body mass. The important point to be made here is that the method does not rely on observation of actual rugby playing. It uses base level characteristics that are proximate to the higher level characteristics that an actual rugby player requires. This is essentially what I have done with the CM models. There is no evidence that CMs are chosen because they have a legal education, use less concrete language or entered 
parliament early. However, these base level characteristics are proximate to higher level characteristics which are selected for.

There is a good argument for saying that the analytical methods are more objective than the traditional methods of selection. The evidence for this is that it is very difficult to determine what the high level characteristics are that an individual is selected for. In chapter 2 I surveyed the literature on the subjective methods used for selecting CMs and found that even interviews with leaders did not provide an analytical framework for determining the criteria for selecting CMs. Fraser, for example, seems to have used completely different methods for choosing Howard on one hand and Chaney on the other. Other literature referred to "parliamentary performance" and such characteristics as the ability to contribute to party policy. However, the indications were that the observational criteria were ephemeral. Similarly, the selection of athletes, until recently, took place using largely subjective methods. Team members for US baseball were traditionally selected by a talent scout who would attend minor league games and look for what he thought was the high level characteristics demonstrative of playing talent. However, Lewis (2004) shows that the careful analysis of statistical data relating to individual players ("sabermetrics") yields better results for the selection of baseball players than the traditional subjective approach. In baseball and rugby player selection and, it is contended, $\mathrm{CM}$ selection, it is very difficult to subjectively determine the characteristics that lead to success. The evidence for this is that it takes a long period of observation in each of these fields to work out who will actually succeed. However, as I have demonstrated, it is possible to determine the objective measurable qualities that are important. 


\section{Summary of Section 10.3}

To summarise this part of the discussion, we can see that the standard method of selecting CMs is basically an observational method which is essentially a species of personnel selection. There are a number of high level characteristics such as "parliamentary performance" which are selected for but these are difficult to pin down. Therefore, the selector needs to observe the potential CM over a long period to make a decision. The analytical methods using CM models do not directly determine the high level characteristics that are determinative of CM selection. Instead, they use measures of characteristics which are proximate to the higher level characteristics that are associated with CM.

\section{Section 10.4: Methods and approach: Problems and Possible Extensions}

As with any research project, there are a number of caveats in respect of the methods used and approach taken. In this section I would like to highlight a number of issues that should be taken into account in any further research undertaken on the topic. The first of these deals with the possibility that parliamentarians may change their language use in response to the findings of the model and therefore any subsequent attempt to use these methods may be thwarted. As we shall see there are alternative speech and text samples that can be used so that this does not present a major threat to the efficacy of the approach. Another issue is the choice of the linguistic variables used. The basic raw materials for the generation of the linguistic variables were the maiden 
speeches of parliamentarians and I made a choice to use a particular set of linguistic variables generated from these speeches in this thesis. However, it is possible that the classification accuracy of the models could be improved by using quite different variables such as n-grams. Finally, the choice of classification algorithm was logistic regression. However, it is possible that classification accuracy could be improved by using different methods.

\section{Changes in parliamentarian's speech behaviour due to awareness of the modelling methods}

In this thesis I have used a public source of information to derive linguistic variables which were then used to derive predictive models. I then examined the variables in the models to derive some characteristics of CMs that, if possessed by a parliamentarian might lead to her becoming a CM. Thus, this thesis has both a practical and a theoretical aspect. The practical aspect is that it provides a method by which future neophyte parliamentarians can be reasonably accurately classified as future CMs or non-CMs. However, it is possible that individuals who come to know of the methods used in this thesis might change their speech behaviour in the future in order to mask their true baseline characteristics. This could potentially alter the behaviour of the variables Con, Img and Def in the sample of incoming parliamentarians. The question we must consider is whether this has implications for the current models.

If neophyte BBs in federal parliament did start using less concrete language, then the predictive ability of the models containing these variables would most likely not be applicable to newcomers to parliament. This is because the models were built 
using speeches which were delivered unselfconsciously. A parliamentarian who is aware that he needs to use more abstract words from the PYMCP sample in order to be classified as a potential CM may deliberately adopt this strategy. This would decrease the predictive validity of the committee of models. In this situation a predictive model would need to be created using an unselfconscious speech or text sample. Contributions to committee proceedings, spontaneous media interviews and even electorate level speeches by candidates could provide a rich source of text for analysis. The problem with using such data is collecting it. While committee proceedings are recorded in Hansard the other sources would be difficult for a researcher to collect. However there is one source that is easily collectable: personal websites. Almost all MPs now have their own personal websites. A member who did not would be at a considerable electoral disadvantage as it is now the accepted method by which a parliamentarian makes contact with the general public. Any criticism that much of this text may not be written by the parliamentarian himself could be met with the answer to the ghost writer problem mentioned in Chapter 4. That is, the ghost writer puts enough information representative of the principal into the speech/text that it is possible to distil the principal's voice. Thus, the primary texts used for analysis would not be maiden speeches but the initial text from the websites of neophyte parliamentarians. This would, of course, have to be collected soon after the parliamentarian entered parliament because we need a sample of text that is written before each parliamentarian begins to follow a particular career trajectory.

Thus, the procedure would be to repeat the procedure undertaken in this thesis but using website texts as the basic documents. 
In sum, a self-conscious desire on the part of neophyte BBs to change their language could conceivably make the committee as it is presented in this thesis inapplicable to newcomers to parliament. However, by using other text sources such as web pages this problem could be overcome.

\section{Using different linguistic variables}

In this thesis I have used two sets of linguistic variables. I have used the variables generated by LIWC and have derived a set of psycholinguistic variables based on the PYMCP data. Only three variables remained in any of the models after the sifting process: Con, Img and Def. However, in the text analysis research there is a plethora of other methods available. The most basic method is the "bag of words" approach which uses the individual words in a document as the basic information unit. The idea here is that a document with a large proportion of its text containing one particular word is unlikely to be in the same class as a document with a low occurrence of that word.

Building on the bag of words approach is the technique of using adjacent word clusters or "n-grams". The idea here is that a word such as "nuclear" can occur in a variety of contexts and it is the context of the word that gives it explanatory power. Thus, the bigram "nuclear power" is conceivably more likely to be used by a conservative than the bigram "nuclear waste". Bigrams have been found deliver statistically significant results in discriminating between types of text. Working with bigrams in the analysis of detective fiction, Lamkin and McCarthy (2011) find that the bigram "my office" is indicative of the hardboiled genre of detective fiction whereas the bigram "upon the" is indicative of the whodunit genre. 
Another possible method is Latent Semantic Analysis which uses certain words to imply the subject of a text. The idea here is that the word "captain" is more likely to appear in a document about airlines and ships than it is to appear in a document about dentistry. Using the latent semantics of the word "captain" can therefore help to classify the document.

This is just a small sample of the methods that are used in text analysis. There is a general finding that certain methods work better in particular areas but there is no general approach that can be expected to work better than any other. It is therefore possible that some different method or even a combination of methods could be used to increase the classification accuracy of the speech samples in this thesis over and above that which has been achieved.

\section{Using other classification algorithms}

In this thesis I have used a logistic regression to classify speeches. This is a very widely accepted method of classification. However, there is increasing evidence that other methods may be better at classifying texts.

Neural networks $(\mathrm{NN})$ have been employed in classification tasks for over 20 years and have been found to be superior to statistical methods such as logistic regression for some applications. They work by "learning" the association between the independent and dependent variables. The internal architecture consists of a set of interconnected "neurons" which react to the inputs (independent variables) and generate an "output" (the dependent variable). During the training stage the internal connections 
between neurons are adjusted in order to get the predicted value of the dependent variable to approximate the actual value of the dependent variable in the training case under consideration. This process continues with all cases in the dataset over many iterations until the association between independent and dependent variables has been inculcated into the interconnections between neurons. The superior classification accuracy of NNs for many applications in comparison to statistical methods occurs because they are able to model highly non-linear data, do not require the explicit specification of the functional relationship between the independent and dependent variables, and are able to achieve accurate classification with a lower sample size than more traditional classification methods. It is possible that neural networks could be used in the classification task undertaken in this thesis, thus increasing the classification accuracy.

The most prominent classification technique in text analysis in recent years has been support vector machines. Like neural networks, the support vector machines (SVMs) do not use statistical concepts to distinguish between classes. The method works by creating a hyperplane (a support vector) between two classes that maximises the distance between the two classes. Because this distance is maximised the classification accuracy is higher than if the dividing line were calculated as an average of the distances between classes. In many studies support vector machines have been found to be superior at classifying text than neural networks. Therefore it may be that SVMs would enable a higher level of classification accuracy in the classification of CMs. As an indication of the efficacy of this approach, Diermeier, Godbout, $\mathrm{Yu}$ and 
Kaufman (2012) achieved an accuracy of $92 \%$ in classifying US senators on the basis of ideology using SVMs to analyse their speeches.

One caveat needs to be kept in mind when considering non-probabilistic methods such as NNs and SVMs. Although these methods achieve higher levels of classification accuracy than probabilistic methods they do not provide explanations as comprehensive as more traditional methods. For example, in logistic regression we can immediately see whether there is a significant relationship between an independent variable and the dependent variable and, if there is such a relationship, how strong the relationship is. With non-statistical methods the relationships between the independent variables and the dependent variable is not as transparent. It is certainly possible to determine the general influence of the independent variables on the dependent variable and the approximate strength in relation to other variables but it is not possible to come up with an explanation of how much the independent variable contributes on its own to the value of the dependent variable holding other variables constant. For this reason non-statistical methods are not good for the development of theory. In Chapters 7, 8 and 9 I was able to develop an explanation for the efficacy of each of the variables in the two CM models because the models explicitly state the direction of their influence on the dependent variable holding the other variables constant. In the non-statistical context this is more problematic because each individual independent variable contributes to the generation of the dependent variable value in concert with the other independent variables. As such, isolating individual influences of dependent variables, as is the standard procedure in theory building, is difficult. 
In sum it can be said that there are possible gains to be made in the classification accuracy of CMs using essentially the same data but different classification methods. Neural networks and SVMs are two that could plausibly be used for this but they suffer from the disadvantage that they make it difficult to develop theoretical insights.

\section{Summary of Section 10.4:}

In this section I have considered a number of issues that may need attention in subsequent related research. I considered the possibility that parliamentarians may change their speech behaviour in response to their knowledge of the model. The solution here was to use other text sources such as websites. I also considered the issue of using different linguistic variables. While there is no a priori reason why different variables might result in better classification it has been shown that various types of linguistic variables have had success in text classification and it is therefore worthwhile trying a number of different methods in order to increase the classification accuracy. Similarly, it is worthwhile considering using classification algorithms that have been shown to yield higher classification accuracies than logistic regression. However, the major caveat here is that those which are most effective, NNs and SVMs, may not be able to yield good theory building results.

Having considered a number of possible improvements to the approach taken in this thesis I would like to turn to two possible applications of the method. 


\section{Section 10.5: Possible applications.}

In this section I wish to discuss two possible applications. The first may be of benefit to party leaders and selectors who wish to identify talent in parliamentary neophytes. The second may be of benefit to lobbyists who wish to identify future CMs in order to cultivate working relationships with them.

\section{Aiding the Selectors}

The most direct application of the models is in the process of potential CM identification. We saw in Chapter 2 that the ministerial selection process was looked at by some researchers as a talent evaluation problem where, despite all the screening based on a candidate having the right ideological leaning and fulfilling the requirements of the various coalition members, the leader still had to take a chance that the selected minister would be able to successfully do the job. The CM models effectively reduce the risk that a leader takes in such situations.

As well as reducing the risk that the leader takes, identifying potential CMs early in their first term has a significant organisational benefit. The idea here is that individuals so identified could be fast-tracked. Such individuals could be given preference in promotions to junior ministerial roles, possibly leapfrogging the less important role of parliamentary secretary. In this way a leader could ensure that there was supply of capable and experienced individuals ready to take over from a CM who was dismissed from or voluntarily left cabinet. 


\section{Knowing whom to Lobby}

Another application is the identification of up and coming CMs for the purposes of cultivation by lobbyists. The idea here is that a lobbyist has an advantage if she is able to identify, from a cohort of entrants to parliament, who is likely to be influential in subsequent years. A lobbyist who cultivates a relationship with such a person is in a better position that a lobbyist who approaches that same person later when they have become a CM. The reason for this is that an existing $\mathrm{CM}$ has multiple demands imposed on her and is less likely to be willing or able to spend time developing a working relationship with an individual lobbyist. On the contrary, there are likely to be many lobbyists vying for the CMs attention. If the lobbyist is able to approach that $\mathrm{CM}$ before they become a CM, preferably when they are a neophyte backbencher, they will have significantly less competition from other lobbyists and they are therefore more likely to be open to developing a working relationship with an individual lobbyist.

One drawback of the CM models for both these applications is that there is a strong inclination to avoid analytical methods in areas which have traditionally used subjective methods. This is despite the fact that the actuarial approach to decision making in repetitive situations has been found to be significantly more efficient than using "clinical” judgment (Dawes et al 1989; Grove et al 2000). This has been shown to be the case in such diverse fields such as predicting legal outcomes (Ruger et al 2004), predicting wine prices (Lecocq and Visser 2006) and breast cancer diagnosis (Eadie et al, 2011). Adoption of such techniques is hindered by the fact that organisations are notoriously slow at responding to the insights gained by using 
analytical methods. A good example comes from Lewis who was one of the originators of sabermetrics, a method of using statistical analysis in selecting baseball players:

The people who were paid to manage professional teams failed to see the point. They hadn't even bothered to compile the information they need to analyze their systems intelligently. Presented with new information (by sabermetricians), they showed little interest in it, even when it was offered to them gratis. (Lewis 2004, p. 84)

Given the initial reluctance to adopt analytical methods, it is worthwhile noting that, over time, such systems are eventually adopted. Even in the fields of wine tasting and baseball where, traditionally, important decisions were made by authority figures who used subjective methods to make evaluations, others in the industry realised that there was merit in using more analytical methods. Thus, despite the likelihood of initial rejection, it is likely that the methods will gain general acceptance over time and those who adopt the methods earlier will have a significant advantage.

\section{Summary of Section 10.5}

In this section I have discussed two possible applications of the model. The first is a straightforward application to the problem of identifying talent early for the purposes of fast-tracking. It is envisaged that this would be of use to party selectors. The second application is intended to solve the problem lobbyists face of which neophyte BBs to invest time and effort in so as to maximise the probability of having long term 
political influence. It is anticipated that neither of these applications are likely to gain acceptance in the short term. However, as with any analytical method that performs better than clinical judgment, it is likely that there will be acceptance in the long term.

\section{Section 10.6: Conclusion}

The object of this thesis has been to answer two related questions:

1) What are the characteristics that lead to individuals becoming CMs in the Australian federal parliament?

2) Why are those characteristics determinant of becoming a CM?

In order to answer the first question I created a logistic regression models to classify members of the ALP and the LNPC into CMs and non-CMs.

In order to address the second question I undertook an analysis of the literature to determine why the characteristics identified in the modelling process should be determinative of CM success. I was able to demonstrate that there are good reasons why the variables in the models should be related to CM success.

In this chapter I have attempted to put these findings into a broader context and demonstrate that $\mathrm{CM}$ selection is really a species of personnel selection. There is no need for a theory of leadership any more than there is a need for a theory of rugbyplayer-ship. This is not to say that there is not a specific set of skills which significantly increases the probability that an individual will perform well in that role and, quite 
possibly be attracted to that role. However, to posit a characteristic over and above this set of baseline characteristics would be to reify a non-existent quality.

In this chapter I also discussed a number of issues that it would be worthwhile to address in any subsequent related work in this area. The first of these is the text source. In this regard it was noted that in order to avoid the problem of using maiden speech text that has been self-consciously altered it would be useful to use other publicly available text sources such as websites. I also discussed the possible advantages of using different linguistic variables to improve the classification accuracy of the models. Another way of increasing classification accuracy is to use different classification methods. Two non-probabilistic methods were discussed NNs and SVMs. Both these methods have the potential to improve classification accuracy. However, being nonstatistical these methods tend to be difficult to use for theory development.

Finally I have attempted to outline two practical applications of the models. Both applications are based on the ability of the models to identify potential CMs from the pool of new entrants to parliament. The first application is potentially of use to selectors who want to have an insight into whom to focus on in cultivating ministerial talent in the party. The idea here is that such individuals can be "fast-tracked" into leadership positions. The second application is of use to lobbyists. The idea is that lobbyists can use the models to determine whom to cultivate as targets for their lobbying activities. The idea here is that it is likely to be easier to cultivate a relationship with a neophyte than an existing CM but if a lobbyist is going to cultivate a relationship with a neophyte parliamentarian it would be best to cultivate a relationship with a neophyte who is likely to become a $\mathrm{CM}$ at some time in the future than to 
cultivate a relationship with a neophyte parliamentarian who is unlikely to become a CM.

Thus, it can be stated that the original research questions have been answered. An original contribution has been made to the field of parliamentary leadership in that I have provided support for the proposition that $\mathrm{CM}$ selection is a species of personnel selection and that the concept of "leadership" may be redundant in the context of the Australian federal parliament. I have also considered some areas in which the methods might be improved. Finally, I have been able to suggest to possible practical applications of the method. 


\section{Bibliography}

Advertiser (2007), 'Where the Poll will be Won or Lost, January 25:18.

Age (2005), 'Dear Diary, the Victorians are Growing Restless', June 25: 10.

Agrafiotis DK, Cedeno W, and Lobanov VS (2002), 'On the Use of Neural Network Ensembles in QSAR and QSPR, Journal of Chemical Information and Computer Sciences, 42(4):903-911

Alderman RK and Cross JA (1985), 'The Reluctant Knife: Reflections on the Prime Minister's Power of Dismissal', Parliamenatary Affairs, 38(4): 387-408.

Alt JE (1975), 'Continuity, Turnover, and Experience in the British Cabinet, 1868 1970', in V Herman and JE Alt (eds.), Cabinet Studies: a Reader, New York: St Martin's Press.

Ambroise C and McLachlan GJ (2002), 'Selection Bias in Gene Extraction on the Basis of Microarray Gene-Expression Data, Proceedings of the National Academy of Science USA, 99: 6562-6566.

Amsel E, Langer R and Loutzenhiser M (1991), 'Do Lawyers Reason Differently from Psychologists: A Comparative Design for Studying Expertise', in RJ Sternberg and PA Frensch (eds.), Complex Problem Solving: Principles and Mechanisms, Hillsdale NJ : Lawrence Erlbaum Associates.

Anderson L (2007), 'PM Needs New Pitch, Advertiser, January 8: 21. 
Australian (2007), 'Howard Deploys for the Electoral Fight', January 24: 13.

Australia, House of Representatives (1990), Debates, May 17 1990: 746-750.

Australia, House of Representatives (1996), Debates, May 1 1996: 192-195

Aubin T (1999), Peter Costello: the Full and Unauthorised Story of the Man who Wants to be PM, Sydney: Harper Collins.

Azuaje F (2010), Bioinformatics and Biomarker Discovery: “Omic” Data Analysis for Personalised Medicine, London: Wiley.

Bagehot W (1963) [1867] The English Constitution, London: Penguin.

Bak D and Palmer G (2010), 'Testing the Biden Hypotheses: Leader Tenure, Age, and International Conflict', Foreign Policy Analysis 6(3):257-273.

Ballard E (1983), 'Canadian Prime Ministers: Complexity in Political Crises', Canadian Psychology, 24(2): 125-129.

Bass B (1990), Bass and Stogdill's handbook of leadership: Theory, research, and managerial applications (3rd ed), New York: Free Press.

Bass B (2000), 'The Future of Leadership in Learning Organizations', The Journal of Leadership Studies, 7(3):18-40.

Baxter RA, Gawlwer M and Ang R (2007) 'Predictive Model of Insolvency Risk for Australian Corporations', Sixth Australasian Data Mining Conference: 19-25. 
Baxter R, Gawler M. and Ang R (2007) 'Predictive Model of Insolvency Risk for Australian Corporations', in P Christen, PJ Kennedy, J Li, I Kolyshkina and GJ Williams (eds.). Proceedings of the Sixth Australasian Data Mining Conference, (AusDM 2007), Gold Coast, Australia ACS, CRPIT 70: 21-28

Bennis WG (1959), 'Leadership Theory and Administrative Behavior: The Problem of Authority', Administrative Science Quarterly, 4(3), pp. 259-301.

Berger MA and Solan LM (2008), 'The Uneasy Relationship Between Science and Law: An Essay and Introduction', [Symposium: A Cross-Disciplinary Look at Scientific Truth] Brooklyn Law Review, 73(3): 847-857.

Berkowitz SJ (2006), 'Developing Critical Thinking through Forensics and Communication Education: Assessing the Impact through Meta-Analysis', in BM Gayle, RW Preiss, N Burrell and M Allen (eds.), Classroom Communication and Instructional Processes: Advances through Meta-analysis, Mahwah, NJ: Lawrence Earlbaum Associates: 43-59.

Berlinski S, Dewan T and Dowding K (2007), 'The Length of Ministerial Tenure in the United Kingdom, 1945-97', British Journal of Political Science, 37(2): 245262.

Berlinski S, Dewan T and Dowding K (2010), 'The impact of Individual and Collective Performance on Ministerial Tenure', Journal of Politics, 72(2):559-571. 
Berlinski S, Dewan T and Dowding K (2012), Accounting for Ministers : Scandal and Survival in British Government, 1945-2007, Cambridge, Cambridge University Press.

Blaines i Vidal J and Leaver C (2010), 'Are Tenured Judges Insulated from Political Pressure?', Journal of Public Economics, 95 (7-8): 570-586.

Blasi G (1995), 'What Lawyers Know: Lawyering Expertise, Cognitive Science, and the Functions of Theory, Journal of Legal Education, 45(3): 313-97.

Blaustein A and Porter C (1954), The American Lawyer: A Summary of the Survey of the Legal Profession, Chicago: University of Chicago Press.

Blewett N 1999, A Cabinet Diary, Kent Town, SA: Wakefield Press.

Blondel J (1991) 'Cabinet Government and Cabinet Ministers', in J Blondel and J Thiebault (eds.), The Profession of Government Minister in Western Europe, London, Macmillan.

Boehm C (1999), Hierarchy in the Forest, Cambridge, MA: Harvard University Press.

Boone C, van Olffen W and Roijakkers N (2004), 'Selection on the Road to a Career: Evidence of Personality Sorting in Educational Choice', Journal of Career Development, 31(1): 61-78. 
Bowden GJ, Nixon JB, Dandy GC, Maier HR and Holmes M (2006), 'Forecasting Chlorine Residuals in a Water Distribution System using a General Regression Neural Network', Mathematical and Computer Modelling, 44(5-6): 469-484.

Box GEP (1979), 'Robustness in the Strategy of Scientific Model Building', in RL Launer and GG Wilkinson (eds.) Robustness in Statistics, Academic, New York.

Brace P (1984), 'Progressive Ambition in the House: A Probabilistic Approach', Journal of Politics, 46(2):556-571.

Brewer MB 1979, 'In-Group Bias in the Minimal Intergroup Situation: A CognitiveMotivational Analysis', Psychological Bulletin, 86(2):307-324.

Buck P (1963), 'The Early Start toward Cabinet Office, 1918-55', The Western Political Quarterly, 16(3): 624-632.

Burke, E (2001), 'Reflections on the Revolution in France, JCD Clark (ed.), Palo Alto, CA: Stanford University Press.

Camp RA (2002), Mexico's Mandarins: Crafting a Power Elite for the Twenty-First Century, Berkley, CA: University of California Press.

Canberra Times (2001), 'Howard's Way Sets Battle Lines for Leadership', November 25:20.

Canberra Times (2006), 'Reshuffle will be a Balancing Act', January 24:12. 
Cawley GC and Talbot NLC (2007), 'Preventing Over-Fitting during Model Selection via Bayesian Regularisation of the Hyper-Parameters', Journal of Machine Learning Research, 8: 841-861

Change JC, Wooten EC, Tsimelzon A, Hilsenbeck SG, Gutierrez MC, Elledge R, Mohsin S, Osborne CK, Chamness GC, Allred, DC and O’Connell P (2003), 'Gene Expression Profiling for the Prediction of Therapeutic Response to Docetaxel in Patients with Breast Cancer, Lancet, 362: 362-69.

Chen CH and Lin ZS (2006), 'A Committee Machine with Empirical Formulas for Permeability Prediction', Computers and Geosciences 32(4): 485-496.

Christensen L (2006), 'The Psychology Behind Case Briefing: A Powerful Cognitive Schema', Campbell Law Review, 29(1): 5-27.

Clark JM and Paivio A (1991), 'Dual Coding Theory and Education', Educational Psychology Review, 3(3): 149-210.

Clark JM and Paivio A (2004) 'Extensions of the Paivio, Yuille, and Madigan (1968) Norms' Behavioral Research Methods, 36(3):371-383.

Cohen B (1990), How to Become Prime Minister, Ringwood, Victoria: Penguin.

Commonwealth of Australia (2005), Hansard Style Guide, Canberra: Author.

Coorey P (2000), ‘Too Old for Top Jobs at 60-Plus', Advertiser, December 21:2.

Costello P (2008), The Costello Memoirs, Carlton, Victoria: Melbourne University Publishing. 
Crabb A (2009), Stop at Nothing: The Life and Times of Malcolm Turnbull, Quarterly Essay Series, Melbourne, Black Inc.

Culhane JG (1997), 'The Emperor Has No Causation: Exposing a Judicial Misconstruction of Science', Widener Law Symposium Journal, 2: 185-193.

Cunningham P (2007) 'Ensemble Techniques', Technical Report UCD-CSI-2007-5, University College Dublin, School of Computer Science and Informatics, https://www.csi.ucd.ie/files/UCD-CSI-2007-5.pdf, accessed 19 July 2011.

Cunningham P (2008), 'Dimension Reduction', in M Cord \& P Cunningham (eds.), Machine Learning Techniques for Multimedia, Berlin, Springer: 91 - 112.

Daley P (1996), 'PM May Shuffle His Team After Budget', Sunday Age, August 4:2.

Dawes R, Faust D and Meehl P (1989), 'Clinical versus Actuarial Judgment, Science, 243(4899):1668-1674.

Day SB and Bartels DM (2008), 'Representation over Time: The Effects of Temporal Distance on Similarity', Cognition,106(3):1504-1513

Day SB and Bartels DM (2004), 'Temporal Distance, Event Representation, and Similarity', in KD Forbus, D Gentner and T Regier (eds.), $26^{\text {th }}$ Annual Meeting of the Cognitive Science Society. Hillsdale, NJ: Lawrence Erlbaum Associates. de Groot AD (1946/1978), Thought and Choice and Chess, The Hague, Netherlands: Mouton 
Department of the House of Representatives (2005), House of Representatives Practice, $5^{\text {th }}$ ed., Canberra: Author.

Department of the Senate (2008), Odgers' Senate Practice, $12^{\text {th }}$ ed., Canberra: Author.

Diermeier, D, Godbout JF, Yu B and Kaufmann S (2012), 'Language and Ideology in Congress', British Journal of Political Science, 42(1): 31-55.

Dietterich TG (2000) 'Ensemble Methods in Machine Learning', in J Kittler and F Roli (eds.), Multiple Classifier Systems, Lecture Notes in Computer Science 1857, Cagliari, Italy, Springer: $1-15$.

Dille B and Young M (2000), 'The Conceptual Complexity of Presidents Carter and Clinton: An Automated Content Analysis of Temporal Stability and Source Bias', Political Psychology, 21(3):587-596.

Donovan B (2004), Mark Latham: The Circuitbreaker, Rowville, Victoria: The Five Mile Press.

Dreiseitl S and Ohno-Machado L (2002), 'Logistic Regression and Artificial Neural Network Classification Models: a Methodology Review', Journal of Biomedical Informatics, 35(5-6): 352-359.

Dustin, DA and Davis, HP, (1970), 'Evaluative Bias in Group and Individual Competition', Journal of Social Psychology, 80(1): 103-108.

Dyson S (2009), 'Cognitive Style and Foreign Policy: Margaret Thatcher's Black-andWhite Thinking', International Political Science Review 30 (1): 33-49. 
Eadie L, Taylor P and Gibson A (2011), 'A Systematic Review of Computer-Assisted Diagnosis used in Mammography, 'International Journal of Computer Assisted Radiology and Surgery, 6(1):367-376.

Eakins KR (2006), 'Lawyers in the Legislature: The Case of Ohio', The Social Science Journal, 43(4):717-725.

Efron B (1986)'How Biased is the Apparent Error Rate of a Prediction Rule?', Journal of the American Statistical Association', 81(394):461-470.

Elder JF and Abbott DW (1997), 'Fusing Diverse Algorithms', 29th Symposium on the Interface: Computing Science and Statistics, American Statistical Association, Houston, Texas, May 14-17,

Ellison PT, Bribiescas RG, Bentley GR, Campbell BC, Lipson SF, Panter-Brick C and Hill K (2002), 'Population Variation in Age-Related Decline in Male Salivary Testosterone', Human Reproduction, 17 (12):3251-3253

Emrich C, Brower H, Feldman J and Garland, H (2001), 'Images in Words: Presidential Rhetoric, Charisma, and Greatness', Administrative Science Quarterly, 46(3): $527-557$.

Ericsson KA and Lehmann AC 1996, 'Expert and Exceptional Performance: Evidence of Maximal Adaptation to Task Constraints', Annual Review of Psychology, $47: 273-305$.

Errington W and van Onselen P (2007), John Winston Howard, Carlton, Victoria: Melbourne University Press. 
Eulau H and Sprague J (1964), Lawyers in Politics: A Study in Professional Convergence, Indianapolis, IA: Bobbs-Merrill Co.

Fast LA and Funder DC (2008) 'Personality as Manifest in Word Use: Correlations With Self-Report, Acquaintance Report, and Behavior', Journal of Personality and Social Psychology, 94(2):334-346.

Fielding AH and Bell JF (1997), 'A Review of Methods for the Assessment of Prediction Errors in Conservation Presence/Absence Models', Environmental Conservation, 24(1): 38-49.

Fishel J (1971), 'Ambition and the Political Vocation: Congressional Challengers in American Politics', The Journal of Politics, 33(1): 25-56

Forgas JP (2007), 'When Sad is Better than Happy: Negative Affect can Improve the Quality and Effectiveness of Persuasive Messages and Social Influence Strategies', Journal of Experimental Social Psychology, 43(4): 513-528

Forman G (2003), 'An Extensive Empirical Study of Feature Selection Metrics for Text Classification, Journal of Machine Learning Research, 3:1289-1306.

Fox RL and Lawless JL (2004), 'Entering the Arena? Gender and the Decision to Run for Office', American Journal of Political Science, 48 (2): 264-80.

Fox RL and Lawless JL (2005), 'To Run or Not to Run for Office: Explaining Nascent Political Ambition', American Journal of Political Science, 49 (3): 642-59. 
Franklin M (2000), 'State's Lack of Foresight gives Mexicans a Leg Up', Courier Mail, December 23:20.

Friedman JH (1994), ‘An Overview of Predictive Learning and Function Approximation', in V Cherkassky, JH Friedman and H Wechsler (eds.), From Statistics to Neural Networks, Proceedings of the NATO/ASI Workshop, Springer Verlag: $1-61$

Friedman JH (1993), ‘An Overview of Predictive Learning and Function Approximation', in V Cherkassky, JH Friedman and H Wechsler, (eds.), From statistics to neural networks: Theory and pattern recognition applications, NATO ASI Series: Computer and Systems Sciences, Springer, Berlin, 136:1-61.

Freitas AL, Gollwitzer P and Trope Y (2004), 'The Influence of Abstract and Concrete Mindsets on Anticipating and Guiding others' Self-Regulatory Efforts', Journal of Experimental Social Psycholog', 40(6): 739-752.

Frey B and Meier S (2003), 'Are Political Economists Selfish and Indoctrinated? Evidence from a Natural Experiment', Economic Inquiry, 41(3):448-462.

Fujita K, Trope Y, Liberman N and Levin-Sagi M (2006), 'Construal Levels and SelfControl', Journal of Personality and Social Psychology, 90(3): 351-367.

Gabrilovich E and Markovitch S (2004), 'Text Categorization with many Redundant Features: Using Aggressive Feature Selection to make SVMs Competitive with C4.5' in Proceedings of the 21th International Conference on Machine Learning, New York: Association for Computing Machinery: 41-48. 
Gaddie RK (2004), Born to Run: Origins of the Political Career, Lantham: Rowman and Littlefield.

Galar M, Fernandez A, Barrenechea E, Bustince H and Herrera F (2011), 'An Overview of Ensemble Methods for Binary Classifiers in Multi-Class Problems: Experimental Study on One-vs-One and One-vs-All Schemes', Pattern Recognition, 44(8): 1761-1776.

Gallagher, M (1985), 'Social Backgrounds and Local Orientations of Members of the Irish Dail', Legislative Studies Quarterly, 10(3):373-394.

Galinsky AD and Moskowitz GB (2000), 'Counterfactuals as Behavioral Primes: Priming the Simulation Heuristic and Consideration of Alternatives', Journal of Experimental Social Psychology, 36(4): 384-409

Garrad MW (2003), ‘Computer Aided Text analysis in Personnel Selection’, PhD Thesis, Griffith University, http://www4.gu.edu.au:8080/adtroot/uploads/approved/adt-QGU20040408.093133/public/02Whole.pdf, accessed $18^{\text {th }}$ July 2008.

Geddes B (1990), 'How the Cases You Choose Affect the Answers You Get: Selection Bias in Comparative Politics', Political Analysis 2(1):131-150.

Gibbs MS, Morgan N, Maier HR, Dandy GC, Holmes M, Nixon JB (2003), 'Use of Artificial Neural Networks for Modeling Chlorine Residuals in Water Distribution Systems', in Proceedings of the International Congress on 
Modeling and Simulation 2, Townsville, Australia: Modeling and Simulation Society of Australia and New Zealand Inc: 789-794

Gordon M (2000), ‘A Reshuffle Fit for an Election', Age, December 20:4.

Gordon M (2005), 'Insider Outsider', Age, February 16, online edition, http://www.theage.com.au/news/National/Insideroutsider/2005/02/15/1108230007168.html, accessed 12 October 2011.

Grattan M (2000), 'Line-up Balances Risk and Opportunity', Sydney Morning Herald, December 20:4.

Grofman B and van Roozendaal (1997), 'Modelling Cabinet Durability and Termination', British Journal of Political Science, 27(3):419-451.

Grove W, Zald D, Lebow B, Snitz B and Nelson C (2000), 'Clinical Versus Mechanical Prediction; A Meta-Analysis', Psychological Assessment, 12(1):19-30.

Guyon I and Elisseeff A (2003), 'An introduction to Variable and Feature Selection', Journal of Machine Learning Research, 3: 1157-1182.

Hain PL (1974), ‘Age, Ambitions, and Political Careers: The Middle-Age Crisis', The Western Political Quarterly, 27(2): 265-274.

Hall MA and Holmes G (2003), 'Benchmarking Attribute Selection Techniques for Discrete Class Data Mining', IEEE Transactions on Knowledge and Data Engineering, 15(6): 1437 - 1447. 
Halstead JBH, Goerger S and McGinnis ML (2006), 'Recruiter Selection Model', Operations Research Center of Excellence Technical Report No: DSE-TR-0623, United States Military Academy, West Point, New York.

Han J and Kamber M (2006), Data Mining, Concepts and Techniques, San Francisco, CA: Morgan Kaufman Publishers.

Hansen LK, Salamon P (1990), 'Neural Network Ensembles'. IEEE Transactions. Pattern Analysis and Machine Intelligence, 12(10): 993-1001.

Harvey, M (2000), 'Newman Rumoured to Quit, The Herald-Sun, June 9: 8.

Headey BW (1974), British Cabinet Ministers : The Roles of Politicians in Executive Office, London: Allen and Unwin.

Heatherton T and Vohs K (2000), 'Interpersonal Evaluations following Threats to Self: Role of Self-esteem, Journal of Personality and Social Psychology, 78(4): 725736.

Henderson I (2000), 'PM Brings in Young Guns - The New Line-up - The Howard Reshuffle', Australian December 20:1.

Hendrick HW (1979), 'Differences in Group Problem-Solving Behavior and Effectiveness as a Function of Abstractness', Journal of Applied Psychology, 64(5): 518-525. 
Herman, M (2005), 'Assessing Leadership Style: Trait Analysis', in Jerrold M Post (ed.), The Psychological Assessment of Political Leaders, Ann Arbor: The University of Michigan Press: 178-212.

Herrick R and Moore MK (1993), 'Political Ambition's Effect on Legislative Behavior: Schlesinger's Typology Reconsidered and Revisited', Journal of Politics 55(3): $765-76$.

Hirst G, Riabinin Y and Graham J (2010), 'Party Status as a Confound in Automatic Classification of Political Speech by Ideology', in S Bolasco, I Chiari and L Giuliano (eds.), Statistical Analysis of Textual Data, Proceedings of 10th International Conference, 9-11 June 2010, Sapienza University of Rome:731742.

Holtzman NS, Vazire S and Mehl M (2010), 'Sounds like a Narcissist: Behavioral Manifestations of Narcissism in Everyday Life', Journal of Research in Personality, 44(4):478-484.

Horn JL and Cattell, RB (1967), 'Age Differences in Fluid and Crystallized Intelligence', Acta Psychologica, 26(2):107-129.

Horowitz M, McDermott R and Stam AC (2005), 'Leader Age, Regime Type, and Violent International Relations', Journal of Conflict Resolution 49(5): 661-685.

House RJ, Spangler WD and Woyke J (1991) 'Personality and Charisma in the U.S. Presidency: A Psychological Theory of Leader Effectiveness', Administrative Science Quarterly, 36(3):364-396. 
Howard J (2010), Lazarus Rising, Sydney: HarperCollinsPublishers.

Huber J and Martinez-Gallardo, C (2008), 'Replacing Cabinet Ministers: Patterns of Ministerial Stability in Parliamentary Democracies', American Political Science Review, 102(2):169-180.

Jackson SE, Brett JF, Sessa VI, Cooper DM, Julin JA and Peyronnin K (1991), 'Some Differences Make a Difference: Individual Dissimilarity and Group Heterogeneity as Correlates of Recruitment, Promotions, and Turnover, Journal of Applied Psychology, 76(5): 675-689.

Just MA, Newman SD, Keller TA McEleney A and Carpenter PA (2004), Imagery in Sentence Comprehension: an fMRI Study', NeuroImage, 21(1): 112- 124.

Kam C, Bianco W, Sened I and Smyth R (2010), 'Ministerial Selection and Intraparty Organization in the Contemporary British Parliament', American Political Science Review, 104(2):289-306.

Kiewiet DR and Zeng L (1993), 'An Analysis of Congressional Career Decisions, 19471986', The American Political Science Review, 87(4): 928-941.

Kelly P (2011), The March of the Patriots: The Struggle for Modern Australia, Carlton, Victoria: Melbourne University Publishing.

Kerby M (2009), 'Worth the Wait: Determinants of Ministerial Appointment in Canada, 1935-2008', Canadian Journal of Political Science, 42(3):593-611. 
Kim H, Rao AR and Lee AY (2008), 'It's Time to Vote: The Effect of Matching Message Orientation and Temporal Frame on Political Persuasion', Journal of Consumer Research, 35(6): 877-889.

King A (1981), 'The Rise of the Career Politician in Britain - And Its Consequences', British Journal of Political Science, 11(3): 249-285.

King A (1985), 'Margaret Thatcher: The Style of a Prime Minister', in A King (ed.), The British Prime Minister, London: Macmillan: 96-140.

King G, Alt J, Burns N and Laver M (1990) 'A Unified Model of Cabinet Dissolution in Parliamentary Democracies’ American Journal of Political Science, 34(3): 846871.

Kohavi R (1995) ‘A Study of Cross-Validation and Bootstrap for Accuracy Estimation and Model Selection' in CS Mellish (ed.), Proceedings IJCAI-95, Montreal, Que. Morgan Kaufmann, Los Altos, CA: 1137-1143.

Kramer A and Rodden K (2008), 'Word Usage and Posting Behaviors: Modeling Blogs with Unobtrusive Data Collection Methods', in Proceedings of the $26^{\text {th }}$ Annual Conference on Human Factors in Computing Systems (CHI) Florence, Italy: $1125-1128$.

Lam SL and Lee DL (1999), 'Feature Reduction for Neural Network Based Text Categorization, in Proceedings of DASFAA-99, 6th IEEE International Conference on Database Advanced Systems for Advanced Application, Hsinchu, Taiwan: 195-202. 
Lamkin T and McCarthy P (2011), 'The Hierarchy of Detective Fiction: A Gramulator Analysis', in C Murray and PM McCarthy (eds.), Proceedings of the TwentyFourth International Florida Artificial Intelligence Research Society Conference, , May 18-20, Palm Beach, Florida, USA, pp. 257-262.

Laver M, Benoit K and Garry J (2003) 'Estimating the policy positions of political actors using words as data', American Political Science Review 97(2): 311-331.

Lecocq S and Visser M (2006), 'What Determines Wine Prices: Objective vs. Sensory Characteristics', Journal of Wine Economics, 1(1): 42-56.

Lehman HC (1947), 'The Age of Eminent Leaders: Then and Now', American Journal of Sociology, 52(4): 342-56.

Lehman DR, Lempert RO and Nisbett E (1988), 'The Effects of Graduate Training on Reasoning: Formal Discipline and Thinking about Everyday-Life Events', American Psychologist, 43(6): 431-442.

Levin S and Stephan P (1991), 'Research Productivity over the Life Cycle: Evidence for Academic Scientists, American Economic Review 81(4), 114-132.

Ledgerwood A, Trope Y and Chaiken C (2008), Attitudes in their Social Context: Malleability, Stability, and the Role of Construal, unpublished manuscript, University of California, Davis.

Lewis M (2004), Moneyball, New York: W.W. Norton and Company. 
Liberman N and Trope Y (2008), 'The Psychology of Transcending the Here and Now', Science, 322(5905):1201-1205.

Lievens F, Coetsier P, De Fruyt F and De Maeseneer J (2002), 'Medical Students' Personality Characteristics and Academic Performance: a Five-Factor Model Perspective', Medical Education, 36(11): 1050-1056.

Liu X, Hancock J, Zhang G, Xu R, Markowitz D and Bazarova N (2012), 'Exploring Linguistic Features for Deception Detection in Unstructured Text' in Proceedings of the Rapid Screening Technologies, Deception Detection and Credibility Assessment Symposium, January 4 - 7, Grand Wailea, Maui, Hawaii: $14-23$.

Lowe W, Benoit K, Mikhaylov S and Laver M (2011), 'Scaling Policy Preferences from Coded Political Texts, Legislative Studies Quarterly, 36(1): 123-155.

Luyckx K and Daelemans W (2011), 'The Effect of Author Set Size and Data Size in Authorship Attribution', Journal of Literary and Linguistic Computing, 26(1): $35-55$

Maass A, Salvi D, Arcuri L and Semin G (1989) 'Language Use in Intergroup Contexts: The Linguistic Intergroup Bias', Journal of Personality and Social Psychology, 57(6): 981-993.

Maiden S (2007), 'Kemp Ready to Quit the Ministry as Reshuffle Looms’, Australian, January 22: 2. 
Malkoc SA, Zauberman G, and Ulu C (2005), 'Consuming Now or Later? The Interactive Effect of Timing and Attribute Alignability', Psychological Science, 16(5): 411-417.

Marsh M (1981), 'Localism, Candidate Selection and Electoral Preferences in Ireland: the General Election of 1977', Economic and Social Review, 12(4): 267-286

Martindale C (1975), Romantic Progression: The Psychology of Literary History, Washington DC: Hemisphere.

Martindale C (1981), Cognition and Consciousness, Homewood, IL: Dorsey.

Martindale C (1984), 'Evolutionary Trends in Poetic Style: The Case of English Metaphysical Poetry', Computers and the Humanities, 18(1): 3-21.

Martindale C (1986), 'Aesthetic Evolution', Poetics, 15(4-6): 439-473.

Martindale C, Covello E and West A (1986), 'Primary Process Cognition and Hemispheric Asymmetry', Journal of Genetic Psychology, 147(1): 79-87.

Martindale C (1990), The Clockwork Muse: The Predictability of Artistic Change, New York: Basic Books.

Martindale C and McKenzie D (1995), 'On the Utility of Content Analysis in Author Attribution: The Federalist', Computers and the Humanities, 29(4): 259-270.

Matthews R (1984), 'Legislative Recruitment and Legislative Careers', Legislative Studies Quarterly, 9(4): 547-585. 
May R, Dandy G and Maier H (2005), 'Review of Input Variable Selection Methods for Artificial Neural Networks', Artificial Neural Networks - Methodological Advances and Biomedical Applications, http://www.intechopen.com/source/pdfs/14882/InTechReview_of_input_variable_selection_methods_for_artificial_neural_networks.p $\underline{d f}$, accessed July 12, 2011.

McAllister I (1997), 'Australia', in Pippa Norris (ed), Passages to Power: Legislative Recruitment in Advanced Democracies, Cambridge: Cambridge University Press: $15-32$.

McClain E and Christiansen M (1970), 'Personality Characteristics of Students Preparing to Teach High School English', Research in the Teaching of English, 4(2): $149-156$.

Middleton K (2004), 'Gains Entitle WA to Second Cabinet Post, West Australian, October 15: 8 .

Milne G (1998), 'LNPC dismay over division of spoils', Australian, 2 November: 17.

Milne G (2003), 'The Minister for Tantrums, Australian, 6 October: 11

Miller M (1995), The High Priests of American Politics: The Role of Lawyers in American Political Institutions, Knoxville, Tennessee: University of Tennessee Press.

Miner JB (2007), Organizational Behavior Vol. 4: From Theory to Practice, Armonk New York: ME Sharp Inc. 
Morgan D (1966) Congress and the constitution: A study of responsibility, Cambridge MA: Harvard University Press.

Morris J Brotheridge C and Urbanski J (2005), 'Bringing Humility to Leadership: Antecedents and Consequences of Leader Humility, Human Relations, 58(10): 1323-1350.

Morrison CM, Ellis A and Quinlan PT (1992), 'Age of Acquisition, not Word Frequency, Affects Object Naming, not Object Recognition', Memory and Cognition, 20(6):705-714.

Nguyen DV (2005), 'Partial Least Squares Dimension Reduction for Microarray Gene Expression Data with a Censored Response', Mathematical Biosciences 193(1): $119-137$.

Niederhoffer KG and Pennebaker, JW 2002, 'Linguistic Style Matching in Social Interaction', Journal of Language and Social Psychology, 21(4):337-360.

Norris, P ed. (1997), Passages to Power: Legislative Recruitment in Advanced Democracies, Cambridge: Cambridge University Press. 
Northouse P (2004), Leadership Theory and Practice, Thousand Oaks, CA: Sage.

Nussbaum S, Trope Y and Liberman N (2003), 'Creeping Dispositionism: The Temporal Dynamics of Behavior Prediction, 'Journal of Personality and Social Psychology, 84(3): 485-497.

O’Dwyer T (1998), 'Front Benches Display the Legal Aspects of Governance, Australian, November 12:13.

O’Dwyer, T (2003), 'Law Sure Way to Win PM's Favour, Canberra Times, October 2: 17.

O’Malley, E. (2006) 'Ministerial Selection in Ireland: Limited Choice in a PoliticalVillage', Irish Political Studies, 21 (3), 319-36.

O'Neill BJ (1972), 'Defineability as an Index of Word Meaning, Journal of Psycholinguistic Research, 1(4): 287-298.

Oreskes N and Conway E (2010), The Merchants of Doubt, New York: Bloomsbury Press.

Pacini R and Epstein S (1999), 'The Relation of Rational and Experiential Information Processing Styles to Personality, Basic Beliefs, and the Ratio-Bias Phenomenon', Journal of Personality and Social Psychology, 76(6): 972-987 
Paivio A, Yuille JC and Madigan SA (1968), 'Concreteness, Imagery, and Meaningfulness Values for 925 Nouns', Journal of Experimental Psychology, 76(1, Pt. 2): 1-25.

Parliamentary Handbook of the Commonwealth of Australia (1968 - 2008), Australian Government Printing Service/Parliamentary Library: Canberra.

Pennebaker JW and King LA (1999), 'Linguistic Styles: Language Use as an Individual Difference', Journal of Personality and Social Psychology, 77(6): 1296-1312.

Pennebaker JW, Chung CK, Ireland M, Gonzales A and Booth RJ (2007), The Development and Psychometric Properties of LIWC 2007, Austin TX: LIWC.net.

Pennebaker JW and Francis ME (1996), 'Cognitive, Emotional and Language Processes in Disclosure', Cognition and Emotion, 10(6): 601-626.

Pennebaker JW, ME Francis and RJ Booth (2001) Linguistic Inquiry and Word Count, Mahwah, NJ: Erlbaum Publishers.

Perez M (2010), ‘'Inequity Aversion Differences: Experimental Evidence Among Prospective Teachers and Lawyers', School of Education, Stanford University, http://www.stanford.edu/ cuky/index_files/MPerez_Draft02.11.10.pdf, accessed August $3^{\text {rd }} 2011$.

Picard RR and Cook RD (1984), 'Cross-Validation of Regression Models', Journal of the American Statistical Association, 79(387): 575-583 
Pickering PA (1998) 'The Class of 96: A Biographical Analysis of New Government Members of the Australian House of Representatives', Australian Journal of Politics and History, 44(1): 95-112.

Pienaar A, Spamer M and Steyn H (1998), 'Identifying and Developing Rugby Talent among 10-year-old Boys: A Practical Model', Journal of Sports Sciences, 16(8): 691-699.

Polsby N (1990), ‘The Social Composition of Congress', in U Thaysene and R Davidson (eds.), The U.S. Congress and the German Bundestag: Comparison of Democratic Processes, Boulder Colorado: Westview Press.

Power MR and Beradone M (1998), 'Speaking in Parliament: First Speeches of Men and Women', Journal of Applied Social Behaviour, 4(2): 42-55.

Prafka D (2009), 'Leadership as Exhibited by a Private Sector Learning Executive; A Descriptive Case Study of Leadership', unpublished EdD thesis, Raleigh, NC: North Carolina State University, http://repository.lib.ncsu.edu/ir/bitstream/1840.16/4094/1/etd.pdf, accessed January 25, 2011.

Price M and Short J (1997), 'Premier at Odds with PM over Make-up of Cabinet', Australian, 1 October: 2.

Pyszczynski T and Greenberg J (1987), 'Toward an Integration of Cognitive and Motivational Perspectives on Social Inference: A Biased Hypothesis-Testing 
Model', in L Berkowitz (ed.), Advances in Experimental Social Psychology 20,

New York: Academic Press:297-340.

Purpura S and Hillard D (2006), 'Automated Classification of Congressional Legislation', in Proceedings of the 2006 International Conference on Digital Government Research, New York: ACM: 219-225.

Raghuraj, R (2008) 'Data Based System Design and Network Analysis Tools for Chemical and Biological Processes, Unpublished PhD thesis, National University of Singapore, http://scholarbank.nus.edu.sg/bitstream/handle/10635/15976/PHDthesis2008_Ra oRaghuraj_HT040638M.pdf?sequence=1, accessed 12 August 2011.

Ranney A (1965), Pathways to Parliament: Candidate Selection in Britain, Madison: University of Wisconsin Press.

Ransohoff DF (2004), 'Rules of Evidence for Cancer Molecular-Marker Discovery and Validation', Nature Reviews Cancer, 4: 309-314.

Raskin R and Shaw R (1988), 'Narcissism and the Use of Personal Pronouns', Journal of Personality, 56(2): 393-404.

Reynolds A and Paivio A (1968), 'Cognitive and Emotional Determinants of Speech, Canadian Journal of Psychology, 22(3): 164-175.

Reynolds RG, Whallon R, Ali MZ and Zadegan BM (2006), 'Agent-Based Modeling of Early Cultural Evolution', in Evolutionary Computation, 2006, CEC 2006, IEEE Congress:1135-1142. 
Rhode DW (1979), 'Risk Bearing and Progressive Ambition: The Case of Members of the US House of Representatives', American Journal of Political Science, 23(1): $1-26$.

Roring RW and Charness N (2007), 'A Multilevel Model Analysis of Expertise in Chess across the Life Span, Psychology and Aging, 22(2): 291-299.

Rose R (1975), 'The Making of Cabinet Ministers', in V Herman and JE Alt (eds.), Cabinet Studies: a Reader, New York: St Martin’s Press.

Ruger T, Kim P, Martin A and Quinn K (2004), 'The Supreme Court Forecasting Project: Legal and Political Science Approaches to Predicting Supreme Court Decision Making', Columbia Law Review, 104(4): 1150-1210.

Russell DT and Adam EE (1987), 'An Empirical Evaluation of Alternative Forecasting Combinations', Management Science, 33(10): 1267-1276

Sargent DJ (2001), 'Comparison of Artificial Neural Networks with other Statistical Approaches: Results from Medical Data Sets', Cancer, 91(8 Suppl): 1636-1642.

Schaie KW (1983), 'The Seattle Longitudinal Study: A Twenty-One Year Exploration of Psychometric Intelligence in Adulthood', in KW Schaie (ed.), Longitudinal Studies of Adult Psychological Development, New York: Guilford Press: 64-135

Schlesinger JA (1966), Ambition and Politics, Chicago, Rand McNally.

Schubert M (2007), 'Vanstone Sacking a 'Backward Step' for Women', Age, 24 January: 15. 
Schubert M, Austin P and Koutsoukis J (2006), 'Angry Nationals Issue Mutiny Threat, Age, 25 January: 2

Schwanenflugel PJ and Shoben EJ (1983), 'Differential Context Effects in the Comprehension of Abstract and Concrete Verbal Materials, 'Journal of Experimental Psychology: Learning, Memory, and Cognition, 9(1)82-102.

Scott K (1999), Gareth Evans, St Leonards, NSW: Allen and Unwin.

Seccombe M (2005), 'Reshuffle Ruffles Nats' Aspirants', The Sydney Morning Herald, June 27: 8 .

Selth PA (2006), 'Political Biographies and Administrative Memoirs: Some Concluding Remarks', in T Arklay, J Nethercote and J Wanna (eds.) Australian Political Lives: Chronicling political careers and administrative histories, Canberra: ANU E Press: 101-114.

Semin GR and Fiedler K (1988), 'The Cognitive Functions of Linguistic Categories in Describing Persons: Social Cognition and Language, Journal of Personality and Social Psychology, 54(4): 558-568.

Shamir B, Arthur M and House R (1994), 'The Rhetoric of Charismatic Leadership: A Theoretical Extension, a Case Study, and Implications for Research, Leadership Quarterly, 5(1): 25-42.

Shao J (1993), 'Linear Model Selection by Cross-Validation, Journal of the American Statistical Association, 88(422):486-494. 
Sherman JS and Corty E (1984), 'Cognitive Heuristics, in RS Wyer and TK Srull (eds.), Handbook of Social Cognition 1, Hillsdale, NJ: Erlbaum: 189-286.

Short J (1997a), ‘Top Women Demoted in Reshuffle', Australian, 6 October: 1.

Short J (1997b), 'Critical Reshuffle', The Australian, 4 October: 19.

Short J and McKenzie D (1997), 'Howard Primes Team for the Big Sell, Australian, 6 October: 4.

Simon R, Radmacher M, Dobbin K, McShane L (2003), 'Pitfalls in the Use of DNA Microarray Data for Diagnostic and Prognostic Classification', Journal of the National Cancer Institute, 95(1):14-18

Simonton DK (1984), 'Leader Age and National Condition: A Longitudinal Analysis of 25 European Monarchs', Social Behavior and Personality, 12(2): 111-114.

Simonton DK (1998) 'Political Leadership across the Life Span: Chronological versus Career Age in the British Monarchy', Leadership Quarterly, 9(3): 309-320.

Shubert M (2007), 'Vanstone Sacking a “Backward Step” for Women', Age, 24 January: 15 .

Skott T (2005), Measuring Moisture Content in Ore Concentrate using Neural Networks, unpublished Master's Thesis, Umea University, Department of Computer Science. 
Slatcher R, Chung C, Pennebaker JW and Stone L (2007), 'Winning Words: Individual Differences in Linguistic Style among U.S. Presidential and Vice Presidential Candidates', Journal of Research in Personality, 41(1): 63-75.

Snyder M and Swann WB (1978), 'Hypotheses Testing Processes in Social Interaction', Journal of Personality and Social Psychology, 36(11): 1202-1212.

Stapleton J (2010), ‘Factual Causation', Federal Law Review, 38(3): 467-484.

Stogdill R (1974), Handbook of Leadership: A Survey of the Literature, New York: The Free Press.

Stuart N (2007), Kevin Rudd: An Unauthorised Political Biography, Carlton North, Victoria: Scribe.

Studlar D and McAllister I (1991), 'Political Recruitment to the Australian Legislature: Toward an Explanation of Women's Electoral Disadvantages', The Western Political Quarterly, 44(2): 467-485.

Suedfeld P and Rank A (1976), 'Revolutionary Leaders: Long-term Success as a Function of Changes in Conceptual Complexity', Journal of Personality and Social Psychology, 34(2): 169-178.

Suedfeld P and Tetlock P (1977), 'Integrative Complexity of Communications in International Crises', Journal of Conflict Resolution, 21(1): 169-184. 
Sung T, Chang N and Lee G (1999), 'Dynamics of Modeling in Data Mining: Interpretive Approach to Bankruptcy Prediction', Journal of Management Information Systems, 16(1): 63-85.

Tajfel H (1982), 'Social Psychology of Intergroup Relations', Annual Review of Psychology, 33:1-39

Taleb N (2008), The Black Swan: the Impact of the Highly Improbable, London: Penguin.

Tausczik Y and Pennebaker, JW (2010), 'The Psychological Meaning of Words: LIWC and Computerized Text Analysis Methods', Journal of Language and Social Psychology, 29(1):24-54.

Tetlock P (1983), 'Accountability and Complexity of Thought', Journal of Personality and Social Psychology, 45(1): 74-83.

Tetlock P, Hannum K and Micheletti P (1984), 'Stability and Change in the Complexity of Senatorial Debate: Testing the Cognitive versus Rhetorical Style Hypotheses', Journal of Personality and Social Psychology, 46(5): 979-990.

Tetlock P, Peterson R and Berry J (1993), 'Flattering and Unflattering Personality Portraits of Integratively Simple and Complex Managers', Journal of Personality and Social Psychology, 64(3): 500-511.

Tian, TS (2009), Dimensionality Reduction for Classification with High-Dimensional Data, unpublished $\mathrm{PhD}$ thesis, University of Southern California. 


\section{HIGH-DIMENSIONAL DATA}

Tiernan, A and Weller P (2010), Learning to be a Minister: Heroic Expectations, Practical Realities, Carlton, Victoria: Melbourne University Publishing.

Trope Y and Liberman A (1996), 'Social Hypothesis Testing: Cognitive and Motivational Mechanisms, in ET Higgins and AW Kruglanski (eds.), Social Psychology: Handbook of Basic Principles, New York: Guilford: 239-270.

Trope Y and Liberman N (2010), 'Construal-Level Theory of Psychological Distance', Psychological Review, 117(2): 440-463.

Trope Y, Liberman N and Wakslak C (2007), 'Construal Levels and Psychological Distance: Effects on Representation, Prediction, Evaluation, and Behavior', Journal of Consumer Psychology, 17(2): 83-95.

Turner JC (1987), Rediscovering the Social Group: A Self-Categorization Theory, Oxford: Blackwell.

Trautwein U and Lüdtke O (2007), 'Epistemological Beliefs, School Achievement, and College Major: A Large-Scale Longitudinal Study on the Impact of Certainty Beliefs, Contemporary Educational Psychology, 32(3): 348-366.

Tversky A and Kahneman D (1981), 'The Framing of Decisions and the Psychology of Choice', Science, 211(4481): 453-458.

Ultsch A and Kämpf D (2004), 'Knowledge Discovery in DNA Microarray Data of Cancer Patients with Emergent Self Organizing Maps’, in ESANN 2004 
Proceedings - European Symposium on Artificial Neural Networks Bruges (Belgium), 28-30 April :501-506.

van der Laan M J (2006), 'Statistical Inference for Variable Importance', The International Journal of Biostatistics: 2(1): 2

van Vugt M (2006) 'Evolutionary Origins of Leadership and Followership', Personality and Social Psychology Review, 10(4): 354-371.

van Vugt M, Johnson DD, Kaiser RB and O'Gorman R (2008), 'Evolution and the Social Psychology of Leadership: The Mismatch Hypothesis', in JB Ciulla (ed), Leadership at the Crossroads: Leadership and psychology, Vols 1,2 and3, Westport CT, Praeger Publishers: 267-282.

Verikas A, Gelzinis M, Kovalenko M and Bacauskienea M (2010) 'Selecting Features from Multiple Feature Sets for SVM Committee-Based Screening of Human Larynx', Expert Systems with Applications, 37(10): 6957-6962.

Walter, J. (1980). The Leader: A Political Biography of Gough Whitlam. St. Lucia, Queensland: University of Queensland Press.

Watson D, Clark LA and Tellegen A (1988) 'Development and Validation of Brief Measures of Positive and Negative Affect: The PANAS Scales', Journal of Personality and Social Psychology, 54(6): 1063-1070.

Weller P (1989), Malcolm Fraser PM: A Study in Prime Ministerial Power in Australia, Ringwood, Victoria: Penguin. 
Weller P (1999), Dodging Raindrops-John Button: A Labour Life, St Leonards NSW:

Allen and Unwin.

Weller P (2007), Cabinet Government in Australia, 1901-2006, Sydney: UNSW Press.

Wiemer-Hastings K Krug J and Xu X (2001), 'Imagery, Context Availability,

Contextual Constraint, and Abstractness, Proceedings of the 23rd Annual

Conference of the Cognitive Science Society, Mahwah, NJ: Erlbaum: 1134-39.

Winter D (1987), 'Leader Appeal, Leader Performance, and the Motives Profile of Leaders and Followers: A Study of American Presidents and Elections', Journal of Personality and Social Psychology, 52(1): 196-202.

Winter D (2007), 'The role of Motivation, Responsibility, and Integrative Complexity in Crisis Escalation: Comparative Studies of War and Peace Crises', Journal of Personality and Social Psychology, 92(5): 920-937.

Witten I and Frank E (2005), Data Mining: Practical Machine Learning Tools and Techniques, $2^{\text {nd }}$ ed., San Francisco, CA: Morgan Kaufman Publishers.

Xu QS, Liang YZ and Du YP (2004), 'Monte Carlo Cross-Validation for Selecting a Model and Estimating the Prediction error in Multivariate Calibration', Journal of Chemometrics, 18(2):112-120.

Yu B, Kaufman S and Diermeier D (2008), 'Classifying Party Affiliation from Political Speech', Journal of Information Technology and Politics, 5(1) 33-48 
Yukl G (1989), Leadership in Organizations, $2^{\text {nd }}$ Ed, Englewood Cliffs, NJ: Prentice Hall.

Zenobi G and Cunningham P (2001), 'Using Diversity in Preparing Ensembles of Classifiers Based on Different Feature Subsets to Minimize Generalization Error', Department of Computer Science, Trinity College Dublin, http://www.tara.tcd.ie/jspui/bitstream/2262/13138/1/TCD-CS-2001-11.pdf, accessed December 2011.

Zhou ZH, Wu JX, Jiang Y and Chen SF (2001) 'Genetic Algorithm based Selective Neural Network Ensemble, in Proceedings of the 17th International Joint Conference on Artificial Intelligence, Seattle, WA, 2001, 2:797-802 


\section{Appendix 1: Data for RIF Models}

\section{LNPC Data}

\begin{tabular}{|r|l|r|r|r|r|r|r|r|r|r|r|r|r|r|r|}
\hline Year & \multicolumn{1}{|c|}{ Name } & Senate & Female & Vic & NSW & Qld & Tas & SA & WA & ACT & NT & NP & Age & Exp' & Cab' \\
\hline 1996 & Abbott, AJ & 0 & 0 & 0 & 1 & 0 & 0 & 0 & 0 & 0 & 0 & 0 & 38.51 & 2.1 & 0 \\
\hline 1999 & Abbott, AJ & 0 & 0 & 0 & 1 & 0 & 0 & 0 & 0 & 0 & 0 & 0 & 41.27 & 4.86 & 0 \\
\hline 2002 & Abbott, AJ & 0 & 0 & 0 & 1 & 0 & 0 & 0 & 0 & 0 & 0 & 0 & 44.27 & 7.86 & 1 \\
\hline 2005 & Abbott, AJ & 0 & 0 & 0 & 1 & 0 & 0 & 0 & 0 & 0 & 0 & 0 & 47.28 & 10.86 & 1 \\
\hline 2007 & Abbott, AJ & 0 & 0 & 0 & 1 & 0 & 0 & 0 & 0 & 0 & 0 & 0 & 49.28 & 12.86 & 1 \\
\hline 1996 & Abetz, E & 1 & 0 & 0 & 0 & 0 & 1 & 0 & 0 & 0 & 0 & 0 & 38.29 & 2.19 & 0 \\
\hline 1999 & Abetz, E & 1 & 0 & 0 & 0 & 0 & 1 & 0 & 0 & 0 & 0 & 0 & 41.05 & 4.95 & 0 \\
\hline 2002 & Abetz, E & 1 & 0 & 0 & 0 & 0 & 1 & 0 & 0 & 0 & 0 & 0 & 44.05 & 7.95 & 0 \\
\hline 2005 & Abetz, E & 1 & 0 & 0 & 0 & 0 & 1 & 0 & 0 & 0 & 0 & 0 & 47.05 & 10.95 & 0 \\
\hline 2007 & Abetz, E & 1 & 0 & 0 & 0 & 0 & 1 & 0 & 0 & 0 & 0 & 0 & 49.05 & 12.95 & 0 \\
\hline 2007 & Adams, JA & 1 & 1 & 0 & 0 & 0 & 0 & 0 & 1 & 0 & 0 & 0 & 63.85 & 1.59 & 0 \\
\hline 1996 & Alston, RK & 1 & 0 & 1 & 0 & 0 & 0 & 0 & 0 & 0 & 0 & 0 & 54.4 & 9.99 & 1 \\
\hline 1999 & Alston, RK & 1 & 0 & 1 & 0 & 0 & 0 & 0 & 0 & 0 & 0 & 0 & 60.16 & 15.75 & 1 \\
\hline 2002 & Alston, RK & 0 & 0 & 0 & 1 & 0 & 0 & 0 & 0 & 0 & 0 & 1 & 39.48 & 7.05 & 1 \\
\hline 1996 & Anderson, JD & 0 & 0 & 0 & 1 & 0 & 0 & 0 & 0 & 0 & 0 & 1 & 42.24 & 9.81 & 1 \\
\hline 1999 & Anderson, JD & 0 & 0 & 0 & 1 & 0 & 0 & 0 & 0 & 0 & 0 & 1 & 45.25 & 12.81 & 1 \\
\hline 2002 & Anderson, JD & & 0 & 1 & 0 & 0 & 0 & 0 & 0 & 0 & 1 & 48.25 & 15.81 & 1 \\
\hline 2005 & Anderson, JD & & 0 & 0 & 0 & 0 & 0 & 0 & 0 & 0 & 0 & 0 & 57.16 & 12.75 & 1 \\
\hline
\end{tabular}




\section{Appendix 1: Data for RIF Models LNPC Data (Continued)}

\begin{tabular}{|l|l|r|r|r|r|r|r|r|r|r|r|r|r|r|r|}
\hline Year & \multicolumn{1}{|c|}{ Name } & Senate & Female & Vic & NSW & Qld & Tas & SA & WA & ACT & NT & NP & Age & Exp' $^{\prime}$ & Cab' $^{\prime}$ \\
\hline 2007 & Anderson, JD & 0 & 0 & 0 & 1 & 0 & 0 & 0 & 0 & 0 & 0 & 1 & 50.25 & 17.81 & 0 \\
\hline 1996 & Andrew, JN & 0 & 0 & 0 & 0 & 0 & 0 & 1 & 0 & 0 & 0 & 0 & 51.93 & 13.16 & 0 \\
\hline 1999 & Andrew, JN & 0 & 0 & 0 & 0 & 0 & 0 & 1 & 0 & 0 & 0 & 0 & 54.69 & 15.92 & 0 \\
\hline 2002 & Andrew, JN & 0 & 0 & 0 & 0 & 0 & 0 & 1 & 0 & 0 & 0 & 0 & 57.69 & 18.93 & 0 \\
\hline 1996 & Andrews, KJ & 0 & 0 & 1 & 0 & 0 & 0 & 0 & 0 & 0 & 0 & 0 & 40.5 & 4.98 & 0 \\
\hline 1999 & Andrews, KJ & 0 & 0 & 1 & 0 & 0 & 0 & 0 & 0 & 0 & 0 & 0 & 43.26 & 7.73 & 0 \\
\hline 2002 & Andrews, KJ & 0 & 0 & 1 & 0 & 0 & 0 & 0 & 0 & 0 & 0 & 0 & 46.26 & 10.74 & 0 \\
\hline 2005 & Andrews, KJ & 0 & 0 & 1 & 0 & 0 & 0 & 0 & 0 & 0 & 0 & 0 & 49.27 & 13.74 & 1 \\
\hline 2007 & Andrews, KJ & 0 & 0 & 1 & 0 & 0 & 0 & 0 & 0 & 0 & 0 & 0 & 51.27 & 15.74 & 1 \\
\hline 1996 & Anthony, LJ & 0 & 0 & 0 & 1 & 0 & 0 & 0 & 0 & 0 & 0 & 1 & 34.39 & 0.16 & 0 \\
\hline 1999 & Anthony, LJ & 0 & 0 & 0 & 1 & 0 & 0 & 0 & 0 & 0 & 0 & 1 & 37.15 & 2.92 & 0 \\
\hline 2002 & Anthony, LJ & 0 & 0 & 0 & 1 & 0 & 0 & 0 & 0 & 0 & 0 & 1 & 40.15 & 5.92 & 0 \\
\hline 1996 & Bailey, FE & 0 & 1 & 1 & 0 & 0 & 0 & 0 & 0 & 0 & 0 & 0 & 49.98 & 3.13 & 0 \\
\hline 1999 & Bailey, FE & 0 & 1 & 1 & 0 & 0 & 0 & 0 & 0 & 0 & 0 & 0 & 52.74 & 5.89 & 0 \\
\hline 2002 & Bailey, FE & 0 & 1 & 1 & 0 & 0 & 0 & 0 & 0 & 0 & 0 & 0 & 55.74 & 8.9 & 0 \\
\hline 2005 & Bailey, FE & 0 & 1 & 1 & 0 & 0 & 0 & 0 & 0 & 0 & 0 & 0 & 58.74 & 11.9 & 0 \\
\hline 2007 & Bailey, FE & 0 & 1 & 1 & 0 & 0 & 0 & 0 & 0 & 0 & 0 & 0 & 60.74 & 13.9 & 0 \\
\hline 1999 & Baird, BG & 0 & 0 & 0 & 1 & 0 & 0 & 0 & 0 & 0 & 0 & 0 & 56.96 & 0.33 & 0 \\
\hline 2002 & Baird, BG & 0 & 0 & 0 & 1 & 0 & 0 & 0 & 0 & 0 & 0 & 0 & 59.97 & 3.33 & 0 \\
\hline 2005 & Baird, BG & 0 & 0 & 0 & 1 & 0 & 0 & 0 & 0 & 0 & 0 & 0 & 62.97 & 6.34 & 0 \\
\hline
\end{tabular}




\section{Appendix 1: Data for RIF Models LNPC Data (Continued)}

\begin{tabular}{|l|l|r|r|r|r|r|r|r|r|r|r|r|r|r|r|}
\hline Year & \multicolumn{1}{|c|}{ Name } & Senate & Female & Vic & NSW & Qld & Tas & SA & WA & ACT & NT & NP & Age & Exp' $^{\prime}$ & Cab' $^{\prime}$ \\
\hline 2007 & Baird, BG & 0 & 0 & 0 & 1 & 0 & 0 & 0 & 0 & 0 & 0 & 0 & 64.97 & 8.34 & 0 \\
\hline 2005 & Baker, MH & 0 & 0 & 0 & 0 & 0 & 1 & 0 & 0 & 0 & 0 & 0 & 46.12 & 0.32 & 0 \\
\hline 2007 & Baker, MH & 0 & 0 & 0 & 0 & 0 & 1 & 0 & 0 & 0 & 0 & 0 & 48.12 & 2.32 & 0 \\
\hline 1996 & Baldwin, RC & 0 & 0 & 0 & 1 & 0 & 0 & 0 & 0 & 0 & 0 & 0 & 41.17 & 0.16 & 0 \\
\hline 2002 & Baldwin, RC & 0 & 0 & 0 & 1 & 0 & 0 & 0 & 0 & 0 & 0 & 0 & 46.93 & 2.82 & 0 \\
\hline 2005 & Baldwin, RC & 0 & 0 & 0 & 1 & 0 & 0 & 0 & 0 & 0 & 0 & 0 & 49.94 & 5.82 & 0 \\
\hline 2007 & Baldwin, RC & 0 & 0 & 0 & 1 & 0 & 0 & 0 & 0 & 0 & 0 & 0 & 51.94 & 7.82 & 0 \\
\hline 2005 & Barnett, G & 1 & 0 & 0 & 0 & 0 & 1 & 0 & 0 & 0 & 0 & 0 & 42.86 & 2.93 & 0 \\
\hline 2007 & Barnett, G & 1 & 0 & 0 & 0 & 0 & 1 & 0 & 0 & 0 & 0 & 0 & 44.86 & 4.93 & 0 \\
\hline 1996 & Barresi, PA & 0 & 0 & 1 & 0 & 0 & 0 & 0 & 0 & 0 & 0 & 0 & 40.76 & 0.16 & 0 \\
\hline 1999 & Barresi, PA & 0 & 0 & 1 & 0 & 0 & 0 & 0 & 0 & 0 & 0 & 0 & 43.52 & 2.92 & 0 \\
\hline 2002 & Barresi, PA & 0 & 0 & 1 & 0 & 0 & 0 & 0 & 0 & 0 & 0 & 0 & 46.52 & 5.92 & 0 \\
\hline 2005 & Barresi, PA & 0 & 0 & 1 & 0 & 0 & 0 & 0 & 0 & 0 & 0 & 0 & 49.52 & 8.93 & 0 \\
\hline 2007 & Barresi, PA & 0 & 0 & 1 & 0 & 0 & 0 & 0 & 0 & 0 & 0 & 0 & 51.52 & 10.93 & 0 \\
\hline 1996 & Bartlett, KJ & 0 & 0 & 0 & 1 & 0 & 0 & 0 & 0 & 0 & 0 & 0 & 47.07 & 0.16 & 0 \\
\hline 1999 & Bartlett, KJ & 0 & 0 & 0 & 1 & 0 & 0 & 0 & 0 & 0 & 0 & 0 & 49.83 & 2.92 & 0 \\
\hline 2002 & Bartlett, KJ & 0 & 0 & 0 & 1 & 0 & 0 & 0 & 0 & 0 & 0 & 0 & 52.84 & 5.92 & 0 \\
\hline 2005 & Bartlett, KJ & 0 & 0 & 0 & 1 & 0 & 0 & 0 & 0 & 0 & 0 & 0 & 55.84 & 8.93 & 0 \\
\hline 2007 & Bartlett, KJ & 0 & 0 & 0 & 1 & 0 & 0 & 0 & 0 & 0 & 0 & 0 & 57.84 & 10.93 & 0 \\
\hline 1996 & Baume, ME & 1 & 0 & 0 & 1 & 0 & 0 & 0 & 0 & 0 & 0 & 0 & 65.86 & 18.07 & 0 \\
\hline
\end{tabular}




\section{Appendix 1: Data for RIF Models LNPC Data (Continued)}

\begin{tabular}{|l|l|r|r|r|r|r|r|r|r|r|r|r|r|r|r|}
\hline Year & \multicolumn{1}{|c|}{ Name } & Senate & Female & Vic & NSW & Qld & Tas & SA & WA & ACT & NT & NP & Age & Exp' $^{\prime}$ & Cab' $^{\prime}$ \\
\hline 2007 & Bernardi, C & 1 & 0 & 0 & 0 & 0 & 0 & 1 & 0 & 0 & 0 & 0 & 37.26 & 0.75 & 0 \\
\hline 1996 & Billson, BF & 0 & 0 & 1 & 0 & 0 & 0 & 0 & 0 & 0 & 0 & 0 & 30.28 & 0.16 & 0 \\
\hline 1999 & Billson, BF & 0 & 0 & 1 & 0 & 0 & 0 & 0 & 0 & 0 & 0 & 0 & 33.04 & 2.92 & 0 \\
\hline 2002 & Billson, BF & 0 & 0 & 1 & 0 & 0 & 0 & 0 & 0 & 0 & 0 & 0 & 36.04 & 5.92 & 0 \\
\hline 2005 & Billson, BF & 0 & 0 & 1 & 0 & 0 & 0 & 0 & 0 & 0 & 0 & 0 & 39.04 & 8.93 & 0 \\
\hline 2007 & Billson, BF & 0 & 0 & 1 & 0 & 0 & 0 & 0 & 0 & 0 & 0 & 0 & 41.04 & 10.93 & 0 \\
\hline 1996 & Bishop, BK & 0 & 1 & 0 & 1 & 0 & 0 & 0 & 0 & 0 & 0 & 0 & 53.57 & 8.73 & 0 \\
\hline 1999 & Bishop, BK & 0 & 1 & 0 & 1 & 0 & 0 & 0 & 0 & 0 & 0 & 0 & 56.33 & 11.49 & 0 \\
\hline 2002 & Bishop, BK & 0 & 1 & 0 & 1 & 0 & 0 & 0 & 0 & 0 & 0 & 0 & 59.33 & 14.49 & 0 \\
\hline 2005 & Bishop, BK & 0 & 1 & 0 & 1 & 0 & 0 & 0 & 0 & 0 & 0 & 0 & 62.33 & 17.49 & 0 \\
\hline 2007 & Bishop, BK & 0 & 1 & 0 & 1 & 0 & 0 & 0 & 0 & 0 & 0 & 0 & 64.33 & 19.49 & 0 \\
\hline 1999 & Bishop, JI & 0 & 1 & 0 & 0 & 0 & 0 & 0 & 1 & 0 & 0 & 0 & 42.57 & 0.33 & 0 \\
\hline 2002 & Bishop, Jl & 0 & 1 & 0 & 0 & 0 & 0 & 0 & 1 & 0 & 0 & 0 & 45.58 & 3.33 & 0 \\
\hline 2005 & Bishop, JI & 0 & 1 & 0 & 0 & 0 & 0 & 0 & 1 & 0 & 0 & 0 & 48.58 & 6.34 & 0 \\
\hline 2007 & Bishop, JI & 0 & 1 & 0 & 0 & 0 & 0 & 0 & 1 & 0 & 0 & 0 & 50.58 & 8.34 & 1 \\
\hline 1996 & Boswell, RL & 1 & 0 & 0 & 0 & 1 & 0 & 0 & 0 & 0 & 0 & 1 & 55.43 & 13.16 & 0 \\
\hline 1999 & Boswell, RL & 1 & 0 & 0 & 0 & 1 & 0 & 0 & 0 & 0 & 0 & 1 & 58.19 & 15.92 & 0 \\
\hline 2002 & Boswell, RL & 1 & 0 & 0 & 0 & 1 & 0 & 0 & 0 & 0 & 0 & 1 & 61.19 & 18.93 & 0 \\
\hline 2005 & Boswell, RL & 1 & 0 & 0 & 0 & 1 & 0 & 0 & 0 & 0 & 0 & 1 & 64.19 & 21.93 & 0 \\
\hline 2007 & Boswell, RL & 1 & 0 & 0 & 0 & 1 & 0 & 0 & 0 & 0 & 0 & 1 & 66.19 & 23.93 & 0 \\
\hline
\end{tabular}




\section{Appendix 1: Data for RIF Models LNPC Data (Continued)}

\begin{tabular}{|l|l|r|r|r|r|r|r|r|r|r|r|r|r|r|r|}
\hline Year & \multicolumn{1}{|c|}{ Name } & Senate & Female & Vic & NSW & Qld & Tas & SA & WA & ACT & NT & NP & Age & Exp' $^{\prime}$ & Cab' $^{\prime}$ \\
\hline 1996 & Bradford, JW & 0 & 0 & 0 & 0 & 1 & 0 & 0 & 0 & 0 & 0 & 0 & 50.36 & 6.11 & 0 \\
\hline 2002 & Brandis, GH & 1 & 0 & 0 & 0 & 1 & 0 & 0 & 0 & 0 & 0 & 0 & 44.64 & 1.72 & 0 \\
\hline 2005 & Brandis, GH & 1 & 0 & 0 & 0 & 1 & 0 & 0 & 0 & 0 & 0 & 0 & 47.65 & 4.72 & 0 \\
\hline 2007 & Brandis, GH & 1 & 0 & 0 & 0 & 1 & 0 & 0 & 0 & 0 & 0 & 0 & 49.65 & 6.72 & 0 \\
\hline 1996 & Broadbent, RE & 0 & 0 & 1 & 0 & 0 & 0 & 0 & 0 & 0 & 0 & 0 & 45.38 & 3.13 & 0 \\
\hline 2005 & Broadbent, RE & 0 & 0 & 1 & 0 & 0 & 0 & 0 & 0 & 0 & 0 & 0 & 54.14 & 5.88 & 0 \\
\hline 2007 & Broadbent, RE & 0 & 0 & 1 & 0 & 0 & 0 & 0 & 0 & 0 & 0 & 0 & 56.14 & 7.88 & 0 \\
\hline 1996 & Brough, MT & 0 & 0 & 0 & 0 & 1 & 0 & 0 & 0 & 0 & 0 & 0 & 34.36 & 0.16 & 0 \\
\hline 1999 & Brough, MT & 0 & 0 & 0 & 0 & 1 & 0 & 0 & 0 & 0 & 0 & 0 & 37.12 & 2.92 & 0 \\
\hline 2002 & Brough, MT & 0 & 0 & 0 & 0 & 1 & 0 & 0 & 0 & 0 & 0 & 0 & 40.12 & 5.92 & 0 \\
\hline 2005 & Brough, MT & 0 & 0 & 0 & 0 & 1 & 0 & 0 & 0 & 0 & 0 & 0 & 43.12 & 8.93 & 0 \\
\hline 2007 & Brough, MT & 0 & 0 & 0 & 0 & 1 & 0 & 0 & 0 & 0 & 0 & 0 & 45.12 & 10.93 & 1 \\
\hline 1996 & Brownhill, DG & 1 & 0 & 0 & 1 & 0 & 0 & 0 & 0 & 0 & 0 & 1 & 60.5 & 11.42 & 0 \\
\hline 1999 & Brownhill, DG & 1 & 0 & 0 & 1 & 0 & 0 & 0 & 0 & 0 & 0 & 1 & 63.25 & 14.18 & 0 \\
\hline 1996 & Cadman, AG & 0 & 0 & 0 & 1 & 0 & 0 & 0 & 0 & 0 & 0 & 0 & 58.8 & 21.97 & 0 \\
\hline 1999 & Cadman, AG & 0 & 0 & 0 & 1 & 0 & 0 & 0 & 0 & 0 & 0 & 0 & 61.56 & 24.73 & 0 \\
\hline 2002 & Cadman, AG & 0 & 0 & 0 & 1 & 0 & 0 & 0 & 0 & 0 & 0 & 0 & 64.56 & 27.73 & 0 \\
\hline 2005 & Cadman, AG & 0 & 0 & 0 & 1 & 0 & 0 & 0 & 0 & 0 & 0 & 0 & 67.57 & 30.73 & 0 \\
\hline 2007 & Cadman, AG & 0 & 0 & 0 & 1 & 0 & 0 & 0 & 0 & 0 & 0 & 0 & 69.57 & 32.73 & 0 \\
\hline 1996 & Calvert, PH & 1 & 0 & 0 & 0 & 0 & 1 & 0 & 0 & 0 & 0 & 0 & 56.32 & 8.81 & 0 \\
\hline
\end{tabular}




\section{Appendix 1: Data for RIF Models LNPC Data (Continued)}

\begin{tabular}{|l|l|r|r|r|r|r|r|r|r|r|r|r|r|r|r|}
\hline Year & \multicolumn{1}{|c|}{ Name } & Senate & Female & Vic & NSW & Qld & Tas & SA & WA & ACT & NT & NP & Age & Exp' $^{\prime}$ & Cab' $^{\prime}$ \\
\hline 1999 & Calvert, PH & 1 & 0 & 0 & 0 & 0 & 1 & 0 & 0 & 0 & 0 & 0 & 59.08 & 11.57 & 0 \\
\hline 2002 & Calvert, PH & 1 & 0 & 0 & 0 & 0 & 1 & 0 & 0 & 0 & 0 & 0 & 62.08 & 14.57 & 0 \\
\hline 2005 & Calvert, PH & 1 & 0 & 0 & 0 & 0 & 1 & 0 & 0 & 0 & 0 & 0 & 65.08 & 17.58 & 0 \\
\hline 2007 & Calvert, PH & 1 & 0 & 0 & 0 & 0 & 1 & 0 & 0 & 0 & 0 & 0 & 67.08 & 19.58 & 0 \\
\hline 1996 & Cameron, EH & 0 & 0 & 0 & 0 & 0 & 0 & 0 & 1 & 0 & 0 & 0 & 45.35 & 3.13 & 0 \\
\hline 1996 & Cameron, RA & 0 & 0 & 0 & 1 & 0 & 0 & 0 & 0 & 0 & 0 & 0 & 30.98 & 0.16 & 0 \\
\hline 1999 & Cameron, RA & 0 & 0 & 0 & 1 & 0 & 0 & 0 & 0 & 0 & 0 & 0 & 33.74 & 2.92 & 0 \\
\hline 2002 & Cameron, RA & 0 & 0 & 0 & 1 & 0 & 0 & 0 & 0 & 0 & 0 & 0 & 36.75 & 5.92 & 0 \\
\hline 1996 & Campbell, IG & 1 & 0 & 0 & 0 & 0 & 0 & 0 & 1 & 0 & 0 & 0 & 36.97 & 5.96 & 0 \\
\hline 1999 & Campbell, IG & 1 & 0 & 0 & 0 & 0 & 0 & 0 & 1 & 0 & 0 & 0 & 39.73 & 8.72 & 0 \\
\hline 2002 & Campbell, IG & 1 & 0 & 0 & 0 & 0 & 0 & 0 & 1 & 0 & 0 & 0 & 42.73 & 11.72 & 0 \\
\hline 2005 & Campbell, IG & 1 & 0 & 0 & 0 & 0 & 0 & 0 & 1 & 0 & 0 & 0 & 45.73 & 14.73 & 1 \\
\hline 2007 & Campbell, IG & 1 & 0 & 0 & 0 & 0 & 0 & 0 & 1 & 0 & 0 & 0 & 47.73 & 16.73 & 1 \\
\hline 1996 & Causley, IR & 0 & 0 & 0 & 1 & 0 & 0 & 0 & 0 & 0 & 0 & 1 & 55.57 & 0.16 & 0 \\
\hline 1999 & Causley, IR & 0 & 0 & 0 & 1 & 0 & 0 & 0 & 0 & 0 & 0 & 1 & 58.33 & 2.92 & 0 \\
\hline 2002 & Causley, IR & 0 & 0 & 0 & 1 & 0 & 0 & 0 & 0 & 0 & 0 & 1 & 61.33 & 5.92 & 0 \\
\hline 2005 & Causley, IR & 0 & 0 & 0 & 1 & 0 & 0 & 0 & 0 & 0 & 0 & 1 & 64.33 & 8.93 & 0 \\
\hline 2007 & Causley, IR & 0 & 0 & 0 & 1 & 0 & 0 & 0 & 0 & 0 & 0 & 1 & 66.33 & 10.93 & 0 \\
\hline 1996 & Chapman, HG & 1 & 0 & 0 & 0 & 0 & 0 & 1 & 0 & 0 & 0 & 0 & 47.04 & 16.04 & 0 \\
\hline 1999 & Chapman, HG & 1 & 0 & 0 & 0 & 0 & 0 & 1 & 0 & 0 & 0 & 0 & 49.8 & 18.8 & 0 \\
\hline
\end{tabular}




\section{Appendix 1: Data for RIF Models LNPC Data (Continued)}

\begin{tabular}{|l|l|r|r|r|r|r|r|r|r|r|r|r|r|r|r|}
\hline Year & \multicolumn{1}{|c|}{ Name } & Senate & Female & Vic & NSW & Qld & Tas & SA & WA & ACT & NT & NP & Age & Exp' $^{\prime}$ & Cab' $^{\prime}$ \\
\hline 2002 & Chapman, HG & 1 & 0 & 0 & 0 & 0 & 0 & 1 & 0 & 0 & 0 & 0 & 52.8 & 21.8 & 0 \\
\hline 2005 & Chapman, HG & 1 & 0 & 0 & 0 & 0 & 0 & 1 & 0 & 0 & 0 & 0 & 55.81 & 24.81 & 0 \\
\hline 2007 & Chapman, HG & 1 & 0 & 0 & 0 & 0 & 0 & 1 & 0 & 0 & 0 & 0 & 57.81 & 26.81 & 0 \\
\hline 1996 & Charles, RE & 0 & 0 & 1 & 0 & 0 & 0 & 0 & 0 & 0 & 0 & 0 & 59.81 & 6.11 & 0 \\
\hline 1999 & Charles, RE & 0 & 0 & 1 & 0 & 0 & 0 & 0 & 0 & 0 & 0 & 0 & 62.57 & 8.87 & 0 \\
\hline 2002 & Charles, RE & 0 & 0 & 1 & 0 & 0 & 0 & 0 & 0 & 0 & 0 & 0 & 65.57 & 11.87 & 0 \\
\hline 2002 & Ciobo, SM & 0 & 0 & 0 & 0 & 1 & 0 & 0 & 0 & 0 & 0 & 0 & 27.7 & 0.23 & 0 \\
\hline 2005 & Ciobo, SM & 0 & 0 & 0 & 0 & 1 & 0 & 0 & 0 & 0 & 0 & 0 & 30.7 & 3.23 & 0 \\
\hline 2007 & Ciobo, SM & 0 & 0 & 0 & 0 & 1 & 0 & 0 & 0 & 0 & 0 & 0 & 32.7 & 5.23 & 0 \\
\hline 2002 & Cobb, JK & 0 & 0 & 0 & 1 & 0 & 0 & 0 & 0 & 0 & 0 & 1 & 52.01 & 0.23 & 0 \\
\hline 2005 & Cobb, JK & 0 & 0 & 0 & 1 & 0 & 0 & 0 & 0 & 0 & 0 & 1 & 55.01 & 3.23 & 0 \\
\hline 2007 & Cobb, JK & 0 & 0 & 0 & 1 & 0 & 0 & 0 & 0 & 0 & 0 & 1 & 57.01 & 5.23 & 0 \\
\hline 1996 & Cobb, MR & 0 & 0 & 0 & 1 & 0 & 0 & 0 & 0 & 0 & 0 & 1 & 51.16 & 11.42 & 0 \\
\hline 2002 & Colbeck, RM & 1 & 0 & 0 & 0 & 0 & 1 & 0 & 0 & 0 & 0 & 0 & 43.86 & 0 & 0 \\
\hline 2005 & Colbeck, RM & 1 & 0 & 0 & 0 & 0 & 1 & 0 & 0 & 0 & 0 & 0 & 46.86 & 2.99 & 0 \\
\hline 2007 & Colbeck, RM & 1 & 0 & 0 & 0 & 0 & 1 & 0 & 0 & 0 & 0 & 0 & 48.86 & 4.99 & 0 \\
\hline 1999 & Coonan, HL & 1 & 1 & 0 & 1 & 0 & 0 & 0 & 0 & 0 & 0 & 0 & 51.3 & 2.59 & 0 \\
\hline 2002 & Coonan, HL & 1 & 1 & 0 & 1 & 0 & 0 & 0 & 0 & 0 & 0 & 0 & 54.3 & 5.59 & 0 \\
\hline 2005 & Coonan, HL & 1 & 1 & 0 & 1 & 0 & 0 & 0 & 0 & 0 & 0 & 0 & 57.3 & 8.59 & 1 \\
\hline 2007 & Coonan, HL & 1 & 1 & 0 & 1 & 0 & 0 & 0 & 0 & 0 & 0 & 0 & 59.3 & 10.59 & 1 \\
\hline
\end{tabular}




\section{Appendix 1: Data for RIF Models LNPC Data (Continued)}

\begin{tabular}{|l|l|r|r|r|r|r|r|r|r|r|r|r|r|r|r|}
\hline Year & \multicolumn{1}{|c|}{ Name } & Senate & Female & Vic & NSW & Qld & Tas & SA & WA & ACT & NT & NP & Age & Exp' $^{\prime}$ & Cab' $^{\prime}$ \\
\hline 1996 & Costello, PH & 0 & 0 & 1 & 0 & 0 & 0 & 0 & 0 & 0 & 0 & 0 & 38.74 & 6.11 & 1 \\
\hline 1999 & Costello, PH & 0 & 0 & 1 & 0 & 0 & 0 & 0 & 0 & 0 & 0 & 0 & 41.5 & 8.87 & 1 \\
\hline 2002 & Costello, PH & 0 & 0 & 1 & 0 & 0 & 0 & 0 & 0 & 0 & 0 & 0 & 44.5 & 11.87 & 1 \\
\hline 2005 & Costello, PH & 0 & 0 & 1 & 0 & 0 & 0 & 0 & 0 & 0 & 0 & 0 & 47.5 & 14.87 & 1 \\
\hline 2007 & Costello, PH & 0 & 0 & 1 & 0 & 0 & 0 & 0 & 0 & 0 & 0 & 0 & 49.5 & 16.87 & 1 \\
\hline 1996 & Crane, AW & 1 & 0 & 0 & 0 & 0 & 0 & 0 & 1 & 0 & 0 & 0 & 54.73 & 5.84 & 0 \\
\hline 1999 & Crane, AW & 1 & 0 & 0 & 0 & 0 & 0 & 0 & 1 & 0 & 0 & 0 & 57.49 & 8.59 & 0 \\
\hline 2002 & Crane, AW & 1 & 0 & 0 & 0 & 0 & 0 & 0 & 1 & 0 & 0 & 0 & 60.49 & 11.6 & 0 \\
\hline 1996 & Dondas, NM & 0 & 0 & 0 & 0 & 0 & 0 & 0 & 0 & 0 & 1 & 0 & 56.55 & 0.16 & 0 \\
\hline 1996 & Downer, AJ & 0 & 0 & 0 & 0 & 0 & 0 & 1 & 0 & 0 & 0 & 0 & 44.67 & 11.42 & 1 \\
\hline 1999 & Downer, AJ & 0 & 0 & 0 & 0 & 0 & 0 & 1 & 0 & 0 & 0 & 0 & 47.43 & 14.18 & 1 \\
\hline 2002 & Downer, AJ & 0 & 0 & 0 & 0 & 0 & 0 & 1 & 0 & 0 & 0 & 0 & 50.43 & 17.18 & 1 \\
\hline 2005 & Downer, AJ & 0 & 0 & 0 & 0 & 0 & 0 & 1 & 0 & 0 & 0 & 0 & 53.44 & 20.18 & 1 \\
\hline 2007 & Downer, AJ & 0 & 0 & 0 & 0 & 0 & 0 & 1 & 0 & 0 & 0 & 0 & 55.44 & 22.18 & 1 \\
\hline 1996 & Draper, P & 0 & 1 & 0 & 0 & 0 & 0 & 1 & 0 & 0 & 0 & 0 & 37.1 & 0.16 & 0 \\
\hline 1999 & Draper, P & 0 & 1 & 0 & 0 & 0 & 0 & 1 & 0 & 0 & 0 & 0 & 39.86 & 2.92 & 0 \\
\hline 2002 & Draper, P & 0 & 1 & 0 & 0 & 0 & 0 & 1 & 0 & 0 & 0 & 0 & 42.87 & 5.92 & 0 \\
\hline 2005 & Draper, P & 0 & 1 & 0 & 0 & 0 & 0 & 1 & 0 & 0 & 0 & 0 & 45.87 & 8.93 & 0 \\
\hline 2007 & Draper, P & 0 & 1 & 0 & 0 & 0 & 0 & 1 & 0 & 0 & 0 & 0 & 47.87 & 10.93 & 0 \\
\hline 2002 & Dutton, PC & 0 & 0 & 0 & 0 & 1 & 0 & 0 & 0 & 0 & 0 & 0 & 31.23 & 0.23 & 0 \\
\hline
\end{tabular}




\section{Appendix 1: Data for RIF Models LNPC Data (Continued)}

\begin{tabular}{|l|l|r|r|r|r|r|r|r|r|r|r|r|r|r|r|}
\hline Year & \multicolumn{1}{|c|}{ Name } & Senate & Female & Vic & NSW & Qld & Tas & SA & WA & ACT & NT & NP & Age & Exp' $^{\prime}$ & Cab' $^{\prime}$ \\
\hline 2005 & Lutton, PC & 0 & 0 & 0 & 0 & 1 & 0 & 0 & 0 & 0 & 0 & 0 & 34.23 & 3.23 & 0 \\
\hline 2007 & Dutton, PC & 0 & 0 & 0 & 0 & 1 & 0 & 0 & 0 & 0 & 0 & 0 & 36.23 & 5.23 & 0 \\
\hline 1999 & Eggleston, A & 1 & 0 & 0 & 0 & 0 & 0 & 0 & 1 & 0 & 0 & 0 & 57.13 & 2.59 & 0 \\
\hline 2002 & Eggleston, A & 1 & 0 & 0 & 0 & 0 & 0 & 0 & 1 & 0 & 0 & 0 & 60.13 & 5.59 & 0 \\
\hline 2005 & Eggleston, A & 1 & 0 & 0 & 0 & 0 & 0 & 0 & 1 & 0 & 0 & 0 & 63.13 & 8.59 & 0 \\
\hline 2007 & Eggleston, A & 1 & 0 & 0 & 0 & 0 & 0 & 0 & 1 & 0 & 0 & 0 & 65.13 & 10.59 & 0 \\
\hline 1996 & Ellison, CM & 1 & 0 & 0 & 0 & 0 & 0 & 0 & 1 & 0 & 0 & 0 & 41.9 & 2.83 & 0 \\
\hline 1999 & Ellison, CM & 1 & 0 & 0 & 0 & 0 & 0 & 0 & 1 & 0 & 0 & 0 & 44.66 & 5.59 & 0 \\
\hline 2002 & Ellison, CM & 1 & 0 & 0 & 0 & 0 & 0 & 0 & 1 & 0 & 0 & 0 & 47.67 & 8.59 & 0 \\
\hline 2005 & Ellison, CM & 1 & 0 & 0 & 0 & 0 & 0 & 0 & 1 & 0 & 0 & 0 & 50.67 & 11.6 & 0 \\
\hline 2007 & Ellison, CM & 1 & 0 & 0 & 0 & 0 & 0 & 0 & 1 & 0 & 0 & 0 & 52.67 & 13.6 & 0 \\
\hline 1996 & Elson, KS & 0 & 1 & 0 & 0 & 1 & 0 & 0 & 0 & 0 & 0 & 0 & 49.3 & 0.16 & 0 \\
\hline 1999 & Elson, KS & 0 & 1 & 0 & 0 & 1 & 0 & 0 & 0 & 0 & 0 & 0 & 52.05 & 2.92 & 0 \\
\hline 2002 & Elson, KS & 0 & 1 & 0 & 0 & 1 & 0 & 0 & 0 & 0 & 0 & 0 & 55.06 & 5.92 & 0 \\
\hline 2005 & Elson, KS & 0 & 1 & 0 & 0 & 1 & 0 & 0 & 0 & 0 & 0 & 0 & 58.06 & 8.93 & 0 \\
\hline 2007 & Elson, KS & 0 & 1 & 0 & 0 & 1 & 0 & 0 & 0 & 0 & 0 & 0 & 60.06 & 10.93 & 0 \\
\hline 1996 & Entsch, WG & 0 & 0 & 0 & 0 & 1 & 0 & 0 & 0 & 0 & 0 & 0 & 45.95 & 0.16 & 0 \\
\hline 1999 & Entsch, WG & 0 & 0 & 0 & 0 & 1 & 0 & 0 & 0 & 0 & 0 & 0 & 48.71 & 2.92 & 0 \\
\hline 2002 & Entsch, WG & 0 & 0 & 0 & 0 & 1 & 0 & 0 & 0 & 0 & 0 & 0 & 51.71 & 5.92 & 0 \\
\hline 2005 & Entsch, WG & 0 & 0 & 0 & 0 & 1 & 0 & 0 & 0 & 0 & 0 & 0 & 54.71 & 8.93 & 0 \\
\hline
\end{tabular}




\section{Appendix 1: Data for RIF Models LNPC Data (Continued)}

\begin{tabular}{|l|l|r|r|r|r|r|r|r|r|r|r|r|r|r|r|}
\hline Year & \multicolumn{1}{|c|}{ Name } & Senate & Female & Vic & NSW & Qld & Tas & SA & WA & ACT & NT & NP & Age & Exp' $^{\prime}$ & Cab' $^{\prime}$ \\
\hline 2007 & Entsch, WG & 0 & 0 & 0 & 0 & 1 & 0 & 0 & 0 & 0 & 0 & 0 & 56.71 & 10.93 & 0 \\
\hline 1996 & Evans, RD & 0 & 0 & 0 & 0 & 0 & 0 & 0 & 1 & 0 & 0 & 0 & 42.67 & 3.13 & 0 \\
\hline 1996 & Fahey, JJ & 0 & 0 & 0 & 1 & 0 & 0 & 0 & 0 & 0 & 0 & 0 & 51.34 & 0.16 & 1 \\
\hline 1999 & Fahey, JJ & 0 & 0 & 0 & 1 & 0 & 0 & 0 & 0 & 0 & 0 & 0 & 54.1 & 2.92 & 1 \\
\hline 2002 & Farmer, PF & 0 & 0 & 0 & 1 & 0 & 0 & 0 & 0 & 0 & 0 & 0 & 39.92 & 0.23 & 0 \\
\hline 2005 & Farmer, PF & 0 & 0 & 0 & 1 & 0 & 0 & 0 & 0 & 0 & 0 & 0 & 42.92 & 3.23 & 0 \\
\hline 2007 & Farmer, PF & 0 & 0 & 0 & 1 & 0 & 0 & 0 & 0 & 0 & 0 & 0 & 44.92 & 5.23 & 0 \\
\hline 2005 & Fawcett, DJ & 0 & 0 & 0 & 0 & 0 & 0 & 1 & 0 & 0 & 0 & 0 & 41.31 & 0.32 & 0 \\
\hline 2007 & Fawcett, DJ & 0 & 0 & 0 & 0 & 0 & 0 & 1 & 0 & 0 & 0 & 0 & 43.31 & 2.32 & 0 \\
\hline 1996 & Ferguson, AB & 1 & 0 & 0 & 0 & 0 & 0 & 1 & 0 & 0 & 0 & 0 & 52.66 & 3.93 & 0 \\
\hline 1999 & Ferguson, AB & 1 & 0 & 0 & 0 & 0 & 0 & 1 & 0 & 0 & 0 & 0 & 55.42 & 6.69 & 0 \\
\hline 2002 & Ferguson, AB & 1 & 0 & 0 & 0 & 0 & 0 & 1 & 0 & 0 & 0 & 0 & 58.42 & 9.69 & 0 \\
\hline 2005 & Ferguson, AB & 1 & 0 & 0 & 0 & 0 & 0 & 1 & 0 & 0 & 0 & 0 & 61.42 & 12.7 & 0 \\
\hline 2007 & Ferguson, AB & 1 & 0 & 0 & 0 & 0 & 0 & 1 & 0 & 0 & 0 & 0 & 63.42 & 14.7 & 0 \\
\hline 2005 & Ferguson, MD & 0 & 0 & 0 & 0 & 0 & 1 & 0 & 0 & 0 & 0 & 0 & 30.88 & 0.32 & 0 \\
\hline 2007 & Ferguson, MD & 0 & 0 & 0 & 0 & 0 & 1 & 0 & 0 & 0 & 0 & 0 & 32.88 & 2.32 & 0 \\
\hline 1999 & Ferris, JM & 1 & 1 & 0 & 0 & 0 & 0 & 1 & 0 & 0 & 0 & 0 & 57.93 & 2.59 & 0 \\
\hline 2002 & Ferris, JM & 1 & 1 & 0 & 0 & 0 & 0 & 1 & 0 & 0 & 0 & 0 & 60.93 & 5.59 & 0 \\
\hline 2005 & Ferris, JM & 1 & 1 & 0 & 0 & 0 & 0 & 1 & 0 & 0 & 0 & 0 & 63.93 & 8.59 & 0 \\
\hline 2007 & Ferris, JM & 1 & 1 & 0 & 0 & 0 & 0 & 1 & 0 & 0 & 0 & 0 & 65.93 & 10.59 & 0 \\
\hline
\end{tabular}




\section{Appendix 1: Data for RIF Models LNPC Data (Continued)}

\begin{tabular}{|l|l|r|r|r|r|r|r|r|r|r|r|r|r|r|r|}
\hline Year & \multicolumn{1}{|c|}{ Name } & Senate & Female & Vic & NSW & Qld & Tas & SA & WA & ACT & NT & NP & Age & Exp' $^{\prime}$ & Cab' $^{\prime}$ \\
\hline 2007 & Fierravanti-Wells, CA & 1 & 1 & 0 & 1 & 0 & 0 & 0 & 0 & 0 & 0 & 0 & 46.73 & 1.75 & 0 \\
\hline 2005 & Fifield, MP & 1 & 0 & 1 & 0 & 0 & 0 & 0 & 0 & 0 & 0 & 0 & 38.07 & 0.84 & 0 \\
\hline 2007 & Fifield, MP & 1 & 0 & 1 & 0 & 0 & 0 & 0 & 0 & 0 & 0 & 0 & 40.07 & 2.84 & 0 \\
\hline 1996 & Fischer, TA & 0 & 0 & 0 & 1 & 0 & 0 & 0 & 0 & 0 & 0 & 1 & 50.03 & 11.42 & 1 \\
\hline 1999 & Fischer, TA & 0 & 0 & 0 & 1 & 0 & 0 & 0 & 0 & 0 & 0 & 1 & 52.79 & 14.18 & 1 \\
\hline 1996 & Forrest, JA & 0 & 0 & 1 & 0 & 0 & 0 & 0 & 0 & 0 & 0 & 1 & 46.72 & 3.13 & 0 \\
\hline 1999 & Forrest, JA & 0 & 0 & 1 & 0 & 0 & 0 & 0 & 0 & 0 & 0 & 1 & 49.47 & 5.89 & 0 \\
\hline 2002 & Forrest, JA & 0 & 0 & 1 & 0 & 0 & 0 & 0 & 0 & 0 & 0 & 1 & 52.48 & 8.9 & 0 \\
\hline 2005 & Forrest, JA & 0 & 0 & 1 & 0 & 0 & 0 & 0 & 0 & 0 & 0 & 1 & 55.48 & 11.9 & 0 \\
\hline 2007 & Forrest, JA & 0 & 0 & 1 & 0 & 0 & 0 & 0 & 0 & 0 & 0 & 1 & 57.48 & 13.9 & 0 \\
\hline 1996 & Gallus, CA & 0 & 1 & 0 & 0 & 0 & 0 & 1 & 0 & 0 & 0 & 0 & 53.1 & 6.11 & 0 \\
\hline 1999 & Gallus, CA & 0 & 1 & 0 & 0 & 0 & 0 & 1 & 0 & 0 & 0 & 0 & 55.86 & 8.87 & 0 \\
\hline 2002 & Gallus, CA & 0 & 1 & 0 & 0 & 0 & 0 & 1 & 0 & 0 & 0 & 0 & 58.87 & 11.87 & 0 \\
\hline 1996 & Gambaro, T & 0 & 1 & 0 & 0 & 1 & 0 & 0 & 0 & 0 & 0 & 0 & 37.44 & 0.16 & 0 \\
\hline 1999 & Gambaro, T & 0 & 1 & 0 & 0 & 1 & 0 & 0 & 0 & 0 & 0 & 0 & 40.2 & 2.92 & 0 \\
\hline 2002 & Gambaro, T & 0 & 1 & 0 & 0 & 1 & 0 & 0 & 0 & 0 & 0 & 0 & 43.21 & 5.92 & 0 \\
\hline 2005 & Gambaro, T & 0 & 1 & 0 & 0 & 1 & 0 & 0 & 0 & 0 & 0 & 0 & 46.21 & 8.93 & 0 \\
\hline 2007 & Gambaro, T & 0 & 1 & 0 & 0 & 1 & 0 & 0 & 0 & 0 & 0 & 0 & 48.21 & 10.93 & 0 \\
\hline 1996 & Gash, J & 0 & 1 & 0 & 1 & 0 & 0 & 0 & 0 & 0 & 0 & 0 & 51.81 & 0.16 & 0 \\
\hline 1999 & Gash, J & 0 & 1 & 0 & 1 & 0 & 0 & 0 & 0 & 0 & 0 & 0 & 54.57 & 2.92 & 0 \\
\hline
\end{tabular}




\section{Appendix 1: Data for RIF Models LNPC Data (Continued)}

\begin{tabular}{|l|l|r|r|r|r|r|r|r|r|r|r|r|r|r|r|}
\hline Year & \multicolumn{1}{|c|}{ Name } & Senate & Female & Vic & NSW & Qld & Tas & SA & WA & ACT & NT & NP & Age & Exp' $^{\prime}$ & Cab' $^{\prime}$ \\
\hline 2002 & Gash, J & 0 & 1 & 0 & 1 & 0 & 0 & 0 & 0 & 0 & 0 & 0 & 57.57 & 5.92 & 0 \\
\hline 2005 & Gash, J & 0 & 1 & 0 & 1 & 0 & 0 & 0 & 0 & 0 & 0 & 0 & 60.58 & 8.93 & 0 \\
\hline 2007 & Gash, J & 0 & 1 & 0 & 1 & 0 & 0 & 0 & 0 & 0 & 0 & 0 & 62.58 & 10.93 & 0 \\
\hline 1996 & Georgiou, P & 0 & 0 & 1 & 0 & 0 & 0 & 0 & 0 & 0 & 0 & 0 & 48.45 & 1.45 & 0 \\
\hline 1999 & Georgiou, P & 0 & 0 & 1 & 0 & 0 & 0 & 0 & 0 & 0 & 0 & 0 & 51.21 & 4.21 & 0 \\
\hline 2002 & Georgiou, P & 0 & 0 & 1 & 0 & 0 & 0 & 0 & 0 & 0 & 0 & 0 & 54.21 & 7.21 & 0 \\
\hline 2005 & Georgiou, P & 0 & 0 & 1 & 0 & 0 & 0 & 0 & 0 & 0 & 0 & 0 & 57.21 & 10.21 & 0 \\
\hline 2007 & Georgiou, P & 0 & 0 & 1 & 0 & 0 & 0 & 0 & 0 & 0 & 0 & 0 & 59.21 & 12.21 & 0 \\
\hline 1996 & Gibson, BF & 1 & 0 & 0 & 0 & 0 & 1 & 0 & 0 & 0 & 0 & 0 & 59.53 & 2.83 & 0 \\
\hline 1999 & Gibson, BF & 1 & 0 & 0 & 0 & 0 & 1 & 0 & 0 & 0 & 0 & 0 & 62.28 & 5.59 & 0 \\
\hline 2002 & Gibson, BF & 1 & 0 & 0 & 0 & 0 & 1 & 0 & 0 & 0 & 0 & 0 & 65.29 & 8.59 & 0 \\
\hline 1996 & Grace, EJ & 0 & 1 & 0 & 0 & 1 & 0 & 0 & 0 & 0 & 0 & 0 & 55.96 & 0.16 & 0 \\
\hline 1999 & Haase, BW & 0 & 0 & 0 & 0 & 0 & 0 & 0 & 1 & 0 & 0 & 0 & 53.24 & 0.33 & 0 \\
\hline 2002 & Haase, BW & 0 & 0 & 0 & 0 & 0 & 0 & 0 & 1 & 0 & 0 & 0 & 56.24 & 3.33 & 0 \\
\hline 2005 & Haase, BW & 0 & 0 & 0 & 0 & 0 & 0 & 0 & 1 & 0 & 0 & 0 & 59.24 & 6.34 & 0 \\
\hline 2007 & Haase, BW & 0 & 0 & 0 & 0 & 0 & 0 & 0 & 1 & 0 & 0 & 0 & 61.24 & 8.34 & 0 \\
\hline 1996 & Halverson, RG & 0 & 0 & 1 & 0 & 0 & 0 & 0 & 0 & 0 & 0 & 0 & 58.56 & 11.42 & 0 \\
\hline 1996 & Hardgrave, GD & 0 & 0 & 0 & 0 & 1 & 0 & 0 & 0 & 0 & 0 & 0 & 36.34 & 0.16 & 0 \\
\hline 1999 & Hardgrave, GD & 0 & 0 & 0 & 0 & 1 & 0 & 0 & 0 & 0 & 0 & 0 & 39.1 & 2.92 & 0 \\
\hline 2002 & Hardgrave, GD & 0 & 0 & 0 & 0 & 1 & 0 & 0 & 0 & 0 & 0 & 0 & 42.1 & 5.92 & 0 \\
\hline
\end{tabular}




\section{Appendix 1: Data for RIF Models LNPC Data (Continued)}

\begin{tabular}{|l|l|r|r|r|r|r|r|r|r|r|r|r|r|r|r|}
\hline Year & \multicolumn{1}{|c|}{ Name } & Senate & Female & Vic & NSW & Qld & Tas & SA & WA & ACT & NT & NP & Age & Exp' $^{\prime}$ & Cab' $^{\prime}$ \\
\hline 2005 & Hardgrave, GD & 0 & 0 & 0 & 0 & 1 & 0 & 0 & 0 & 0 & 0 & 0 & 45.11 & 8.93 & 0 \\
\hline 2007 & Hardgrave, GD & 0 & 0 & 0 & 0 & 1 & 0 & 0 & 0 & 0 & 0 & 0 & 47.11 & 10.93 & 0 \\
\hline 2002 & Hartsuyker, L & 0 & 0 & 0 & 1 & 0 & 0 & 0 & 0 & 0 & 0 & 1 & 42.79 & 0.23 & 0 \\
\hline 2005 & Hartsuyker, L & 0 & 0 & 0 & 1 & 0 & 0 & 0 & 0 & 0 & 0 & 1 & 45.8 & 3.23 & 0 \\
\hline 2007 & Hartsuyker, L & 0 & 0 & 0 & 1 & 0 & 0 & 0 & 0 & 0 & 0 & 1 & 47.8 & 5.23 & 0 \\
\hline 1996 & Hawker, DP & 0 & 0 & 1 & 0 & 0 & 0 & 0 & 0 & 0 & 0 & 0 & 47.03 & 12.99 & 0 \\
\hline 1999 & Hawker, DP & 0 & 0 & 1 & 0 & 0 & 0 & 0 & 0 & 0 & 0 & 0 & 49.79 & 15.75 & 0 \\
\hline 2002 & Hawker, DP & 0 & 0 & 1 & 0 & 0 & 0 & 0 & 0 & 0 & 0 & 0 & 52.79 & 18.75 & 0 \\
\hline 2005 & Hawker, DP & 0 & 0 & 1 & 0 & 0 & 0 & 0 & 0 & 0 & 0 & 0 & 55.79 & 21.76 & 0 \\
\hline 2007 & Hawker, DP & 0 & 0 & 1 & 0 & 0 & 0 & 0 & 0 & 0 & 0 & 0 & 57.79 & 23.76 & 0 \\
\hline 1999 & Heffernan, WD & 1 & 0 & 0 & 1 & 0 & 0 & 0 & 0 & 0 & 0 & 0 & 55.96 & 2.37 & 0 \\
\hline 2002 & Heffernan, WD & 1 & 0 & 0 & 1 & 0 & 0 & 0 & 0 & 0 & 0 & 0 & 58.96 & 5.38 & 0 \\
\hline 2005 & Heffernan, WD & 1 & 0 & 0 & 1 & 0 & 0 & 0 & 0 & 0 & 0 & 0 & 61.96 & 8.38 & 0 \\
\hline 2007 & Heffernan, WD & 1 & 0 & 0 & 1 & 0 & 0 & 0 & 0 & 0 & 0 & 0 & 63.96 & 10.38 & 0 \\
\hline 2005 & Henry, SI & 0 & 0 & 0 & 0 & 0 & 0 & 0 & 1 & 0 & 0 & 0 & 58.66 & 0.32 & 0 \\
\hline 2007 & Henry, SI & 0 & 0 & 0 & 0 & 0 & 0 & 0 & 1 & 0 & 0 & 0 & 60.66 & 2.32 & 0 \\
\hline 1996 & Herron, JJ & 1 & 0 & 0 & 0 & 1 & 0 & 0 & 0 & 0 & 0 & 0 & 63.7 & 5.84 & 0 \\
\hline 1999 & Herron, JJ & 1 & 0 & 0 & 0 & 1 & 0 & 0 & 0 & 0 & 0 & 0 & 66.45 & 8.59 & 0 \\
\hline 2002 & Herron, JJ & 1 & 0 & 0 & 0 & 1 & 0 & 0 & 0 & 0 & 0 & 0 & 69.46 & 11.6 & 0 \\
\hline 1996 & Hicks, NJ & 0 & 0 & 0 & 1 & 0 & 0 & 0 & 0 & 0 & 0 & 1 & 55.52 & 15.54 & 0 \\
\hline
\end{tabular}




\section{Appendix 1: Data for RIF Models LNPC Data (Continued)}

\begin{tabular}{|l|l|r|r|r|r|r|r|r|r|r|r|r|r|r|r|}
\hline Year & \multicolumn{1}{|c|}{ Name } & Senate & Female & Vic & NSW & Qld & Tas & SA & WA & ACT & NT & NP & Age & Exp' $^{\prime}$ & Cab' $^{\prime}$ \\
\hline 1996 & Hill, RM & 1 & 0 & 0 & 0 & 0 & 0 & 1 & 0 & 0 & 0 & 0 & 49.63 & 14.84 & 1 \\
\hline 1999 & Hill, RM & 1 & 0 & 0 & 0 & 0 & 0 & 1 & 0 & 0 & 0 & 0 & 52.39 & 17.6 & 1 \\
\hline 2002 & Hill, RM & 1 & 0 & 0 & 0 & 0 & 0 & 1 & 0 & 0 & 0 & 0 & 55.39 & 20.6 & 1 \\
\hline 2005 & Hill, RM & 1 & 0 & 0 & 0 & 0 & 0 & 1 & 0 & 0 & 0 & 0 & 58.39 & 23.61 & 1 \\
\hline 1996 & Hockey, JB & 0 & 0 & 0 & 1 & 0 & 0 & 0 & 0 & 0 & 0 & 0 & 30.76 & 0.16 & 0 \\
\hline 1999 & Hockey, JB & 0 & 0 & 0 & 1 & 0 & 0 & 0 & 0 & 0 & 0 & 0 & 33.52 & 2.92 & 0 \\
\hline 2002 & Hockey, JB & 0 & 0 & 0 & 1 & 0 & 0 & 0 & 0 & 0 & 0 & 0 & 36.53 & 5.92 & 0 \\
\hline 2005 & Hockey, JB & 0 & 0 & 0 & 1 & 0 & 0 & 0 & 0 & 0 & 0 & 0 & 39.53 & 8.93 & 0 \\
\hline 2007 & Hockey, JB & 0 & 0 & 0 & 1 & 0 & 0 & 0 & 0 & 0 & 0 & 0 & 41.53 & 10.93 & 1 \\
\hline 1996 & Howard, JW & 0 & 0 & 0 & 1 & 0 & 0 & 0 & 0 & 0 & 0 & 0 & 56.8 & 21.97 & 1 \\
\hline 1999 & Howard, JW & 0 & 0 & 0 & 1 & 0 & 0 & 0 & 0 & 0 & 0 & 0 & 59.56 & 24.73 & 1 \\
\hline 2002 & Howard, JW & 0 & 0 & 0 & 1 & 0 & 0 & 0 & 0 & 0 & 0 & 0 & 62.56 & 27.73 & 1 \\
\hline 2005 & Howard, JW & 0 & 0 & 0 & 1 & 0 & 0 & 0 & 0 & 0 & 0 & 0 & 65.57 & 30.73 & 1 \\
\hline 2007 & Howard, JW & 0 & 0 & 0 & 1 & 0 & 0 & 0 & 0 & 0 & 0 & 0 & 67.57 & 32.73 & 1 \\
\hline 1999 & Hull, KE & 0 & 1 & 0 & 1 & 0 & 0 & 0 & 0 & 0 & 0 & 1 & 45.02 & 0.33 & 0 \\
\hline 2002 & Hull, KE & 0 & 1 & 0 & 1 & 0 & 0 & 0 & 0 & 0 & 0 & 1 & 48.03 & 3.33 & 0 \\
\hline 2005 & Hull, KE & 0 & 1 & 0 & 1 & 0 & 0 & 0 & 0 & 0 & 0 & 1 & 51.03 & 6.34 & 0 \\
\hline 2007 & Hull, KE & 0 & 1 & 0 & 1 & 0 & 0 & 0 & 0 & 0 & 0 & 1 & 53.03 & 8.34 & 0 \\
\hline 2005 & Humphries, GJ & 1 & 0 & 0 & 0 & 0 & 0 & 0 & 0 & 1 & 0 & 0 & 46.61 & 1.96 & 0 \\
\hline 2007 & Humphries, GJ & 1 & 0 & 0 & 0 & 0 & 0 & 0 & 0 & 1 & 0 & 0 & 48.61 & 3.96 & 0 \\
\hline
\end{tabular}




\section{Appendix 1: Data for RIF Models LNPC Data (Continued)}

\begin{tabular}{|l|l|r|r|r|r|r|r|r|r|r|r|r|r|r|r|}
\hline Year & \multicolumn{1}{|c|}{ Name } & Senate & Female & Vic & NSW & Qld & Tas & SA & WA & ACT & NT & NP & Age & Exp' $^{\prime}$ & Cab' $^{\prime}$ \\
\hline 2002 & Hunt, GA & 0 & 0 & 1 & 0 & 0 & 0 & 0 & 0 & 0 & 0 & 0 & 36.23 & 0.23 & 0 \\
\hline 2005 & Hunt, GA & 0 & 0 & 1 & 0 & 0 & 0 & 0 & 0 & 0 & 0 & 0 & 39.23 & 3.23 & 0 \\
\hline 2007 & Hunt, GA & 0 & 0 & 1 & 0 & 0 & 0 & 0 & 0 & 0 & 0 & 0 & 41.23 & 5.23 & 0 \\
\hline 1996 & Jeanes, SB & 0 & 1 & 0 & 0 & 0 & 0 & 1 & 0 & 0 & 0 & 0 & 38.21 & 0.16 & 0 \\
\hline 2005 & Jensen, DG & 0 & 0 & 0 & 0 & 0 & 0 & 0 & 1 & 0 & 0 & 0 & 42.96 & 0.32 & 0 \\
\hline 2007 & Jensen, DG & 0 & 0 & 0 & 0 & 0 & 0 & 0 & 1 & 0 & 0 & 0 & 44.96 & 2.32 & 0 \\
\hline 2002 & Johnson, MA & 0 & 0 & 0 & 0 & 1 & 0 & 0 & 0 & 0 & 0 & 0 & 32.02 & 0.23 & 0 \\
\hline 2005 & Johnson, MA & 0 & 0 & 0 & 0 & 1 & 0 & 0 & 0 & 0 & 0 & 0 & 37.03 & 5.23 & 0 \\
\hline 2007 & Johnson, MA & 1 & 0 & 0 & 0 & 0 & 0 & 0 & 1 & 0 & 0 & 0 & 49 & 2.59 & 0 \\
\hline 2005 & Johnston, DA & 1 & 0 & 0 & 0 & 0 & 0 & 0 & 1 & 0 & 0 & 0 & 51 & 4.59 & 0 \\
\hline 2007 & Johnston, DA & 0 & 0 & 0 & 0 & 0 & 0 & 0 & 1 & 0 & 0 & 0 & 52.62 & 0.16 & 0 \\
\hline 1996 & Johnston, R & 1 & 0 & 0 & 0 & 1 & 0 & 0 & 0 & 0 & 0 & 1 & 39.82 & 1.59 & 0 \\
\hline 2007 & Joyce, BT & 0 & 0 & 0 & 0 & 1 & 0 & 0 & 0 & 0 & 0 & 0 & 51.61 & 18.65 & 0 \\
\hline 1996 & Jull, DF & 0 & 0 & 0 & 0 & 1 & 0 & 0 & 0 & 0 & 0 & 0 & 54.36 & 21.41 & 0 \\
\hline 1999 & Jull, DF & 0 & 0 & 0 & 0 & 1 & 0 & 0 & 0 & 0 & 0 & 0 & 57.37 & 24.41 & 0 \\
\hline 2002 & Jull, DF & 0 & 0 & 0 & 0 & 1 & 0 & 0 & 0 & 0 & 0 & 0 & 60.37 & 27.41 & 0 \\
\hline 2005 & Jull, DF & 0 & 0 & 0 & 0 & 1 & 0 & 0 & 0 & 0 & 0 & 0 & 62.37 & 29.41 & 0 \\
\hline 2007 & Jull, DF & 0 & 0 & 0 & 0 & 1 & 0 & 0 & 0 & 0 & 0 & 1 & 50.98 & 3.13 & 0 \\
\hline 1996 & Katter, RC & 0 & 0 & 0 & 0 & 1 & 0 & 0 & 0 & 0 & 0 & 1 & 53.73 & 5.89 & 0 \\
\hline 1999 & Katter, RC & & & & & & &
\end{tabular}




\section{Appendix 1: Data for RIF Models LNPC Data (Continued)}

\begin{tabular}{|c|c|c|c|c|c|c|c|c|c|c|c|c|c|c|c|}
\hline Year & Name & Senate & Female & Vic & NSW & Qld & Tas & SA & WA & ACT & NT & NP & Age & Exp' & Cab' \\
\hline 2005 & Keenan, MF & 0 & 0 & 0 & 0 & 0 & 0 & 0 & 1 & 0 & 0 & 0 & 32.9 & 0.32 & 0 \\
\hline 2007 & Keenan, MF & 0 & 0 & 0 & 0 & 0 & 0 & 0 & 1 & 0 & 0 & 0 & 34.9 & 2.32 & 0 \\
\hline 1996 & Kelly, DM & 0 & 1 & 0 & 0 & 1 & 0 & 0 & 0 & 0 & 0 & 1 & 42.14 & 0.16 & 0 \\
\hline 1999 & Kelly, DM & 0 & 1 & 0 & 0 & 1 & 0 & 0 & 0 & 0 & 0 & 1 & 44.9 & 2.92 & 0 \\
\hline 2002 & Kelly, DM & 0 & 1 & 0 & 0 & 1 & 0 & 0 & 0 & 0 & 0 & 1 & 47.9 & 5.92 & 0 \\
\hline 2005 & Kelly, DM & 0 & 1 & 0 & 0 & 1 & 0 & 0 & 0 & 0 & 0 & 1 & 50.9 & 8.93 & 0 \\
\hline 2007 & Kelly, DM & 0 & 1 & 0 & 0 & 1 & 0 & 0 & 0 & 0 & 0 & 1 & 52.9 & 10.93 & 0 \\
\hline 1996 & Kelly, JM & 0 & 1 & 0 & 1 & 0 & 0 & 0 & 0 & 0 & 0 & 0 & 32.22 & 0.16 & 0 \\
\hline 1999 & Kelly, JM & 0 & 1 & 0 & 1 & 0 & 0 & 0 & 0 & 0 & 0 & 0 & 34.98 & 2.92 & 0 \\
\hline 2002 & Kelly, JM & 0 & 1 & 0 & 1 & 0 & 0 & 0 & 0 & 0 & 0 & 0 & 37.98 & 5.92 & 0 \\
\hline 2005 & Kelly, JM & 0 & 1 & 0 & 1 & 0 & 0 & 0 & 0 & 0 & 0 & 0 & 40.98 & 8.93 & 0 \\
\hline 2007 & Kelly, JM & 0 & 1 & 0 & 1 & 0 & 0 & 0 & 0 & 0 & 0 & 0 & 42.98 & 10.93 & 0 \\
\hline 1996 & Kemp, CR & 1 & 0 & 1 & 0 & 0 & 0 & 0 & 0 & 0 & 0 & 0 & 51.39 & 5.84 & 0 \\
\hline 1999 & Kemp, CR & 1 & 0 & 1 & 0 & 0 & 0 & 0 & 0 & 0 & 0 & 0 & 54.15 & 8.59 & 0 \\
\hline 2002 & Kemp, CR & 1 & 0 & 1 & 0 & 0 & 0 & 0 & 0 & 0 & 0 & 0 & 57.15 & 11.6 & 0 \\
\hline 2005 & Kemp, CR & 1 & 0 & 1 & 0 & 0 & 0 & 0 & 0 & 0 & 0 & 0 & 60.16 & 14.6 & 0 \\
\hline 2007 & Kemp, CR & 1 & 0 & 1 & 0 & 0 & 0 & 0 & 0 & 0 & 0 & 0 & 62.16 & 16.6 & 0 \\
\hline 1996 & Kemp, DA & 0 & 0 & 1 & 0 & 0 & 0 & 0 & 0 & 0 & 0 & 0 & 54.58 & 6.11 & 0 \\
\hline 1999 & Kemp, DA & 0 & 0 & 1 & 0 & 0 & 0 & 0 & 0 & 0 & 0 & 0 & 57.34 & 8.87 & 1 \\
\hline 2002 & Kemp, DA & 0 & 0 & 1 & 0 & 0 & 0 & 0 & 0 & 0 & 0 & 0 & 60.34 & 11.87 & 1 \\
\hline
\end{tabular}




\section{Appendix 1: Data for RIF Models LNPC Data (Continued)}

\begin{tabular}{|l|l|r|r|r|r|r|r|r|r|r|r|r|r|r|r|}
\hline Year & \multicolumn{1}{|c|}{ Name } & Senate & Female & Vic & NSW & Qld & Tas & SA & WA & ACT & NT & NP & Age & Exp' $^{\prime}$ & Cab' $^{\prime}$ \\
\hline 2002 & King, PE & 0 & 0 & 0 & 1 & 0 & 0 & 0 & 0 & 0 & 0 & 0 & 49.63 & 0.23 & 0 \\
\hline 1996 & Knowles, SC & 1 & 1 & 0 & 0 & 0 & 0 & 0 & 1 & 0 & 0 & 0 & 45.09 & 11.42 & 0 \\
\hline 1999 & Knowles, SC & 1 & 1 & 0 & 0 & 0 & 0 & 0 & 1 & 0 & 0 & 0 & 47.85 & 14.18 & 0 \\
\hline 2002 & Knowles, SC & 1 & 1 & 0 & 0 & 0 & 0 & 0 & 1 & 0 & 0 & 0 & 50.85 & 17.18 & 0 \\
\hline 2005 & Knowles, SC & 1 & 1 & 0 & 0 & 0 & 0 & 0 & 1 & 0 & 0 & 0 & 53.85 & 20.18 & 0 \\
\hline 2005 & Laming, AC & 0 & 0 & 0 & 0 & 1 & 0 & 0 & 0 & 0 & 0 & 0 & 38.37 & 0.32 & 0 \\
\hline 2007 & Laming, AC & 0 & 0 & 0 & 0 & 1 & 0 & 0 & 0 & 0 & 0 & 0 & 40.37 & 2.32 & 0 \\
\hline 1999 & Lawler, AJ & 0 & 0 & 0 & 1 & 0 & 0 & 0 & 0 & 0 & 0 & 1 & 37.32 & 0.33 & 0 \\
\hline 2002 & Ley, SP & 0 & 1 & 0 & 1 & 0 & 0 & 0 & 0 & 0 & 0 & 0 & 40.16 & 0.23 & 0 \\
\hline 2005 & Ley, SP & 0 & 1 & 0 & 1 & 0 & 0 & 0 & 0 & 0 & 0 & 0 & 43.16 & 3.23 & 0 \\
\hline 2007 & Ley, SP & 0 & 1 & 0 & 1 & 0 & 0 & 0 & 0 & 0 & 0 & 0 & 45.16 & 5.23 & 0 \\
\hline 1996 & Liberman, LS & 0 & 0 & 1 & 0 & 0 & 0 & 0 & 0 & 0 & 0 & 0 & 57.98 & 3.13 & 0 \\
\hline 1999 & Liberman, LS & 0 & 0 & 1 & 0 & 0 & 0 & 0 & 0 & 0 & 0 & 0 & 60.74 & 5.89 & 0 \\
\hline 1999 & Lightfoot, PR & 1 & 0 & 0 & 0 & 0 & 0 & 0 & 1 & 0 & 0 & 0 & 62.52 & 1.71 & 0 \\
\hline 2002 & Lightfoot, PR & 1 & 0 & 0 & 0 & 0 & 0 & 0 & 1 & 0 & 0 & 0 & 65.52 & 4.71 & 0 \\
\hline 2005 & Lightfoot, PR & 1 & 0 & 0 & 0 & 0 & 0 & 0 & 1 & 0 & 0 & 0 & 68.52 & 7.71 & 0 \\
\hline 2007 & Lightfoot, PR & 1 & 0 & 0 & 0 & 0 & 0 & 0 & 1 & 0 & 0 & 0 & 70.52 & 9.71 & 0 \\
\hline 1996 & Lindsay, PJ & 0 & 0 & 0 & 0 & 1 & 0 & 0 & 0 & 0 & 0 & 0 & 52.02 & 0.16 & 0 \\
\hline 1999 & Lindsay, PJ & 0 & 0 & 0 & 0 & 1 & 0 & 0 & 0 & 0 & 0 & 0 & 54.78 & 2.92 & 0 \\
\hline 2002 & Lindsay, PJ & 0 & 0 & 0 & 0 & 1 & 0 & 0 & 0 & 0 & 0 & 0 & 57.79 & 5.92 & 0 \\
\hline
\end{tabular}




\section{Appendix 1: Data for RIF Models LNPC Data (Continued)}

\begin{tabular}{|c|c|c|c|c|c|c|c|c|c|c|c|c|c|c|c|}
\hline Year & Name & Senate & Female & Vic & NSW & Qld & Tas & SA & WA & ACT & NT & NP & Age & Exp' & $\mathrm{Cab}^{\prime}$ \\
\hline 2005 & Lindsay, PJ & 0 & 0 & 0 & 0 & 1 & 0 & 0 & 0 & 0 & 0 & 0 & 60.79 & 8.93 & 0 \\
\hline 2007 & Lindsay, PJ & 0 & 0 & 0 & 0 & 1 & 0 & 0 & 0 & 0 & 0 & 0 & 62.79 & 10.93 & 0 \\
\hline 1996 & Lloyd, JE & 0 & 0 & 0 & 1 & 0 & 0 & 0 & 0 & 0 & 0 & 0 & 41.82 & 0.16 & 0 \\
\hline 1999 & Lloyd, JE & 0 & 0 & 0 & 1 & 0 & 0 & 0 & 0 & 0 & 0 & 0 & 44.58 & 2.92 & 0 \\
\hline 2002 & Lloyd, JE & 0 & 0 & 0 & 1 & 0 & 0 & 0 & 0 & 0 & 0 & 0 & 47.58 & 5.92 & 0 \\
\hline 2005 & Lloyd, JE & 0 & 0 & 0 & 1 & 0 & 0 & 0 & 0 & 0 & 0 & 0 & 50.58 & 8.93 & 0 \\
\hline 2007 & Lloyd, JE & 0 & 0 & 0 & 1 & 0 & 0 & 0 & 0 & 0 & 0 & 0 & 52.58 & 10.93 & 0 \\
\hline 1996 & Macdonald, ID & 1 & 0 & 0 & 0 & 1 & 0 & 0 & 0 & 0 & 0 & 0 & 50.45 & 5.84 & 0 \\
\hline 1999 & Macdonald, ID & 1 & 0 & 0 & 0 & 1 & 0 & 0 & 0 & 0 & 0 & 0 & 53.21 & 8.59 & 0 \\
\hline 2002 & Macdonald, ID & 1 & 0 & 0 & 0 & 1 & 0 & 0 & 0 & 0 & 0 & 0 & 56.21 & 11.6 & 0 \\
\hline 2005 & Macdonald, ID & 1 & 0 & 0 & 0 & 1 & 0 & 0 & 0 & 0 & 0 & 0 & 59.22 & 14.6 & 0 \\
\hline 2007 & Macdonald, ID & 1 & 0 & 0 & 0 & 1 & 0 & 0 & 0 & 0 & 0 & 0 & 61.22 & 16.6 & 0 \\
\hline 1996 & Macdonald, JA & 1 & 0 & 0 & 1 & 0 & 0 & 0 & 0 & 0 & 0 & 1 & 42 & 2.83 & 0 \\
\hline 1999 & Macdonald, JA & 1 & 0 & 0 & 1 & 0 & 0 & 0 & 0 & 0 & 0 & 1 & 44.76 & 5.59 & 0 \\
\hline 2002 & Macdonald, JA & 1 & 0 & 0 & 1 & 0 & 0 & 0 & 0 & 0 & 0 & 1 & 47.76 & 7.75 & 0 \\
\hline 2005 & Macdonald, JA & 1 & 0 & 0 & 1 & 0 & 0 & 0 & 0 & 0 & 0 & 1 & 50.77 & 10.75 & 0 \\
\hline 2007 & Macdonald, JA & 1 & 0 & 0 & 1 & 0 & 0 & 0 & 0 & 0 & 0 & 1 & 52.77 & 12.75 & 0 \\
\hline 1999 & Macfarlane, IE & 0 & 0 & 0 & 0 & 1 & 0 & 0 & 0 & 0 & 0 & 0 & 43.86 & 0.33 & 0 \\
\hline 2002 & Macfarlane, IE & 0 & 0 & 0 & 0 & 1 & 0 & 0 & 0 & 0 & 0 & 0 & 46.86 & 3.33 & 1 \\
\hline 2005 & Macfarlane, IE & 0 & 0 & 0 & 0 & 1 & 0 & 0 & 0 & 0 & 0 & 0 & 49.86 & 6.34 & 1 \\
\hline
\end{tabular}




\section{Appendix 1: Data for RIF Models LNPC Data (Continued)}

\begin{tabular}{|c|c|c|c|c|c|c|c|c|c|c|c|c|c|c|c|}
\hline Year & Name & Senate & Female & Vic & NSW & Qld & Tas & SA & WA & ACT & NT & NP & Age & Exp' & $\mathrm{Cab}^{\prime}$ \\
\hline 2007 & Macfarlane, IE & 0 & 0 & 0 & 0 & 1 & 0 & 0 & 0 & 0 & 0 & 0 & 51.86 & 8.34 & 1 \\
\hline 1996 & MacGibbon, DJ & 1 & 0 & 0 & 0 & 1 & 0 & 0 & 0 & 0 & 0 & 0 & 62.01 & 17.84 & 0 \\
\hline 1999 & MacGibbon, DJ & 1 & 0 & 0 & 0 & 1 & 0 & 0 & 0 & 0 & 0 & 0 & 64.77 & 20.6 & 0 \\
\hline 1996 & Marek, $\mathrm{P}$ & 0 & 0 & 0 & 0 & 1 & 0 & 0 & 0 & 0 & 0 & 1 & 31.79 & 0.16 & 0 \\
\hline 2005 & Markus, LE & 0 & 1 & 0 & 1 & 0 & 0 & 0 & 0 & 0 & 0 & 0 & 46.44 & 0.32 & 0 \\
\hline 2007 & Markus, LE & 0 & 1 & 0 & 1 & 0 & 0 & 0 & 0 & 0 & 0 & 0 & 48.44 & 2.32 & 0 \\
\hline 2002 & Mason, BJ & 1 & 0 & 0 & 0 & 1 & 0 & 0 & 0 & 0 & 0 & 0 & 39.94 & 2.59 & 0 \\
\hline 2005 & Mason, BJ & 1 & 0 & 0 & 0 & 1 & 0 & 0 & 0 & 0 & 0 & 0 & 42.94 & 5.59 & 0 \\
\hline 2007 & Mason, BJ & 1 & 0 & 0 & 0 & 1 & 0 & 0 & 0 & 0 & 0 & 0 & 44.94 & 7.59 & 0 \\
\hline 1999 & May, MA & 0 & 1 & 0 & 0 & 1 & 0 & 0 & 0 & 0 & 0 & 0 & 48.62 & 0.33 & 0 \\
\hline 2002 & May, MA & 0 & 1 & 0 & 0 & 1 & 0 & 0 & 0 & 0 & 0 & 0 & 51.63 & 3.33 & 0 \\
\hline 2005 & May, MA & 0 & 1 & 0 & 0 & 1 & 0 & 0 & 0 & 0 & 0 & 0 & 54.63 & 6.34 & 0 \\
\hline 2007 & May, MA & 0 & 1 & 0 & 0 & 1 & 0 & 0 & 0 & 0 & 0 & 0 & 56.63 & 8.34 & 0 \\
\hline 1996 & McArthur, FS & 0 & 0 & 1 & 0 & 0 & 0 & 0 & 0 & 0 & 0 & 0 & 58.55 & 12.21 & 0 \\
\hline 1999 & McArthur, FS & 0 & 0 & 1 & 0 & 0 & 0 & 0 & 0 & 0 & 0 & 0 & 61.31 & 14.96 & 0 \\
\hline 2002 & McArthur, FS & 0 & 0 & 1 & 0 & 0 & 0 & 0 & 0 & 0 & 0 & 0 & 64.31 & 17.97 & 0 \\
\hline 2005 & McArthur, FS & 0 & 0 & 1 & 0 & 0 & 0 & 0 & 0 & 0 & 0 & 0 & 67.31 & 20.97 & 0 \\
\hline 2007 & McArthur, FS & 0 & 0 & 1 & 0 & 0 & 0 & 0 & 0 & 0 & 0 & 0 & 69.31 & 22.97 & 0 \\
\hline 1996 & McDougall, GR & 0 & 0 & 0 & 0 & 1 & 0 & 0 & 0 & 0 & 0 & 0 & 49.47 & 0.16 & 0 \\
\hline 1996 & McGauran, JJ & 1 & 0 & 1 & 0 & 0 & 0 & 0 & 0 & 0 & 0 & 1 & 39.18 & 5.81 & 0 \\
\hline
\end{tabular}




\section{Appendix 1: Data for RIF Models LNPC Data (Continued)}

\begin{tabular}{|l|l|r|r|r|r|r|r|r|r|r|r|r|r|r|r|}
\hline Year & \multicolumn{1}{|c|}{ Name } & Senate & Female & Vic & NSW & Qld & Tas & SA & WA & ACT & NT & NP & Age & Exp' $^{\prime}$ & Cab' $^{\prime}$ \\
\hline 1999 & McGauran, JJ & 1 & 0 & 1 & 0 & 0 & 0 & 0 & 0 & 0 & 0 & 1 & 41.94 & 8.56 & 0 \\
\hline 2002 & McGauran, JJ & 1 & 0 & 1 & 0 & 0 & 0 & 0 & 0 & 0 & 0 & 1 & 44.94 & 11.57 & 0 \\
\hline 2005 & McGauran, JJ & 1 & 0 & 1 & 0 & 0 & 0 & 0 & 0 & 0 & 0 & 1 & 47.95 & 14.57 & 0 \\
\hline 2007 & McGauran, JJ & 1 & 0 & 1 & 0 & 0 & 0 & 0 & 0 & 0 & 0 & 0 & 49.95 & 16.57 & 0 \\
\hline 1996 & McGauran, PJ & 0 & 0 & 1 & 0 & 0 & 0 & 0 & 0 & 0 & 0 & 1 & 40.48 & 13.16 & 0 \\
\hline 1999 & McGauran, PJ & 0 & 0 & 1 & 0 & 0 & 0 & 0 & 0 & 0 & 0 & 1 & 43.24 & 15.92 & 0 \\
\hline 2002 & McGauran, PJ & 0 & 0 & 1 & 0 & 0 & 0 & 0 & 0 & 0 & 0 & 1 & 46.24 & 18.93 & 0 \\
\hline 2005 & McGauran, PJ & 0 & 0 & 1 & 0 & 0 & 0 & 0 & 0 & 0 & 0 & 1 & 49.25 & 21.93 & 0 \\
\hline 2007 & McGauran, PJ & 0 & 0 & 1 & 0 & 0 & 0 & 0 & 0 & 0 & 0 & 1 & 51.25 & 23.93 & 1 \\
\hline 1996 & McLachlan, IM & 0 & 0 & 0 & 0 & 0 & 0 & 1 & 0 & 0 & 0 & 0 & 59.62 & 6.11 & 1 \\
\hline 1996 & Miles, CG & 0 & 0 & 0 & 0 & 0 & 1 & 0 & 0 & 0 & 0 & 0 & 48.73 & 11.42 & 0 \\
\hline 1996 & Minchin, NH & 1 & 0 & 0 & 0 & 0 & 0 & 1 & 0 & 0 & 0 & 0 & 43.07 & 2.83 & 0 \\
\hline 1999 & Minchin, NH & 1 & 0 & 0 & 0 & 0 & 0 & 1 & 0 & 0 & 0 & 0 & 45.83 & 5.59 & 1 \\
\hline 2002 & Minchin, NH & 1 & 0 & 0 & 0 & 0 & 0 & 1 & 0 & 0 & 0 & 0 & 48.83 & 8.59 & 1 \\
\hline 2005 & Minchin, NH & 1 & 0 & 0 & 0 & 0 & 0 & 1 & 0 & 0 & 0 & 0 & 51.84 & 11.6 & 1 \\
\hline 2007 & Minchin, NH & 1 & 0 & 0 & 0 & 0 & 0 & 1 & 0 & 0 & 0 & 0 & 53.84 & 13.6 & 1 \\
\hline 2002 & Mirabella, S & 0 & 1 & 1 & 0 & 0 & 0 & 0 & 0 & 0 & 0 & 0 & 33.29 & 0.23 & 0 \\
\hline 2005 & Mirabella, S & 0 & 1 & 1 & 0 & 0 & 0 & 0 & 0 & 0 & 0 & 0 & 36.29 & 3.23 & 0 \\
\hline 2007 & Mirabella, S & 0 & 1 & 1 & 0 & 0 & 0 & 0 & 0 & 0 & 0 & 0 & 38.29 & 5.23 & 0 \\
\hline 1996 & Moore, JC & 0 & 0 & 0 & 0 & 1 & 0 & 0 & 0 & 0 & 0 & 0 & 59.49 & 20.39 & 1 \\
\hline
\end{tabular}




\section{Appendix 1: Data for RIF Models LNPC Data (Continued)}

\begin{tabular}{|l|l|r|r|r|r|r|r|r|r|r|r|r|r|r|r|}
\hline Year & \multicolumn{1}{|c|}{ Name } & Senate & Female & Vic & NSW & Qld & Tas & SA & WA & ACT & NT & NP & Age & Exp' $^{\prime}$ & Cab' $^{\prime}$ \\
\hline 1999 & Moore, JC & 0 & 0 & 0 & 0 & 1 & 0 & 0 & 0 & 0 & 0 & 0 & 62.25 & 23.15 & 1 \\
\hline 1996 & Moylan, JE & 0 & 1 & 0 & 0 & 0 & 0 & 0 & 1 & 0 & 0 & 0 & 52.22 & 3.13 & 0 \\
\hline 1999 & Moylan, JE & 0 & 1 & 0 & 0 & 0 & 0 & 0 & 1 & 0 & 0 & 0 & 54.98 & 5.89 & 0 \\
\hline 2002 & Moylan, JE & 0 & 1 & 0 & 0 & 0 & 0 & 0 & 1 & 0 & 0 & 0 & 57.98 & 8.9 & 0 \\
\hline 2005 & Moylan, JE & 0 & 1 & 0 & 0 & 0 & 0 & 0 & 1 & 0 & 0 & 0 & 60.98 & 11.9 & 0 \\
\hline 2007 & Moylan, JE & 0 & 1 & 0 & 0 & 0 & 0 & 0 & 1 & 0 & 0 & 0 & 62.98 & 13.9 & 0 \\
\hline 1996 & Mutch, SB & 0 & 0 & 0 & 1 & 0 & 0 & 0 & 0 & 0 & 0 & 0 & 40.26 & 0.16 & 0 \\
\hline 1996 & Nairn, GR & 0 & 0 & 0 & 1 & 0 & 0 & 0 & 0 & 0 & 0 & 0 & 45.35 & 0.16 & 0 \\
\hline 1999 & Nairn, GR & 0 & 0 & 0 & 1 & 0 & 0 & 0 & 0 & 0 & 0 & 0 & 48.11 & 2.92 & 0 \\
\hline 2002 & Nairn, GR & 0 & 0 & 0 & 1 & 0 & 0 & 0 & 0 & 0 & 0 & 0 & 51.12 & 5.92 & 0 \\
\hline 2005 & Nairn, GR & 0 & 0 & 0 & 1 & 0 & 0 & 0 & 0 & 0 & 0 & 0 & 54.12 & 8.93 & 0 \\
\hline 2007 & Nairn, GR & 0 & 0 & 0 & 1 & 0 & 0 & 0 & 0 & 0 & 0 & 0 & 56.12 & 10.93 & 0 \\
\hline 2007 & Nash, FJ & 1 & 1 & 0 & 1 & 0 & 0 & 0 & 0 & 0 & 0 & 1 & 41.77 & 1.59 & 0 \\
\hline 1996 & Nehl, GB & 0 & 0 & 0 & 1 & 0 & 0 & 0 & 0 & 0 & 0 & 1 & 62.24 & 11.42 & 0 \\
\hline 1999 & Nehl, GB & 0 & 0 & 0 & 1 & 0 & 0 & 0 & 0 & 0 & 0 & 1 & 64.99 & 14.18 & 0 \\
\hline 1996 & Nelson, BJ & 0 & 0 & 0 & 1 & 0 & 0 & 0 & 0 & 0 & 0 & 0 & 36.72 & 0.16 & 0 \\
\hline 1999 & Nelson, BJ & 0 & 0 & 0 & 1 & 0 & 0 & 0 & 0 & 0 & 0 & 0 & 39.48 & 2.92 & 0 \\
\hline 2002 & Nelson, BJ & 0 & 0 & 0 & 1 & 0 & 0 & 0 & 0 & 0 & 0 & 0 & 45.49 & 8.93 & 1 \\
\hline 2005 & Nelson, BJ & 0 & 0 & 0 & 1 & 0 & 0 & 0 & 0 & 0 & 0 & 0 & 47.49 & 10.93 & 1 \\
\hline 2007 & Nelson, BJ & & & & & & & &
\end{tabular}




\section{Appendix 1: Data for RIF Models LNPC Data (Continued)}

\begin{tabular}{|c|c|c|c|c|c|c|c|c|c|c|c|c|c|c|c|}
\hline Year & Name & Senate & Female & Vic & NSW & Qld & Tas & SA & WA & ACT & NT & NP & Age & Exp' & Cab' \\
\hline 1996 & Neville, PC & 0 & 0 & 0 & 0 & 1 & 0 & 0 & 0 & 0 & 0 & 1 & 56.13 & 3.13 & 0 \\
\hline 1999 & Neville, PC & 0 & 0 & 0 & 0 & 1 & 0 & 0 & 0 & 0 & 0 & 1 & 58.89 & 5.89 & 0 \\
\hline 2002 & Neville, PC & 0 & 0 & 0 & 0 & 1 & 0 & 0 & 0 & 0 & 0 & 1 & 61.89 & 8.9 & 0 \\
\hline 2005 & Neville, PC & 0 & 0 & 0 & 0 & 1 & 0 & 0 & 0 & 0 & 0 & 1 & 64.89 & 11.9 & 0 \\
\hline 2007 & Neville, PC & 0 & 0 & 0 & 0 & 1 & 0 & 0 & 0 & 0 & 0 & 1 & 66.89 & 13.9 & 0 \\
\hline 1996 & Newman, JM & 1 & 1 & 0 & 0 & 0 & 1 & 0 & 0 & 0 & 0 & 0 & 58.85 & 10.14 & 1 \\
\hline 1999 & Newman, JM & 1 & 1 & 0 & 0 & 0 & 1 & 0 & 0 & 0 & 0 & 0 & 61.61 & 12.9 & 1 \\
\hline 1996 & Nugent, PE & 0 & 0 & 1 & 0 & 0 & 0 & 0 & 0 & 0 & 0 & 0 & 58.12 & 6.11 & 0 \\
\hline 1999 & Nugent, PE & 0 & 0 & 1 & 0 & 0 & 0 & 0 & 0 & 0 & 0 & 0 & 60.88 & 8.87 & 0 \\
\hline 1996 & O'Chee, WG & 1 & 0 & 0 & 0 & 1 & 0 & 0 & 0 & 0 & 0 & 1 & 30.88 & 5.98 & 0 \\
\hline 1999 & O'Chee, WG & 1 & 0 & 0 & 0 & 1 & 0 & 0 & 0 & 0 & 0 & 1 & 33.64 & 8.74 & 0 \\
\hline 1996 & Panizza, JH & 1 & 0 & 0 & 0 & 0 & 0 & 0 & 1 & 0 & 0 & 0 & 65.15 & 8.81 & 0 \\
\hline 1996 & Parer, WR & 1 & 0 & 0 & 0 & 1 & 0 & 0 & 0 & 0 & 0 & 0 & 60.11 & 11.44 & 0 \\
\hline 1999 & Parer, WR & 1 & 0 & 0 & 0 & 1 & 0 & 0 & 0 & 0 & 0 & 0 & 62.87 & 14.2 & 0 \\
\hline 2007 & Parry, SS & 1 & 0 & 0 & 0 & 0 & 1 & 0 & 0 & 0 & 0 & 0 & 46.28 & 1.59 & 0 \\
\hline 1996 & Patterson, KC & 1 & 1 & 1 & 0 & 0 & 0 & 0 & 0 & 0 & 0 & 0 & 51.47 & 8.81 & 0 \\
\hline 1999 & Patterson, $\mathrm{KC}$ & 1 & 1 & 1 & 0 & 0 & 0 & 0 & 0 & 0 & 0 & 0 & 54.23 & 11.57 & 0 \\
\hline 2002 & Patterson, KC & 1 & 1 & 1 & 0 & 0 & 0 & 0 & 0 & 0 & 0 & 0 & 57.24 & 14.57 & 1 \\
\hline 2005 & Patterson, $\mathrm{KC}$ & 1 & 1 & 1 & 0 & 0 & 0 & 0 & 0 & 0 & 0 & 0 & 60.24 & 17.58 & 1 \\
\hline 2007 & Patterson, KC & 1 & 1 & 1 & 0 & 0 & 0 & 0 & 0 & 0 & 0 & 0 & 62.24 & 19.58 & 0 \\
\hline
\end{tabular}




\section{Appendix 1: Data for RIF Models LNPC Data (Continued)}

\begin{tabular}{|r|l|r|r|r|r|r|r|r|r|r|r|r|r|r|r|}
\hline Year & \multicolumn{1}{|c|}{ Name } & Senate & Female & Vic & NSW & Qld & Tas & SA & WA & ACT & NT & NP & Age & Exp' $^{\prime}$ & Cab' $^{\prime}$ \\
\hline 1999 & Payne, MA & 1 & 1 & 0 & 1 & 0 & 0 & 0 & 0 & 0 & 0 & 0 & 34.53 & 1.82 & 0 \\
\hline 2002 & Payne, MA & 1 & 1 & 0 & 1 & 0 & 0 & 0 & 0 & 0 & 0 & 0 & 37.54 & 4.82 & 0 \\
\hline 2005 & Payne, MA & 1 & 1 & 0 & 1 & 0 & 0 & 0 & 0 & 0 & 0 & 0 & 40.54 & 7.82 & 0 \\
\hline 2007 & Payne, MA & 1 & 1 & 0 & 1 & 0 & 0 & 0 & 0 & 0 & 0 & 0 & 42.54 & 9.82 & 0 \\
\hline 2002 & Pearce, CJ & 0 & 0 & 1 & 0 & 0 & 0 & 0 & 0 & 0 & 0 & 0 & 38.95 & 0.55 & 0 \\
\hline 2005 & Pearce, CJ & 0 & 0 & 1 & 0 & 0 & 0 & 0 & 0 & 0 & 0 & 0 & 41.95 & 3.56 & 0 \\
\hline 2007 & Pearce, CJ & 0 & 0 & 1 & 0 & 0 & 0 & 0 & 0 & 0 & 0 & 0 & 43.95 & 5.56 & 0 \\
\hline 1996 & Prosser, GD & 0 & 0 & 0 & 0 & 0 & 0 & 0 & 1 & 0 & 0 & 0 & 47.51 & 8.81 & 0 \\
\hline 1999 & Prosser, GD & 0 & 0 & 0 & 0 & 0 & 0 & 0 & 1 & 0 & 0 & 0 & 50.27 & 11.57 & 0 \\
\hline 2002 & Prosser, GD & 0 & 0 & 0 & 0 & 0 & 0 & 0 & 1 & 0 & 0 & 0 & 53.27 & 14.57 & 0 \\
\hline 2005 & Prosser, GD & 0 & 0 & 0 & 0 & 0 & 0 & 0 & 1 & 0 & 0 & 0 & 56.28 & 17.58 & 0 \\
\hline 2007 & Prosser, GD & 0 & 0 & 0 & 0 & 0 & 0 & 0 & 1 & 0 & 0 & 0 & 58.28 & 19.58 & 0 \\
\hline 1996 & Pyne, CM & 0 & 0 & 0 & 0 & 0 & 0 & 1 & 0 & 0 & 0 & 0 & 28.73 & 3.13 & 0 \\
\hline 1999 & Pyne, CM & 0 & 0 & 0 & 0 & 0 & 0 & 1 & 0 & 0 & 0 & 0 & 31.49 & 5.89 & 0 \\
\hline 2002 & Pyne, CM & 0 & 0 & 0 & 0 & 0 & 0 & 1 & 0 & 0 & 0 & 0 & 34.5 & 8.9 & 0 \\
\hline 2005 & Pyne, CM & 0 & 0 & 0 & 0 & 0 & 0 & 1 & 0 & 0 & 0 & 0 & 37.5 & 11.9 & 0 \\
\hline 2007 & Pyne, CM & 0 & 0 & 0 & 0 & 0 & 0 & 1 & 0 & 0 & 0 & 0 & 39.5 & 13.9 & 0 \\
\hline 1996 & Randall, DJ & 0 & 0 & 0 & 0 & 0 & 0 & 0 & 1 & 0 & 0 & 0 & 43.02 & 0.16 & 0 \\
\hline 2002 & Randall, DJ & 0 & 0 & 0 & 0 & 0 & 0 & 0 & 1 & 0 & 0 & 0 & 51.79 & 5.82 & 0 \\
\hline 2005 & Randall, DJ & & & & & & &
\end{tabular}




\section{Appendix 1: Data for RIF Models LNPC Data (Continued)}

\begin{tabular}{|l|l|r|r|r|r|r|r|r|r|r|r|r|r|r|r|}
\hline Year & \multicolumn{1}{|c|}{ Name } & Senate & Female & Vic & NSW & Qld & Tas & SA & WA & ACT & NT & NP & Age & Exp' $^{\prime}$ & Cab' $^{\prime}$ \\
\hline 2007 & Randall, DJ & 0 & 0 & 0 & 0 & 0 & 0 & 0 & 1 & 0 & 0 & 0 & 53.79 & 7.82 & 0 \\
\hline 1996 & Reid, ME & 1 & 1 & 0 & 0 & 0 & 0 & 0 & 0 & 1 & 0 & 0 & 60.97 & 15 & 0 \\
\hline 1999 & Reid, ME & 1 & 1 & 0 & 0 & 0 & 0 & 0 & 0 & 1 & 0 & 0 & 63.73 & 17.76 & 0 \\
\hline 2002 & Reid, ME & 1 & 1 & 0 & 0 & 0 & 0 & 0 & 0 & 1 & 0 & 0 & 66.73 & 20.76 & 0 \\
\hline 1996 & Reid, NB & 0 & 0 & 1 & 0 & 0 & 0 & 0 & 0 & 0 & 0 & 0 & 60.79 & 6.11 & 0 \\
\hline 1996 & Reith, PK & 0 & 0 & 1 & 0 & 0 & 0 & 0 & 0 & 0 & 0 & 0 & 48.58 & 14.43 & 1 \\
\hline 1999 & Reith, PK & 0 & 0 & 0 & 0 & 0 & 0 & 1 & 0 & 0 & 0 & 0 & 46.92 & 0.32 & 0 \\
\hline 2005 & Richardson, KC & 0 & 0 & 0 & 0 & 0 & 0 & 1 & 0 & 0 & 0 & 0 & 48.92 & 2.32 & 0 \\
\hline 2007 & Richardson, KC & 0 & 0 & 1 & 0 & 0 & 0 & 0 & 0 & 0 & 0 & 0 & 53.49 & 0.32 & 0 \\
\hline 2005 & Robb, AJ & 0 & 0 & 1 & 0 & 0 & 0 & 0 & 0 & 0 & 0 & 0 & 55.49 & 2.32 & 0 \\
\hline 2007 & Robb, AJ & 0 & 0 & 1 & 0 & 0 & 0 & 0 & 0 & 0 & 0 & 0 & 42.24 & 6.11 & 0 \\
\hline 1996 & Ronaldson, M & 0 & 0 & 1 & 0 & 0 & 0 & 0 & 0 & 0 & 0 & 0 & 45 & 8.87 & 0 \\
\hline 1999 & Ronaldson, M & 1 & 0 & 1 & 0 & 0 & 0 & 0 & 0 & 0 & 0 & 0 & 53 & 13.14 & 0 \\
\hline 2007 & Ronaldson, M & 0 & 0 & 0 & 1 & 0 & 0 & 0 & 0 & 0 & 0 & 0 & 53.17 & 22.62 & 0 \\
\hline 1996 & Ruddock, PM & 0 & 0 & 0 & 1 & 0 & 0 & 0 & 0 & 0 & 0 & 0 & 55.93 & 25.38 & 1 \\
\hline 1999 & Ruddock, PM & 0 & 0 & 0 & 1 & 0 & 0 & 0 & 0 & 0 & 0 & 0 & 58.93 & 28.38 & 1 \\
\hline 2002 & Ruddock, PM & 0 & 0 & 0 & 1 & 0 & 0 & 0 & 0 & 0 & 0 & 0 & 61.94 & 31.38 & 1 \\
\hline 2005 & Ruddock, PM & 0 & 0 & 0 & 1 & 0 & 0 & 0 & 0 & 0 & 0 & 0 & 63.94 & 33.38 & 1 \\
\hline 2007 & Ruddock, PM & 1 & 0 & 0 & 0 & 1 & 0 & 0 & 0 & 0 & 0 & 0 & 48.8 & 2.26 & 0 \\
\hline 2005 & Santoro, S & & & & & & & & &
\end{tabular}




\section{Appendix 1: Data for RIF Models LNPC Data (Continued)}

\begin{tabular}{|l|l|r|r|r|r|r|r|r|r|r|r|r|r|r|r|}
\hline Year & \multicolumn{1}{|c|}{ Name } & Senate & Female & Vic & NSW & Qld & Tas & SA & WA & ACT & NT & NP & Age & Exp' $^{\prime}$ & Cab' $^{\prime}$ \\
\hline 2007 & Santoro, S & 1 & 0 & 0 & 0 & 1 & 0 & 0 & 0 & 0 & 0 & 0 & 50.8 & 4.26 & 0 \\
\hline 1999 & Schultz, AJ & 0 & 0 & 0 & 1 & 0 & 0 & 0 & 0 & 0 & 0 & 0 & 59.72 & 0.33 & 0 \\
\hline 2002 & Schultz, AJ & 0 & 0 & 0 & 1 & 0 & 0 & 0 & 0 & 0 & 0 & 0 & 62.72 & 3.33 & 0 \\
\hline 2005 & Schultz, AJ & 0 & 0 & 0 & 1 & 0 & 0 & 0 & 0 & 0 & 0 & 0 & 65.73 & 6.34 & 0 \\
\hline 2007 & Schultz, AJ & 0 & 0 & 0 & 1 & 0 & 0 & 0 & 0 & 0 & 0 & 0 & 67.73 & 8.34 & 0 \\
\hline 1996 & Scott, BC & 0 & 0 & 0 & 0 & 1 & 0 & 0 & 0 & 0 & 0 & 1 & 52.56 & 6.11 & 0 \\
\hline 1999 & Scott, BC & 0 & 0 & 0 & 0 & 1 & 0 & 0 & 0 & 0 & 0 & 1 & 55.32 & 8.87 & 0 \\
\hline 2002 & Scott, BC & 0 & 0 & 0 & 0 & 1 & 0 & 0 & 0 & 0 & 0 & 1 & 58.33 & 11.87 & 0 \\
\hline 2005 & Scott, BC & 0 & 0 & 0 & 0 & 1 & 0 & 0 & 0 & 0 & 0 & 1 & 61.33 & 14.87 & 0 \\
\hline 2007 & Scott, BC & 0 & 0 & 0 & 0 & 1 & 0 & 0 & 0 & 0 & 0 & 1 & 63.33 & 16.87 & 0 \\
\hline 2002 & Scullion, NG & 1 & 0 & 0 & 0 & 0 & 0 & 0 & 0 & 0 & 1 & 0 & 45.78 & 0.23 & 0 \\
\hline 2005 & Scullion, NG & 1 & 0 & 0 & 0 & 0 & 0 & 0 & 0 & 0 & 1 & 0 & 48.78 & 3.23 & 0 \\
\hline 2007 & Scullion, NG & 1 & 0 & 0 & 0 & 0 & 0 & 0 & 0 & 0 & 1 & 0 & 50.78 & 5.23 & 0 \\
\hline 1999 & Secker, PD & 0 & 0 & 0 & 0 & 0 & 0 & 1 & 0 & 0 & 0 & 0 & 42.68 & 0.33 & 0 \\
\hline 2002 & Secker, PD & 0 & 0 & 0 & 0 & 0 & 0 & 1 & 0 & 0 & 0 & 0 & 45.69 & 3.33 & 0 \\
\hline 2005 & Secker, PD & 0 & 0 & 0 & 0 & 0 & 0 & 1 & 0 & 0 & 0 & 0 & 48.69 & 6.34 & 0 \\
\hline 2007 & Secker, PD & 0 & 0 & 0 & 0 & 0 & 0 & 1 & 0 & 0 & 0 & 0 & 50.69 & 8.34 & 0 \\
\hline 1996 & Sharp, JR & 0 & 0 & 0 & 1 & 0 & 0 & 0 & 0 & 0 & 0 & 1 & 41.4 & 11.42 & 1 \\
\hline 1996 & Short, JR & 1 & 0 & 1 & 0 & 0 & 0 & 0 & 0 & 0 & 0 & 0 & 59.44 & 16.27 & 0 \\
\hline 1996 & Sinclair, IM & 0 & 0 & 0 & 1 & 0 & 0 & 0 & 0 & 0 & 0 & 1 & 66.93 & 32.44 & 0 \\
\hline
\end{tabular}




\section{Appendix 1: Data for RIF Models LNPC Data (Continued)}

\begin{tabular}{|l|l|r|r|r|r|r|r|r|r|r|r|r|r|r|r|}
\hline Year & \multicolumn{1}{|c|}{ Name } & Senate & Female & Vic & NSW & Qld & Tas & SA & WA & ACT & NT & NP & Age & Exp' $^{\prime}$ & Cab' $^{\prime}$ \\
\hline 1996 & Slipper, PN & 0 & 0 & 0 & 0 & 1 & 0 & 0 & 0 & 0 & 0 & 0 & 46.24 & 5.74 & 0 \\
\hline 1999 & Slipper, PN & 0 & 0 & 0 & 0 & 1 & 0 & 0 & 0 & 0 & 0 & 0 & 49 & 8.5 & 0 \\
\hline 2002 & Slipper, PN & 0 & 0 & 0 & 0 & 1 & 0 & 0 & 0 & 0 & 0 & 0 & 52 & 11.5 & 0 \\
\hline 2005 & Slipper, PN & 0 & 0 & 0 & 0 & 1 & 0 & 0 & 0 & 0 & 0 & 0 & 55 & 14.51 & 0 \\
\hline 2007 & Slipper, PN & 0 & 0 & 0 & 0 & 1 & 0 & 0 & 0 & 0 & 0 & 0 & 57 & 16.51 & 0 \\
\hline 1996 & Smith, AC & 0 & 0 & 0 & 0 & 1 & 0 & 0 & 0 & 0 & 0 & 0 & 45.82 & 0.16 & 0 \\
\hline 2002 & Smith, AD & 0 & 0 & 1 & 0 & 0 & 0 & 0 & 0 & 0 & 0 & 0 & 34.92 & 0.23 & 0 \\
\hline 2005 & Smith, AD & 0 & 0 & 1 & 0 & 0 & 0 & 0 & 0 & 0 & 0 & 0 & 37.92 & 3.23 & 0 \\
\hline 2007 & Smith, AD & 0 & 0 & 1 & 0 & 0 & 0 & 0 & 0 & 0 & 0 & 0 & 39.92 & 5.23 & 0 \\
\hline 1996 & Smith, WL & 0 & 0 & 0 & 0 & 1 & 0 & 0 & 0 & 0 & 0 & 0 & 50.32 & 6.11 & 0 \\
\hline 1996 & Somlyay, AM & 0 & 0 & 0 & 0 & 1 & 0 & 0 & 0 & 0 & 0 & 0 & 53.07 & 8.87 & 0 \\
\hline 1999 & Somlyay, AM & 0 & 0 & 0 & 0 & 1 & 0 & 0 & 0 & 0 & 0 & 0 & 56.08 & 11.87 & 0 \\
\hline 2002 & Somlyay, AM & 0 & 0 & 0 & 0 & 1 & 0 & 0 & 0 & 0 & 0 & 0 & 59.08 & 14.87 & 0 \\
\hline 2005 & Somlyay, AM & 0 & 0 & 0 & 0 & 1 & 0 & 0 & 0 & 0 & 0 & 0 & 61.08 & 16.87 & 0 \\
\hline 2007 & Somlyay, AM & 0 & 0 & 0 & 0 & 0 & 0 & 1 & 0 & 0 & 0 & 0 & 28.56 & 0.16 & 0 \\
\hline 1996 & Southcott, AJ & 0 & 0 & 0 & 0 & 0 & 0 & 1 & 0 & 0 & 0 & 0 & 31.32 & 2.92 & 0 \\
\hline 1999 & Southcott, AJ & 0 & 0 & 0 & 0 & 0 & 0 & 1 & 0 & 0 & 0 & 0 & 34.32 & 5.92 & 0 \\
\hline 2002 & Southcott, AJ & 0 & 0 & 0 & 0 & 0 & 0 & 1 & 0 & 0 & 0 & 0 & 37.33 & 8.93 & 0 \\
\hline 2005 & Southcott, AJ & 0 & 0 & 0 & 0 & 0 & 0 & 1 & 0 & 0 & 0 & 0 & 39.33 & 10.93 & 0 \\
\hline 2007 & Southcott, AJ & & 0 & & & & & & & &
\end{tabular}




\section{Appendix 1: Data for RIF Models LNPC Data (Continued)}

\begin{tabular}{|l|l|r|r|r|r|r|r|r|r|r|r|r|r|r|r|}
\hline Year & \multicolumn{1}{|c|}{ Name } & Senate & Female & Vic & NSW & Qld & Tas & SA & WA & ACT & NT & NP & Age & Exp' $^{\prime}$ & Cab' $^{\prime}$ \\
\hline 1999 & St Clair, SS & 0 & 0 & 0 & 1 & 0 & 0 & 0 & 0 & 0 & 0 & 1 & 49.23 & 0.33 & 0 \\
\hline 1996 & Stone, SN & 0 & 1 & 1 & 0 & 0 & 0 & 0 & 0 & 0 & 0 & 0 & 45.05 & 0.16 & 0 \\
\hline 1999 & Stone, SN & 0 & 1 & 1 & 0 & 0 & 0 & 0 & 0 & 0 & 0 & 0 & 47.81 & 2.92 & 0 \\
\hline 2002 & Stone, SN & 0 & 1 & 1 & 0 & 0 & 0 & 0 & 0 & 0 & 0 & 0 & 50.81 & 5.92 & 0 \\
\hline 2005 & Stone, SN & 0 & 1 & 1 & 0 & 0 & 0 & 0 & 0 & 0 & 0 & 0 & 53.82 & 8.93 & 0 \\
\hline 2007 & Stone, SN & 0 & 1 & 1 & 0 & 0 & 0 & 0 & 0 & 0 & 0 & 0 & 55.82 & 10.93 & 0 \\
\hline 1996 & Sullivan, KJ & 0 & 1 & 0 & 0 & 1 & 0 & 0 & 0 & 0 & 0 & 0 & 54.18 & 21.9 & 0 \\
\hline 1999 & Sullivan, KJ & 1 & 0 & 0 & 1 & 0 & 0 & 0 & 0 & 0 & 0 & 56.94 & 24.65 & 0 \\
\hline 1999 & Synon, KM & 1 & 1 & 1 & 0 & 0 & 0 & 0 & 0 & 0 & 0 & 0 & 39.41 & 1.72 & 0 \\
\hline 1996 & Tambling, GE & 1 & 0 & 0 & 0 & 0 & 0 & 0 & 0 & 0 & 1 & 0 & 52.9 & 11.19 & 0 \\
\hline 1999 & Tambling, GE & 1 & 0 & 0 & 0 & 0 & 0 & 0 & 0 & 0 & 1 & 0 & 55.66 & 13.95 & 0 \\
\hline 1996 & Taylor, WL & 1 & 0 & 0 & 0 & 1 & 0 & 0 & 0 & 0 & 0 & 0 & 57.67 & 8.06 & 0 \\
\hline 2002 & Tchen, T & 1 & 0 & 1 & 0 & 0 & 0 & 0 & 0 & 0 & 0 & 0 & 63.94 & 5.59 & 0 \\
\hline 2005 & Tchen, T & 1 & 0 & 0 & 0 & 0 & 0 & 1 & 0 & 0 & 0 & 0 & 51.65 & 17.84 & 0 \\
\hline 1996 & Teague, BC & 0 & 0 & 0 & 0 & 1 & 0 & 0 & 0 & 0 & 0 & 0 & 38.36 & 0.33 & 0 \\
\hline 1999 & Thompson, CP & 0 & 0 & 0 & 0 & 1 & 0 & 0 & 0 & 0 & 0 & 0 & 41.36 & 3.33 & 0 \\
\hline 2002 & Thompson, CP & 0 & 0 & 0 & 0 & 1 & 0 & 0 & 0 & 0 & 0 & 0 & 44.37 & 6.34 & 0 \\
\hline 2005 & Thompson, CP & 0 & 0 & 0 & 0 & 1 & 0 & 0 & 0 & 0 & 0 & 0 & 46.37 & 8.34 & 0 \\
\hline 2007 & Thompson, CP & 0 & 0 & 0 & 1 & 0 & 0 & 0 & 0 & 0 & 0 & 0 & 35.33 & 1.06 & 0 \\
\hline 1996 & Thomson, AP & & & & & & & & & &
\end{tabular}




\section{Appendix 1: Data for RIF Models LNPC Data (Continued)}

\begin{tabular}{|l|l|r|r|r|r|r|r|r|r|r|r|r|r|r|r|}
\hline Year & \multicolumn{1}{|c|}{ Name } & Senate & Female & Vic & NSW & Qld & Tas & SA & WA & ACT & NT & NP & Age & Exp' $^{\prime}$ & Cab' $^{\prime}$ \\
\hline 1999 & Thomson, AP & 0 & 0 & 0 & 1 & 0 & 0 & 0 & 0 & 0 & 0 & 0 & 38.09 & 3.82 & 0 \\
\hline 2002 & Ticehurst, KV & 0 & 0 & 0 & 1 & 0 & 0 & 0 & 0 & 0 & 0 & 0 & 57.07 & 0.23 & 0 \\
\hline 2005 & Ticehurst, KV & 0 & 0 & 0 & 1 & 0 & 0 & 0 & 0 & 0 & 0 & 0 & 60.07 & 3.23 & 0 \\
\hline 2007 & Ticehurst, KV & 0 & 0 & 0 & 1 & 0 & 0 & 0 & 0 & 0 & 0 & 0 & 62.07 & 5.23 & 0 \\
\hline 1996 & Tierney, JW & 1 & 0 & 0 & 1 & 0 & 0 & 0 & 0 & 0 & 0 & 0 & 50.31 & 5.22 & 0 \\
\hline 1999 & Tierney, JW & 1 & 0 & 0 & 1 & 0 & 0 & 0 & 0 & 0 & 0 & 0 & 53.07 & 7.98 & 0 \\
\hline 2002 & Tierney, JW & 1 & 0 & 0 & 1 & 0 & 0 & 0 & 0 & 0 & 0 & 0 & 56.07 & 10.98 & 0 \\
\hline 2005 & Tierney, JW & 1 & 0 & 0 & 1 & 0 & 0 & 0 & 0 & 0 & 0 & 0 & 59.07 & 13.98 & 0 \\
\hline 2002 & Tollner, DW & 0 & 0 & 0 & 0 & 0 & 0 & 0 & 0 & 0 & 1 & 0 & 36.03 & 0.23 & 0 \\
\hline 2005 & Tollner, DW & 0 & 0 & 0 & 0 & 0 & 0 & 0 & 0 & 0 & 1 & 0 & 39.03 & 3.23 & 0 \\
\hline 2007 & Tollner, DW & 0 & 0 & 0 & 0 & 0 & 0 & 0 & 0 & 0 & 1 & 0 & 41.03 & 5.23 & 0 \\
\hline 1996 & Troeth, JM & 1 & 1 & 1 & 0 & 0 & 0 & 0 & 0 & 0 & 0 & 0 & 55.78 & 2.83 & 0 \\
\hline 1999 & Troeth, JM & 1 & 1 & 1 & 0 & 0 & 0 & 0 & 0 & 0 & 0 & 0 & 58.54 & 5.59 & 0 \\
\hline 2002 & Troeth, JM & 1 & 1 & 1 & 0 & 0 & 0 & 0 & 0 & 0 & 0 & 0 & 61.54 & 8.59 & 0 \\
\hline 2005 & Troeth, JM & 1 & 1 & 1 & 0 & 0 & 0 & 0 & 0 & 0 & 0 & 0 & 64.54 & 11.6 & 0 \\
\hline 2007 & Troeth, JM & 1 & 1 & 1 & 0 & 0 & 0 & 0 & 0 & 0 & 0 & 0 & 66.54 & 13.6 & 0 \\
\hline 2007 & Trood, RB & 1 & 0 & 0 & 0 & 1 & 0 & 0 & 0 & 0 & 0 & 0 & 58.2 & 1.59 & 0 \\
\hline 1996 & Truss, WE & 0 & 0 & 0 & 0 & 1 & 0 & 0 & 0 & 0 & 0 & 1 & 47.59 & 6.11 & 0 \\
\hline 1999 & Truss, WE & 0 & 0 & 0 & 0 & 1 & 0 & 0 & 0 & 0 & 0 & 1 & 50.35 & 8.87 & 0 \\
\hline 2002 & Truss, WE & 0 & 0 & 0 & 0 & 1 & 0 & 0 & 0 & 0 & 0 & 1 & 53.35 & 11.87 & 1 \\
\hline
\end{tabular}




\section{Appendix 1: Data for RIF Models LNPC Data (Continued)}

\begin{tabular}{|l|l|r|r|r|r|r|r|r|r|r|r|r|r|r|r|}
\hline Year & \multicolumn{1}{|c|}{ Name } & Senate & Female & Vic & NSW & Qld & Tas & SA & WA & ACT & NT & NP & Age & Exp' $^{\prime}$ & Cab' $^{\prime}$ \\
\hline 2005 & Truss, WE & 0 & 0 & 0 & 0 & 1 & 0 & 0 & 0 & 0 & 0 & 1 & 56.36 & 14.87 & 1 \\
\hline 2007 & Truss, WE & 0 & 0 & 0 & 0 & 1 & 0 & 0 & 0 & 0 & 0 & 1 & 58.36 & 16.87 & 1 \\
\hline 1996 & Tuckey, CW & 0 & 0 & 0 & 0 & 0 & 0 & 0 & 1 & 0 & 0 & 0 & 60.85 & 15.54 & 0 \\
\hline 1999 & Tuckey, CW & 0 & 0 & 0 & 0 & 0 & 0 & 0 & 1 & 0 & 0 & 0 & 63.61 & 18.3 & 0 \\
\hline 2002 & Tuckey, CW & 0 & 0 & 0 & 0 & 0 & 0 & 0 & 1 & 0 & 0 & 0 & 66.61 & 21.3 & 0 \\
\hline 2005 & Tuckey, CW & 0 & 0 & 0 & 0 & 0 & 0 & 0 & 1 & 0 & 0 & 0 & 69.61 & 24.31 & 0 \\
\hline 2007 & Tuckey, CW & 0 & 0 & 0 & 0 & 0 & 0 & 0 & 1 & 0 & 0 & 0 & 71.61 & 26.31 & 0 \\
\hline 2005 & Turnbull, MB & 0 & 0 & 0 & 1 & 0 & 0 & 0 & 0 & 0 & 0 & 0 & 50.31 & 0.32 & 0 \\
\hline 2007 & Turnbull, MB & 0 & 0 & 0 & 1 & 0 & 0 & 0 & 0 & 0 & 0 & 0 & 52.31 & 2.32 & 1 \\
\hline 1996 & Vaile, MA & 0 & 0 & 0 & 1 & 0 & 0 & 0 & 0 & 0 & 0 & 1 & 40.06 & 3.13 & 0 \\
\hline 1999 & Vaile, MA & 0 & 0 & 0 & 1 & 0 & 0 & 0 & 0 & 0 & 0 & 1 & 42.82 & 5.89 & 1 \\
\hline 2002 & Vaile, MA & 0 & 0 & 0 & 1 & 0 & 0 & 0 & 0 & 0 & 0 & 1 & 45.82 & 8.9 & 1 \\
\hline 2005 & Vaile, MA & 0 & 0 & 0 & 1 & 0 & 0 & 0 & 0 & 0 & 0 & 1 & 48.82 & 11.9 & 1 \\
\hline 2007 & Vaile, MA & 0 & 0 & 0 & 1 & 0 & 0 & 0 & 0 & 0 & 0 & 1 & 50.82 & 13.9 & 1 \\
\hline 1996 & Vale, DS & 0 & 1 & 0 & 1 & 0 & 0 & 0 & 0 & 0 & 0 & 0 & 51.49 & 0.16 & 0 \\
\hline 1999 & Vale, DS & 0 & 1 & 0 & 1 & 0 & 0 & 0 & 0 & 0 & 0 & 0 & 54.25 & 2.92 & 0 \\
\hline 2002 & Vale, DS & 0 & 1 & 0 & 1 & 0 & 0 & 0 & 0 & 0 & 0 & 0 & 57.25 & 5.92 & 0 \\
\hline 2005 & Vale, DS & 0 & 1 & 0 & 1 & 0 & 0 & 0 & 0 & 0 & 0 & 0 & 60.26 & 8.93 & 0 \\
\hline 2007 & Vale, DS & 1 & 1 & 0 & 1 & 0 & 0 & 0 & 0 & 0 & 0 & 0 & 62.26 & 10.93 & 0 \\
\hline 1996 & Vanstone, AE & 1 & 0 & 0 & 0 & 0 & 1 & 0 & 0 & 0 & 0 & 43.42 & 11.42 & 1 \\
\hline
\end{tabular}




\section{Appendix 1: Data for RIF Models LNPC Data (Continued)}

\begin{tabular}{|l|l|r|r|r|r|r|r|r|r|r|r|r|r|r|r|}
\hline Year & \multicolumn{1}{|c|}{ Name } & Senate & Female & Vic & NSW & Qld & Tas & SA & WA & ACT & NT & NP & Age & Exp' $^{\prime}$ & Cab' $^{\prime}$ \\
\hline 1999 & Vanstone, AE & 1 & 1 & 0 & 0 & 0 & 0 & 1 & 0 & 0 & 0 & 0 & 46.18 & 14.18 & 0 \\
\hline 2002 & Vanstone, AE & 1 & 1 & 0 & 0 & 0 & 0 & 1 & 0 & 0 & 0 & 0 & 49.19 & 17.18 & 1 \\
\hline 2005 & Vanstone, AE & 1 & 1 & 0 & 0 & 0 & 0 & 1 & 0 & 0 & 0 & 0 & 52.19 & 20.18 & 1 \\
\hline 2007 & Vanstone, AE & 1 & 1 & 0 & 0 & 0 & 0 & 1 & 0 & 0 & 0 & 0 & 54.19 & 22.18 & 0 \\
\hline 2005 & Vasta, RX & 0 & 0 & 0 & 0 & 1 & 0 & 0 & 0 & 0 & 0 & 0 & 38.35 & 0.32 & 0 \\
\hline 2007 & Vasta, RX & 0 & 0 & 0 & 0 & 1 & 0 & 0 & 0 & 0 & 0 & 0 & 40.35 & 2.32 & 0 \\
\hline 1996 & Wakelin, BH & 0 & 0 & 0 & 0 & 0 & 0 & 1 & 0 & 0 & 0 & 0 & 50.02 & 3.13 & 0 \\
\hline 1999 & Wakelin, BH & 0 & 0 & 0 & 0 & 0 & 0 & 1 & 0 & 0 & 0 & 0 & 52.78 & 5.89 & 0 \\
\hline 2002 & Wakelin, BH & 0 & 0 & 0 & 0 & 0 & 0 & 1 & 0 & 0 & 0 & 0 & 55.78 & 8.9 & 0 \\
\hline 2005 & Wakelin, BH & 0 & 0 & 0 & 0 & 0 & 0 & 1 & 0 & 0 & 0 & 0 & 58.78 & 11.9 & 0 \\
\hline 2007 & Wakelin, BH & 0 & 0 & 0 & 0 & 0 & 0 & 1 & 0 & 0 & 0 & 0 & 60.78 & 13.9 & 0 \\
\hline 1999 & Washer, MJ & 0 & 0 & 0 & 0 & 0 & 0 & 0 & 1 & 0 & 0 & 0 & 53.51 & 0.33 & 0 \\
\hline 2002 & Washer, MJ & 0 & 0 & 0 & 0 & 0 & 0 & 0 & 1 & 0 & 0 & 0 & 56.51 & 3.33 & 0 \\
\hline 2005 & Washer, MJ & 0 & 0 & 0 & 0 & 0 & 0 & 0 & 1 & 0 & 0 & 0 & 59.52 & 6.34 & 0 \\
\hline 2007 & Washer, MJ & 0 & 0 & 0 & 0 & 0 & 0 & 0 & 1 & 0 & 0 & 0 & 61.52 & 8.34 & 0 \\
\hline 1996 & Watson, JO & 1 & 0 & 0 & 0 & 0 & 1 & 0 & 0 & 0 & 0 & 0 & 59.3 & 17.84 & 0 \\
\hline 1999 & Watson, JO & 1 & 0 & 0 & 0 & 0 & 1 & 0 & 0 & 0 & 0 & 0 & 62.06 & 20.6 & 0 \\
\hline 2002 & Watson, JO & 1 & 0 & 0 & 0 & 0 & 1 & 0 & 0 & 0 & 0 & 0 & 65.06 & 23.61 & 0 \\
\hline 2005 & Watson, JO & 1 & 0 & 0 & 0 & 0 & 1 & 0 & 0 & 0 & 0 & 0 & 68.07 & 26.61 & 0 \\
\hline 2007 & Watson, JO & 1 & 0 & 0 & 0 & 0 & 1 & 0 & 0 & 0 & 0 & 0 & 70.07 & 28.61 & 0 \\
\hline
\end{tabular}




\section{Appendix 1: Data for RIF Models LNPC Data (Continued)}

\begin{tabular}{|l|l|r|r|r|r|r|r|r|r|r|r|r|r|r|r|}
\hline Year & \multicolumn{1}{|c|}{ Name } & Senate & Female & Vic & NSW & Qld & Tas & SA & WA & ACT & NT & NP & Age & Exp' $^{\prime}$ & Cab' $^{\prime}$ \\
\hline 1996 & West, AG & 0 & 1 & 0 & 0 & 1 & 0 & 0 & 0 & 0 & 0 & 0 & 43.65 & 0.16 & 0 \\
\hline 1996 & Williams, DR & 0 & 0 & 0 & 0 & 0 & 0 & 0 & 1 & 0 & 0 & 0 & 53.73 & 3.13 & 0 \\
\hline 1999 & Williams, DR & 0 & 0 & 0 & 0 & 0 & 0 & 0 & 1 & 0 & 0 & 0 & 56.49 & 5.89 & 1 \\
\hline 2002 & Williams, DR & 0 & 0 & 0 & 0 & 0 & 0 & 0 & 1 & 0 & 0 & 0 & 59.49 & 8.9 & 1 \\
\hline 2005 & Wood, JP & 0 & 0 & 1 & 0 & 0 & 0 & 0 & 0 & 0 & 0 & 0 & 36.72 & 0.32 & 0 \\
\hline 2007 & Wood, JP & 0 & 0 & 1 & 0 & 0 & 0 & 0 & 0 & 0 & 0 & 0 & 38.72 & 2.32 & 0 \\
\hline 1996 & Woods, RL & 1 & 0 & 0 & 1 & 0 & 0 & 0 & 0 & 0 & 0 & 0 & 49.08 & 7.82 & 0 \\
\hline 1996 & Wooldridge, MR & 0 & 0 & 1 & 0 & 0 & 0 & 0 & 0 & 0 & 0 & 0 & 39.5 & 8.81 & 1 \\
\hline 1999 & Wooldridge, MR & 0 & 0 & 1 & 0 & 0 & 0 & 0 & 0 & 0 & 0 & 0 & 42.26 & 11.57 & 1 \\
\hline 1996 & Worth, PM & 0 & 1 & 0 & 0 & 0 & 0 & 1 & 0 & 0 & 0 & 0 & 50.06 & 3.13 & 0 \\
\hline 1999 & Worth, PM & 0 & 1 & 0 & 0 & 0 & 0 & 1 & 0 & 0 & 0 & 0 & 52.82 & 5.89 & 0 \\
\hline 2002 & Worth, PM & 0 & 1 & 0 & 0 & 0 & 0 & 1 & 0 & 0 & 0 & 0 & 55.82 & 8.9 & 0 \\
\hline 1996 & Zammit, PJ & 0 & 0 & 0 & 1 & 0 & 0 & 0 & 0 & 0 & 0 & 0 & 55.04 & 0.16 & 0 \\
\hline
\end{tabular}


This page is intentionally blank 


\begin{tabular}{|l|l|c|c|c|c|c|c|c|c|c|c|c|c|c|c|c|c|}
\hline Year & Name & Senate & Female & Vic & NSW & Qld & Tas & SA & WA & ACT & NT & L & R & Cl & Age & Exp & ShadCab \\
\hline 2005 & Adams, DG & 0 & 0 & 0 & 0 & 0 & 1 & 0 & 0 & 0 & 0 & 1 & 0 & 0 & 53.8 & 11.9 & 0 \\
\hline 2006 & Adams, DG & 0 & 0 & 0 & 0 & 0 & 1 & 0 & 0 & 0 & 0 & 1 & 0 & 0 & 54.8 & 12.9 & 0 \\
\hline 2005 & Albanese, AN & 0 & 0 & 0 & 1 & 0 & 0 & 0 & 0 & 0 & 0 & 1 & 0 & 0 & 41.95 & 8.93 & 1 \\
\hline 2006 & Albanese, AN & 0 & 0 & 0 & 1 & 0 & 0 & 0 & 0 & 0 & 0 & 1 & 0 & 0 & 42.95 & 9.93 & 1 \\
\hline 2005 & Beazley, KC & 0 & 0 & 0 & 0 & 0 & 0 & 0 & 1 & 0 & 0 & 0 & 1 & 0 & 56.17 & 24.31 & 1 \\
\hline 2006 & Beazley, KC & 0 & 0 & 0 & 0 & 0 & 0 & 0 & 1 & 0 & 0 & 0 & 1 & 0 & 57.17 & 25.31 & 1 \\
\hline 2005 & Bevis, AR & 0 & 0 & 0 & 0 & 1 & 0 & 0 & 0 & 0 & 0 & 0 & 1 & 0 & 49.85 & 14.87 & 0 \\
\hline 2006 & Bevis, AR & 0 & 0 & 0 & 0 & 1 & 0 & 0 & 0 & 0 & 0 & 0 & 1 & 0 & 50.85 & 15.87 & 0 \\
\hline 2005 & Bird, S & 0 & 1 & 0 & 1 & 0 & 0 & 0 & 0 & 0 & 0 & 0 & 1 & 0 & 42.24 & 0.32 & 0 \\
\hline 2006 & Bird, S & 0 & 1 & 0 & 1 & 0 & 0 & 0 & 0 & 0 & 0 & 0 & 1 & 0 & 43.24 & 1.32 & 0 \\
\hline 2005 & Bishop, M & 1 & 0 & 0 & 0 & 0 & 0 & 0 & 1 & 0 & 0 & 0 & 1 & 0 & 50.63 & 8.59 & 0 \\
\hline 2006 & Bishop, M & 1 & 0 & 0 & 0 & 0 & 0 & 0 & 1 & 0 & 0 & 0 & 1 & 0 & 51.63 & 9.59 & 0 \\
\hline 2005 & Bolkus, N & 1 & 0 & 0 & 0 & 0 & 0 & 1 & 0 & 0 & 0 & 1 & 0 & 0 & 54.58 & 23.61 & 0 \\
\hline 2005 & Bowen, CE & 0 & 0 & 0 & 1 & 0 & 0 & 0 & 0 & 0 & 0 & 0 & 1 & 0 & 32.06 & 0.32 & 0 \\
\hline 2006 & Bowen, CE & 0 & 0 & 0 & 1 & 0 & 0 & 0 & 0 & 0 & 0 & 0 & 1 & 0 & 33.06 & 1.32 & 0 \\
\hline 2006 & Brown, CL & 1 & 1 & 0 & 0 & 0 & 1 & 0 & 0 & 0 & 0 & 1 & 0 & 0 & 42.57 & 0.44 & 0 \\
\hline 2005 & Buckland, GF & 1 & 0 & 0 & 0 & 0 & 0 & 1 & 0 & 0 & 0 & 0 & 1 & 0 & 57.27 & 4.39 & 0 \\
\hline
\end{tabular}




\begin{tabular}{|l|l|c|c|c|c|c|c|c|c|c|c|c|c|c|c|c|c|}
\hline Year & Name & Senate & Female & Vic & NSW & Qld & Tas & SA & WA & ACT & NT & L & R & CI & Age & Exp & ShadCab \\
\hline 2005 & Burke, AE & 0 & 1 & 1 & 0 & 0 & 0 & 0 & 0 & 0 & 0 & 0 & 1 & 0 & 39.11 & 6.34 & 0 \\
\hline 2006 & Burke, AE & 0 & 1 & 1 & 0 & 0 & 0 & 0 & 0 & 0 & 0 & 0 & 1 & 0 & 40.11 & 7.34 & 0 \\
\hline 2005 & Burke, AS & 0 & 0 & 0 & 1 & 0 & 0 & 0 & 0 & 0 & 0 & 0 & 1 & 0 & 35.27 & 0.32 & 0 \\
\hline 2006 & Burke, AS & 0 & 0 & 0 & 1 & 0 & 0 & 0 & 0 & 0 & 0 & 0 & 1 & 0 & 36.27 & 1.32 & 0 \\
\hline 2005 & Byrne, AM & 0 & 0 & 1 & 0 & 0 & 0 & 0 & 0 & 0 & 0 & 0 & 1 & 0 & 42.2 & 5.24 & 0 \\
\hline 2006 & Byrne, AM & 0 & 0 & 1 & 0 & 0 & 0 & 0 & 0 & 0 & 0 & 0 & 1 & 0 & 43.2 & 6.24 & 0 \\
\hline 2005 & Campbell, G & 1 & 0 & 0 & 1 & 0 & 0 & 0 & 0 & 0 & 0 & 1 & 0 & 0 & 62 & 7.38 & 0 \\
\hline 2006 & Campbell, G & 1 & 0 & 0 & 1 & 0 & 0 & 0 & 0 & 0 & 0 & 1 & 0 & 0 & 63 & 8.38 & 0 \\
\hline 2005 & Carr, KJ & 1 & 0 & 1 & 0 & 0 & 0 & 0 & 0 & 0 & 0 & 1 & 0 & 0 & 49.62 & 11.77 & 1 \\
\hline 2006 & Carr, KJ & 1 & 0 & 1 & 0 & 0 & 0 & 0 & 0 & 0 & 0 & 1 & 0 & 0 & 50.62 & 12.77 & 1 \\
\hline 2005 & Collins, JM & 1 & 1 & 1 & 0 & 0 & 0 & 0 & 0 & 0 & 0 & 0 & 1 & 0 & 42.44 & 9.76 & 0 \\
\hline 2005 & Conroy, SM & 1 & 0 & 1 & 0 & 0 & 0 & 0 & 0 & 0 & 0 & 0 & 1 & 0 & 42.07 & 8.76 & 1 \\
\hline 2006 & Conroy, SM & 1 & 0 & 1 & 0 & 0 & 0 & 0 & 0 & 0 & 0 & 0 & 1 & 0 & 43.07 & 9.76 & 1 \\
\hline 2005 & Cook, PF & 1 & 0 & 0 & 0 & 0 & 0 & 0 & 1 & 0 & 0 & 0 & 0 & 1 & 61.28 & 21.93 & 0 \\
\hline 2005 & Corcoran, AK & 0 & 1 & 1 & 0 & 0 & 0 & 0 & 0 & 0 & 0 & 0 & 0 & 1 & 53.4 & 4.48 & 0 \\
\hline 2006 & Corcoran, AK & 0 & 1 & 1 & 0 & 0 & 0 & 0 & 0 & 0 & 0 & 0 & 0 & 1 & 54.4 & 5.48 & 0 \\
\hline 2005 & Crean, SF & 0 & 0 & 1 & 0 & 0 & 0 & 0 & 0 & 0 & 0 & 0 & 1 & 0 & 55.97 & 14.87 & 1 \\
\hline 2006 & Crean, SF & 0 & 0 & 1 & 0 & 0 & 0 & 0 & 0 & 0 & 0 & 0 & 1 & 0 & 56.97 & 15.87 & 1 \\
\hline 2005 & Crossin, PM & 1 & 1 & 0 & 0 & 0 & 0 & 0 & 0 & 0 & 1 & 1 & 0 & 0 & 48.9 & 6.64 & 0 \\
\hline
\end{tabular}




\begin{tabular}{|l|l|c|c|c|c|c|c|c|c|c|c|c|c|c|c|c|c|}
\hline Year & Name & Senate & Female & Vic & NSW & QId & Tas & SA & WA & ACT & NT & L & R & CI & Age & Exp & ShadCab \\
\hline 2006 & Crossin, PM & 1 & 1 & 0 & 0 & 0 & 0 & 0 & 0 & 0 & 1 & 1 & 0 & 0 & 49.9 & 7.64 & 0 \\
\hline 2005 & Danby, MD & 0 & 0 & 1 & 0 & 0 & 0 & 0 & 0 & 0 & 0 & 0 & 1 & 0 & 49.99 & 6.34 & 0 \\
\hline 2006 & Danby, MD & 0 & 0 & 1 & 0 & 0 & 0 & 0 & 0 & 0 & 0 & 0 & 1 & 0 & 50.99 & 7.34 & 0 \\
\hline 2005 & Denman, KJ & 1 & 1 & 0 & 0 & 0 & 1 & 0 & 0 & 0 & 0 & 0 & 0 & 1 & 67.58 & 11.45 & 0 \\
\hline 2005 & Edwards, GJ & 0 & 0 & 0 & 0 & 0 & 0 & 0 & 1 & 0 & 0 & 0 & 1 & 0 & 58.58 & 6.34 & 0 \\
\hline 2006 & Edwards, GJ & 0 & 0 & 0 & 0 & 0 & 0 & 0 & 1 & 0 & 0 & 0 & 1 & 0 & 59.58 & 7.34 & 0 \\
\hline 2005 & Elliot, MJ & 0 & 1 & 0 & 1 & 0 & 0 & 0 & 0 & 0 & 0 & 0 & 1 & 0 & 37.54 & 0.32 & 0 \\
\hline 2006 & Elliot, MJ & 0 & 1 & 0 & 1 & 0 & 0 & 0 & 0 & 0 & 0 & 0 & 1 & 0 & 38.54 & 1.32 & 0 \\
\hline 2005 & Ellis, AL & 0 & 1 & 0 & 0 & 0 & 0 & 0 & 0 & 1 & 0 & 0 & 1 & 0 & 58.35 & 8.93 & 0 \\
\hline 2006 & Ellis, AL & 0 & 1 & 0 & 0 & 0 & 0 & 0 & 0 & 1 & 0 & 0 & 1 & 0 & 59.35 & 9.93 & 0 \\
\hline 2005 & Ellis, KM & 0 & 1 & 0 & 0 & 0 & 0 & 1 & 0 & 0 & 0 & 0 & 1 & 0 & 27.38 & 0.32 & 0 \\
\hline 2006 & Ellis, KM & 0 & 1 & 0 & 0 & 0 & 0 & 1 & 0 & 0 & 0 & 0 & 1 & 0 & 28.38 & 1.32 & 0 \\
\hline 2005 & Emerson, CA & 0 & 0 & 0 & 0 & 1 & 0 & 0 & 0 & 0 & 0 & 0 & 1 & 0 & 50.25 & 6.34 & 0 \\
\hline 2006 & Emerson, CA & 0 & 0 & 0 & 0 & 1 & 0 & 0 & 0 & 0 & 0 & 0 & 1 & 0 & 51.25 & 7.34 & 0 \\
\hline 2005 & Evans, CV & 1 & 0 & 0 & 0 & 0 & 0 & 0 & 1 & 0 & 0 & 1 & 0 & 0 & 46.75 & 11.6 & 1 \\
\hline 2006 & Evans, CV & 1 & 0 & 0 & 0 & 0 & 0 & 0 & 1 & 0 & 0 & 1 & 0 & 0 & 47.75 & 12.6 & 1 \\
\hline 2005 & Faulkner, JP & 1 & 0 & 0 & 1 & 0 & 0 & 0 & 0 & 0 & 0 & 1 & 0 & 0 & 50.84 & 15.84 & 0 \\
\hline 2006 & Faulkner, JP & 1 & 0 & 0 & 1 & 0 & 0 & 0 & 0 & 0 & 0 & 1 & 0 & 0 & 51.84 & 16.84 & 0 \\
\hline 2005 & Ferguson, LD & 0 & 0 & 0 & 1 & 0 & 0 & 0 & 0 & 0 & 0 & 1 & 0 & 0 & 52.61 & 14.87 & 1 \\
\hline
\end{tabular}




\begin{tabular}{|l|l|c|c|c|c|c|c|c|c|c|c|c|c|c|c|c|c|}
\hline Year & Name & Senate & Female & Vic & NSW & Qld & Tas & SA & WA & ACT & NT & L & R & CI & Age & Exp & ShadCab \\
\hline 2006 & Ferguson, LD & 0 & 0 & 0 & 1 & 0 & 0 & 0 & 0 & 0 & 0 & 1 & 0 & 0 & 53.61 & 15.87 & 0 \\
\hline 2005 & Ferguson, MJ & 0 & 0 & 1 & 0 & 0 & 0 & 0 & 0 & 0 & 0 & 1 & 0 & 0 & 51.18 & 8.93 & 0 \\
\hline 2006 & Ferguson, MJ & 0 & 0 & 1 & 0 & 0 & 0 & 0 & 0 & 0 & 0 & 1 & 0 & 0 & 52.18 & 9.93 & 1 \\
\hline 2005 & Fitzgibbon, JA & 0 & 0 & 0 & 1 & 0 & 0 & 0 & 0 & 0 & 0 & 0 & 1 & 0 & 43.07 & 8.93 & 0 \\
\hline 2006 & Fitzgibbon, JA & 0 & 0 & 0 & 1 & 0 & 0 & 0 & 0 & 0 & 0 & 0 & 1 & 0 & 44.07 & 9.93 & 0 \\
\hline 2005 & Forshaw, MG & 1 & 0 & 0 & 1 & 0 & 0 & 0 & 0 & 0 & 0 & 0 & 1 & 0 & 53.1 & 10.74 & 0 \\
\hline 2006 & Forshaw, MG & 1 & 0 & 0 & 1 & 0 & 0 & 0 & 0 & 0 & 0 & 0 & 1 & 0 & 54.1 & 11.74 & 0 \\
\hline 2005 & Garrett, PR & 0 & 0 & 0 & 1 & 0 & 0 & 0 & 0 & 0 & 0 & 0 & 0 & 1 & 51.83 & 0.32 & 0 \\
\hline 2006 & Garrett, PR & 0 & 0 & 0 & 1 & 0 & 0 & 0 & 0 & 0 & 0 & 0 & 0 & 1 & 52.83 & 1.32 & 0 \\
\hline 2005 & Georganas, S & 0 & 0 & 0 & 0 & 0 & 0 & 1 & 0 & 0 & 0 & 1 & 0 & 0 & 45.67 & 0.32 & 0 \\
\hline 2006 & Georganas, S & 0 & 0 & 0 & 0 & 0 & 0 & 1 & 0 & 0 & 0 & 1 & 0 & 0 & 46.67 & 1.32 & 0 \\
\hline 2005 & George, J & 0 & 1 & 0 & 1 & 0 & 0 & 0 & 0 & 0 & 0 & 1 & 0 & 0 & 57.49 & 3.23 & 0 \\
\hline 2006 & George, J & 0 & 1 & 0 & 1 & 0 & 0 & 0 & 0 & 0 & 0 & 1 & 0 & 0 & 58.49 & 4.23 & 0 \\
\hline 2005 & Gibbons, SW & 0 & 0 & 1 & 0 & 0 & 0 & 0 & 0 & 0 & 0 & 1 & 0 & 0 & 55.43 & 6.34 & 0 \\
\hline 2006 & Gibbons, SW & 0 & 0 & 1 & 0 & 0 & 0 & 0 & 0 & 0 & 0 & 1 & 0 & 0 & 56.43 & 7.34 & 0 \\
\hline 2005 & Gillard, JE & 0 & 1 & 1 & 0 & 0 & 0 & 0 & 0 & 0 & 0 & 1 & 0 & 0 & 43.37 & 6.34 & 1 \\
\hline 2006 & Gillard, JE & 0 & 1 & 1 & 0 & 0 & 0 & 0 & 0 & 0 & 0 & 1 & 0 & 0 & 44.37 & 7.34 & 1 \\
\hline 2005 & Grierson, SJ & 0 & 1 & 0 & 1 & 0 & 0 & 0 & 0 & 0 & 0 & 1 & 0 & 0 & 53.79 & 3.23 & 0 \\
\hline 2006 & Grierson, SJ & 0 & 1 & 0 & 1 & 0 & 0 & 0 & 0 & 0 & 0 & 1 & 0 & 0 & 54.79 & 4.23 & 0 \\
\hline
\end{tabular}




\begin{tabular}{|l|l|c|c|c|c|c|c|c|c|c|c|c|c|c|c|c|c|}
\hline Year & Name & Senate & Female & Vic & NSW & Qld & Tas & SA & WA & ACT & NT & L & R & CI & Age & Exp & ShadCab \\
\hline 2005 & Griffin, AP & 0 & 0 & 1 & 0 & 0 & 0 & 0 & 0 & 0 & 0 & 1 & 0 & 0 & 44.97 & 11.9 & 0 \\
\hline 2006 & Griffin, AP & 0 & 0 & 1 & 0 & 0 & 0 & 0 & 0 & 0 & 0 & 1 & 0 & 0 & 45.97 & 12.9 & 0 \\
\hline 2005 & Hall, JG & 0 & 1 & 0 & 1 & 0 & 0 & 0 & 0 & 0 & 0 & 1 & 0 & 0 & 55.25 & 6.34 & 0 \\
\hline 2006 & Hall, JG & 0 & 1 & 0 & 1 & 0 & 0 & 0 & 0 & 0 & 0 & 1 & 0 & 0 & 56.25 & 7.34 & 0 \\
\hline 2005 & Hatton, MJ & 0 & 0 & 0 & 1 & 0 & 0 & 0 & 0 & 0 & 0 & 0 & 1 & 0 & 53.48 & 8.64 & 0 \\
\hline 2006 & Hatton, MJ & 0 & 0 & 0 & 1 & 0 & 0 & 0 & 0 & 0 & 0 & 0 & 1 & 0 & 54.48 & 9.64 & 0 \\
\hline 2006 & Hayes, CP & 0 & 0 & 0 & 1 & 0 & 0 & 0 & 0 & 0 & 0 & 0 & 1 & 0 & 50.58 & 0.87 & 0 \\
\hline 2005 & Hoare, KJ & 0 & 1 & 0 & 1 & 0 & 0 & 0 & 0 & 0 & 0 & 0 & 0 & 1 & 41.62 & 6.34 & 0 \\
\hline 2006 & Hoare, KJ & 0 & 1 & 0 & 1 & 0 & 0 & 0 & 0 & 0 & 0 & 0 & 0 & 1 & 42.62 & 7.34 & 0 \\
\hline 2005 & Hogg, JJ & 1 & 0 & 0 & 0 & 1 & 0 & 0 & 0 & 0 & 0 & 0 & 1 & 0 & 55.91 & 8.59 & 0 \\
\hline 2006 & Hogg, JJ & 1 & 0 & 0 & 0 & 1 & 0 & 0 & 0 & 0 & 0 & 0 & 1 & 0 & 56.91 & 9.59 & 0 \\
\hline 2006 & Hurley, AK & 1 & 1 & 0 & 0 & 0 & 0 & 1 & 0 & 0 & 0 & 0 & 1 & 0 & 50.63 & 0.59 & 0 \\
\hline 2005 & Hutchins, SP & 1 & 0 & 0 & 1 & 0 & 0 & 0 & 0 & 0 & 0 & 0 & 1 & 0 & 48.81 & 6.31 & 0 \\
\hline 2006 & Hutchins, SP & 1 & 0 & 0 & 1 & 0 & 0 & 0 & 0 & 0 & 0 & 0 & 1 & 0 & 49.81 & 7.31 & 0 \\
\hline 2005 & Irwin, JC & 0 & 1 & 0 & 1 & 0 & 0 & 0 & 0 & 0 & 0 & 0 & 1 & 0 & 53.27 & 6.34 & 0 \\
\hline 2006 & Irwin, JC & 0 & 1 & 0 & 1 & 0 & 0 & 0 & 0 & 0 & 0 & 0 & 1 & 0 & 54.27 & 7.34 & 0 \\
\hline 2005 & Jenkins, HA & 0 & 0 & 1 & 0 & 0 & 0 & 0 & 0 & 0 & 0 & 1 & 0 & 0 & 52.49 & 18.99 & 0 \\
\hline 2006 & Jenkins, HA & 0 & 0 & 1 & 0 & 0 & 0 & 0 & 0 & 0 & 0 & 1 & 0 & 0 & 53.49 & 19.99 & 0 \\
\hline 2005 & Kerr, DJ & 0 & 0 & 0 & 0 & 0 & 1 & 0 & 0 & 0 & 0 & 1 & 0 & 0 & 52.97 & 17.58 & 0 \\
\hline
\end{tabular}




\begin{tabular}{|l|l|c|c|c|c|c|c|c|c|c|c|c|c|c|c|c|c|}
\hline Year & Name & Senate & Female & Vic & NSW & Qld & Tas & SA & WA & ACT & NT & L & R & CI & Age & Exp & ShadCab \\
\hline 2006 & Kerr, DJ & 0 & 0 & 0 & 0 & 0 & 1 & 0 & 0 & 0 & 0 & 1 & 0 & 0 & 53.97 & 18.58 & 0 \\
\hline 2005 & King, CF & 0 & 1 & 1 & 0 & 0 & 0 & 0 & 0 & 0 & 0 & 1 & 0 & 0 & 38.7 & 3.23 & 0 \\
\hline 2006 & King, CF & 0 & 1 & 1 & 0 & 0 & 0 & 0 & 0 & 0 & 0 & 1 & 0 & 0 & 39.7 & 4.23 & 0 \\
\hline 2005 & Kirk, LJ & 1 & 1 & 0 & 0 & 0 & 0 & 1 & 0 & 0 & 0 & 0 & 1 & 0 & 37.72 & 2.59 & 0 \\
\hline 2006 & Kirk, LJ & 1 & 1 & 0 & 0 & 0 & 0 & 1 & 0 & 0 & 0 & 0 & 1 & 0 & 38.72 & 3.59 & 0 \\
\hline 2005 & Lawrence, CM & 0 & 1 & 0 & 0 & 0 & 0 & 0 & 1 & 0 & 0 & 1 & 0 & 0 & 56.96 & 10.9 & 0 \\
\hline 2006 & Lawrence, CM & 0 & 1 & 0 & 0 & 0 & 0 & 0 & 1 & 0 & 0 & 1 & 0 & 0 & 57.96 & 11.9 & 0 \\
\hline 2005 & Livermore, KF & 0 & 1 & 0 & 0 & 1 & 0 & 0 & 0 & 0 & 0 & 1 & 0 & 0 & 35.25 & 6.34 & 0 \\
\hline 2006 & Livermore, KF & 0 & 1 & 0 & 0 & 1 & 0 & 0 & 0 & 0 & 0 & 1 & 0 & 0 & 36.25 & 7.34 & 0 \\
\hline 2005 & Ludwig, JW & 1 & 0 & 0 & 0 & 1 & 0 & 0 & 0 & 0 & 0 & 0 & 1 & 0 & 45.57 & 5.59 & 0 \\
\hline 2006 & Ludwig, JW & 1 & 0 & 0 & 0 & 1 & 0 & 0 & 0 & 0 & 0 & 0 & 1 & 0 & 46.57 & 6.59 & 0 \\
\hline 2005 & Lundy, KA & 1 & 1 & 0 & 0 & 0 & 0 & 0 & 0 & 1 & 0 & 1 & 0 & 0 & 37.16 & 8.93 & 0 \\
\hline 2006 & Lundy, KA & 1 & 1 & 0 & 0 & 0 & 0 & 0 & 0 & 1 & 0 & 1 & 0 & 0 & 38.16 & 9.93 & 0 \\
\hline 2005 & Mackay, SM & 1 & 1 & 0 & 0 & 0 & 1 & 0 & 0 & 0 & 0 & 1 & 0 & 0 & 44.83 & 8.91 & 0 \\
\hline 2005 & Macklin, JL & 0 & 1 & 1 & 0 & 0 & 0 & 0 & 0 & 0 & 0 & 1 & 0 & 0 & 51.13 & 8.93 & 1 \\
\hline 2006 & Macklin, JL & 0 & 1 & 1 & 0 & 0 & 0 & 0 & 0 & 0 & 0 & 1 & 0 & 0 & 52.13 & 9.93 & 1 \\
\hline 2005 & Marshall, GM & 1 & 0 & 1 & 0 & 0 & 0 & 0 & 0 & 0 & 0 & 1 & 0 & 0 & 44.89 & 2.59 & 0 \\
\hline 2006 & Marshall, GM & 1 & 0 & 1 & 0 & 0 & 0 & 0 & 0 & 0 & 0 & 1 & 0 & 0 & 45.89 & 3.59 & 0 \\
\hline 2005 & McClelland, RB & 0 & 0 & 0 & 1 & 0 & 0 & 0 & 0 & 0 & 0 & 0 & 1 & 0 & 47.05 & 8.93 & 1 \\
\hline
\end{tabular}




\begin{tabular}{|l|l|c|c|c|c|c|c|c|c|c|c|c|c|c|c|c|c|}
\hline Year & Name & Senate & Female & Vic & NSW & QId & Tas & SA & WA & ACT & NT & L & R & CI & Age & Exp & ShadCab \\
\hline 2006 & McClelland, RB & 0 & 0 & 0 & 1 & 0 & 0 & 0 & 0 & 0 & 0 & 0 & 1 & 0 & 48.05 & 9.93 & 1 \\
\hline 2006 & McEwen, A & 1 & 1 & 0 & 0 & 0 & 0 & 1 & 0 & 0 & 0 & 1 & 0 & 0 & 51.53 & 0.59 & 0 \\
\hline 2005 & McLucas, JE & 1 & 1 & 0 & 0 & 1 & 0 & 0 & 0 & 0 & 0 & 1 & 0 & 0 & 46.88 & 5.59 & 0 \\
\hline 2006 & McLucas, JE & 1 & 1 & 0 & 0 & 1 & 0 & 0 & 0 & 0 & 0 & 1 & 0 & 0 & 47.88 & 6.59 & 0 \\
\hline 2005 & McMullan, RF & 0 & 0 & 0 & 0 & 0 & 0 & 0 & 0 & 1 & 0 & 0 & 0 & 1 & 57.19 & 16.9 & 0 \\
\hline 2006 & McMullan, RF & 0 & 0 & 0 & 0 & 0 & 0 & 0 & 0 & 1 & 0 & 0 & 0 & 1 & 58.19 & 17.9 & 0 \\
\hline 2005 & Melham, D & 0 & 0 & 0 & 1 & 0 & 0 & 0 & 0 & 0 & 0 & 1 & 0 & 0 & 50.22 & 14.87 & 0 \\
\hline 2006 & Melham, D & 0 & 0 & 0 & 1 & 0 & 0 & 0 & 0 & 0 & 0 & 1 & 0 & 0 & 51.22 & 15.87 & 0 \\
\hline 2005 & Moore, CM & 1 & 1 & 0 & 0 & 1 & 0 & 0 & 0 & 0 & 0 & 1 & 0 & 0 & 48.99 & 2.59 & 0 \\
\hline 2006 & Moore, CM & 1 & 1 & 0 & 0 & 1 & 0 & 0 & 0 & 0 & 0 & 1 & 0 & 0 & 49.99 & 3.59 & 0 \\
\hline 2005 & Murphy, JP & 0 & 0 & 0 & 1 & 0 & 0 & 0 & 0 & 0 & 0 & 0 & 1 & 0 & 54.71 & 6.34 & 0 \\
\hline 2006 & Murphy, JP & 0 & 0 & 0 & 1 & 0 & 0 & 0 & 0 & 0 & 0 & 0 & 1 & 0 & 55.71 & 7.34 & 0 \\
\hline 2005 & O'Brien, KW & 1 & 0 & 0 & 0 & 0 & 1 & 0 & 0 & 0 & 0 & 1 & 0 & 0 & 53.58 & 8.41 & 0 \\
\hline 2006 & O'Brien, KW & 1 & 0 & 0 & 0 & 0 & 1 & 0 & 0 & 0 & 0 & 1 & 0 & 0 & 54.58 & 9.41 & 0 \\
\hline 2005 & O'Connor, BP & 0 & 0 & 1 & 0 & 0 & 0 & 0 & 0 & 0 & 0 & 1 & 0 & 0 & 42.95 & 3.23 & 0 \\
\hline 2006 & O'Connor, BP & 0 & 0 & 1 & 0 & 0 & 0 & 0 & 0 & 0 & 0 & 1 & 0 & 0 & 43.95 & 4.23 & 0 \\
\hline 2005 & O'Connor, GM & 0 & 0 & 1 & 0 & 0 & 0 & 0 & 0 & 0 & 0 & 0 & 0 & 1 & 57.21 & 11.9 & 0 \\
\hline 2006 & O'Connor, GM & 0 & 0 & 1 & 0 & 0 & 0 & 0 & 0 & 0 & 0 & 0 & 0 & 1 & 58.21 & 12.9 & 0 \\
\hline 2005 & Owens, JA & 0 & 1 & 0 & 1 & 0 & 0 & 0 & 0 & 0 & 0 & 1 & 0 & 0 & 46.33 & 0.32 & 0 \\
\hline
\end{tabular}




\begin{tabular}{|l|l|c|c|c|c|c|c|c|c|c|c|c|c|c|c|c|c|}
\hline Year & Name & Senate & Female & Vic & NSW & QId & Tas & SA & WA & ACT & NT & L & R & CI & Age & Exp & ShadCab \\
\hline 2006 & Owens, JA & 0 & 1 & 0 & 1 & 0 & 0 & 0 & 0 & 0 & 0 & 1 & 0 & 0 & 47.33 & 1.32 & 0 \\
\hline 2005 & Plibersek, TJ & 0 & 1 & 0 & 1 & 0 & 0 & 0 & 0 & 0 & 0 & 1 & 0 & 0 & 35.19 & 6.34 & 1 \\
\hline 2006 & Plibersek, TJ & 0 & 1 & 0 & 1 & 0 & 0 & 0 & 0 & 0 & 0 & 1 & 0 & 0 & 36.19 & 7.34 & 1 \\
\hline 2006 & Polley, HB & 1 & 1 & 0 & 0 & 0 & 1 & 0 & 0 & 0 & 0 & 0 & 1 & 0 & 49.01 & 0.59 & 0 \\
\hline 2005 & Price, LR & 0 & 0 & 0 & 1 & 0 & 0 & 0 & 0 & 0 & 0 & 0 & 1 & 0 & 59.22 & 20.18 & 0 \\
\hline 2006 & Price, LR & 0 & 0 & 0 & 1 & 0 & 0 & 0 & 0 & 0 & 0 & 0 & 1 & 0 & 60.22 & 21.18 & 0 \\
\hline 2005 & Quick, HV & 0 & 0 & 0 & 0 & 0 & 1 & 0 & 0 & 0 & 0 & 0 & 0 & 1 & 63.64 & 11.9 & 0 \\
\hline 2006 & Quick, HV & 0 & 0 & 0 & 0 & 0 & 1 & 0 & 0 & 0 & 0 & 0 & 0 & 1 & 64.64 & 12.9 & 0 \\
\hline 2005 & Ray, RF & 1 & 0 & 1 & 0 & 0 & 0 & 0 & 0 & 0 & 0 & 0 & 1 & 0 & 57.86 & 23.61 & 0 \\
\hline 2006 & Ray, RF & 1 & 0 & 1 & 0 & 0 & 0 & 0 & 0 & 0 & 0 & 0 & 1 & 0 & 58.86 & 24.61 & 0 \\
\hline 2005 & Ripoll, BF & 0 & 0 & 0 & 0 & 1 & 0 & 0 & 0 & 0 & 0 & 0 & 1 & 0 & 39.1 & 6.34 & 0 \\
\hline 2006 & Ripoll, BF & 0 & 0 & 0 & 0 & 1 & 0 & 0 & 0 & 0 & 0 & 0 & 1 & 0 & 40.1 & 7.34 & 0 \\
\hline 2005 & Roxon, NL & 0 & 1 & 1 & 0 & 0 & 0 & 0 & 0 & 0 & 0 & 0 & 1 & 0 & 37.87 & 6.34 & 0 \\
\hline 2006 & Roxon, NL & 0 & 1 & 1 & 0 & 0 & 0 & 0 & 0 & 0 & 0 & 0 & 1 & 0 & 38.87 & 7.34 & 1 \\
\hline 2005 & Rudd, KM & 0 & 0 & 0 & 0 & 1 & 0 & 0 & 0 & 0 & 0 & 0 & 1 & 0 & 47.4 & 6.34 & 1 \\
\hline 2006 & Rudd, KM & 0 & 0 & 0 & 0 & 1 & 0 & 0 & 0 & 0 & 0 & 0 & 1 & 0 & 48.4 & 7.34 & 1 \\
\hline 2005 & Sawford, RW & 0 & 0 & 0 & 0 & 0 & 0 & 1 & 0 & 0 & 0 & 0 & 0 & 1 & 60.64 & 16.87 & 0 \\
\hline 2006 & Sawford, RW & 0 & 0 & 0 & 0 & 0 & 0 & 1 & 0 & 0 & 0 & 0 & 0 & 1 & 61.64 & 17.87 & 0 \\
\hline 2005 & Sercombe, RC & 0 & 0 & 1 & 0 & 0 & 0 & 0 & 0 & 0 & 0 & 0 & 0 & 1 & 55.87 & 8.93 & 0 \\
\hline
\end{tabular}




\begin{tabular}{|l|l|c|c|c|c|c|c|c|c|c|c|c|c|c|c|c|c|}
\hline Year & Name & Senate & Female & Vic & NSW & QId & Tas & SA & WA & ACT & NT & L & R & CI & Age & Exp & ShadCab \\
\hline 2006 & Sercombe, RC & 0 & 0 & 1 & 0 & 0 & 0 & 0 & 0 & 0 & 0 & 0 & 0 & 1 & 56.87 & 9.93 & 0 \\
\hline 2005 & Sherry, NJ & 1 & 0 & 0 & 0 & 0 & 1 & 0 & 0 & 0 & 0 & 0 & 0 & 1 & 49.24 & 14.6 & 1 \\
\hline 2006 & Sherry, NJ & 1 & 0 & 0 & 0 & 0 & 1 & 0 & 0 & 0 & 0 & 0 & 0 & 1 & 50.24 & 15.6 & 1 \\
\hline 2005 & Smith, SF & 0 & 0 & 0 & 0 & 0 & 0 & 0 & 1 & 0 & 0 & 0 & 1 & 0 & 49.18 & 11.9 & 1 \\
\hline 2006 & Smith, SF & 0 & 0 & 0 & 0 & 0 & 0 & 0 & 1 & 0 & 0 & 0 & 1 & 0 & 50.18 & 12.9 & 1 \\
\hline 2005 & Snowdon, WE & 0 & 0 & 0 & 0 & 0 & 0 & 0 & 0 & 0 & 1 & 1 & 0 & 0 & 54.91 & 14.99 & 0 \\
\hline 2006 & Snowdon, WE & 0 & 0 & 0 & 0 & 0 & 0 & 0 & 0 & 0 & 1 & 1 & 0 & 0 & 55.91 & 15.99 & 0 \\
\hline 2005 & Stephens, UM & 1 & 1 & 0 & 1 & 0 & 0 & 0 & 0 & 0 & 0 & 0 & 1 & 0 & 50.61 & 2.59 & 0 \\
\hline 2006 & Stephens, UM & 1 & 1 & 0 & 1 & 0 & 0 & 0 & 0 & 0 & 0 & 0 & 1 & 0 & 51.61 & 3.59 & 0 \\
\hline 2006 & Sterle, G & 1 & 0 & 0 & 0 & 0 & 0 & 0 & 1 & 0 & 0 & 0 & 1 & 0 & 46.11 & 0.59 & 0 \\
\hline 2005 & Swan, WM & 0 & 0 & 0 & 0 & 1 & 0 & 0 & 0 & 0 & 0 & 0 & 1 & 0 & 50.63 & 9.31 & 1 \\
\hline 2006 & Swan, WM & 0 & 0 & 0 & 0 & 1 & 0 & 0 & 0 & 0 & 0 & 0 & 1 & 0 & 51.63 & 10.31 & 1 \\
\hline 2005 & Tanner, LJ & 0 & 0 & 1 & 0 & 0 & 0 & 0 & 0 & 0 & 0 & 1 & 0 & 0 & 48.81 & 11.9 & 0 \\
\hline 2006 & Tanner, LJ & 0 & 0 & 1 & 0 & 0 & 0 & 0 & 0 & 0 & 0 & 1 & 0 & 0 & 49.81 & 12.9 & 1 \\
\hline 2005 & Thomson, KJ & 0 & 0 & 1 & 0 & 0 & 0 & 0 & 0 & 0 & 0 & 0 & 1 & 0 & 49.79 & 8.93 & 1 \\
\hline 2006 & Thomson, KJ & 0 & 0 & 1 & 0 & 0 & 0 & 0 & 0 & 0 & 0 & 0 & 1 & 0 & 50.79 & 9.93 & 1 \\
\hline 2005 & Vamvakinou, M & 0 & 1 & 1 & 0 & 0 & 0 & 0 & 0 & 0 & 0 & 1 & 0 & 0 & 46.11 & 3.23 & 0 \\
\hline 2006 & Vamvakinou, M & 0 & 1 & 1 & 0 & 0 & 0 & 0 & 0 & 0 & 0 & 1 & 0 & 0 & 47.11 & 4.23 & 0 \\
\hline 2005 & Webber, RS & 1 & 1 & 0 & 0 & 0 & 0 & 0 & 1 & 0 & 0 & 1 & 0 & 0 & 39.89 & 2.59 & 0 \\
\hline
\end{tabular}




\begin{tabular}{|c|l|c|c|c|c|c|c|c|c|c|c|c|c|c|c|c|c|}
\hline Year & Name & Senate & Female & Vic & NSW & Qld & Tas & SA & WA & ACT & NT & L & R & Cl & Age & Exp & ShadCab \\
\hline 2006 & Webber, RS & 1 & 1 & 0 & 0 & 0 & 0 & 0 & 1 & 0 & 0 & 1 & 0 & 0 & 40.89 & 3.59 & 0 \\
\hline 2005 & Wilkie, K & 0 & 0 & 0 & 0 & 0 & 0 & 0 & 1 & 0 & 0 & 1 & 0 & 0 & 45.7 & 6.34 & 0 \\
\hline 2006 & Wilkie, K & 0 & 0 & 0 & 0 & 0 & 0 & 0 & 1 & 0 & 0 & 1 & 0 & 0 & 46.7 & 7.34 & 0 \\
\hline 2005 & Wong, PY & 1 & 1 & 0 & 0 & 0 & 0 & 1 & 0 & 0 & 0 & 1 & 0 & 0 & 36.27 & 2.59 & 1 \\
\hline 2006 & Wong, PY & 1 & 1 & 0 & 0 & 0 & 0 & 1 & 0 & 0 & 0 & 1 & 0 & 0 & 37.27 & 3.59 & 1 \\
\hline 2006 & Wortley, DJ & 1 & 1 & 0 & 0 & 0 & 0 & 1 & 0 & 0 & 0 & 0 & 1 & 0 & 46.62 & 0.59 & 0 \\
\hline
\end{tabular}




\section{Appendix 2: Cohort Details $(n=384)$}

\begin{tabular}{|c|c|c|c|c|c|}
\hline \multirow[t]{2}{*}{ Name } & \multirow[t]{2}{*}{ ALP/LNPC } & \multicolumn{2}{|c|}{ Modelling Sample } & \multicolumn{2}{|c|}{ Removed from Sample } \\
\hline & & $\mathrm{CM}$ & Non-CM & $\begin{array}{r}\text { In Parl' } \\
@ F e b^{\prime} 08\end{array}$ & $\begin{array}{c}\text { BB \& } \\
I G E<8.5 y r s\end{array}$ \\
\hline Abbott, Anthony John & LNPC & 1 & & & \\
\hline Abetz, Eric & LNPC & & & 1 & \\
\hline Adams, Dick Godfrey Harry & ALP & & & 1 & \\
\hline Adams, Judith Anne & LNPC & & & 1 & \\
\hline Albanese, Anthony Norman & ALP & 1 & & & \\
\hline Alston, Richard Kenneth Robert & LNPC & 1 & & & \\
\hline Anderson, John Duncan & LNPC & 1 & & & \\
\hline Andrew, John Neil & LNPC & & 1 & & \\
\hline Andrews, Kevin James & LNPC & 1 & & & \\
\hline Anthony, Lawrence James & LNPC & & 1 & & \\
\hline Bailey, Frances Esther & LNPC & & & 1 & \\
\hline Baird, Bruce George & LNPC & & 1 & & \\
\hline Baker, Mark Horden & LNPC & & & & 1 \\
\hline Baldwin, Peter Jeremy & ALP & 1 & & & \\
\hline Baldwin, Robert Charles & LNPC & & & 1 & \\
\hline Barnett, Guy & LNPC & & & 1 & \\
\hline Barresi, Phillip Anthony & LNPC & & 1 & & \\
\hline Bartlett, Kerry Joseph & LNPC & & 1 & & \\
\hline Baume, Michael Ehrenfried & LNPC & & 1 & & \\
\hline Beahan, Michael Eamon & ALP & & 1 & & \\
\hline Beazley, Kim Christian & ALP & 1 & & & \\
\hline Beddall, David Peter & ALP & & 1 & & \\
\hline Bernardi, Cory & LNPC & & & 1 & \\
\hline Bevis, Archibald Ronald & ALP & & & 1 & \\
\hline Bidgood, James Mark & ALP & & & 1 & \\
\hline Billson, Bruce Fredrick & LNPC & & & 1 & \\
\hline Bird, Sharon & ALP & & & 1 & \\
\hline Birmingham, Simon John & LNPC & & & 1 & \\
\hline Bishop, (Thomas) Mark & ALP & & & 1 & \\
\hline Bishop, Bronwyn Kathleen & LNPC & & & 1 & \\
\hline Bishop, Julie Isabel & LNPC & 1 & & & \\
\hline Bolkus, Nick & ALP & 1 & & & \\
\hline Boswell, Ronald Leslie Doyle & LNPC & & & 1 & \\
\hline Bowen, Christopher Eyles & ALP & & & 1 & \\
\hline
\end{tabular}




\section{Appendix 2: Cohort Details (Continued)}

\begin{tabular}{|c|c|c|c|c|c|}
\hline \multirow{2}{*}{ Name } & \multirow{2}{*}{ ALP/LNPC } & \multicolumn{2}{|c|}{ Modelling Sample } & \multicolumn{2}{|c|}{ Removed from Sample } \\
\hline & & $\mathrm{CM}$ & Non-CM & $\begin{array}{r}\text { In Parl' } \\
\text { @Feb'08 }\end{array}$ & $\begin{array}{c}\text { BB \& } \\
\text { IGE }<8.5 y r s\end{array}$ \\
\hline Boyce, Suzanne Kay & LNPC & & & 1 & \\
\hline Bradbury, David John & ALP & & & 1 & \\
\hline Bradford, John Walter & LNPC & & & & 1 \\
\hline Brandis, George Henry & LNPC & & & 1 & \\
\hline Brereton, Laurence John & ALP & 1 & & & \\
\hline Broadbent, Russell Evan & LNPC & & & 1 & \\
\hline Brough, Malcolm Thomas & LNPC & 1 & & & \\
\hline Brown, Carol Louise & ALP & & & 1 & \\
\hline Brown, RJ & ALP & & 1 & & \\
\hline Brownhill, David Gordon Cadell & LNPC & & 1 & & \\
\hline Buckland, Geoffrey Frederick & ALP & & & & 1 \\
\hline Burke, Anna Elizabeth & ALP & & & 1 & \\
\hline Burke, Anthony Stephen & ALP & 1 & & & \\
\hline Burns, Bryant Robert & ALP & & 1 & & \\
\hline Bushby, David Christopher & LNPC & & & 1 & \\
\hline Butler, Mark Christopher & ALP & & & 1 & \\
\hline Byrne, Anthony Michael & ALP & & & 1 & \\
\hline Cadman, Alan Glyndwr & LNPC & & 1 & & \\
\hline Calvert, Paul Henry & LNPC & & 1 & & \\
\hline Cameron, Eoin Harrap & LNPC & & & & 1 \\
\hline Cameron, Ross Alexander & LNPC & & 1 & & \\
\hline Campbell, George & ALP & & & 1 & \\
\hline Campbell, Ian Gordon & LNPC & 1 & & & \\
\hline Campbell, Jodie Louise & ALP & & & 1 & \\
\hline Carr, Kim John & ALP & 1 & & & \\
\hline Causley, Ian Raymond & LNPC & & 1 & & \\
\hline Champion, Nicholas David & ALP & & & 1 & \\
\hline Chapman, Hedley Grant Pearson & LNPC & & & 1 & \\
\hline Charles, Robert Edwin & LNPC & & 1 & & \\
\hline Cheeseman, Darren Leicester & ALP & & & 1 & \\
\hline Childs, Bruce Kenneth & ALP & & 1 & & \\
\hline Ciobo, Steven Michele & LNPC & & & 1 & \\
\hline Clare, Jason Dean & ALP & & & 1 & \\
\hline Coates, John & ALP & & 1 & & \\
\hline Cobb, John Kenneth & LNPC & & & 1 & \\
\hline Cobb, Michael Roy & LNPC & & & & 1 \\
\hline Colbeck, Richard Mansell & LNPC & & & 1 & \\
\hline Collins, Jacinta Mary Ann & ALP & & & 1 & \\
\hline
\end{tabular}


Appendix 2: Cohort Details (Continued)

\begin{tabular}{|c|c|c|c|c|c|}
\hline \multirow[t]{2}{*}{ Name } & \multirow[t]{2}{*}{ ALP/LNPC } & \multicolumn{2}{|c|}{ Modelling Sample } & \multicolumn{2}{|c|}{ Removed from Sample } \\
\hline & & $\mathrm{CM}$ & Non-CM & $\begin{array}{r}\text { In Parl' } \\
@ F^{\prime} b^{\prime} 08\end{array}$ & $\begin{array}{c}\text { BB \& } \\
\mathrm{IGE}<8.5 \mathrm{yrs}\end{array}$ \\
\hline Collins, Julie Maree & ALP & & & 1 & \\
\hline Collins, Robert Lindsay & ALP & 1 & & & \\
\hline Colston, Malcolm Arthur & ALP & & 1 & & \\
\hline Combet, Gregory Ivan & ALP & & & 1 & \\
\hline Conroy, Stephen Michael & ALP & 1 & & & \\
\hline Cook, Peter Francis Salmon & ALP & 1 & & & \\
\hline Coonan, Helen Lloyd & LNPC & 1 & & & \\
\hline Cooney, Bernard Cornelius & ALP & & 1 & & \\
\hline Corcoran, Ann Kathleen & ALP & & & & 1 \\
\hline Cormann, Mathias Hubert Paul & LNPC & & & 1 & \\
\hline Costello, Peter Howard & LNPC & 1 & & & \\
\hline Coulton, Mark Maclean & LNPC & & & 1 & \\
\hline Cox, David Alexander & ALP & & & & 1 \\
\hline Crane, Arthur Winston & LNPC & & & & 1 \\
\hline Crean, Simon Findlay & ALP & 1 & & & \\
\hline Crosio, Janice Anne & ALP & & & & 1 \\
\hline Crossin, Patricia Margaret & ALP & & & 1 & \\
\hline Crowley, Rosemary Anne & ALP & & 1 & & \\
\hline D'Ath, Yvette Maree & ALP & & & 1 & \\
\hline Danby, Michael David & ALP & & & 1 & \\
\hline Dargavel, Steven John & ALP & & & & 1 \\
\hline Debus, Robert John & ALP & & & 1 & \\
\hline Denman, Kay Janet & ALP & & & & 1 \\
\hline Dondas, Nicholas Manuel & LNPC & & & & 1 \\
\hline Downer, Alexander John Gosse & LNPC & 1 & & & \\
\hline Draper, Patricia & LNPC & & 1 & & \\
\hline Dreyfus, Mark Alfred & ALP & & & 1 & \\
\hline Dutton, Peter Craig & LNPC & & & 1 & \\
\hline Edwards, Graham John & ALP & & & & 1 \\
\hline Eggleston, Alan & LNPC & & & 1 & \\
\hline Elliot, Maria Justine & ALP & & & 1 & \\
\hline Ellis, Annette Louise & ALP & & & 1 & \\
\hline Ellis, Katherine Margaret & ALP & & & 1 & \\
\hline Ellison, Christopher Martin & LNPC & & & 1 & \\
\hline Elson, Kay Selma & LNPC & & 1 & & \\
\hline Emerson, Craig Anthony & ALP & & & 1 & \\
\hline Entsch, Warren George & LNPC & & 1 & & \\
\hline Evans, Christopher Vaughan & ALP & 1 & & & \\
\hline
\end{tabular}




\section{Appendix 2: Cohort Details (Continued)}

\begin{tabular}{|c|c|c|c|c|c|}
\hline \multirow{2}{*}{ Name } & \multirow{2}{*}{ ALP/LNPC } & \multicolumn{2}{|c|}{ Modelling Sample } & \multicolumn{2}{|c|}{ Removed from Sample } \\
\hline & & $\mathrm{CM}$ & Non-CM & $\begin{array}{r}\text { In Parl' } \\
\text { @Feb'08 }\end{array}$ & $\begin{array}{c}\text { BB \& } \\
\text { IGE }<8.5 y r s\end{array}$ \\
\hline Evans, Gareth John & ALP & 1 & & & \\
\hline Evans, Martyn John & ALP & & & & 1 \\
\hline Evans, Richard David Conroy & LNPC & & & & 1 \\
\hline Fahey, John Joseph & LNPC & 1 & & & \\
\hline Farmer, Patrick Francis & LNPC & & & 1 & \\
\hline Faulkner, John Philip & ALP & 1 & & & \\
\hline Fawcett, David Julian & LNPC & & & & 1 \\
\hline Ferguson, Alan Baird & LNPC & & & 1 & \\
\hline Ferguson, Laurie Donald Thomas & ALP & & & 1 & \\
\hline Ferguson, Martin John & ALP & 1 & & & \\
\hline Ferguson, Michael Darrel & LNPC & & & & 1 \\
\hline Ferris, Jeannie Margaret & LNPC & & 1 & & \\
\hline Fierravanti-Wells, Concetta Anna & LNPC & & & 1 & \\
\hline Fifield, Mitchell Peter & LNPC & & & 1 & \\
\hline Fischer, Timothy Andrew & LNPC & 1 & & & \\
\hline Fisher, Mary Jo & LNPC & & & 1 & \\
\hline Fitzgibbon, Joel Andrew & ALP & 1 & & & \\
\hline Foreman, Dominic John & ALP & & 1 & & \\
\hline Forrest, John Alexander & LNPC & & & 1 & \\
\hline Forshaw, Michael George & ALP & & & 1 & \\
\hline Gallus, Christine Ann & LNPC & & 1 & & \\
\hline Gambaro, Teresa & LNPC & & 1 & & \\
\hline Garrett, Peter Robert & ALP & 1 & & & \\
\hline Gash, Joanna & LNPC & & & 1 & \\
\hline Georganas, Steven & ALP & & & 1 & \\
\hline George, Jennie & ALP & & & 1 & \\
\hline Georgiou, Petro & LNPC & & & 1 & \\
\hline Gerick, Jane Frances & ALP & & & & 1 \\
\hline Gibbons, Stephen William & ALP & & & 1 & \\
\hline Gibbs, Brenda & ALP & & & & 1 \\
\hline Gibson, Brian Francis & LNPC & & & & 1 \\
\hline Gillard, Julia Eileen & ALP & 1 & & & \\
\hline Grace, Edward Laurence & ALP & & 1 & & \\
\hline Grace, Elizabeth Jane & LNPC & & & & 1 \\
\hline Gray, Gary & ALP & & & 1 & \\
\hline Grierson, Sharon Joy & ALP & & & 1 & \\
\hline Griffin, Alan Peter & ALP & & & 1 & \\
\hline Haase, Barry Wayne & LNPC & & & 1 & \\
\hline
\end{tabular}


Appendix 2: Cohort Details (Continued)

\begin{tabular}{|c|c|c|c|c|c|}
\hline \multirow[t]{2}{*}{ Name } & \multirow[t]{2}{*}{ ALP/LNPC } & \multicolumn{2}{|c|}{ Modelling Sample } & \multicolumn{2}{|c|}{ Removed from Sample } \\
\hline & & $\mathrm{CM}$ & Non-CM & $\begin{array}{r}\text { In Parl' } \\
@ F e b^{\prime} 08\end{array}$ & $\begin{array}{c}\text { BB \& } \\
I G E<8.5 y r s\end{array}$ \\
\hline Hale, Damian Francis & ALP & & & 1 & \\
\hline Hall, Jill Griffiths & ALP & & & 1 & \\
\hline Halverson, Robert George & LNPC & & & & 1 \\
\hline Hardgrave, Gary Douglas & LNPC & & 1 & & \\
\hline Hartsuyker, Luke & LNPC & & & 1 & \\
\hline Hatton, Michael John & ALP & & & & 1 \\
\hline Hawke, Alexander George & LNPC & & & 1 & \\
\hline Hawker, David Peter Maxwell & LNPC & & & 1 & \\
\hline Hayes, Christopher Patrick & ALP & & & 1 & \\
\hline Heffernan, William Daniel & LNPC & & & 1 & \\
\hline Henry, Stuart Irwin & LNPC & & & & 1 \\
\hline Herron, John Joseph & LNPC & & 1 & & \\
\hline Hicks, Noel Jeffrey & LNPC & & & & 1 \\
\hline Hill, Robert Murray & LNPC & 1 & & & \\
\hline Hoare, Kelly Joy & ALP & & & & 1 \\
\hline Hockey, Joseph Benedict & LNPC & 1 & & & \\
\hline Hogg, John Joseph & ALP & & & 1 & \\
\hline Holding, Allan Clyde & ALP & 1 & & & \\
\hline Hollis, Colin & ALP & & 1 & & \\
\hline Horne, Robert Hodges & ALP & & & & 1 \\
\hline Howard, John Winston & LNPC & 1 & & & \\
\hline Hull, Kay Elizabeth & LNPC & & & 1 & \\
\hline Humphries, Gary John Joseph & LNPC & & & & 1 \\
\hline Hunt, Gregory Andrew & LNPC & & & 1 & \\
\hline Hurley, Annette Kay & ALP & & & 1 & \\
\hline Hutchins, Stephen Patrick & ALP & & & 1 & \\
\hline Irons, Stephen James & LNPC & & & 1 & \\
\hline Irwin, Julia Claire & ALP & & & 1 & \\
\hline Jackson, Sharryn Maree & ALP & & & & 1 \\
\hline Jeanes, Susan Barbara & LNPC & & & & 1 \\
\hline Jenkins, Henry Alfred & ALP & & & 1 & \\
\hline Jensen, Dennis Geoffrey & LNPC & & & 1 & \\
\hline Johnson, Michael Andrew & LNPC & & & 1 & \\
\hline Johnston, David Albert Lloyd & LNPC & & & 1 & \\
\hline Johnston, Ricky & LNPC & & & & 1 \\
\hline Jones, Barry Owen & ALP & & 1 & & \\
\hline Jones, Gerry Norman & ALP & & 1 & & \\
\hline Joyce, Barnaby Thomas Gerrard & LNPC & & & 1 & \\
\hline
\end{tabular}




\section{Appendix 2: Cohort Details (Continued)}

\begin{tabular}{|c|c|c|c|c|c|}
\hline \multirow[t]{2}{*}{ Name } & \multirow[t]{2}{*}{ ALP/LNPC } & \multicolumn{2}{|c|}{ Modelling Sample } & \multicolumn{2}{|c|}{ Removed from Sample } \\
\hline & & $\mathrm{CM}$ & Non-CM & $\begin{array}{r}\text { In Parl' } \\
@ \text { Feb'08 }\end{array}$ & $\begin{array}{c}\text { BB \& } \\
\mathrm{IGE}<8.5 \mathrm{yrs}\end{array}$ \\
\hline Jull, David Francis & LNPC & & 1 & & \\
\hline Katter, Robert Carl & LNPC & & & 1 & \\
\hline Keenan, Michael Fayat & LNPC & & & 1 & \\
\hline Kelly, Michael Joseph & ALP & & & 1 & \\
\hline Kelly, De-Anne Margaret & LNPC & & 1 & & \\
\hline Kelly, Jacqueline Marie & LNPC & & 1 & & \\
\hline Kemp, Charles Roderick & LNPC & & & 1 & \\
\hline Kemp, David Alistair & LNPC & 1 & & & \\
\hline Kernot, Cheryl & ALP & & & & 1 \\
\hline Kerr, Duncan James Colquhoun & ALP & & & 1 & \\
\hline King, Catherine Fiona & ALP & & & 1 & \\
\hline King, Peter Edward & LNPC & & & & 1 \\
\hline Kirk, Linda Jean & ALP & & & 1 & \\
\hline Knowles, Susan Christine & LNPC & & 1 & & \\
\hline Laming, Andrew Charles & LNPC & & & 1 & \\
\hline Langmore, John Vance & ALP & & 1 & & \\
\hline Latham, Mark William & ALP & & & & 1 \\
\hline Lawler, Anthony John & LNPC & & & & 1 \\
\hline Lawrence, Carmen Mary & ALP & 1 & & & \\
\hline Lee, Michael John & ALP & 1 & & & \\
\hline Ley, Sussan Penelope & LNPC & & & 1 & \\
\hline Liberman, Louis Stuart & LNPC & & & & 1 \\
\hline Lightfoot, Philip Ross & LNPC & & & 1 & \\
\hline Lindsay, Peter John & LNPC & & & 1 & \\
\hline Livermore, Kirsten Fiona & ALP & & & 1 & \\
\hline Lloyd, James Eric & LNPC & & 1 & & \\
\hline Ludwig, Joseph William & ALP & 1 & & & \\
\hline Lundy, Kate Alexandra & ALP & & & 1 & \\
\hline Macdonald, Ian Douglas & LNPC & & & 1 & \\
\hline $\begin{array}{l}\text { Macdonald, John Alexander } \\
\text { Lindsay }\end{array}$ & LNPC & & & 1 & \\
\hline Macfarlane, Ian Elgin & LNPC & 1 & & & \\
\hline MacGibbon, David John & LNPC & & & & 1 \\
\hline Mackay, Susan Mary & ALP & & & & 1 \\
\hline Macklin, Jennifer Louise & ALP & 1 & & & \\
\hline Marek, Paul & LNPC & & & & 1 \\
\hline Marino, Nola Bethwyn & LNPC & & & 1 & \\
\hline Markus, Louise Elizabeth & LNPC & & & 1 & \\
\hline
\end{tabular}


Appendix 2: Cohort Details (Continued)

\begin{tabular}{|c|c|c|c|c|c|}
\hline \multirow[t]{2}{*}{ Name } & \multirow[t]{2}{*}{ ALP/LNPC } & \multicolumn{2}{|c|}{ Modelling Sample } & \multicolumn{2}{|c|}{ Removed from Sample } \\
\hline & & $\mathrm{CM}$ & Non-CM & $\begin{array}{r}\text { In Parl' } \\
@ F^{\prime} b^{\prime} 08\end{array}$ & $\begin{array}{c}\text { BB \& } \\
I G E<8.5 y r s\end{array}$ \\
\hline Marles, Richard Donald & ALP & & & 1 & \\
\hline Marshall, Gavin Mark & ALP & & & 1 & \\
\hline Martin, Stephen Paul & ALP & & 1 & & \\
\hline Mason, Brett John & LNPC & & & 1 & \\
\hline May, Margaret Ann & LNPC & & & 1 & \\
\hline McArthur, Fergus Stewart & LNPC & & 1 & & \\
\hline McClelland, Robert Bruce & ALP & 1 & & & \\
\hline McDougall, Graeme Robert & LNPC & & & & 1 \\
\hline McEwen, Anne & ALP & & & 1 & \\
\hline McFarlane, Jann Sonya & ALP & & & & 1 \\
\hline McGauran, Julian John James & LNPC & & & 1 & \\
\hline McGauran, Peter John & LNPC & 1 & & & \\
\hline McKew, Maxine Margaret & ALP & & & 1 & \\
\hline McKiernan, James Philip & ALP & & 1 & & \\
\hline McLachlan, Ian Murray & LNPC & 1 & & & \\
\hline McLeay, Leo Boyce & ALP & & 1 & & \\
\hline McLucas, Jan Elizabeth & ALP & & & 1 & \\
\hline McMullan, Robert Francis & ALP & 1 & & & \\
\hline Melham, Daryl & ALP & & & 1 & \\
\hline Miles, Christopher Gordon & LNPC & & 1 & & \\
\hline Minchin, Nicholas Hugh & LNPC & 1 & & & \\
\hline Mirabella (Panopoulos), Sophie & LNPC & & & 1 & \\
\hline Moore, Claire Mary & ALP & & & 1 & \\
\hline Moore, John Colinton & LNPC & 1 & & & \\
\hline Morris, Allan Agapitos & ALP & & 1 & & \\
\hline Morris, Peter Frederick & ALP & 1 & & & \\
\hline Morrison, Scott John & LNPC & & & 1 & \\
\hline Mossfield, Frank William & ALP & & & & 1 \\
\hline Moylan, Judith Eleanor & LNPC & & & 1 & \\
\hline Murphy, John Paul & ALP & & & 1 & \\
\hline Murphy, Shayne Michael & ALP & & & & 1 \\
\hline Mutch, Stephen Bruce & LNPC & & & & 1 \\
\hline Nairn, Gary Roy & LNPC & & 1 & & \\
\hline Nash, Fiona Joy & LNPC & & & 1 & \\
\hline Neal, Belinda Jane & ALP & & & 1 & \\
\hline Nehl, Garry Barr & LNPC & & & & 1 \\
\hline Nelson, Brendan John & LNPC & 1 & & & \\
\hline Neumann, Shayne Kenneth & ALP & & & 1 & \\
\hline
\end{tabular}


Appendix 2: Cohort Details (Continued)

\begin{tabular}{|c|c|c|c|c|c|}
\hline \multirow[t]{2}{*}{ Name } & \multirow[t]{2}{*}{ ALP/LNPC } & \multicolumn{2}{|c|}{ Modelling Sample } & \multicolumn{2}{|c|}{ Removed from Sample } \\
\hline & & $\mathrm{CM}$ & Non-CM & $\begin{array}{r}\text { In Parl' } \\
@ \text { Feb' } 08\end{array}$ & $\begin{array}{c}\mathrm{BB} \& \\
\mathrm{IGE}<8.5 \mathrm{yrs}\end{array}$ \\
\hline Neville, Paul Christopher & LNPC & & & 1 & \\
\hline Newman, Jocelyn Margaret & LNPC & 1 & & & \\
\hline Nugent, Peter Edward & LNPC & & & & 1 \\
\hline O'Brien, Kerry Williams Kelso & ALP & & & 1 & \\
\hline O’Byrne, Michelle Anne & ALP & & & & 1 \\
\hline O'Chee, William George & LNPC & & & & 1 \\
\hline O'Connor, Brendan Patrick & ALP & & & 1 & \\
\hline O'Connor, Gavan Michael & ALP & & & & 1 \\
\hline O’Keefe, Neil Patrick & ALP & & 1 & & \\
\hline Owens, Julie Ann & ALP & & & 1 & \\
\hline Panizza, John Horace & LNPC & & & & 1 \\
\hline Parer, Warwick Raymond & LNPC & & 1 & & \\
\hline Parke, Melissa & ALP & & & 1 & \\
\hline Parry, Stephen Shane & LNPC & & & 1 & \\
\hline Patterson, Kay Christine Lesley & LNPC & 1 & & & \\
\hline Payne, Marise Ann & LNPC & & & 1 & \\
\hline Pearce, Christopher John & LNPC & & & 1 & \\
\hline Perrett, Graham Douglas & ALP & & & 1 & \\
\hline Plibersek, Tanya Joan & ALP & & & 1 & \\
\hline Polley, Helen Beatrice & ALP & & & 1 & \\
\hline Price, Leo Roger Spurway & ALP & & & 1 & \\
\hline Prosser, Geoffrey Daniel & LNPC & & 1 & & \\
\hline Pyne, Christopher Maurice & LNPC & & & 1 & \\
\hline Quick, Harry Vernon & ALP & & & & 1 \\
\hline Quirke, John Andrew & ALP & & & & 1 \\
\hline Raguse, Brett Blair & ALP & & & 1 & \\
\hline Ramsey, Rowan Eric & LNPC & & & 1 & \\
\hline Randall, Donald James & LNPC & & & 1 & \\
\hline Ray, Robert Francis & ALP & 1 & & & \\
\hline Rea, Kerry Marie & ALP & & & 1 & \\
\hline Reid, Margaret Elizabeth & LNPC & & 1 & & \\
\hline Reid, Nicholas Bruce & LNPC & & & & 1 \\
\hline Reith, Peter Keaston & LNPC & 1 & & & \\
\hline Reynolds, Margaret & ALP & & 1 & & \\
\hline Richardson, Kym Charles & LNPC & & & & 1 \\
\hline Ripoll, Bernard Fernando & ALP & & & 1 & \\
\hline Rishworth, Amanda Louise & ALP & & & 1 & \\
\hline Robb, Andrew John & LNPC & & & 1 & \\
\hline
\end{tabular}


Appendix 2: Cohort Details (Continued)

\begin{tabular}{|c|c|c|c|c|c|}
\hline \multirow[t]{2}{*}{ Name } & \multirow[t]{2}{*}{ ALP/LNPC } & \multicolumn{2}{|c|}{ Modelling Sample } & \multicolumn{2}{|c|}{ Removed from Sample } \\
\hline & & $\mathrm{CM}$ & Non-CM & $\begin{array}{r}\text { In Parl' } \\
@ F^{\prime} b^{\prime} 08\end{array}$ & $\begin{array}{c}\text { BB \& } \\
I G E<8.5 y r s\end{array}$ \\
\hline Robert, Stuart Rowland & LNPC & & & 1 & \\
\hline Ronaldson, $\mathrm{M}$ & LNPC & & & 1 & \\
\hline Roxon, Nicola Louise & ALP & 1 & & & \\
\hline Rudd, Kevin Michael & ALP & 1 & & & \\
\hline Ruddock, Philip Maxwell & LNPC & 1 & & & \\
\hline Saffin, Janelle Anne & ALP & & & 1 & \\
\hline Santoro, Santo & LNPC & & 1 & & \\
\hline Sawford, Rodney Weston & ALP & & & & 1 \\
\hline Schacht, Christopher Cleland & ALP & & 1 & & \\
\hline Schultz, Albert John & LNPC & & & 1 & \\
\hline Sciacca, Concetto Antonio & ALP & & 1 & & \\
\hline Scott, Bruce Craig & LNPC & & & 1 & \\
\hline Scullion, Nigel Gregory & LNPC & & & 1 & \\
\hline Secker, Patrick Damien & LNPC & & & 1 & \\
\hline Sercombe, Robert Charles Grant & ALP & & & & 1 \\
\hline Sharp, John Randall & LNPC & 1 & & & \\
\hline Sherry, Nicholas John & ALP & & & 1 & \\
\hline Short, James Robert & LNPC & & 1 & & \\
\hline Short, Leonie Marjorie & ALP & & & & 1 \\
\hline Shorten, William Richard & ALP & & & 1 & \\
\hline Sidebottom, Peter Sid & ALP & & & 1 & \\
\hline Simpkins, Luke Xavier Linton & LNPC & & & 1 & \\
\hline Sinclair, Ian McCahon & LNPC & 1 & & & \\
\hline Slipper, Peter Neil & LNPC & & & 1 & \\
\hline Smith, Anthony Charles & LNPC & & & & 1 \\
\hline Smith, Anthony David Hawthorn & LNPC & & & 1 & \\
\hline Smith, Stephen Francis & ALP & 1 & & & \\
\hline Smith, Warwick Leslie & LNPC & & 1 & & \\
\hline Snowdon, Warren Edward & ALP & & & 1 & \\
\hline Somlyay, Alexander Michael & LNPC & & & 1 & \\
\hline Southcott, Andrew John & LNPC & & & 1 & \\
\hline St Clair, Stuart Roy & LNPC & & & & 1 \\
\hline Stephens, Ursula Mary & ALP & & & 1 & \\
\hline Sterle, Glenn & ALP & & & 1 & \\
\hline Stone, Sharman Nancy & LNPC & & & 1 & \\
\hline Sullivan, Jonathan Harold & ALP & & & 1 & \\
\hline Sullivan, Kathryn Jean Martin & LNPC & & 1 & & \\
\hline Swan, Wayne Maxwell & ALP & 1 & & & \\
\hline
\end{tabular}


Appendix 2: Cohort Details (Continued)

\begin{tabular}{|c|c|c|c|c|c|}
\hline \multirow[t]{2}{*}{ Name } & \multirow[t]{2}{*}{ ALP/LNPC } & \multicolumn{2}{|c|}{ Modelling Sample } & \multicolumn{2}{|c|}{ Removed from Sample } \\
\hline & & $\mathrm{CM}$ & Non-CM & $\begin{array}{r}\text { In Parl' } \\
@ \text { Feb' } 08\end{array}$ & $\begin{array}{c}\mathrm{BB} \& \\
\mathrm{IGE}<8.5 \mathrm{yrs}\end{array}$ \\
\hline Symon, Michael Stuart & ALP & & & 1 & \\
\hline Synon, Karen Margaret & LNPC & & & & 1 \\
\hline Tambling, Grant Ernest John & LNPC & & 1 & & \\
\hline Tanner, Lindsay James & ALP & 1 & & & \\
\hline Taylor, William Leonard & LNPC & & & & 1 \\
\hline Tchen, Tsebin & LNPC & & & & 1 \\
\hline Teague, Baden Chapman & LNPC & & & & 1 \\
\hline Theophanous, Andrew Charles & ALP & & 1 & & \\
\hline Thompson, Cameron Paul & LNPC & & 1 & & \\
\hline Thomson, Andrew Peter & LNPC & & 1 & & \\
\hline Thomson, Craig Robert & ALP & & & 1 & \\
\hline Thomson, Kelvin John & ALP & & & 1 & \\
\hline Ticehurst, Kenneth Vincent & LNPC & & & & 1 \\
\hline Tierney, John William & LNPC & & 1 & & \\
\hline Tollner, David William & LNPC & & & & 1 \\
\hline Trevor, Chris Allan & ALP & & & 1 & \\
\hline Troeth, Judith Mary & LNPC & & & 1 & \\
\hline Trood, Russell Brunell & LNPC & & & 1 & \\
\hline Truss, Warren Errol & LNPC & 1 & & & \\
\hline Tuckey, Charles Wilson & LNPC & & & 1 & \\
\hline Turnbull, Malcolm Bligh & LNPC & 1 & & & \\
\hline Turnour, James Pearce & ALP & & & 1 & \\
\hline Vaile, Mark Anthony James & LNPC & 1 & & & \\
\hline Vale, Danna Sue & LNPC & & & 1 & \\
\hline Vamvakinou, Maria & ALP & & & 1 & \\
\hline Vanstone, Amanda Eloise & LNPC & 1 & & & \\
\hline Vasta, Ross Xavier & LNPC & & & & 1 \\
\hline Wakelin, Barry Hugh & LNPC & & 1 & & \\
\hline Washer, Malcolm James & LNPC & & & 1 & \\
\hline Watson, John Odin Wentworth & LNPC & & & 1 & \\
\hline Webber, Ruth Stephanie & ALP & & & 1 & \\
\hline West, Andrea Gail & LNPC & & & & 1 \\
\hline West, Suzanne Margaret & ALP & & & & 1 \\
\hline Wheelwright, Thomas Clive & ALP & & & & 1 \\
\hline Wilkie, Kim & ALP & & & & 1 \\
\hline Williams, Daryl Robert & LNPC & 1 & & & \\
\hline Willis, Ralph & ALP & 1 & & & \\
\hline Wilton, Gregory Stuart & ALP & & & & 1 \\
\hline
\end{tabular}


Appendix 2: Cohort Details (Continued)

\begin{tabular}{|c|c|c|c|c|c|}
\hline \multirow[t]{2}{*}{ Name } & \multirow[t]{2}{*}{ ALP/LNPC } & \multicolumn{2}{|c|}{ Modelling Sample } & \multicolumn{2}{|c|}{ Removed from Sample } \\
\hline & & $\mathrm{CM}$ & Non-CM & $\begin{array}{r}\text { In Parl' } \\
@ F e b^{\prime} 08\end{array}$ & $\begin{array}{c}\text { BB \& } \\
\text { IGE }<8.5 y r s\end{array}$ \\
\hline Wong, Penelope Ying Yen & ALP & 1 & & & \\
\hline Wood, Jason Peter & LNPC & & & 1 & \\
\hline Woods, Robert Leslie & LNPC & & 1 & & \\
\hline Wooldridge, Michael Richard L & LNPC & 1 & & & \\
\hline Worth, Patricia Mary & LNPC & & 1 & & \\
\hline Wortley, Dana Johanna & ALP & & & 1 & \\
\hline Zahra, Christian John & ALP & & & & 1 \\
\hline Zammit, Paul John & LNPC & & & & 1 \\
\hline Zappia, Tony & ALP & & & 1 & \\
\hline Total & & 68 & 66 & 177 & 73 \\
\hline & & & & & \\
\hline
\end{tabular}




\section{Appendix 3: Data Used for Committee Modelling}

\begin{tabular}{|c|c|c|c|c|c|c|c|c|c|}
\hline Name & CM & Law & Arts & ParlAge & IMG & CON & AOA & CONAV & DEF \\
\hline AbbottA & 1 & 1 & 1 & 37 & -0.16 & -0.43 & -0.77 & 0.53 & -0.47 \\
\hline AlbaneseA & 1 & 0 & 0 & 33 & 0.12 & -0.06 & -0.46 & -0.35 & 0.77 \\
\hline AlstonR & 1 & 1 & 1 & 45 & -0.68 & -0.8 & 1.21 & -0.6 & -2.01 \\
\hline AndersonJ & 1 & 0 & 1 & 33 & -0.85 & -0.99 & 0.35 & -1.38 & -1.17 \\
\hline AndrewJN & 0 & 0 & 0 & 39 & 2.02 & 2.23 & -0.9 & 1.51 & 1.37 \\
\hline AndrewsK & 1 & 1 & 1 & 36 & -0.54 & -0.98 & 0.4 & -0.02 & -0.19 \\
\hline AnthonyL & 0 & 0 & 0 & 35 & 1.52 & 1.09 & -0.8 & 1.36 & 0.42 \\
\hline BairdB & 0 & 0 & 1 & 56 & 1.31 & 1.41 & -1.16 & 0.65 & 0.22 \\
\hline BaldwinP & 1 & 0 & 1 & 32 & $\begin{array}{l}-1.1 \\
\end{array}$ & -0.75 & 0.26 & -0.14 & -0.86 \\
\hline BarresiP & 0 & 0 & 1 & 41 & 1.53 & 1.32 & -1.08 & 0.9 & 0.69 \\
\hline BartlettK & 0 & 0 & 0 & 47 & -0.54 & -0.7 & 0.21 & 0.02 & -0.57 \\
\hline BaumeME & 0 & 0 & 1 & 45 & 0.22 & 0.23 & -1.2 & 1.11 & 1.46 \\
\hline BeahanME & 0 & 0 & 1 & 50 & -1.01 & -0.85 & 0.42 & -0.6 & -1.74 \\
\hline Beasleyk & 1 & 0 & 1 & 32 & -1.32 & -0.54 & 0.3 & -0.79 & -0.78 \\
\hline BeddallD & 0 & 0 & 0 & 35 & 0.43 & 0.82 & 0.76 & -0.52 & 0.35 \\
\hline BishopJl & 1 & 1 & 0 & 42 & -1.43 & -1.51 & 1.02 & -1.16 & -2.12 \\
\hline BolkusN & 1 & 1 & 0 & 30 & 0.21 & -0.51 & -0.27 & -0.01 & 0.06 \\
\hline BreretonL & 1 & 0 & 0 & 44 & -0.88 & -1.09 & 0.83 & -0.15 & -1.5 \\
\hline BroughM & 1 & 0 & 0 & 35 & 0.53 & 0.51 & -1.12 & 0.85 & -0.32 \\
\hline BrownBJ & 0 & 0 & 0 & 47 & -1.92 & -0.49 & 1.75 & -2.17 & -0.36 \\
\hline BrownhillDG & 0 & 0 & 0 & 49 & 0.64 & 0.94 & -1.09 & 1.31 & 1.13 \\
\hline BurkeAT & 1 & 1 & 1 & 35 & -0.05 & -0.25 & -0.58 & 0.03 & -0.05 \\
\hline BurnsBR & 0 & 0 & 0 & 58 & 0.08 & 0.5 & -1.01 & 0.94 & 0.67 \\
\hline CadmanA & 0 & 0 & 0 & 37 & 1.15 & 1.65 & -0.69 & 0.46 & 1.12 \\
\hline CalvertP & 0 & 0 & 0 & 47 & 0.31 & 0.19 & 0.82 & -0.86 & -0.8 \\
\hline CameronRA & 0 & 1 & 0 & 31 & 0.76 & 1.22 & -0.79 & 0.22 & 0.78 \\
\hline CampbellIG & 1 & 0 & 0 & 31 & -0.5 & -0.69 & 0.95 & -0.63 & -0.74 \\
\hline CarrK & 1 & 0 & 1 & 38 & -1 & -0.97 & 0.92 & -1.72 & -0.43 \\
\hline CausleyIR & 0 & 0 & 0 & 56 & 2.3 & 2.59 & -1.11 & 0.86 & 1.23 \\
\hline CharlesRE & 0 & 0 & 0 & 54 & -0.6 & -0.58 & 0.83 & -0.25 & -1.23 \\
\hline ChildsBK & 0 & 0 & 0 & 46 & 0.12 & 0.42 & 0.81 & -0.45 & 0.72 \\
\hline CoatesJ & 0 & 0 & 0 & 28 & -0.41 & -1.26 & 0.85 & 0.17 & -0.09 \\
\hline CollinsRL & 1 & 0 & 0 & 41 & 0.82 & 1.29 & -0.5 & 1.24 & 1.08 \\
\hline ColstonM & 0 & 0 & 1 & 37 & 0.75 & 0.21 & -0.98 & 0.84 & 1.45 \\
\hline ConroyS & 1 & 0 & 0 & 33 & -0.69 & -1.16 & 0.67 & -0.6 & -0.5 \\
\hline CookP & 1 & 0 & 0 & 40 & -0.88 & -0.5 & 1.05 & -1.32 & -0.15 \\
\hline
\end{tabular}


Appendix 3: Data Used for Committee Modelling (Continued)

\begin{tabular}{|c|c|c|c|c|c|c|c|c|c|}
\hline Name & CM & Law & Arts & ParlAge & IMG & CON & AOA & CONAV & DEF \\
\hline CoonanH & 1 & 1 & 1 & 49 & -0.48 & -0.46 & 0.64 & -0.11 & 0.08 \\
\hline CooneyB & 0 & 1 & 0 & 50 & -0.42 & -1.35 & 0.61 & -1.06 & -1.24 \\
\hline CostelloP & 1 & 1 & 1 & 33 & -1.63 & -0.75 & 0.34 & -0.62 & -1.28 \\
\hline CreanS & 1 & 1 & 0 & 41 & -1.29 & -1.06 & 2.27 & -2.29 & -3.14 \\
\hline CrowleyR & 0 & 0 & 0 & 45 & 0.08 & -0.21 & -0.44 & 1.3 & 1.37 \\
\hline DownerA & 1 & 0 & 1 & 33 & -1.17 & -1.37 & 1.43 & -1.82 & -2.55 \\
\hline DraperP & 0 & 0 & 1 & 37 & 0.78 & 0.78 & -0.37 & 0.62 & 1.06 \\
\hline ElsonK & 0 & 0 & 0 & 49 & 1.91 & 1.08 & -1.05 & 1.89 & 1.64 \\
\hline EntchW & 0 & 0 & 0 & 46 & 0.57 & 0.39 & -1.07 & 0.34 & 1.08 \\
\hline EvansC & 1 & 0 & 1 & 35 & -1.45 & -1.24 & 1.62 & -2.13 & -1.56 \\
\hline EvansG & 1 & 1 & 1 & 33 & -1.06 & -0.67 & 0.26 & -0.51 & -1.01 \\
\hline FaheyJ & 1 & 1 & 0 & 51 & 0.68 & 0.51 & -0.8 & 0.25 & 1.16 \\
\hline FaulknerJP & 1 & 0 & 1 & 35 & 1.04 & 0.58 & -0.62 & 0.48 & 1.49 \\
\hline FergusonM & 1 & 0 & 0 & 43 & 0.65 & -0.05 & -1.34 & 1.03 & 0.71 \\
\hline FerrisJ & 0 & 0 & 0 & 55 & 0.66 & 0.51 & -0.65 & 0.28 & -0.1 \\
\hline FischerT & 1 & 0 & 0 & 38 & 0.84 & 1.63 & 0.15 & 0.65 & 0.27 \\
\hline FitzgibbonJ & 1 & 0 & 0 & 34 & -0.13 & -0.12 & 0.71 & -1 & -0.16 \\
\hline ForemanD & 0 & 0 & 0 & 47 & 0.69 & 0.66 & -0.1 & 0.17 & 0.34 \\
\hline GallusC & 0 & 0 & 1 & 47 & -0.36 & -0.58 & -1.02 & 0.74 & 0.09 \\
\hline GambaroT & 0 & 0 & 0 & 38 & 0.74 & 0.43 & -1.33 & 0.81 & 0.68 \\
\hline GarrettP & 1 & 1 & 1 & 51 & -0.6 & -0.93 & 0.35 & -0.4 & -0.16 \\
\hline GillardJ & 1 & 1 & 1 & 37 & 0.76 & 0.14 & -0.87 & 0.72 & 0.29 \\
\hline GraceE & 0 & 0 & 0 & 53 & 0.52 & 0.23 & 0.88 & -0.2 & -0.08 \\
\hline HardgraveG & 0 & 0 & 0 & 36 & 0.83 & 0.83 & -0.99 & 0.79 & 0.12 \\
\hline HerronJJ & 0 & 0 & 0 & 58 & -1.69 & -1.61 & 0.13 & -0.13 & 0.58 \\
\hline HillRM & 1 & 1 & 1 & 34 & -1.2 & -0.13 & 2.39 & -2.37 & -1.52 \\
\hline HockeyJ & 1 & 1 & 1 & 31 & -0.82 & -1.03 & -0.84 & 0.44 & -0.25 \\
\hline HoldingC & 1 & 1 & 0 & 46 & 0.28 & 0.9 & -0.02 & -0.45 & 0.91 \\
\hline HollisC & 0 & 0 & 1 & 45 & 0.39 & 0.76 & 1.27 & -1.11 & -0.24 \\
\hline HowardJ & 1 & 1 & 0 & 35 & -0.57 & -0.17 & -0.77 & 0.33 & 0.36 \\
\hline JonesB & 0 & 1 & 1 & 45 & 0.22 & 0.21 & -0.93 & 0.23 & 0.77 \\
\hline JonesG & 0 & 0 & 0 & 48 & 1.21 & 1.59 & -1.33 & 0.65 & 2.27 \\
\hline JullD & 0 & 0 & 0 & 31 & -0.44 & 0.1 & -0.02 & 0.38 & 1.03 \\
\hline KellyD & 0 & 0 & 0 & 42 & 3.02 & 2.65 & -2.68 & 2.35 & 1.69 \\
\hline KellyJ & 0 & 1 & 0 & 32 & 1.16 & 0.52 & -1.77 & 1.03 & -0.21 \\
\hline KempD & 1 & 1 & 1 & 49 & -1.35 & -1.86 & 2.1 & -1.09 & -1.93 \\
\hline KnowlesS & 0 & 0 & 0 & 33 & -1.19 & -1.82 & 1.07 & -0.4 & -0.74 \\
\hline LangmoreJ & 0 & 0 & 0 & 45 & -0.57 & -0.32 & 0.81 & -1.21 & -0.03 \\
\hline
\end{tabular}


Appendix 3: Data Used for Committee Modelling (Continued)

\begin{tabular}{|c|c|c|c|c|c|c|c|c|c|}
\hline Name & CM & Law & Arts & ParlAge & IMG & CON & AOA & CONAV & DEF \\
\hline LawrenceC & 1 & 0 & 0 & 46 & -0.79 & -0.4 & -0.44 & -0.04 & -0.3 \\
\hline LeeM & 1 & 0 & 0 & 27 & 1.66 & 1.39 & -1.62 & 2.06 & 1.81 \\
\hline LloydJ & 0 & 0 & 0 & 42 & 1.73 & 1.3 & -2.41 & 2.07 & 0.2 \\
\hline LudwigJ & 1 & 1 & 1 & 39 & -0.42 & -0.85 & -0.16 & 0.34 & -0.17 \\
\hline MacfarlanelE & 1 & 0 & 0 & 43 & 1.11 & 1.16 & -0.98 & 0.65 & 0.67 \\
\hline MacklinJ & 1 & 0 & 0 & 43 & -1.87 & -2.2 & 0.72 & -0.84 & -0.86 \\
\hline MartinSP & 0 & 0 & 1 & 36 & 1.73 & 1.83 & 0.12 & 0.29 & 0.2 \\
\hline McArthurFS & 0 & 0 & 1 & 47 & 1.29 & 1.73 & -0.27 & 0.63 & 0.22 \\
\hline McClellandR & 1 & 1 & 1 & 38 & -1.62 & -1.15 & 1.19 & -2.28 & -0.76 \\
\hline McGauranP & 1 & 1 & 1 & 28 & -1.45 & -1.45 & 1.46 & -0.96 & -1.18 \\
\hline McKiernanJ & 0 & 0 & 0 & 40 & 0.79 & 1.1 & -0.39 & 0.29 & 0.97 \\
\hline McLachlanIM & 1 & 0 & 1 & 54 & 0.87 & 0.42 & -1.41 & 1.74 & 0.91 \\
\hline McLeayL & 0 & 0 & 0 & 34 & 0.35 & 0.28 & -1.21 & 1.53 & 1.08 \\
\hline McMullanRF & 1 & 0 & 1 & 41 & -1.71 & -0.92 & 1.31 & -2.26 & -0.46 \\
\hline MilesC & 0 & 0 & 0 & 37 & -0.57 & -0.44 & -0.23 & 0.45 & 0.02 \\
\hline MinchinN & 1 & 1 & 0 & 40 & 0.61 & 0.02 & 0.26 & -0.66 & 0.21 \\
\hline Moorej & 1 & 0 & 0 & 45 & -0.86 & -0.59 & 1.08 & -1.18 & -2.07 \\
\hline MorrisA & 0 & 0 & 1 & 43 & 0.92 & 0.77 & -0.16 & 0.4 & 0.74 \\
\hline MorrisP & 1 & 0 & 0 & 40 & 1.87 & 2.06 & -1.7 & 1.05 & 2.99 \\
\hline NairnG & 0 & 0 & 0 & 45 & 1.6 & 1.64 & 0.23 & 1.16 & 0.67 \\
\hline NelsonB & 1 & 0 & 0 & 38 & 0.54 & 0.07 & -2.07 & 1.9 & 1.13 \\
\hline NewmanJM & 1 & 1 & 0 & 49 & -0.18 & -0.13 & 0.09 & 0.43 & 0.14 \\
\hline O'KeefeN & 0 & 0 & 0 & 37 & 0.53 & 0.81 & 0.72 & -0.06 & -0.15 \\
\hline ParerW & 0 & 0 & 0 & 48 & 0.39 & 0.4 & 0.79 & -0.26 & -0.55 \\
\hline PattersonK & 1 & 0 & 1 & 43 & -0.06 & 0.45 & -0.37 & -0.41 & 0.02 \\
\hline ProsserG & 0 & 0 & 0 & 39 & 0.11 & 0.71 & 0.05 & 0.13 & 0.69 \\
\hline RayR & 1 & 0 & 1 & 33 & -0.24 & -0.26 & -0.04 & 0.46 & 0.49 \\
\hline ReidME & 0 & 1 & 0 & 46 & 0.84 & 0.59 & -2.32 & 2.07 & 0.6 \\
\hline ReithP & 1 & 1 & 0 & 32 & 0.34 & -0.01 & 0.04 & 0.28 & 0.39 \\
\hline ReynoldsM & 0 & 0 & 1 & 42 & -0.34 & -0.48 & 0.72 & -0.57 & 0.03 \\
\hline RoxonN & 1 & 1 & 1 & 31 & -0.64 & -1.14 & -0.58 & 0.35 & 0 \\
\hline RuddK & 1 & 0 & 1 & 41 & -0.48 & -0.79 & 0.66 & -0.27 & -0.09 \\
\hline RuddockP & 1 & 1 & 1 & 30 & -0.25 & 0.01 & 1.19 & -1.55 & -0.81 \\
\hline Santoros & 0 & 0 & 1 & 46 & -0.87 & -0.98 & 0.55 & -0.78 & -0.85 \\
\hline SchachtC & 0 & 0 & 0 & 41 & 0.18 & 0.69 & -0.86 & -0.24 & -0.05 \\
\hline SciaccaC & 0 & 1 & 0 & 40 & 0.14 & -0.08 & -0.49 & -0.32 & 0.6 \\
\hline SharpJR & 1 & 0 & 0 & 30 & 1.03 & 1.4 & 0.47 & -0.45 & -0.85 \\
\hline ShortJR & 0 & 0 & 1 & 39 & -0.15 & -0.11 & 0.01 & 0.59 & 0.2 \\
\hline
\end{tabular}


Appendix 3: Data Used for Committee Modelling (Continued)

\begin{tabular}{|l|r|r|r|r|r|r|r|r|r|}
\hline Name & CM & Law & Arts & ParlAge & IMG & CON & AOA & CONAV & DEF \\
\hline Sinclairl & 1 & 1 & 1 & 34 & -1.33 & -0.66 & 1.39 & -1.37 & -1.52 \\
\hline SmithSF & 1 & 1 & 1 & 38 & 0.13 & -0.25 & -0.23 & -0.13 & 0.61 \\
\hline SmithWL & 0 & 1 & 0 & 30 & -0.67 & -0.54 & 0.9 & -0.52 & -0.87 \\
\hline SullivanK & 0 & 0 & 1 & 32 & -1.44 & -1.34 & 0.24 & 0.36 & -0.92 \\
\hline SwanW & 1 & 0 & 1 & 39 & 1.44 & 1.3 & -0.33 & 0.44 & 0.67 \\
\hline Tambling & 0 & 0 & 0 & 37 & -1.13 & -0.41 & 1.31 & -1.67 & -0.42 \\
\hline TannerL & 1 & 1 & 1 & 37 & -0.54 & -0.07 & 1.01 & -0.52 & -0.89 \\
\hline TheophanousA & 0 & 0 & 1 & 34 & -1.72 & -1.8 & 1.33 & -1.06 & -0.29 \\
\hline ThompsonCP & 0 & 0 & 0 & 38 & 0.81 & 0.54 & -1.26 & 1.13 & 0.69 \\
\hline ThomsonAP & 0 & 1 & 1 & 34 & -0.3 & -1.04 & -1.04 & 0.87 & -1.11 \\
\hline TierneyJW & 0 & 0 & 0 & 45 & 0.53 & 0.96 & 0.13 & -0.19 & 1.18 \\
\hline TrussW & 1 & 0 & 0 & 42 & 0.02 & -0.02 & 0.55 & -0.65 & -1.18 \\
\hline TurnbulIM & 1 & 1 & 1 & 50 & 0.94 & -0.1 & -1.01 & 1.27 & -0.37 \\
\hline VaileM & 1 & 0 & 0 & 37 & 0.54 & 1 & 0.83 & -0.56 & -0.03 \\
\hline VanstoneA & 1 & 1 & 1 & 32 & -1.37 & -1.52 & 1.5 & -0.81 & -0.84 \\
\hline WakelinB & 0 & 0 & 0 & 47 & -0.51 & -0.2 & 0.33 & 0.07 & -0.41 \\
\hline WillamsDR & 1 & 1 & 0 & 51 & -0.84 & 0.05 & 0.93 & -1.1 & 0.21 \\
\hline WillisR & 1 & 0 & 0 & 34 & -0.42 & -0.3 & 0.92 & 0.32 & 0.4 \\
\hline WongP & 1 & 1 & 1 & 33 & -0.89 & -1.53 & 0.18 & -0.29 & -1.08 \\
\hline WoodsRL & 0 & 0 & 0 & 40 & -1 & -1.11 & 0.82 & -0.88 & -0.97 \\
\hline WooldridgeMRL & 1 & 0 & 0 & 31 & -0.08 & -0.91 & -0.3 & 0.95 & 1.55 \\
\hline WorthP & 0 & 0 & 0 & 47 & 0.84 & 0.86 & -0.06 & 0.68 & 0.57 \\
\hline
\end{tabular}




\section{Appendix 4: Committee Modelling Procedure}

For each of the five iterations of the committee model building process the same basic procedure is undertaken.

The first stage of the procedure is to divide the sample of 134 is divided into a training sample $(\mathrm{n}=107)$ and a testing sample $(\mathrm{n}=27)$.

The training sample $(\mathrm{n}=107)$ is used to isolate the variables that are significantly $(\mathrm{p}<.01)$ associated with $\mathrm{CM}$ on the basis of t-tests of the differences of means. These variables are then used to create a "naïve" model which consists of all variables that have $p<.01$. The classification accuracy on the holdout sample $(n=27)$ of this model is recorded and used as a baseline to compare with the subsequent attempts to improve the classification accuracy of the naïve model.

The next stage attempts to improve the classification accuracy of the naïve model by eliminating redundant variables. Here, redundancy is defined as a situation in which, for two independent variables, there is a higher level of correlation than either variable has with the dependent variable. In order to assess the presence of redundancy a correlation matrix is generated. It is apparent form the correlation matrix that, as the linguistic variables are highly inter-correlated, it is possible there is redundancy in relation to the linguistic variables. This indicates that including more than one linguistic independent variable is unlikely to increase classification accuracy. However, the question is which of the linguistic variables to retain. Several models are created In order to determine which of the linguistic variables is the best predictor, each model consisting of one of the linguistic variables and the other non-linguistic variables from 
the "naïve" model. The model containing the linguistic variable with the highest classification accuracy is retained. This is referred to as the "reduced" model.

Thus, the "reduced" model consists of at most one linguistic variable and at least two other variables. The classification accuracy of the "reduced" model can be potentially increased by eliminating further variables. The procedure here is to use every possible combination of the variables in the "reduced" model to create a number of candidate "optimum" models. The optimum model is chosen by comparing these candidate "optimum" models on the basis of how well they classify the holdout sample.

Finally, the parameter estimates of the optimum model are calculated.

This entire procedure is undertaken for each of the 5 models in the committee.

\section{Committee Model 1}

Holdout Sample:

AndersonJ ColstonM HerronJJ MilesC ThomsonAP

AnthonyL CrowleyR HoldingC MinchinN WillamsDR

BaumeME DownerA KellyJ NewmanJM WooldridgeMRL

BeahanME FaulknerJP LangmoreJ PattersonK 
Appendix 4: Committee Modelling Procedure (Continued)

BolkusN FischerT LawrenceC RayR

CadmanA ForemanD McMullanRF ShortJR

Using the training sample, the first stage is to find the variables that have different means for CMs as opposed to non-CMs. These are ranked by p-values. Those for which $\mathrm{p}<.01$ are selected for use in the model (Table A4-1.

Table A4-1: Variables for which $p<.01$ (Committee Model 1)

\begin{tabular}{|c|c|c|c|c|}
\hline & $\begin{array}{c}\text { Mean } \\
\text { Non-CMs }\end{array}$ & $\begin{array}{c}\text { Mean } \\
\text { CMs }\end{array}$ & p-value & Description \\
\hline Law & 0.11 & 0.52 & 0.000 & Binary Variable: 1 = legal qualification, 0 = no legal qualification \\
\hline $\mathrm{CON}^{*}$ & 0.41 & -0.36 & 0.000 & Concreteness \\
\hline ParlAge & 42.74 & 37.87 & 0.000 & Age of first entry to Federal Parliament \\
\hline IMG* & 0.37 & -0.33 & 0.000 & Imagability. A measure of concreteness \\
\hline DEF* & 0.28 & -0.37 & 0.001 & Ease of definitions. \\
\hline Arts & 0.25 & 0.56 & 0.001 & Binary Variable: 1 = Arts qualification, $0=$ no Arts qualification \\
\hline CONAV* & 0.24 & -0.26 & 0.009 & Context availability. A measure of concreteness \\
\hline
\end{tabular}

The next stage is to calculate the holdout sample classification accuracy of a model consisting of all 7 of the variables identified with $p<.01$. The results are as follow: Accuracy $=66.67 \% ;$ Sensitivity $=50.00 \% ;$ Specificity $=84.62 \% ;$ Kappa $=$ $.3415(\mathrm{p}=.0566)$.

It is important to look for potential redundancy in the training sample $(n=107)$. To do this we calculate a table of intercorrelations of the variables in the naïve model and look for variables that are more correlated with each other than with the dependent variable (Table A4-2). 
Appendix 4: Committee Modelling Procedure (Continued)

Table A4-2: Intercorrelations between Variables (Committee Model 1)

\begin{tabular}{|c|c|c|c|c|c|c|c|c|}
\hline & $\operatorname{CH}\{1\}$ & $\operatorname{Law}\{1\}$ & $\operatorname{Arts}\{1\}$ & ParlAge & I HG & CON & CONAU & DEF \\
\hline $\operatorname{CH}\{1\}$ & 1.0500 & 0.4352 & 0.3164 & -0.3400 & -0.3399 & -0.3729 & -0.2500 & -0.3266 \\
\hline $\operatorname{Law}\{1\}$ & 0.4352 & 1.0505 & 0. 4232 & -0.1867 & -0.3347 & -0.3828 & -0.2363 & -0.3363 \\
\hline $\operatorname{Arts}\{1\}$ & 0.3164 & 5. 4232 & 1.0505 & -0.1334 & -0.2873 & -0.3070 & -0.2090 & -0.2688 \\
\hline Parlage & -0.3490 & -0.1867 & -6.1334 & 1.0500 & 6. 2843 & 6.2449 & 6.1836 & 6.1382 \\
\hline I HidG & -0.3399 & -0.3347 & -0.2873 & 0.2843 & 1.0505 & 0.9179 & 0. 7579 & 0.7442 \\
\hline CON & -0.3729 & -0.3828 & -5.3575 & 0.2449 & 6.9179 & 1.0505 & 0.5985 & 0.7113 \\
\hline CONAU & -0.2506 & -6.2363 & -5.2595 & 0. 1836 & 0.7579 & 6.5985 & 1. 5050 & 0.7193 \\
\hline DEF & -0.3266 & -0.3363 & -0.2688 & 0.1382 & 0.7442 & 0.7113 & 5.7193 & 1.5905 \\
\hline
\end{tabular}

The linguistic variables have higher correlation with each other than they have with the dependent variable so such we can remove three of them. IN order to decide which one to retain is to create four models are created, each of which has one of the linguistic variables and all of the non-linguistic variables (Table 4A-3). The model with the best holdout sample classification accuracy is retained. Where there are two models with the identical classification accuracy the model with the higher Kappa is chosen.

Table A4-3: Accuracies of Models with One Linguistic Variable (Committee Model 1)

\begin{tabular}{|lcccc|}
\hline \multicolumn{1}{c}{ Model } & Accuracy & Sensitivity & Specificity & Kappa \\
Law, Parlage, Arts, IMG & 74.07 & 78.57 & 69.23 & $0.48^{*}$ \\
Law, Parlage, Arts, CON & 66.67 & 64.29 & 69.23 & 0.33 \\
Law, Parlage, Arts, CONAV & 74.07 & 71.43 & 76.92 & $0.48^{*}$ \\
Law, Parlage, Arts, DEF & 62.96 & 42.86 & 84.62 & 0.27 \\
\hline
\end{tabular}

The accuracies of the Law, Parlage, Arts and IMG model and the Law Parlage Arts and CONAV models are the same at $74.07 \%$ but the Kappa of the latter is marginally higher at .4822 while that of the former is .4793 . As such the CONAV model is selected. 
Appendix 4: Committee Modelling Procedure (Continued)

The next stage is to create models consisting of all possible combinations of CONAV, Law. Parlage and Arts. The Optimum model is the one with the highest classification accuracy or Kappa (Table 4A-4).

Table A4-4: Accuracies - All Possible Variable Combinations (Committee Model 1)

\begin{tabular}{|l|ccc|cc|}
\hline \multicolumn{1}{|c|}{ Model Variables } & Accuracy & Sensitivity & Specificity & Kappa & p \\
\hline Law, Parlage & 74.07 & 64.29 & 84.62 & 0.49 & 0.0098 \\
Law, Parlage, Conav & 74.07 & 71.43 & 76.92 & 0.48 & 0.0120 \\
Arts, Conav, Law & 70.37 & 64.29 & 76.92 & 0.41 & 0.0313 \\
Law, Conav & 66.67 & 50.00 & 84.62 & 0.34 & 0.0566 \\
Law, Parlage, Arts & 66.67 & 64.29 & 69.23 & 0.33 & 0.0816 \\
Parlage, Arts, Conav & 62.96 & 57.14 & 69.23 & 0.26 & 0.1682 \\
Law,Arts & 59.26 & 35.71 & 84.62 & 0.20 & 0.2284 \\
Parlage, Conav & 59.26 & 57.14 & 61.54 & 0.19 & 0.3317 \\
Parlage, Arts & 55.56 & 57.14 & 53.85 & 0.11 & 0.5680 \\
Arts, Conav & 51.85 & 50.00 & 53.85 & 0.04 & 0.8416 \\
\hline
\end{tabular}

The highest score is $74.07 \%$ for the model consisting of Law and Parlage. The Kappa of the Law and Parlage model is .4850 which is marginally higher than the Kappa of the Law, Parlage and CONAV model. As such the Law, Parlage model is the optimum model.

The final stage is to calculate the parameter estimates for the Optimum Model.

Table A4-5: Parameter Estimates for the Optimum Model (Committee Model 1)

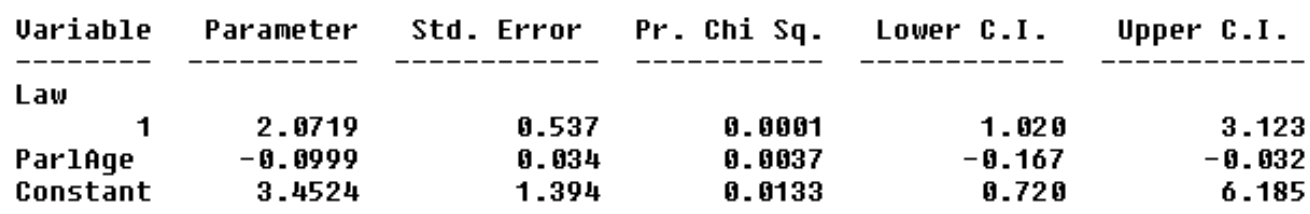


Appendix 4: Committee Modelling Procedure (Continued)

Table A4-6: Odds Ratios (Committee Model 1)

\begin{tabular}{lrrr} 
Uariable & Odds Ratio & Lower C.I. & \multicolumn{1}{c}{ Upper C.I . } \\
\hline Law & & & \\
1 & 7.9397 & 2.7741 & 22.7240 \\
Parlfge & 0.9949 & 0.8458 & 0.9681
\end{tabular}

Details of the four other models in the committee follow:

Committee Model 2

Holdout Sample:

AndersonJ BishopJI CollinsRL McGauranP WillamsDR

AndrewsK BurkeAT DraperP McLachlanIM WillisR

AnthonyL Burns, Bryant GillardJ McLeayL WorthP

BairdB CampbellIG HowardJ MorrisA

BarresiP CausleyIR LangmoreJ MorrisP

BartlettK CoatesJ McClellandR ParerW 
Appendix 4: Committee Modelling Procedure (Continued)

Table A4-7: Variables for which $p<.01$ (Committee Model 2)

\begin{tabular}{|c|c|c|c|}
\hline & $\begin{array}{c}\text { Mean } \\
\text { Non-CMs }\end{array}$ & $\begin{array}{c}\text { Mean } \\
\text { CMs }\end{array}$ & $\mathrm{p}$-value \\
\hline Law & 0.15 & 0.46 & 0.000 \\
\hline DEF & 0.25 & -0.35 & 0.001 \\
\hline CON & 0.26 & -0.33 & 0.002 \\
\hline ParlAge & 42.09 & 38.13 & 0.002 \\
\hline Arts & 0.26 & 0.54 & 0.004 \\
\hline IMG & 0.23 & -0.31 & 0.004 \\
\hline CONAV & 0.24 & -0.32 & 0.004 \\
\hline
\end{tabular}

"Naïve" Model Performance:

Accuracy $=77.78 ;$ Sensitivity $=64.29 ;$ Specificity $=92.31$, Kappa $=.5598$ $(\mathrm{p}=.0023)$.

Table A4-8: Intercorrelations between Variables (Committee Model 2)

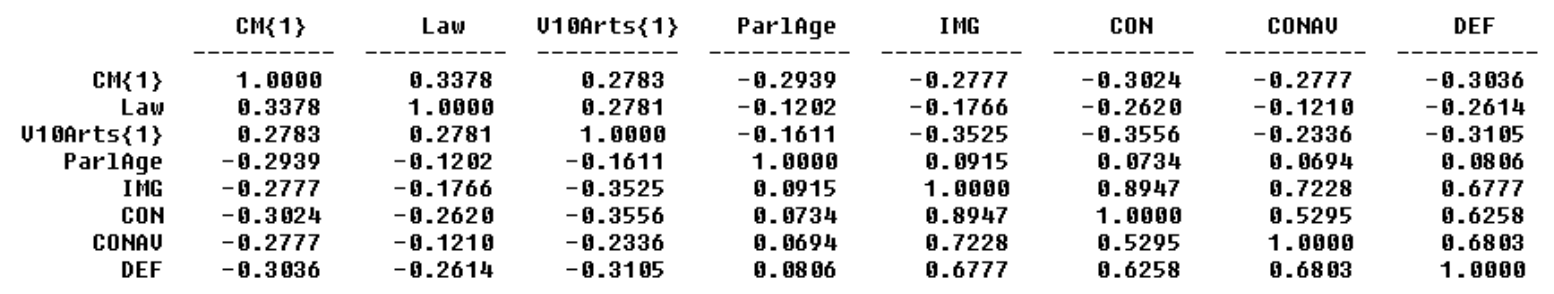


Appendix 4: Committee Modelling Procedure (Continued)

Table A4-9: Accuracies of Models with One Linguistic Variable (Committee Model 2)

\begin{tabular}{|lcccc|}
\hline \multicolumn{1}{|c}{ Model } & Accuracy & Sensitivity & Specificity & Kappa \\
Law, Parlage, Arts, IMG & 85.19 & 78.57 & 92.31 & $0.70^{* *}$ \\
Law, Parlage, Arts, CON & 81.48 & 71.43 & 92.31 & $0.63^{* *}$ \\
Law, Parlage, Arts, DEF & 77.78 & 64.29 & 92.31 & $0.56^{* *}$ \\
Law, Parlage, Arts, CONAV & 81.48 & 71.43 & 92.31 & $0.63^{* *}$ \\
\hline
\end{tabular}

Table A4-10: Accuracies - All Possible Variable Combinations (Committee Model 2)

\begin{tabular}{|l|ccc|cc|}
\hline \multicolumn{1}{|c|}{ Model Variables } & Accuracy & Sensitivity & Specificity & Kappa & $\mathrm{p}$ \\
\hline Law, Parlage, IMG & $\mathbf{8 5 . 1 9}$ & $\mathbf{7 8 . 5 7}$ & $\mathbf{9 2 . 3 1}$ & $\mathbf{0 . 7 0}$ & $\mathbf{0 . 0 0 0 2}$ \\
Parlage, IMG & 74.07 & 64.29 & 84.62 & 0.49 & 0.0098 \\
Law, Parlage & 77.78 & 78.57 & 76.92 & 0.55 & 0.0039 \\
Law, IMG & 81.48 & 64.29 & 100.00 & $\mathrm{n} / \mathrm{a}^{*}$ & $\mathrm{n} / \mathrm{a}^{*}$ \\
Law, Parlage, Arts & 70.37 & 64.29 & 76.92 & 0.41 & 0.0313 \\
Arts, IMG, Law & 81.48 & 64.29 & 100.00 & $\mathrm{n} / \mathrm{a}^{*}$ & $\mathrm{n} / \mathrm{a}^{*}$ \\
Law,Arts & 70.37 & 71.43 & 69.23 & 0.41 & 0.0346 \\
Arts, IMG & 74.07 & 64.29 & 84.62 & 0.49 & 0.0098 \\
Parlage, Arts & 59.26 & 64.29 & 53.85 & 0.18 & 0.3434 \\
Parlage, Arts, IMG & 74.07 & 71.43 & 76.92 & 0.48 & 0.0120 \\
\hline
\end{tabular}

Table A4-11: Parameter Estimates for the Optimum Model (Committee Model 2)

\begin{tabular}{lrrrrr} 
Uariable & Parameter & Std. Error & Pr. Chi Sq. & Lower C.I. & Upper C.I. \\
\hline-1 & -1.4549 & 0.505 & 0.0939 & 0.466 & 2.444 \\
Law & -0.0899 & 0.034 & 0.0983 & -0.157 & -0.023 \\
ParlAge & -0.5221 & 0.235 & 0.0264 & -0.983 & -0.061 \\
IHG & 3.1892 & 1.383 & 0.0211 & 0.479 & 5.909
\end{tabular}

Table A4-12: Odds Ratios (Committee Model 2)

$\begin{array}{lrrr}\text { Uariable } & \text { Odds Ratio } & \text { Lower C.I. } & \text { Upper C.I . } \\ --1 & 4.2840 & 1.5928 & 11.5221 \\ \text { Law } & 0.9140 & 0.8550 & 0.9771 \\ \text { Parlfge } & 0.5933 & 0.3742 & 0.9407\end{array}$


Appendix 4: Committee Modelling Procedure (Continued)

\section{Committee Model 3}

Holdout Sample:

$\begin{array}{lllll}\text { BartlettK } & \text { DraperP } & \text { HerronJJ } & \text { MorrisP } & \text { VanstoneA } \\ \text { BrownBJ } & \text { EvansG } & \text { JonesB } & \text { ProsserG } & \text { WakelinB } \\ \text { CameronRA } & \text { FaulknerJP } & \text { JullD } & \text { SharpJR } & \text { WongP } \\ \text { CarrK } & \text { FerrisJ } & \text { KempD } & \text { SinclairI } & \\ & & & & \\ \text { CreanS } & \text { GallusC } & \text { LloydJ } & \text { TierneyJW } & \\ & & & & \\ \text { DownerA } & \text { GarrettP } & \text { MacklinJ } & \text { TrussW }\end{array}$

Table A4-13: Variables for which p<.01 (Committee Model 3)

\begin{tabular}{|l|ccc|}
\hline & Mean & Mean & \\
& Non-CMs & CMs & p-value \\
\hline Law & 0.11 & 0.48 & 0.000 \\
IMG & 0.41 & -0.24 & 0.000 \\
CON & 0.36 & -0.24 & 0.001 \\
Parlage & 42.17 & 38.15 & 0.003 \\
\hline
\end{tabular}

"Naïve" Model Performance: 
Appendix 4: Committee Modelling Procedure (Continued)

Accuracy $=70.37 ;$ Sensitivity $=71.43 ;$ Specificity $=69.23$, Kappa $=.4066$ $(\mathrm{p}=.0346)$.

Table A4-14: Intercorrelations between Variables (Committee Model 3)

\begin{tabular}{|c|c|c|c|c|c|}
\hline & $\operatorname{CH}\{1\}$ & $\operatorname{Law}\{1\}$ & ParlAge & I HG & $\mathrm{CON}$ \\
\hline & & & & -0.33 & -6 \\
\hline aw $\{1\}$ & 22 & & -0 & -0.2416 & -0.3971 \\
\hline arlage & -0 & -0. & & 0.2764 & 0.3201 \\
\hline I HAG & -0. & -0.2416 & 0.2764 & 1.0000 & 0.8998 \\
\hline CON & -0.3124 & -0.3071 & 0.3201 & 0.8998 & 1.0555 \\
\hline
\end{tabular}

Table A4-15: Accuracies of Models with One Linguistic Variable (Committee Model 3)

\begin{tabular}{|ccccc|}
\hline Model & Accuracy & Sensitivity & Specificity & Kappa \\
Law, Parlage, IMG & 70.37 & 71.43 & 69.23 & $0.41^{*}$ \\
Law, Parlage, CON & 74.07 & 71.43 & 76.92 & $0.48^{*}$ \\
\hline
\end{tabular}

Table A4-16: Accuracies - All Possible Variable Combinations (Committee Model 3)

\begin{tabular}{|l|ccc|cc|}
\hline \multicolumn{1}{|c|}{ Model Variables } & Accuracy & Sensitivity & Specificity & Kappa & $\mathrm{p}$ \\
\hline Law, Parlage, Con & 74.07 & 71.43 & 76.92 & 0.48 & 0.0120 \\
Parlage, Con & $\mathbf{7 7 . 7 8}$ & $\mathbf{7 1 . 4 3}$ & $\mathbf{8 4 . 6 2}$ & $\mathbf{0 . 5 6}$ & $\mathbf{0 . 0 0 3 4}$ \\
Law, Parlage & 70.37 & 64.29 & 76.92 & 0.41 & 0.0313 \\
Law, Con & 74.07 & 71.43 & 76.92 & 0.48 & 0.0120 \\
\hline
\end{tabular}

Table A4-17: Parameter Estimates for the Optimum Model (Committee Model 3)

\begin{tabular}{|c|c|c|c|c|c|}
\hline Uariable & Parameter & Std. Error & Pr. Chi Sq. & Lower C.I. & Upper C.I . \\
\hline $\begin{array}{l}\text { ParlAge } \\
\text { CoN } \\
\text { Constant }\end{array}$ & $\begin{array}{r}-0.0674 \\
-0.5866 \\
2.7551\end{array}$ & $\begin{array}{l}0.532 \\
0.246 \\
1.299\end{array}$ & $\begin{array}{l}0.0355 \\
0.0145 \\
0.0340\end{array}$ & $\begin{array}{r}-0.130 \\
-1.657 \\
0.208\end{array}$ & $\begin{array}{r}-0.095 \\
-0.116 \\
5.392\end{array}$ \\
\hline
\end{tabular}


Appendix 4: Committee Modelling Procedure (Continued)

Table A4-18: Odds Ratios (Committee Model 3)

\begin{tabular}{lrrr} 
Uariable & Odds Ratio & Lower C.I. & Upper C.I . \\
\hline ParlAge & -0.9349 & 0.8779 & 0.9955 \\
CON & 0.5562 & 0.3476 & 0.8961
\end{tabular}

\section{Committee Model 4}

Holdout Sample:

AndersonJ ColstonM HowardJ ProsserG TierneyJW

AndrewJN CoonanH JonesB ReidME VaileM

BarresiP CostelloP LeeM ReithP WooldridgeMRL

Beasleyk EntchW McArthurFS RuddockP

BeddallD EvansG McLeayL SwanW

BurkeAT FergusonM ParerW TheophanousA 
Appendix 4: Committee Modelling Procedure (Continued)

Table A4-19: Variables for which $p<.01$ (Committee Model 4)

\begin{tabular}{|c|c|c|c|}
\hline & $\begin{array}{c}\text { Mean } \\
\text { Non-CMs }\end{array}$ & $\begin{array}{c}\text { Mean } \\
\text { CMs }\end{array}$ & $\mathrm{p}$-value \\
\hline Law & 0.11 & 0.48 & 0.000 \\
\hline CON & 0.25 & -0.38 & 0.001 \\
\hline IMG & 0.26 & -0.36 & 0.001 \\
\hline CONAV & 0.25 & -0.35 & 0.002 \\
\hline Arts & 0.25 & 0.52 & 0.003 \\
\hline DEF & 0.19 & -0.36 & 0.004 \\
\hline ParlAge & 42.83 & 38.98 & 0.006 \\
\hline $\mathrm{AOA}$ & -0.19 & 0.31 & 0.010 \\
\hline
\end{tabular}

"Naïve" Model Performance:

Accuracy $=74.04 ;$ Sensitivity $=64.29 ;$ Specificity $=84.62$, Kappa $=.4850$ $(\mathrm{p}=.0098)$.

Table A4-20: Intercorrelations between Variables (Committee Model 4)

\begin{tabular}{|c|c|c|c|c|c|c|c|c|c|}
\hline & $\operatorname{cr}\{1\}$ & $\operatorname{Law}\{1\}$ & $\operatorname{Arts}\{1\}$ & Parlfage & IMG & CON & AGE & CONAU & DEF \\
\hline $\operatorname{CN}\{1\}$ & 1.0000 & 4022 & 2810 & -0.26 & -0.3058 & -0.3125 & 0.24 & -0.2 & -0.2729 \\
\hline Law $\{1\}$ & 0.4022 & & & -0. & -0.2 & -6. & & -0. & -0.2890 \\
\hline $\operatorname{Arts}\{1\}$ & 0.2810 & 0.2829 & 1. & -6 & -0.2704 & -0. & 572 & -0.1618 & -0.2446 \\
\hline Parlige & -0.2654 & -0.1729 & -0.1 & 1.0000 & 0.1627 & 0.1953 & -0.1284 & 0.12 & 0.1567 \\
\hline I HG & -0.3658 & -0.2327 & -0.2704 & 0.1627 & 1.0090 & 0.9648 & -0.7381 & 0.7446 & 0. 6924 \\
\hline CON & -0.3 & -0 & -0 & & & & -0. & & 857 \\
\hline AGE & 0. 2481 & 0.1 & 0.1 & -0.1284 & -6.7381 & -0.5969 & 1.0500 & -0.8747 & -0.6999 \\
\hline CONAU & -0.2957 & -0.2081 & -0.1618 & 0.1217 & 0.7446 & 0.5682 & -0.8747 & 1.0000 & 0.6706 \\
\hline DEF & -0.2729 & -0.2890 & -0.2446 & 0.1567 & 0.6924 & 0.6857 & -6.6999 & 0.6706 & 1.0000 \\
\hline
\end{tabular}


Appendix 4: Committee Modelling Procedure (Continued)

Table A4-21: Accuracies of Models with One Linguistic Variable (Committee Model 4)

\begin{tabular}{|lcccl|}
\hline \multicolumn{1}{|c}{ Model } & Accuracy & Sensitivity & Specificity & Kappa \\
Law, Parlage, Arts, IMG & 70.37 & 64.29 & 76.92 & $0.41^{*}$ \\
Law, Parlage, Arts, CON & 70.37 & 71.43 & 69.23 & $0.41^{*}$ \\
Law, Parlage, Arts, DEF & 70.37 & 64.29 & 76.92 & $0.41^{*}$ \\
Law, Parlage, Arts, CONAV & 74.07 & 64.29 & 84.62 & $0.49^{* *}$ \\
Law, Parlage, Arts, AOA & 74.07 & 64.29 & 84.62 & $0.49^{* *}$ \\
\hline
\end{tabular}

None of the linguistic variables adds to classification accuracy so they are all excluded.

Table A4-22: Accuracies - All Possible Variable Combinations (Committee Model 4)

\begin{tabular}{|lcccc|}
\hline \multicolumn{1}{|c}{ Model } & Accuracy & Sensitivity & Specificity & Kappa \\
Law, Parlage, Arts & 70.37 & 78.57 & 61.54 & $0.40^{*}$ \\
Law, Parlage & $\mathbf{8 1 . 4 8}$ & $\mathbf{7 8 . 5 7}$ & $\mathbf{8 4 . 6 2}$ & $\mathbf{0 . 6 3 * *}$ \\
Law, Arts & 62.96 & 71.43 & 53.85 & 0.25 \\
Parlage, Arts & 66.67 & 85.71 & 46.15 & 0.32 \\
\hline
\end{tabular}

Table A4-23: Parameter Estimates for the Optimum Model (Committee Model 4)

\begin{tabular}{|c|c|c|c|c|c|}
\hline Uariable & Parameter & Std. Error & Pr. Chi Sq. & Lower C.I. & Upper C. I . \\
\hline U9Law & & & & & \\
\hline 1 & 1.9553 & 5.524 & 5. 5953 & 5.879 & 2.932 \\
\hline U16ParlAge & -0.0750 & 6. 932 & 5. 5276 & -0.132 & -0.598 \\
\hline Constant & 2.3691 & 1.319 & 5. 5724 & -0.216 & 4.954 \\
\hline
\end{tabular}

Table A4-24: Odds Ratios (Committee Model 4)

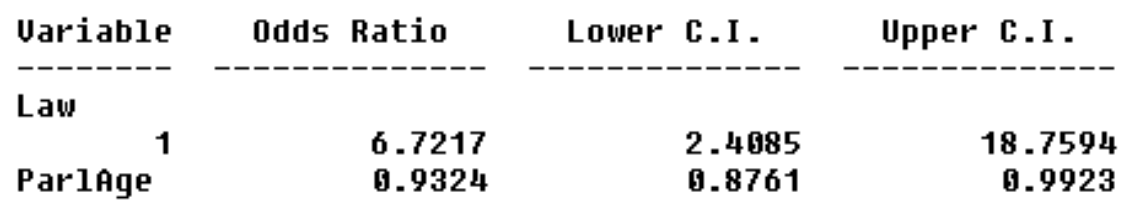


Appendix 4: Committee Modelling Procedure (Continued)

\section{Committee Model 5}

Holdout Sample:

AnthonyL CostelloP HoldingC MorrisP TierneyJW

BartlettK CreanS HollisC $\quad$ RuddockP TrussW

BeddallD EntchW JonesB SmithSF WakelinB

CampbelliG EvansC McGauranP TannerL

CoatesJ EvansG McKiernanJ TheophanousA

CookP FaheyJ MilesC ThomsonAP

Table A4-25: Variables for which $p<.01$ (Committee Model 5)

\begin{tabular}{|c|c|c|c|}
\hline & $\begin{array}{c}\text { Mean } \\
\text { Non-CMs }\end{array}$ & $\begin{array}{c}\text { Mean } \\
\text { CMs }\end{array}$ & $\mathrm{p}$-value \\
\hline CON & 0.41 & -0.34 & 0.000 \\
\hline Law & 0.11 & 0.44 & 0.000 \\
\hline ParlAge & 43.17 & 38.31 & 0.000 \\
\hline IMG & 0.39 & -0.27 & 0.001 \\
\hline DEF & 0.32 & -0.23 & 0.002 \\
\hline Arts & 0.26 & 0.54 & 0.004 \\
\hline CONAV & 0.34 & -0.16 & 0.009 \\
\hline
\end{tabular}

Performance of "Naïve" Model 
Appendix 4: Committee Modelling Procedure (Continued)

Accuracy $=66.67 ;$ Sensitivity $=64.29 ;$ Specificity $=69.23$, Kappa $=.3342$ $(\mathrm{p}=.0816)$.

Table A4-26: Intercorrelations between Variables (Committee Model 5)

\begin{tabular}{|c|c|c|c|c|c|c|c|c|}
\hline & $\operatorname{CH}\{1\}$ & $\operatorname{Law}\{1\}$ & $\operatorname{Arts}\{1\}$ & ParlAge & I MG & $\mathrm{CON}$ & CONAU & DEF \\
\hline $\operatorname{CH}\{1\}$ & 1.0950 & 0.3687 & 0.2783 & -0.3336 & -0.3257 & -0.3679 & -0.2513 & -0.2925 \\
\hline $\operatorname{Law}\{1\}$ & 0.3687 & 1.0000 & 0.2098 & -0.1504 & -0.2487 & -0.3398 & -0.1819 & -0.2910 \\
\hline $\operatorname{Arts}\{1\}$ & 0.2783 & 0.2098 & 1.0000 & -0.0994 & -0.2440 & -0.2813 & -0.1882 & -0.2539 \\
\hline Parlage & -0.3336 & -0.1564 & -0.0994 & 1.0505 & 0.1992 & 0.1253 & 0.0755 & 0.0474 \\
\hline I HitG & -0.3257 & -0.2487 & -0.2440 & 5.1592 & 1.0505 & 0.9544 & 0.7503 & 5.6798 \\
\hline CON & -0.3679 & -0.3398 & -0.2813 & 0.1253 & 0.9544 & 1.0500 & 0.5835 & 0.6476 \\
\hline CONAU & -0.2513 & -0.1819 & -0.1882 & 0.0755 & 0.7503 & 0.5835 & 1.0000 & 0.7116 \\
\hline DEF & -0.2925 & -0.2916 & -0.2539 & 0.0474 & 0.6798 & 0.6476 & 0.7116 & 1.5505 \\
\hline
\end{tabular}

Table A4-27: Accuracies of Models with One Linguistic Variable (Committee Model 5)

\begin{tabular}{|lcccc|}
\hline \multicolumn{1}{|c}{ Model } & Accuracy & Sensitivity & Specificity & Kappa \\
Law, Parlage, Arts, IMG & 66.67 & 71.43 & 61.54 & 0.33 \\
Law, Parlage, Arts, CON & 62.96 & 64.29 & 61.54 & 0.26 \\
Law, Parlage, Arts, DEF & 66.67 & 64.29 & 69.23 & 0.33 \\
Law, Parlage, Arts, CONAV & 62.96 & 71.43 & 53.85 & 0.25 \\
\hline
\end{tabular}

Table A4-28: Accuracies - All Possible Variable Combinations (Committee Model 5)

\begin{tabular}{|l|ccc|cc|}
\hline \multicolumn{1}{|c|}{ Model Variables } & Accuracy & Sensitivity & Specificity & Kappa & $\mathrm{p}$ \\
\hline Law, Parlage, DEF & 62.96 & 78.57 & 46.15 & 0.25 & 0.1733 \\
Parlage, DEF & 62.96 & 71.43 & 53.85 & 0.25 & 0.1817 \\
Law, Parlage & 66.67 & 78.57 & 53.85 & 0.33 & 0.0814 \\
Law, DEF & $\mathbf{7 4 . 0 7}$ & $\mathbf{6 4 . 2 9}$ & $\mathbf{8 4 . 6 2}$ & $\mathbf{0 . 4 9}$ & $\mathbf{0 . 0 0 9 8}$ \\
Law, Parlage, Arts & 70.37 & 71.43 & 69.23 & 0.41 & 0.0346 \\
Arts, DEF, Law & 70.37 & 71.43 & 69.23 & 0.41 & 0.0346 \\
Law,Arts & 70.37 & 71.43 & 69.23 & 0.41 & 0.0346 \\
Arts, DEF & 70.37 & 71.43 & 69.23 & 0.41 & 0.0346 \\
Parlage, Arts & 51.85 & 57.14 & 46.15 & 0.03 & 0.8632 \\
Parlage, Arts, DEF & 59.26 & 71.43 & 46.15 & 0.18 & 0.3445 \\
\hline
\end{tabular}


Appendix 4: Committee Modelling Procedure (Continued)

Table A4-29: Parameter Estimates for the Optimum Model (Committee Model 5)

\begin{tabular}{|c|c|c|c|c|c|}
\hline Variable & Parameter & Std. Error & Pr. Chi Sq. & Lower C.I. & Upper C.I . \\
\hline Law & & & & & \\
\hline $\begin{array}{l}\text { DEF } \\
\text { Constant }\end{array}$ & $\begin{array}{r}1.5939 \\
-0.5682 \\
-0.3631\end{array}$ & $\begin{array}{l}0.527 \\
0.244 \\
0.242\end{array}$ & $\begin{array}{l}0.0325 \\
0.0376 \\
0.1338\end{array}$ & $\begin{array}{r}0.561 \\
-0.987 \\
-0.838\end{array}$ & $\begin{array}{r}2.627 \\
-0.629 \\
0.112\end{array}$ \\
\hline
\end{tabular}

Table A4-30: Odds Ratios (Committee Model 5)

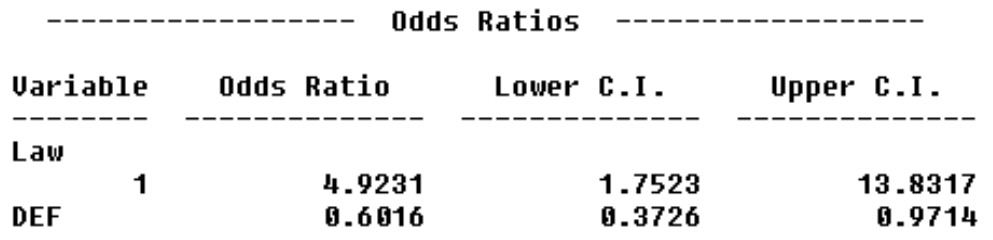

